\title{
IMPACTS OF MAN-MADE STRUCTURES ON MARINE BIODIVERSITY AND SPECIES STATUS - NATIVE \& NON- NATIVE SPECIES
}

BY

\section{SONALI PAWASKAR}

\author{
A thesis submitted to \\ Victoria University of Wellington \\ in fulfilment of the requirements for the degree of \\ Doctor of Philosophy in Marine Biology.
}



This thesis was conducted under the supervision of:

\author{
Professor Jonathan P. A. Gardner (Primary supervisor) \\ Victoria University of Wellington, \\ Wellington, New Zealand
}

\author{
Professor Chad Hewitt (Secondary supervisor) \\ Murdoch University, \\ Perth, Western Australia
}

And

Professor Marnie Campbell (Secondary supervisor)

Deakin University,

Melbourne, Victoria, Australia 



\section{Abstract}

Coastal environments are exposed to anthropogenic activities such as frequent marine traffic and restructuring, i.e., addition, removal or replacing with man-made structures. Although maritime shipping and coastal infrastructures provide socio-economic benefits, they both cause varied perturbations to marine ecosystems. The ports and marinas receiving a high frequency of international vessels, act as 'hot-spots' for marine invasions. The disturbed and modified habitats found in harbours and ports provide opportunities for non-native species to settle due to their competitive traits. Once established, the non-native species may spread to neighbouring habitats, thereby modifying the adjacent natural environment, its biodiversity, ecosystem structure and functioning.

Up to $70 \%$ of coastlines around the world have now been modified and is expected to rise in future. New bioinvasions are still being reported even with various biosecurity and management approaches across the globe. It is essential to understand the potential factors influencing the bioinvasions to have effective biosecurity measures and management plans. The overall aim of this thesis is to determine the influence of man-made structures on the marine biodiversity and presumptive fitness of native and non-native species on these structures. This thesis investigates ports and harbours as man-made environments, their impacts on marine biodiversity and the species status - native, non-native and cryptogenic, and the factors facilitating the spread of non-native species.

Chapter 2 focussed on two large national-scale baseline port surveys; a) Australian Port Survey (APS), and b) New Zealand Port Survey (NZPS). The two datasets were analysed to determine the community structure and species status, i.e., native, non-native and cryptogenic as a function of the surveyed ports, port type (major vs minor ports) (based on the volume of vessels) and latitudinal groups. A) APS: The results for community composition indicated significant effects as a function of surveyed ports, port type and latitudinal group. The community composition was relatively more abundant at major ports than at minor ports. The factor, the latitudinal group indicated significant results, and a distinct separation in community composition was observed between low $\left(15,20^{\circ} \mathrm{S}\right)$ and high $\left(35,40^{\circ} \mathrm{S}\right)$ latitudes. The species status showed a significant and positive relationship between native vs non-native, indicating with an increase in the number of native species there was an increase in the number of nonnative species. The species status indicated significant results for the factors; surveyed ports, port type and latitudinal group. The native species were abundant throughout the study. 
However, the non-native species were relatively abundant at major ports compared to minor ports. Regarding the latitudinal groups, the abundance of non-native species was observed to increase at higher latitudes (latitudinal gradients). B) NZPS: The community composition and species status showed significance among the 27 surveyed ports; however, no significant results were observed for the factor port type (major vs minor). The community composition significantly varied as a function of latitudinal groups, with species at higher latitudes $\left(45^{\circ} \mathrm{S}\right)$ being better discriminator explaining the differences. Latitudinal groups, however, highlighted sub-groupings of ports with similar community composition (e.g. Bluff and Dunedin; Nelson, Wellington and Picton; Lyttelton and Timaru; Whangarei, Tauranga and Taranaki; Auckland, Gulf Harbour Marina and Opua Marina). The ports in question are within close proximity of each other (distance). This suggests the possibility of natural dispersal of species between ports on top of the human-mediated dispersal. The responses in Australia were very different from those in New Zealand, which suggests that the responses are regional or country-specific and not global.

Chapter 3 describes fieldwork using settlement tile arrays to examine the effects of man-made built structures and natural rocky reefs on marine biological community composition and successional patterns over two years. The work also tests the preference of native and non-native species in terms of habitat type (natural reef vs man-made habitat) and substratum type (PVC vs slate tile). The results showed a rapid increase in species settlement on bare tiles as the available bare space was 30\% just after 3 months of submersion. The community composition significantly differed as a function of the interaction of factors, habitat $\times$ substratum $\times$ sample interval. However, differences between the habitat types and substratum types, respectively, were explained by the difference in abundance of the same suite of species. The species were abundant at marina sites compared to reef sites; however, in terms of substrata, the species were abundant on slate (natural) tiles than on PVC tiles.

The succession patterns of species over time ( 8 sample intervals) showed a similar trend on both the habitat type and substratum type, with differences in the average abundances of each species. The differences in abundances highlight the influence of species dispersal patterns, recruitment patterns and post-settlement processes of species between habitat type and substratum type, respectively. Subsequently, the species status indicated significance as a function of habitat type, substratum type and sample intervals. The cryptogenic species were abundant throughout the study. The cryptogenic species, however, decreased in abundance over time, with an increase in abundance of native and non-native species. Subsequently, the 
non-native species significantly varied between habitat type, with relatively higher abundance at marina (man-made) sites compared to reef (natural) sites. However, the non-native species did not show significant variation as a function of substratum type (PVC vs slate). The results are discussed in the context of the recruitment of species on a new barren substrate, and the preference of habitat type and substratum type by native, non-native and cryptogenic species.

In Chapter 4, the reproduction output (gonadosomatic index, GSI) of the Southern hemisphere, native ( $\mathrm{SHMg}$ ) and Northern hemisphere, non-native ( $\mathrm{NH} M g$ ) lineages of the blue mussel, Mytilus galloprovincialis were measured. The GSI and shell length of NHMg and $\mathrm{SH} M g$ were compared between habitat type; reef (natural) vs marina (man-made) sites. This study aimed to identify reproductive patterns (i.e., timing and magnitude of spawning events) and differences in performance (presumptive fitness) of the native and non-native blue mussel lineages at the natural and man-made habitats. The results for shell length indicated significance for habitat type and no significance as a function of lineage. The mussels were relatively bigger mussels at marina sites compared to reef sites; however, the differences were trivial. The GSI values as a function of habitat type, lineage and sampling time showed a significant difference between habitat type, with high GSI values at reef sites than at marina sites. However, this indicates that the blue mussels at marina sites had comparatively higher spawning activity than at reef sites. The temporal variation of GSI of NHMg and SHMg showed a similar reproductive trend (i.e., spawning and gametogenesis) at both habitats. However, significant spawning activity was observed in July and November when compared between reef and marina habitats. The results are discussed in the context of management implications and strategies regarding the establishment and success of non-native M. galloprovincialis lineage and whether their eradication is necessary or even possible.

The findings of this research are summarised and discussed in relation to our understanding of biological community composition and diversity on man-made habitats and the subsequent invasion in the neighbouring natural habitats. This study, from an ecoengineering perspective, highlights the importance of complex habitats and surfaces, and not just material type. However, from a biosecurity and management approach, even though Australia and New Zealand have one of the strong international biosecurity country-specific legislation; the continuous arrival of non-native species in these countries indicates that such marine legislation is not sufficiently compelling on its own. This study highlights the interaction of non-native species at proximity ports, and it provides recommendations towards regional-scale management measures concentrating on intra-coastal transfer of invaders 
through domestic maritime traffic or natural dispersal. The life-history traits, recruitment timing and post-settlement processes, plays an essential role in determining long term patterns. Lastly, this research indicated that native and non-native species with ecologically similar responses lead to limited management options to some extent. Therefore, from a manager's perspective, the eradication of non-native species may not be necessary if it does not cause any negative impacts to the biodiversity or the environment. 


\section{Acknowledgements}

Completion of my thesis was made possible through the support of many people that have contributed to my journey of self-development as a person and a scientist. First of all, I am deeply grateful to my supervisor, Prof. Jonathan P.A. Gardner, for all his guidance, patience and encouragement throughout this work. It has always been a pleasure and an honour to work under him and keep me steered along the steady track towards completion of this thesis. Thanks to Prof. Chad Hewitt and Prof. Marnie Campbell for providing me with the data for the Australian Port surveys and valuable advice in the early stage of my study. I would not have been able to start my $\mathrm{PhD}$ let alone finish without funding; therefore, I am grateful for the New Zealand Educated International Doctoral Scholarship, Victoria University Wellington and Victoria PhD Submission Scholarship.

Many thanks to all the staff in the School of Biological Sciences, Faculty of Sciences and Faculty of Graduate Research, especially Mary Murray, Paul Marsden, Sandra Taylor, Mark Stephen, Patricia Stein and Barry Lewis for all the advice and support when needed. The field experimental study would not be possible without the technicians at the Victoria University Coastal Ecology Laboratory (VUCEL) John, Snout and Dan for helping me with diving sample retrievals even in Wellington's cold, windy weather. Special thanks to John for helping with the design and set-up of my experimental study. Special thanks to Neville for helping me cut the settlement tiles. I thank the marina managers at Seaview Marina, Chaffers Marina and Evans Bay Marina for facilitating access to the marina and berths as my sampling locations to deploy my settlement tile setups.

Many people have been there, day-to-day, throughout my $\mathrm{PhD}$ who have been more help than they realise. Thank you, Jo, for helping me set-up and helping me with different techniques in the lab, Ruojin for being a great colleague and a friend. Many thanks to the 'Gardner Lab', Ian, Lorenzo, Giulia, Calvin and Jana for all the encouragement, support and distractions when 'I've needed a break. I am grateful to my friends who have coped with me throughout this journey and kept me sane outside the lab, Rohan, Zeineb, Vaibhav, Ashish, Garima, Aileen, Manu, Lucy, Lee and all my friends back home for checking up on me. Special thanks to Rohan without whom my field collections and settlement tile drillings would not have been fun, thanks for your immense support throughout this journey. Finally, I would like to thank my family, dad Rajan, mom Bhagyashree and my brother Akshay. Thank you for your unwavering love and support. You are all important to me in so many ways. Thank you! 


\section{Table of contents}







List of Tables ............................................................................................................................ XI

List of Figures...........................................................................................................

Chapter 1. General Introduction ..........................................................................................................1











1.3.3 Non-native species - characteristics and impacts............................................. 8



1.4.1 Marine port management approaches …...................................................... 10



1.4.3 Mitigation approach - Eco-engineering ..................................................... 13

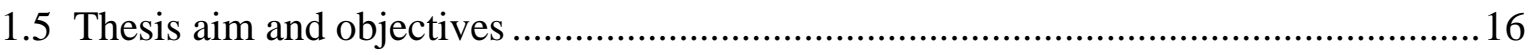



Chapter 2. Port areas as introduction foci for non-native species .....................................20













B) New Zealand Port Biological Baseline Survey ............................................24








2.2.1 Data analysis .26

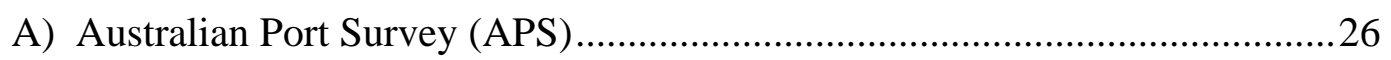

B) New Zealand Port Biological Baseline Survey (NZPS) ..............................22

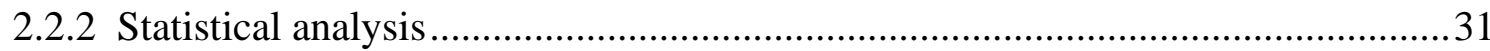

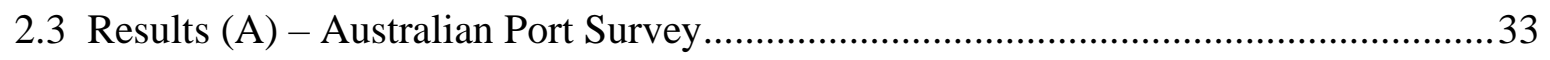

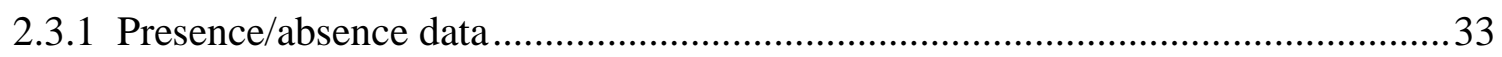

2.3.2 Variations in total presence of species as a function of replicates of each surveyed port

2.3.3 Variations in community composition as a function of the surveyed port, port type

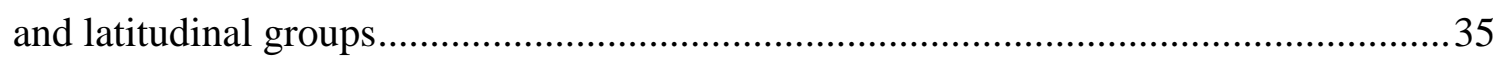

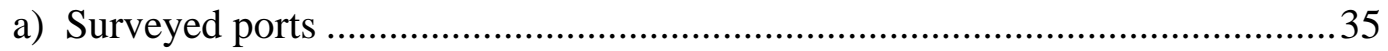





2.3.4 Variations in species status - native, non-native and cryptogenic species as a function of the surveyed port, port type and latitudinal groups .....................................48

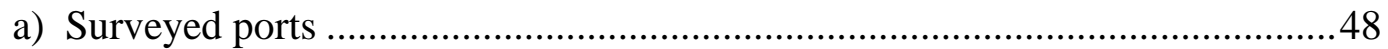





2.4 Results (B) - New Zealand Port Biological Baseline Survey ......................................57

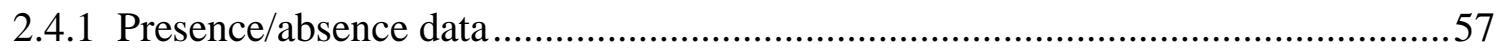

2.4.2 Variations in total presence of species as a function of replicates of each surveyed



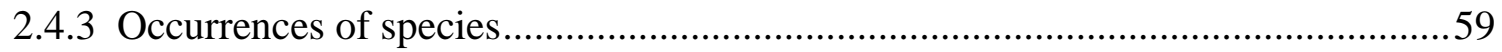

2.4.4 Variations in the community composition as a function of the surveyed port, port



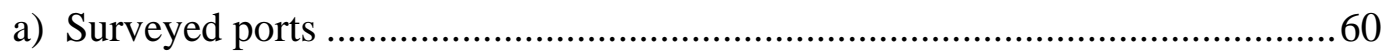



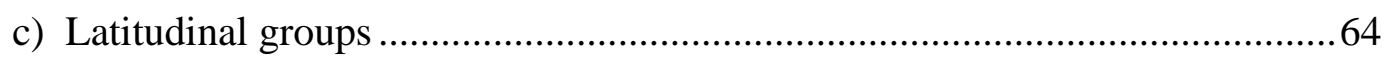

2.4.5 Variations in species status - native, non-native and cryptogenic species as a

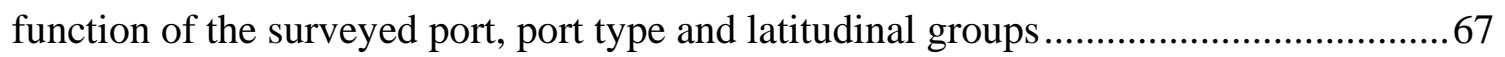

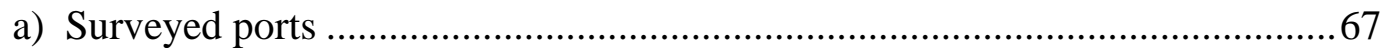

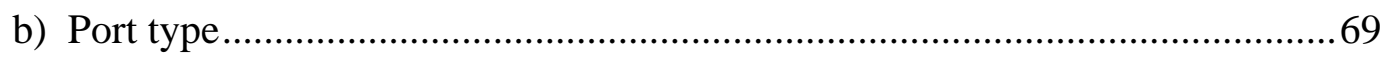




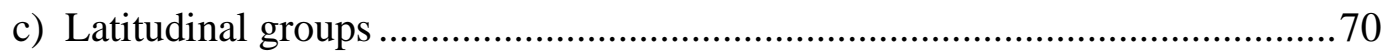

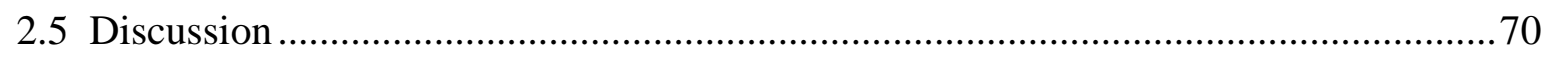

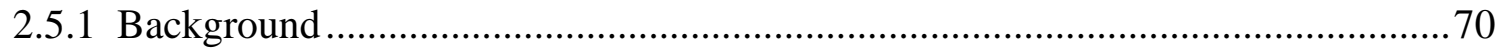

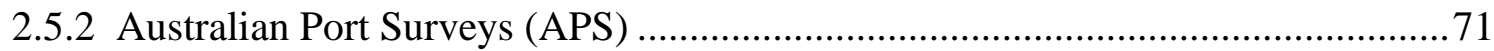

2.5.3 New Zealand Port Biological Baseline Survey (NZPS) ..................................... 72

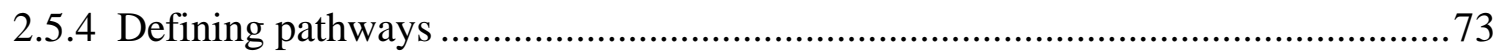

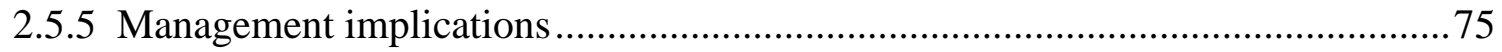

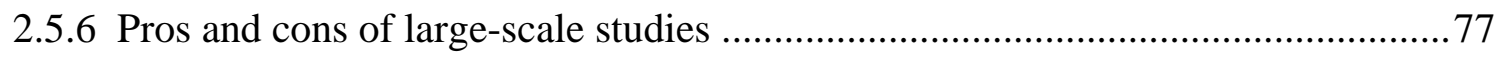

Chapter 3. Community development and structure on natural and man-made substrata in natural and man-made environments...........................................................................79

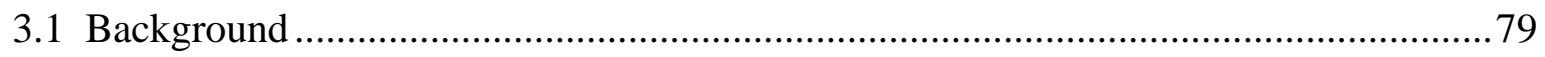

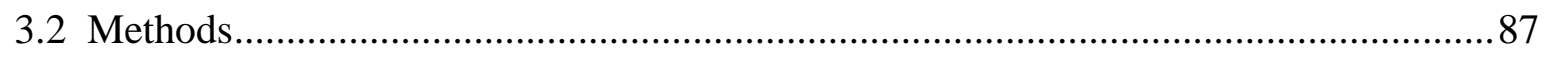

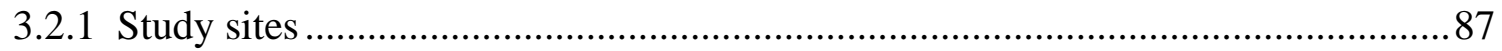

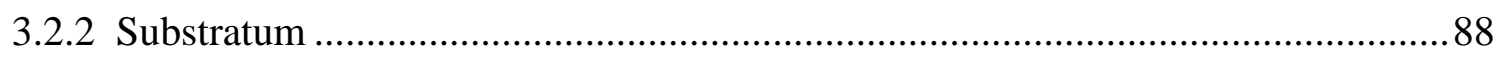

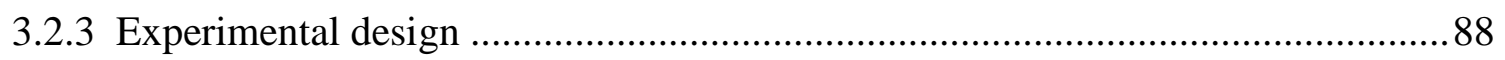

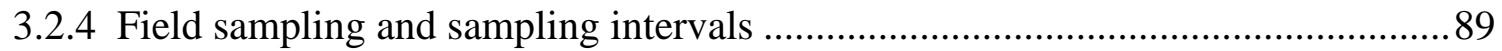

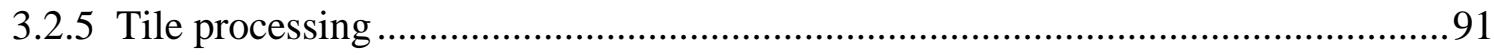

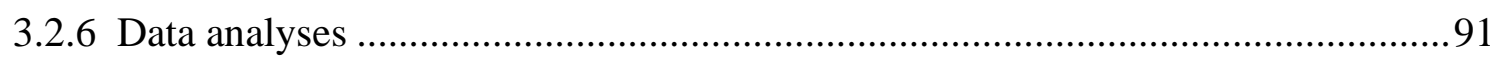

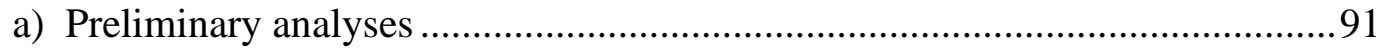

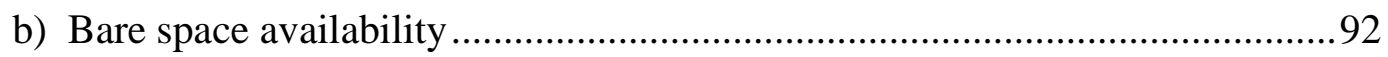

c) Fouling community composition ............................................................. 92

d) Species status (native, non-native, cryptogenic) .......................................... 93

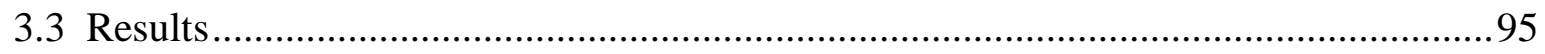

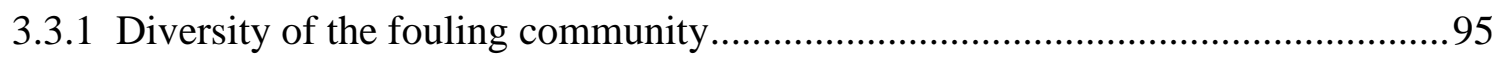

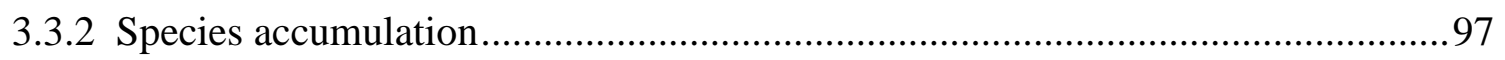

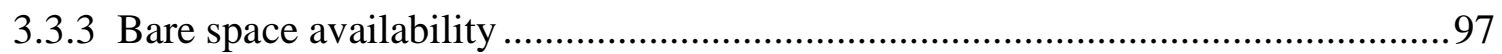

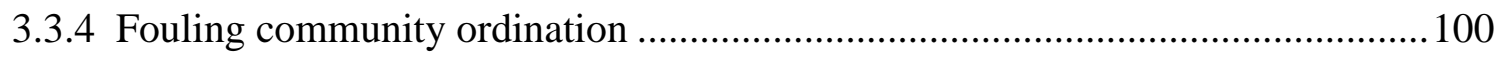

3.3.5 Variations in fouling community composition as a function of habitat, site(habitat),

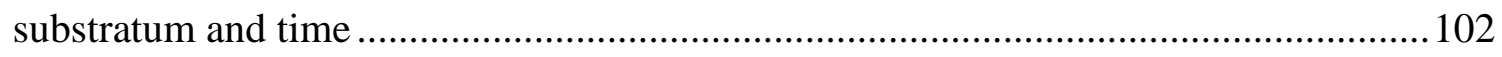

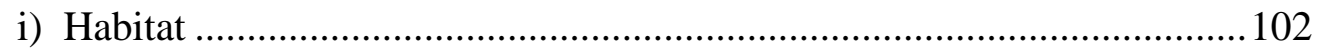

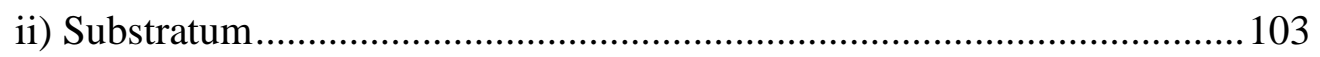

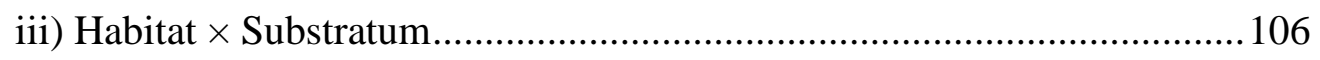






3.3.6 Species status (native, non-native and cryptogenic) ...........................................110

a) Species status and their occurrences .............................................................. 110

b) Status of species as a function of habitat, substratum and sample interval ...110

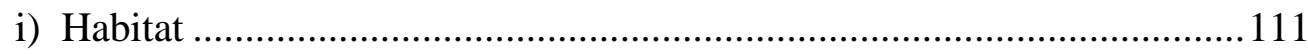

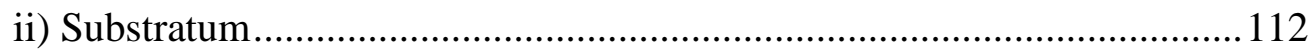

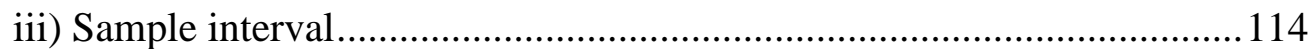

3.3.7 Correlation between native and non-native species as a function of sample interval .116

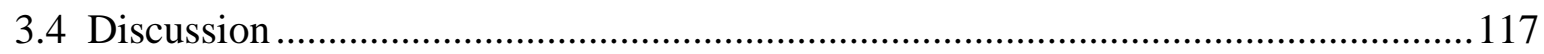

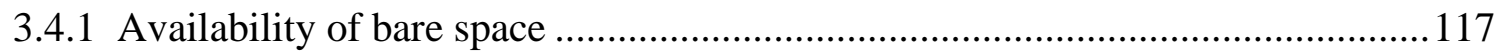

3.4.2 Fouling community composition as a function of habitat and substratum ...........117

3.4.3 Species status - native, non-native, cryptogenic species ................................... 120

Chapter 4. Do native Mytilus galloprovincialis lineage, and its non-native lineage congener differ in reproductive response to man-made habitats? ..........................................................123

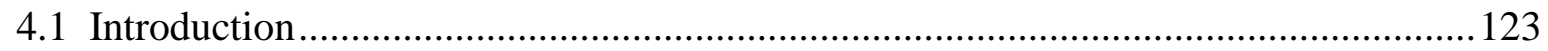

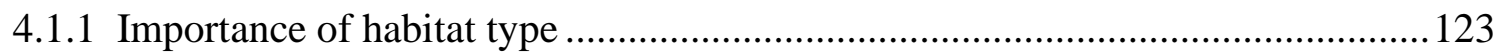

4.1.2 Impacts of man-made structures on bioinvasions ..................................................124

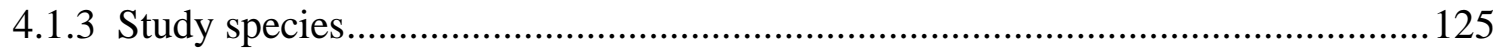

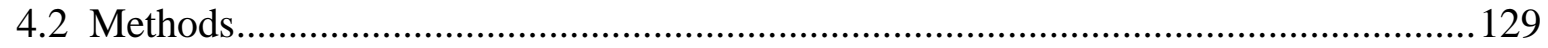

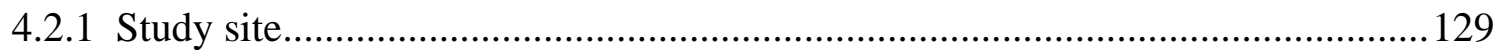

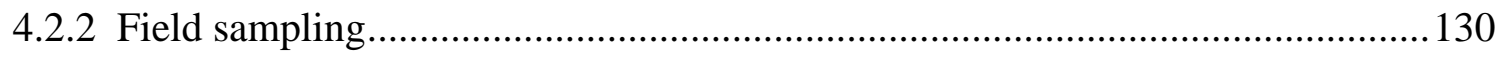

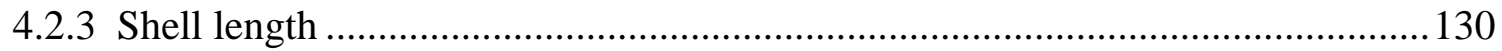

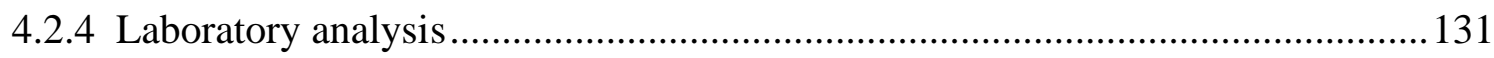

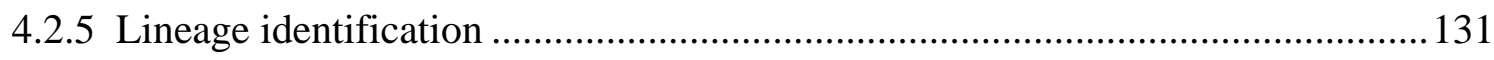





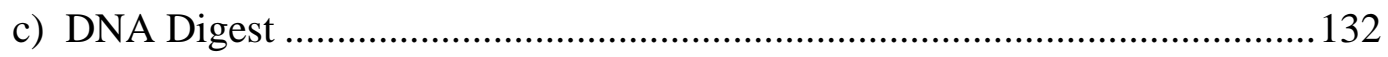

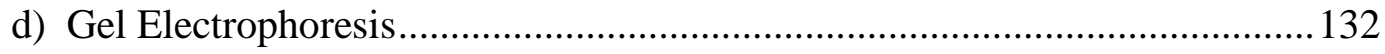

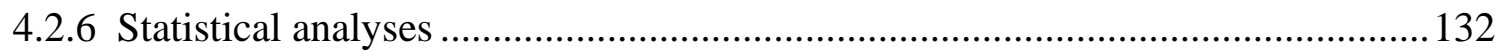

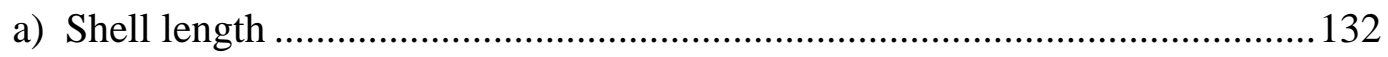

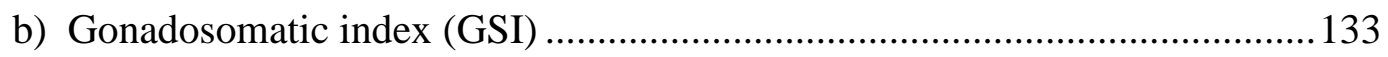


4.3 Results

4.3.1 Shell length

4.3.2 Regression - GSI as a function of shell length for the lineages, $\mathrm{NHMg}$ and $\mathrm{SHMg}$

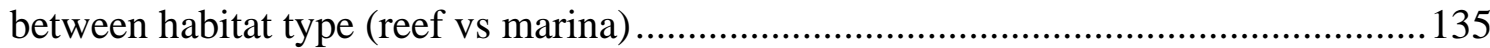

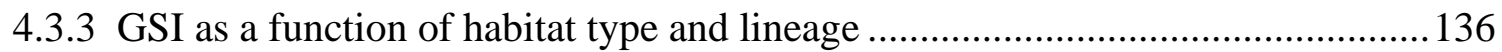

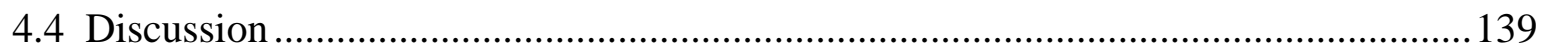

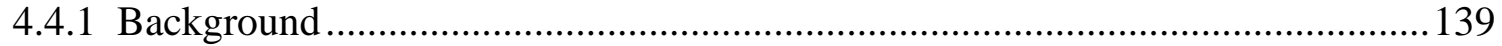

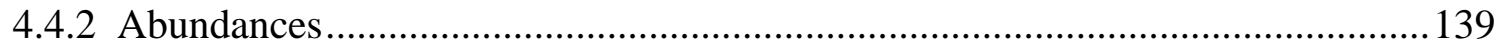

4.4.3 Shell length as a function of habitat type and lineage ...................................... 140

4.4.4 GSI as a function of habitat type and lineage ................................................ 141

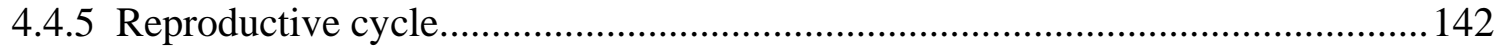

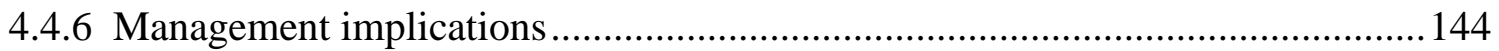

Chapter 5. General Discussion..............................................................................................146

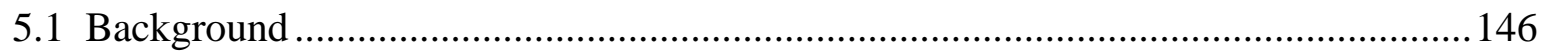

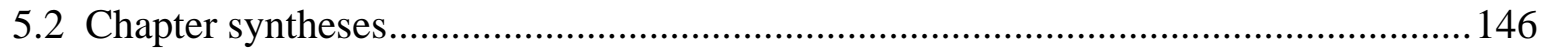

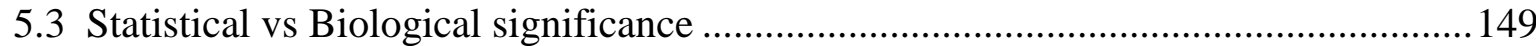

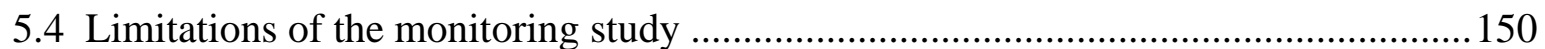

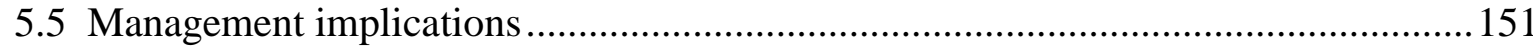

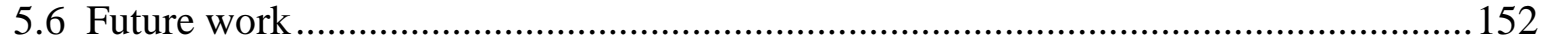

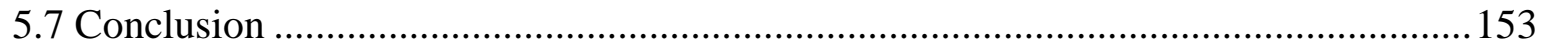

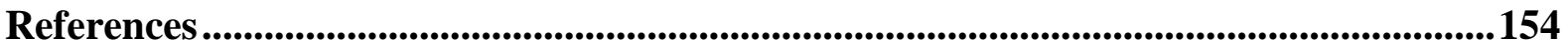

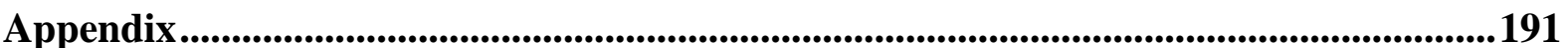




\section{List of Tables}

Table 2.1.1 Sampling methods for port surveys as per CRIMP protocols..................26

Table 2.2.1. Ports sampled for the Australian Port Surveys with latitudinal and longitudinal groups, port type and replicates (sampling effort) ................................. 28

Table 2.2.2. Ports sampled for the New Zealand Port Biological Baseline Surveys with latitudinal and longitudinal groups, port type and replicates (sampling effort) ...............30

Table 2.3.1. The total number of species noted in Australian Port Surveys grouped to Phylum and status (native, non-native and cryptogenic) ....................................... 33

Table 2.3.2. The total number, sampling effort (replicates) and relative number of species as a function of replicates at each surveyed port........................................... 34

Table 2.3.3. Results of the PERMANOVA test performed on the presence/absence of species as a function of the surveyed port. Significance marked in bold........................... 36

Table 2.3.4. The average similarity of the presence/absence of species as a function of the surveyed port....................................................................

Table 2.3.5. SIMPER analysis: average similarity in presence/absence of species as a function



Table 2.3.6. Results of the PERMANOVA and pairwise test performed as a function of port type (2 levels)

Table 2.3.7. SIMPER analysis: average similarity in the community composition as a function

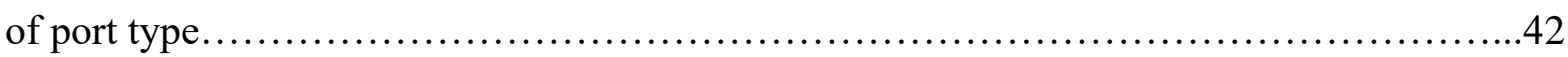

Table 2.3.8. Results of the PERMANOVA test performed as a function of latitude....

Table 2.3.9. Results of pairwise PERMANOVA test performed on the community composition as a function of latitude............................................................. 44

Table 2.3.10. SIMPER analysis: average dissimilarity for the community composition as a function of latitude.

Table 2.3.11. The list of species that indicated variations as a function of the port type and latitudinal groups

Table 2.3.12. The total number of species, species status, replicates (sampling effort) and the relative number of native, non-native and cryptogenic species - across 27 surveyed ports.

Table 2.3.13. Results of the PERMANOVA test performed on the species status as a function of the surveyed port.

Table 2.3.14. Results of the PERMANOVA test and pairwise test performed on the species status as a function of port type. 
Table 2.3.15. SIMPER analysis: percent contribution of species status as a function of port type

Table 2.3.16. Results of the PERMANOVA test performed on the status of the species as a function of latitude.

Table 2.3.17. Results of the pairwise PERMANOVA test performed on the presence of species as a function of latitude

Table 2.3.18. SIMPER analysis: percent contribution $(\mathrm{C} \%)$ of species status as a function of the latitudinal groups.

Table 2.3.19. SIMPER analysis: species status contributing $(\mathrm{C} \%)$ to the average dissimilarity as a function of the latitude.

Table 2.4.1. The total number of species noted in New Zealand Port Surveys grouped as per their Phyla and species status (native, non-native and cryptogenic)

Table 2.4.2. The total relative number of species as a function of replicates (sampling effort) at each surveyed port. .58

Table 2.4.3. Total occurrences of top 10 species across 15 surveyed ports .59

Table 2.4.4. Results of the PERMANOVA test performed on the presence/absence of species as a function of the surveyed port.

Table 2.4.5. SIMPER analysis: average similarity in the presence/absence of species as a function of the surveyed port....

Table 2.4.6. Results of the PERMANOVA analysis and pairwise test performed as a function of port type

Table 2.4.7. Results of the PERMANOVA test performed as a function of latitude. .64

Table 2.4.8. Results of the PERMANOVA and pairwise test as a function of port type

Table 2.4.9. SIMPER analysis: average dissimilarity of community composition as a function of latitude.

Table 2.4.10. The list of species that indicated variations as a function of surveyed ports and latitudinal groups. .66

Table 2.4.11. The total number of species as a function of status - native, non-native and cryptogenic species - across 15 surveyed ports.

Table 2.4.12. Results for regression for species status - native, non-native and cryptogenic species

Table 2.4.13. Results of the PERMANOVA test performed on the species status as a function of surveyed port. 68

Table 2.4.14. SIMPER analysis: percent contribution of species status - native, non-native and cryptogenic species, as a function of the surveyed port. 
Table 2.4.15. The PERMANOVA analysis used to determine differences in the species status as a function of port type.

Table 2.4.16. The PERMANOVA analysis used to determine differences in the species status

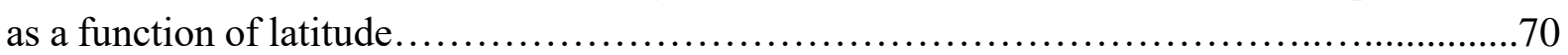

Table 3.2.1. List of sampling sites with habitat types, codes, latitude and longitudes.

Table 3.2.2. List of sampling intervals, months, seasons and sampling year examined in this study, following set-up and deployment in August 2017.

Table 3.3.1. List of species and major groups recorded at the six sampling sites for all 8 sample intervals in Wellington Harbour.

Table 3.3.2. Results for PERMANOVA to determine the availability of bare space as a function of habitat, substratum and sample intervals with their interactions.

Table 3.3.3. Results of pairwise PERMANOVA test for the availability of bare space as a function of habitat type, substratum type and habitat $\times$ sample interval

Table 3.3.4. Permutational ANOVA (PERMANOVA) analysis used to determine differences in community composition between factors: habitat type, site (habitat), substratum type and sampling intervals.

Table 3.3.5. Results of pairwise PERMANOVA test performed on fouling communities as a function of habitat and substratum with the average similarities between groups....

Table 3.3.6. SIMPER results for major species contributing to the average similarity between habitat type and substratum type.

Table 3.3.7. Results for SIMPER analysis. Average similarities within groups and average dissimilarities in fouling communities between habitat and substratum. .105

Table 3.3.8. Results of pairwise PERMANOVA test performed on fouling communities as a function of the interaction between habitat $\times$ substratum with the average similarities between groups.

Table 3.3.9. SIMPER results for ten major consistent species contributing to the average similarity within each sampling interval.... .108

Table 3.3.10. Permutational ANOVA (PERMANOVA) analysis used to determine differences in the status of the species between factors: habitat type, site (habitat), substratum type and sampling interval. . .

Table 3.3.11. Results of pairwise PERMANOVA test performed on species status as a function of habitat type and substratum type.

Table 3.3.12. Results of pairwise PERMANOVA test performed on non-native species as a function of habitat type and substratum type 
Table 3.3.13. SIMPER results for species status contributing to the average within-group similarity and dissimilarity between a) habitat type (Reef vs Marina and b) substratum type (PVC vs Slate)....

Table 3.3.14. Major species contributing to the average similarity within each sampling interval. 114

Table 3.3.15. The temporal variation of species status (percent contribution) as per SIMPER results for habitat type (reef vs marina) and substratum type (slate vs PVC) 115

Table 4.3.1. Two-way ANOVA for shell length $(\mathrm{cm})$ as a function of habitat type and lineage

Table 4.3.2. Paired $t$-tests for shell length as a function of habitat type and lineage and Cohen's $\mathrm{d}$ effect size ' $\mathrm{r}$ ' of shell length for habitat type (reef vs marina) and lineage (NHMg vs $\mathrm{SH} M g$ ).

Table 4.3.3. Results for regression for Gonadosomatic index (GSI \%) as a function of shell length for $\mathrm{NH} M g$ and $\mathrm{SHMg}$ at the marina and reef habitats.

Table 4.3.4. Results of ANCOVA for GSI values and shell length (cm; Co-variate) as a function of Month $\times$ Lineage $x$ Habitat type.

Table 4.3.5. Tukey HSD post hoc tests for GSI values as a function of significant factors as per ANCOVA, i.e. habitat type and month and Cohen's d effect size of GSI for habitat type (reef vs marina) for significant effects.

Table 4.3.6. Monthly variations in Gonadosomatic Index $(\%) \pm$ standard deviation (SD) of $\mathrm{SH} M g$ and NHMg at reef and marina habitats during June 2017-May 2018. 138

Table A1. SIMPER analysis: average similarity in the status of species as a function of the surveyed port. .191

Table A2. Species identified in the 27 port surveys around Australia and species status - native, non-native and cryptogenic species.

Table A3. Species identified in the 15 port surveys around New Zealand and species status native, non-native and cryptogenic species.

Table A4. Pairwise PERMANOVA test for the community composition for the interaction factors; Habitat $\times$ Sample interval and Substratum $\times$ Sample interval. Significance marked in bold $(P<0.05)$ 


\section{List of Figures}

Figure 2.2.1. Map of Australia with commercial shipping ports surveyed for Australian Port Survey study....

Figure 2.2.2. Map of Australia with commercial shipping ports surveyed for New Zealand Port Biological Baseline Survey study.............................................. 31

Figure 2.3.1. The total relative number of species across all 27 surveyed ports...............34

Figure 2.3.2. Multidimensional Scaling (MDS) plot. The proximity of surveyed ports to each other indicates similarity in species (based on presence/absence data) ......................35

Figure 2.3.3. Multidimensional Scaling (MDS) plot. The proximity of surveyed ports to each other indicates similarity in community composition as a function of port type. 41

Figure 2.3.4. Multidimensional Scaling (MDS) plot. The proximity of surveyed ports to each other indicates similarity in community composition as a function of latitudinal groups.....43

Figure 2.3.5. The total relative number of species status - native, non-native and cryptogenic species across 27 surveyed ports.

Figure 2.3.6. Correlation between relative native and non-native species across 27 surveyed ports; a) Native vs Cryptogenic species, b) Cryptogenic vs Non-native species and c) Native vs Non-native species.......................................................... 50

Figure 2.3.7. SIMPER analysis: Percent contribution of species status- native, non-native, cryptogenic to the average similarity as a function of surveyed port.....................51

Figure 2.3.8. Multidimensional Scaling (MDS) plot. The proximity of surveyed ports to each other indicates similarity in species status (native, non-native, cryptogenic) as a function of port type...

Figure 2.3.9. Multidimensional Scaling (MDS) plot. The proximity of surveyed ports to each other indicates similarity in species status (native, non-native, cryptogenic) as a function of latitudinal groups..........................................................54

Figure 2.4.1. The total relative number of species across all 15 surveyed ports...............58

Figure 2.4.2 Multidimensional Scaling (MDS) plot. The proximity of surveyed ports to each other indicates similarity in community composition as a function of port type.............63

Figure 2.4.3. Multidimensional Scaling (MDS) plot. The proximity of latitudes to each other indicates similarity in the community composition.

Figure 2.4.4. The total relative number of species status - native, non-native and cryptogenic species across 15 surveyed ports. 
Figure 3.2.1. Map of Wellington Harbour, New Zealand, indicating natural reef and man-made habitats (marinas) as sampling sites for the study....

Figure 3.2.2. Set-up of settlement tiles deployed in the a) marinas and at b) natural reef sites; c) front view and d) side view of the PVC and slate substrata. .90

Figure 3.2.3. Representative PVC and slate tiles collected in the study, showing the community growth at a first sampling interval (Nov 2017) and last sampling interval (Aug 2019).... .94

Figure 3.3.1. Species accumulation curves for observed species $\left(\mathrm{S}_{\mathrm{obs}}\right)$ and non-parametric estimators of species count richness (Chao1, Jacknife1, Bootstrap). .97

Figure 3.3.2. Temporal variation of average bare space availability (\%) and species richness (\%) for the 2-year study....

Figure 3.3.3. Two-dimensional MDS plot based on community composition between a) habitat type (marina and reef) b) substratum type (PVC and slate), and c) sampling interval (1-8)..100

Figure 3.3.4. MDS ordination of temporal variation of the fouling community on three marina sites and reef sites 101

Figure 3.3.5. The percent cover of top 8 major consistent species contributing to within-group similarity for each sample interval indicating variations with time at a) man-made habitat b) natural habitat c) man-made substratum and d) natural substratum.

Figure 3.3.6. Temporal change in the number of species with respect to - species status (native, non-native and cryptogenic) as a function of habitat type (Reef vs Marina).

Figure 3.3.7. Temporal change in the number of species with respect to the species status (native, non-native and cryptogenic) as a function of substratum type (Slate vs PVC)

Figure 3.3.8. Correlation of number of native and non-native species as a function of time at a) habitat type (Reef vs Marina); b) substratum type (Slate vs PVC). 116

Figure 4.2.1. Map of Wellington Harbour, New Zealand. Points denoting marinas as man-made structure sites and natural rocky reefs as natural sites for this study.

Figure 4.2.2. Illustration representing the measurements taken for shell length, height and width; a) frontal view; b) lateral view.

Figure 4.3.1. Total number of Northern hemisphere (NHMg- non-native) and Southern hemisphere (SHMg-native) Mytilus galloprovincialis at the marina and reef habitats

Figure 4.3.2. Monthly variations of the GSI values of SHMg and NHMg lineages at a) marina and b) reef habitats in Wellington Harbour from June 2017 - May 2018. 138 


\section{CHAPTER 1}

\section{GENERAL INTRODUCTION}

\subsection{Modification of marine ecosystems}

Marine ecosystems provide a large number of ecological benefits, including complex habitats for marine biodiversity and socio-economic benefits, including tourism, fisheries, mariculture and trade (Costanza et al. 1997, 2014). More than $40 \%$ of the world's population lives along the coastline leading to exploitation of marine resources and altering the coastline by building coastal infrastructures (Dafforn et al. 2015a; Dafforn et al. 2015b). With an increase in the human population, an increase in demand for food and energy production is evident. More than $90 \%$ of global trade is dependent on marine shipping routes, resulting in the building of numerous shipping ports and berths on the coasts (Kaluza et al. 2010; Cope et al. 2015). Additionally, natural phenomena such as storms, flooding, erosion, and sea-level rise due to climate change have led to the building of coastal defence structures such as seawalls, groynes and breakwaters (Naylor et al. 2012; Hinkel et al. 2014). Subsequently, the profound changes to the coastlines due to the dominance of man-made structures are called 'ocean sprawl' (Duarte et al. 2013; Firth et al. 2016). This proliferation of 'ocean sprawl' has already modified up to $70 \%$ of coastlines around the world and a rise in this percentage can be expected in the future (Bulleri \& Airoldi 2005; Dafforn et al. 2015b).

Studies focussing on changes to the biological species assemblage following the changes in habitats have been fundamental in ecology studies. Early studies concentrated on how the man-made structures modify coastal marine communities (Connell \& Glasby 1999; Bacchiocchi \& Airoldi 2003; Chapman \& Bulleri 2003; Moschella et al. 2005). These studies further developed to examine if man-made structures can be surrogates for the natural rocky reefs (Bulleri \& Chapman 2010; Perkol-Finkel et al. 2012; Carvalho et al. 2013; Pastro et al. 2017). The results clearly show the alteration of the local habitats as well as local community (Browne \& Chapman 2011; Perkol-Finkel et al. 2012; Firth et al. 2013; Serrano et al. 2013). Furthermore, man-made habitats are often shown to support different marine communities compared to natural rocky reefs (Moschella et al. 2005; Perkol-Finkel et al. 2006; Clynick et al. 2007; Lam et al. 2009; Bulleri \& Chapman 2010; Airoldi \& Bulleri 2011; Chapman \& 
Underwood 2011; Bulleri \& Chapman 2015; Lai et al. 2018). For example, relatively low numbers of individuals (with associated low species diversity), high abundances of early colonisers, opportunistic and non-native species colonised man-made structures.(e.g. Glasby et al. 2007; Vaselli et al. 2008; Dafforn et al. 2009; Bulleri \& Chapman 2010; Airoldi \& Bulleri 2011; Chapman \& Underwood 2011; Firth et al. 2011, 2015; Dafforn et al. 2012; Floerl et al. 2012; Mineur et al. 2012; Bracewell et al. 2013; Airoldi et al. 2015; Pastro et al. 2017). The realisation of facilitation of non-natives due to proliferation of man-made coastal structures has only been relatively recent (Thompson et al. 2002; Airoldi et al. 2005; Chapman \& Underwood 2011; Kueffer \& Kaiser-Bunbury 2014; Firth et al. 2016; Bishop et al. 2017; Dafforn et al. 2017).

Commercial shipping ports, harbours, seawalls and other man-made structures play an important role in providing suitable habitats 'hot-spots' and act as 'stepping stones' for the introduction of species (Apte et al. 2000; Moschella et al. 2005; Clark \& Johnston 2009; Bulleri \& Chapman 2010; Dumont et al. 2011; Firth et al. 2013, 2015; Rivero et al. 2013; Firth et al. 2016; Johnston et al. 2017). For example, hard coastal structures along the North Adriatic, Italy (Bacchiocchi \& Airoldi 2003; Airoldi et al. 2005) and along the coast of the Yangtze River, China (Ma et al. 2014; Huang et al. 2015) create corridors for species expansion. The high supply of introductions (propagule pressure) at port areas due to receiving marine traffic (e.g. biofouling and ballast water discharge) results in a high probability of successful establishment of non-native species in port areas (Lockwood et al. 2005; Clark \& Johnston 2009; Johnston et al. 2009; Lo et al. 2012).

Marine trade around the world is thought to have transported thousands of species through accidental introductions such as ballast water tanks and attachment on ship hulls (Gollasch et al. 2002; Hewitt et al. 2009). Attachment and detachment of species on the hulls of vessels and exchange of large volumes of ballast water holding numerous planktonic species, larvae and egg masses are major marine pathways for marine introductions (Hewitt and Martin 2001; Campbell et al. 2007; Hewitt et al. 2009; Lo et al. 2012). The marine vessels form connectivity pathways linking all the major shipping ports and harbours, thereby exchanging marine species from their native habitat to a new environment (Apte et al. 2000; Wyatt et al. 2005; Clark \& Johnston 2009; Clarke et al. 2011; Hopkins et al. 2011a; O'Brien et al. 2017). Marine transport facilitates a steppingstone model for the spread of species by overcoming biogeographical barriers and by providing direct introductions (Adams et al. 2014). Regional domestic marine traffic and recreational boating may then act as a secondary source of non- 
native species dispersal within a country (e.g. Forrest et al. 2009; Clarke \& Johnston 2011; Hänfling et al. 2011). For example, the non-native tunicate, Didemnum vexillum, was first introduced in New Zealand in 2001 and has spread over various harbours and ports on marine vessel hulls and ballast water (Coutts \& Forrest 2007).

\subsection{Man-made habitat characteristics and impacts}

Development of coastal man-made structures has led to the displacement of natural habitats resulting in habitat loss and fragmentation, thereby altering physical, chemical and biological environments (Dugan et al. 2012; Firth et al. 2016; Todd et al. 2019). Man-made structures differ in terms of physical aspects to adjacent natural reefs, factors including structure materials (e.g. wood, plastic, cement) (Andersson et al. 2009; Burt et al. 2009; Chapman \& Blockley 2009; Spagnolo et al. 2014; Tan et al. 2015; Cacabelos et al. 2016; Johnston et al. 2017; Albano \& Obenat 2019), vertical orientation (e.g. seawalls, breakwaters) (Andersson et al. 2009; Perkol-Finkel et al. 2012; Albano \& Obenat 2019; O'Shaughnessy et al. 2019), surface complexity (e.g. smooth flat surfaces) (Perkol-Finkel et al. 2012; Ferrario et al. 2016), movement (e.g. floating pontoons) (Holloway \& Connell 2002) and age (newly built structures) (Perkol-Finkel et al. 2006; Burt et al. 2011; Dong et al. 2016). There is growing evidence of non-native species taking advantage of these built structures, which is not the case for local species (Bulleri \& Airoldi 2005; Glasby et al. 2007; Tyrrell \& Byers 2007; Vaselli et al. 2008; Ruiz et al. 2009; Dafforn et al. 2012; Mineur et al. 2012; Duarte et al. 2013; Airoldi et al. 2015; Ferrario et al. 2016).

Man-made structures may form physical barriers obstructing ecological connectivity (e.g. larval dispersal and movement of mobile species), nutrient flow, altering genetic and trophic connectivity (Moschella et al. 2005; Airoldi et al. 2010; Duarte et al. 2013; Adams et al. 2014; Firth et al. 2016; Moss 2017). Loss of connectivity between species results in biotic homogenisation, thereby altering ecosystem functioning and ecosystem services (PerkolFinkel et al. 2011; Macdonald \& King 2018; Mayer-Pinto et al. 2018a; Mayer-Pinto et al. 2018b). For instance, species with low dispersal potential may fail to overcome physical barriers and settle at short distances, however, with time the genetic diversity decreases resulting in a reduced gene pool (Fauvelot et al. 2009; Sammarco et al. 2012). This limitation of the spread of species to regional scales may lead to changes in the biogeographic ranges of species (Schiel 2011). Construction of offshore structures provides a steppingstone for the spread of species across biogeographical boundaries (Adams et al. 2014). Therefore, it is 
essential to evaluate the ecological impacts of man-made structures on the local marine ecosystem at local, regional and national scales (Airoldi, et al. 2005; Ma et al. 2014).

Movement of marine vessels in marinas and the building of new structures along the coast cause physio-chemical disturbances and may affect both the marine biodiversity and the invasibility of communities (Clark \& Johnston 2011; Ceccherelli et al. 2014). Physical disturbances can cause sedimentation, displacement of the intertidal community, and provide bare substrata (Guerra-García et al. 2004; Oricchio et al. 2016; Pastro et al. 2017). Studies have shown a subsequent increase in occupancy of bare substratum by non-native species and opportunistic species (Sousa 1979; Paine \& Levin 1981; Sousa 1985; Airoldi et al. 2000; Erlandsson et al. 2006). For example, physical removal of seagrass due to anchoring and dredging led to the fragmentation of seagrass habitat, which promoted the spread of the nonnative green alga (Ceccherelli et al. 2014). Several manipulative experiments, for example, applying disturbance (e.g. dredging) to reduce the already existing local species cover resulted in the habitat to be susceptible to invasions (Valentine \& Johnson, 2003; Airoldi \& Bulleri 2011; Clark \& Johnston 2011; Bulleri et al. 2016).

The modification of environments may result in changes to biological interactions, distribution of species and ecosystem functioning, at both natural and man-made environments (Bulleri \& Chapman 2010; Boström et al. 2011; Knights et al. 2012; Johnston et al. 2017). For instance, limited resource availability can alter prey-predation interactions (Kimbro et al. 2009). Therefore, species-specific interactions and life-history traits of species determine the negative and positive connectivity between lower and higher trophic levels and genetic transfer between species (Boudouresque \& Verlaque 2012; van de Koppel et al. 2015; Firth et al. 2017). Ocean sprawl and alteration of natural habitats may cause changes to the energy allocation of species for reproduction, growth or survival (Mayer-Pinto et al. 2018). At disturbed habitats and low resource availability, the species tend to allocate/ exert more energy towards survival and feeding instead of reproduction and growth (reviewed in Bishop et al. 2017). For instance, seawalls exhibit relatively reduced reproductive output of limits with fewer and small egg masses compared to adjacent natural rocky reefs (Moreira et al. 2006). However, it is still not evident if there is a difference observed in the energy exertion by native and invasive species on man-made or disturbed habitats. 


\subsection{Bioinvasions}

Biological invasion, i.e. bioinvasions, in a broad sense, means the movement of local species from their native habitat to a new environment (Olenin et al. 2017). Bioinvasions are ubiquitous and universally accepted as one of the significant threats to marine biodiversity and the global economy (Ojaveer et al. 2015; Gestoso et al. 2017; Olenin et al. 2017; Simpson et al. 2017). Apart from human-mediated spread of species through maritime transport, the species show natural range expansion due to changing global climate (Occhipinti-Ambrogi 2007). With changing climates, the species have been showing anti-equatorial shift, i.e., moving from highly diverse, warm equatorial regions to slightly cooler, less diverse temperate regions (higher latitudes) 'Latitude diversity groups hypothesis' (Darwin 1860; Sax 2001). Biological stresses are important in natural selection and evolution of species (Lockwood et al. 2005). The colder environmental temperatures in the temperate regions may hinder the natural selection processes. However, this is not the case in terms of tropical regions (Currie et al. 2004). The introduction of species in higher latitudes can lead to competition among species (introduced and local species) for habitat and food, change predator-prey interactions or cause co-existence (Shea \& Chesson 2002; Jeschke et al. 2012; Marraffini \& Geller 2015; Papacostas et al. 2017).

There are many terminological ambiguities around the definition of non-native species. Throughout the invasion process, the species are called 'introduced species', once established they are called exotic, non-native, non-indigenous or alien species. However, when the species causes negative impacts in the marine habitats they are termed 'invasive' or 'unwanted species' but when the species is introduced without causing any adverse effects in the habitat are 'naturalised' species (Lockwood et al. 2005). There have been emerging studies related to 'invasion biology', non-native species and their impacts on the native assemblages and permanent destruction of marine ecosystems where they are introduced (Johnston et al. 2015). Knowledge about mitigation and management approaches towards marine invasions, and human impacts have also been growing in recent years (Moschella et al. 2005; Pyšek \& Richardson 2010; Airoldi \& Bulleri 2011; Airoldi et al. 2015; Dafforn et al. 2015; Dafforn 2017).

\subsubsection{Invasion ecology}

Invasion ecology is the study of establishment, spread and ecological impact of species translocated from their natural geographical boundaries (Lockwood et al. 2007). Specific individuals within a species or group of species which are successful colonisers and immigrants that expand their native range are called invasive species. However, not all invasive species 
can survive in new environments. The invasive species tend to disrupt the already existing species community therein to affect the species interaction and further poses a threat to the marine ecosystems (Shea \& Chesson 2002). Consequently, studies related to biological invasions, also called as 'invasion ecology' has gained much attention to investigating the ecology and evolution of populations and their interactions to maintain the natural ecosystems (Ricciardi 2007).

Elton (1958) first identified biological invasions as an ecological threat, since then ecologists around the world have made efforts to understand the patterns of non-native species, their establishment - successful or failed, spread and impacts on natural ecosystems once established. Considerable progress has been made in understanding the species traits such as life history, genetic and other biological characteristics promoting invasion (Ehrlich 1984; Sakai et al., 2001; Callaway \& Ridenour 2004; Snyder \& Evans 2006). Recently much work has been focussed on developing methods to predict and even quantify the impacts of nonnative species (Hewitt et al. 2009; Ruiz et al. 2011). Invasion ecology thus far could guide managers and policymakers to identify the risks of invaders and undertake appropriate management plans.

To understand and to reduce the impact of invasive species on ecosystem functioning, it is crucial to identify the key mechanisms which contribute to the invasion success of a species. Most of the invasion conceptual framework theories are dependent on factors such as a) human-mediated activities move species overcoming environmental, physical or biological barriers (Campbell \& Hewitt 1999; Carlton \& Rutz 2005; Hewitt et al. 2009; Ruiz et al. 2011), b) despite the increase in invasive species into novel environments, invasion success is low and variable (Williamson 1996; Sala et al. 2000), c) the number and quality of offspring released into a novel environment i.e. 'invasion pressure' or the 'propagule pressure' is important for the establishment and success of non-native species (Lockwood et al. 2009), d) the traits of non-native species determine the rate of spread and invasion success (competitive abilities, ecological and evolutionary species history), e) biotic interaction hypotheses- 'biotic acceptance' by native species to establishment and coexistence of non-native species, 'competitive release hypothesis' where non-native species are released from competition with the native competitors or no competitors for food and space (Sorte et al. 2010), 'biotic homogenisation' of replacement of native species by non-native species (McKinney \& Lockwood 1999), 'biotic resistance' by native species to the establishment of non-native species (diversity-invasibility hypothesis) (Elton 1958), 'invasional meltdown' is where the non-native 
facilitates establishment and spread of other non-native species (Simberloff \& Von Holle 1999; Simberloff 2006).

\subsubsection{Invasion stages}

The typical biological invasion process includes steps such as introduction, establishment, spread and impact (Hulme 2006). The non-native species are introduced through human mediation (e.g. shipping) or natural processes (e.g. rafting) from their native environment to a new environment. The invasion through human mediation helps the nonnative species to overcome biogeographical barriers (Gribben et al. 2013; Adams et al. 2014). However, once introduced to a new environment, the non-native species must overcome environmental barriers (e.g. temperature, salinity) to the successful establishment (reviewed by Olenin et al. 2017). The probability of the species' successful establishment in a new environment is influenced by the species' life-history traits and the environmental conditions of the receiving habitat (Glasby et al. 2007; Petes et al. 2008; Piola et al. 2009; van de Koppel et al. 2015; Fava et al. 2016; Firth et al. 2017; Purroy et al. 2019). There is evidence of nonnative species being relatively competitive and adaptable to harsh and disturbed environments. These competitive and adaptable traits of non-native species help them overcome biological (e.g. predation) and environmental stressors (e.g. turbidity) (Leppäkoski et al. 2002; Bownes \& McQuaid 2010; Marraffini \& Geller 2015).

Propagule pressure plays an important role in the successful establishment of nonnative species, i.e. potential for introduction (Johnston et al. 2009). The 'propagule pressure' includes not only the number of arriving individuals in an area (propagule supply) but also the rate at which they arrive (propagule frequency) (Lockwood et al. 2005). For instance, ports and marinas are areas that are susceptible to invasions due to marine traffic bringing with it increased propagule pressure (e.g. biofouling and ballast water exchange) (Lockwood et al. 2005; Clark \& Johnston 2009; Lo et al. 2012). It is often presumed that of the vast number of introductions, only a few introductions are successful (Leppäkoski et al. 2002). However, it is difficult to determine the number of successful introductions and more challenging to quantify the number of failed introductions due to the lag phase, i.e. the time between introduction and spread/ expansion of the non-native species (Mack et al. 2000). This lag phase might last for years or decades due to differences in environmental conditions, genetic factors and habitat heterogeneity (Melbourne \& Hastings 2009; Zaiko et al. 2016). For instance, where introductions are relatively frequent, the invasive species may show overall positive effects after establishment, i.e. 'equilibrium state' (Clark \& Johnston 2011). 
Once a non-native species has established, it may spread at regional levels to new environments (Forrest et al. 2009), i.e. the expansion phase. The spread of the species may be due to domestic, commercial ships or recreational boats and spread may also be via larval dispersal which is highly dependent on larva dispersal potential (Forrest et al. 2009; Fava et al. 2016). Species with a low larval dispersal rate will settle at semi-enclosed ports and harbours and can only spread to regional distances through human mediation (Johnston et al. 2011). Following the successful introduction, establishment and spread of the non-native species, there may be possibilities for negative and positive impacts on the marine ecosystem and economic services (Hänfling et al. 2011; Oliver et al. 2015). For example, a recent metaanalysis reported that $35 \%$ of non-native species have a positive impact on other species (Katsanevakis et al. 2014). Many non-native species may facilitate other non-native species which may be harmful, and that can impact the native environment, native species and the economy (Simberloff \& Von Holle 1999; Leppäkoski et al. 2002; Hänfling et al. 2011; Simberloff et al. 2013; Oliver et al. 2015).

\subsubsection{Non-native species - characteristics and impacts}

Most of the non-native species have r-selected life-history traits, where the species have high fecundity, small-sized, have early maturity, competitive, phenotypic plasticity and can live in a novel low-quality environments (Glasby et al. 2007; Petes et al. 2008; Piola et al. 2009; Fava et al. 2016; Purroy et al. 2019). Few experimental studies comparing the native and non-natives and their response to pollution (e.g. metal pollution, turbidity) indicated high tolerance to pollutants and increased non-native species dominance with increased pollution (Piola \& Johnston 2008; Crooks et al. 2011; Johnston \& Keough 2011). These traits help the non-native species to rapidly colonise the available substratum even in disturbed coastal habitats and thereby contribute to invasion success (Marraffini \& Geller 2015). However, the success of their introduction is dependent on the abundances and competitive abilities of native species. For example, there is evidence of relatively less occupancy of native species on manmade structures, i.e. absence of competitors or predators of non-native species, thereby resulting in successful invasion 'enemy release hypothesis' (Shea \& Chesson 2002; Bulleri \& Airoldi 2005; Glasby et al. 2007; Tyrrell \& Byers 2007; Vaselli et al. 2008; Ruiz et al. 2009; Dafforn et al. 2012; Jeschke et al. 2012; Mineur et al. 2012; Duarte et al. 2013; Airoldi et al. 2015; Ferrario et al. 2016; Papacostas et al. 2017).

Studies have suggested that man-made habitats have a negative impact on the adjacent natural habitats especially in terms of modifications to water flow, sedimentation, nutrient 
transport, light availability and turbidity (Dugan et al. 2012; Dafforn et al. 2015a; Heery et al. 2018) and native community structure (Byers 2000; Ojaveer et al. 2002; Rodriguez 2006; Browne \& Chapman 2014; Airoldi et al. 2015; Tan et al. 2015; Ferrario et al. 2017). Competition for resources and food utilisation between native and non-native species can lead to 'competitive exclusion' of native species as non-native species have high levels of phenotypic plasticity (Griffen et al. 2011). However, with time, displacement/replacement of native species impairs 'biotic resistance' by reducing species diversity, species interactions and alter trophic level (top-down or bottom-up trophic cascades) at natural habitats (reviewed by Johnston et al. 2011; Bulleri et al. 2016; Johnston et al. 2017; Skein et al. 2020). 'Biotic resistance' resulting from an increased number of native species and/or individuals, competition between native and non-native species and/or predation pressure by native species on non-native species may contribute to invasion failure (reviewed by Johnston et al. 2017; Skein et al. 2020). Recent management approaches consider monitoring the performance of the key species at different trophic levels, reduction of key species and alterations in species interactions may aid as predictors of possible invasions as the native species may not support biotic resistance (Bulleri et al. 2016; Skein et al. 2020).

Multiple introductions, i.e., increased propagule pressure, may result in changes to the evolutionary and adaptation processes at genetic levels (Roman \& Darling 2007; Hänfling 2007; Hänfling et al. 2011). The multiple introductions influence hybridisation between native and non-native species (Hänfling 2007; Chan \& Briski 2017). The increased exchange of alleles makes the non-native more adaptable whereas there are some instances where the hybrid individuals perform better than the parent lineages (Williams \& Grosholz 2008; Hänfling et al. 2011; Franscisco et al. 2018). Hybridisation further raises concerns of genotypic displacement of native species by non-native species (reviewed by Geller et al. 2010; Johnston et al. 2011; Saarman \& Pogson 2015; Bulleri et al. 2016; Johnston et al. 2017; Skein et al. 2020). Molecular genetic studies have been used for many years to identify the origin, pathways of introductions and interactions of closely related native and non-native species (Daguin \& Borsa 2000; Goldstien et al. 2013; Westfall \& Gardner 2013; Tay et al. 2015; Gardner et al. 2016; Oyarzún et al. 2016; Larraín et al. 2018). However, the question remains whether the rate of native species displacement increases or decreases with the interbreeding of native and non-native genotypes. 


\subsection{Management and Mitigation}

With changing global climate and the vastness of marine systems, it is difficult to detect, investigate, manage marine bioinvasions, and predict future impacts on the marine environment and economy (Firth et al. 2016). Growing evidence of adverse effects of marine urbanisation and bioinvasions has raised the need for ecologically-driven planning and long-term mitigation and management approaches (Airoldi et al. 2005; Airoldi \& Beck 2007; Bulleri \& Chapman 2010; Airoldi \& Bulleri 2011; Browne \& Chapman 2011; Perkol-Finkel et al. 2012; Firth et al. 2014).

\subsubsection{Marine port management approaches}

The most critical approach in the management of non-native species is to prevent introductions (Hulme 2006). Pre-border, at-border and post-border management measures have been undertaken in different countries around the globe (e.g. Australia and New Zealand). These measures help to reduce successful introductions, establishment and spread of nonnative species in the recipient environment (Hewitt \& Campbell 2007; Forrest at al. 2009; Hopkins et al. 2011b; Ojaveer et al. 2015). Effective preventive measures are mainly conducted on the human-mediated vectors that may involve ballast water treatments and hull maintenance 'anti-fouling' to avoid propagule pressure (Secord 2003; Hewitt and Campbell 2007; Coutts et al. 2010a, 2010b; Tamelander et al. 2010; Hopkins et al. 2011b. For example, the New Zealand Government developed a preventive management action, Craft Risk Management standard to minimise the arrival and spread of non-native biofouling species through marine vectors (MPI 2014). Such management approaches to limit their spread has been undertaken by many countries and have shown gradual effectiveness (GloBallast 2014 and GloFouling 2017).

The International Marine Organisation's (IMO) International Convention for the Control and Management of Ships' Ballast Water and Sediments" implemented ballast water management plans and recorded the per tank basis onboard mid-ocean ballast water exchange as the intermediate solution (IMO 2017). IMO created the GloBallast and GloFouling programmes that provide training, technical support and help with ballast water management and antifouling methods. However, no international regulations have been established to prevent the regional spread of non-native species through domestic marine trade or recreational boating (Forrest et al. 2009; Sinner et al. 2013; Inglis et al. 2014). There have been management ideas to establish contingency de-ballasting zones to discharge the ballast water safely (Hobday et al. 2002); however, establishing suitable areas for the same is still a struggle. Goldsmit et al. 
(2019), examined two alternative de-ballasting zones in eastern Canada through these zones were formed without any scientific ecological assessments. The authors described the locations to be the primary route for marine traffic in the eastern Canadian Arctic, thereby risking the establishment of non-native species at coastal areas (Goldsmit et al. 2019).

New introductions of non-native species are still likely as some introductions go undetected and establish before they are reported (Ruiz et al. 1999; Hewitt et al. 2004; Floerl et al. 2009). It is important to have surveillance or risk-assessment to detect non-native species early on to enable fast and more effective eradication response (Hewitt \& Campbell 2007; Gardner et al. 2016; Zaiko et al. 2016). For example, successful eradication of the invasive black striped mussel in Darwin Harbour occurred within 6-7 months of its detection (Willan et al. 2000). However, such successful detection and eradication of non-native species are infrequent (Hopkins et al. 2011a). For instance, eradication programmes of the fouling pest, Didemnum vexillum, failed miserably in New Zealand due to its widespread - first recorded in 2001 in Whangamata, North Island after its establishment but quickly spread to the South Island on barges, recreational vessels and moorings (Coutts \& Forrest 2007). The attempt to eradicate D. vexillum from New Zealand cost NZ\$2.2 million (Biosecurity New Zealand 2010). Therefore, cost-effective and timely eradication approaches are necessary for positive ecological and economic impacts. Even though a species has been eradicated, it may be required to have a continuous survey and monitoring of high-risk pests to enable quick detection of re-introductions (Hewitt et al. 2004, de Rivera et al. 2005; Campbell et al. 2007; Brockerhoff et al. 2010; Tobin et al. 2014). Local fishers, local boat owners and commercial vessel operators should be made aware of high-risk marine pest species through educational or awareness programmes (Pollard \& Pethebridge 2002).

\subsubsection{Marine ecosystem monitoring}

In the light of increasing pressures on the marine ecosystem globally, the impacts on the ecological and environmental conditions and the conservation and management of marine biodiversity is a complex issue. Monitoring is a crucial component in marine management; it provides a more consistent spatial and temporal analysis of different chemical, physical and biological parameters in a marine system. These programmes offer integrated knowledge of the current functioning of the ecological systems and the disturbances caused by human impacts. Appropriate evaluations of data can determine the effectiveness of the surveys and monitoring programmes, report key gaps and weaknesses for future monitoring (Miller et al. 2019). The monitoring reports provide scientific advice to the stakeholders and managers to 
take adequate conservation planning and successful management measures (Hewitt et al. 2004; Hewitt \& Campbell 2007; Ojaveer et al. 2018).

Monitoring programmes' key role is to provide an understanding of community structure (species abundance, species diversity, spatial distribution, species status), the health of the habitat, environmental conditions and socio-economic characteristics and impacts. Different monitoring techniques provide the different type and quality of information. Standardised protocols and consistent survey designs will help achieve the purpose of the surveys (Hewitt \& Martin 2001). Baseline assessment of an area provides information about the overall species diversity for temporal and spatial variations in species composition. Species diversity is one of the indicators of the functioning of trophic levels in marine ecosystems. Species diversity affects the top-down (prey-predators) and bottom-up (space and nutrients) interactions which are fundamental in the functioning of marine ecosystems (Paine 1966). Species diversity can be quantified by species richness, species abundances, species composition and species interactions. These assessments provide an opportunity to understand the changes in ecosystems and species diversity due to human impacts. Long-term surveys detect effects of environmental variables on species diversity, composition, abundances and spread of non-native species (Branch et al. 2008; Goldstien et al. 2013). Species-specific surveys focus on a particular species or taxa and its ecosystem functioning; in contrast, highrisk pest surveys concentrate on detection and quantification of high-risk invasive species to form effective management and eradication plans (Hewitt et al. 2004, de Rivera et al. 2005; Campbell et al. 2007; Brockerhoff et al. 2010; Tobin et al. 2014).

Monitoring surveys act as tools to detect invaders and implement rapid management and eradication strategies (Hewitt \& Campbell 2007). Early detection is critical for effective control and eradication. Several countries in recent years have adopted national scale surveys to identify the already entered non-native species as well as new arrivals (Simberloff 2003; Olenin et al. 2014; Ojaveer et al. 2016). Monitoring surveys provide a baseline for native and non-native biodiversity, which will further inform about the impacts of invasions on the biodiversity. For instance, nationwide based Australian port surveys with standardised CRIMP protocols and designs aimed to examine the marine biological invasions in Australian waters (Hewitt \& Martin 1999, 2001). In addition, the New Zealand government implemented marine biosecurity monitoring strategies focussed on nationwide baseline surveys, New Zealand Port Biological Baseline Survey Marine (NZPS). Development of NZPS led to form monitoring surveys for target species, i.e. High-Risk Site Surveillance Programmes (Woods et al. 2015). 
The high dispersal rate of marine species has implications for the geographic distribution and genetic connectivity among marine populations. Therefore, the dispersal potential of various species can be tested using genome divergence patterns. Development of molecular techniques for genetic analyses helps analyse the genetic connectivity among populations (Palumbi 2000). However, the use of molecular tools in invasion ecology have been adopted in recent years (Holland 2000; Ruiz \& Fofnoff 2000). The molecular techniques (PCR tools and genetic markers) examine the genetic structure of native and non-native species and their geographic distribution (Ruiz \& Fofnoff 2000; Holland et al. 2004; Goldstein et al. 2011). Several molecular studies now are focussing on early detection of non-native species and provide optimal identification of non-native species especially congeners which are morphologically similar to their native species (Darling \& Blum 2007; Pochon et al. 2013). Several countries, including the USA, Canada, New Zealand, and Australia have already adopted molecular techniques to survey non-native species and aid management decisions (Geller et al. 2020; Ruis et al. 2015; Zaiko et al. 2015, 2018). For successful monitoring and management plans, it is crucial to have a robust taxonomic foundation. Current limited taxonomic knowledge and decline in taxonomic specialists are a big concern to have effective monitoring and management programmes. Misidentification of introduced species may lead to cryptic invasions, and most of the non-native species remain unnoticed. Molecular analyses, together with large-scale surveys, form the basis of rapid and effective monitoring programmes, however, are costly and time-consuming.

\subsubsection{Mitigation approach - Eco-engineering}

Human-mediated vectors are mostly responsible for initial transport of non-native species from their native ranges, whilst anthropogenic urbanised habitats facilitate invasion success, establishment and further spread (Mineur et al. 2012; Airoldi et al. 2015; Johnston et al. 2015; Ferrario et al. 2017). Recent management attention has focussed on re-designing and engineering coastal structures to have multifunctional uses, i.e. benefit ecosystems and economic services via 'eco-engineering' or 'green engineering' (Chapman \& Underwood 2011; Dafforn et al. 2015; Morris et al. 2019). Marine urbanisation and bioinvasions are ubiquitous and are predicted to increase in the coming years. Studies adopting eco-engineered coastal structures have revealed enhanced habitats and enhancing the biodiversity of different functioning species groups (Morris et al. 2017, 2019; Strain et al. 2018). Hence, there is a strong argument to focus on the design of the structures not just to enhance assemblages but to target specific species or taxa (Correia et al. 2013). For example, increased micro-habitats on 
seawalls reduced fish predation on native mussel species (Strain et al. 2018b) and reduced shading improved native species growth (Dafforn et al. 2012). Studies have shown increased colonisation of benthic encrusting species such as algae, barnacles, mussels and oysters to promote a 'bioprotective effort', i.e. contributing to the structure's stability and longevity. For instance, to increase protection against extreme environmental conditions, e.g. fluctuating temperature or wave action (Coombes et al. 2013; Coombes et al. 2015). Another factor to consider whilst re-assessing man-made structures and the ecological processes that occur on them is to preserve the natural marine biodiversity (Perkol-Finkel et al. 2012; Dafforn et al. 2015). An increase in native biodiversity will facilitate enhanced biotic resistance and may help to reduce or avoid invasions, i.e. 'bio-control' (reviewed by Johnston et al. 2017; Skein et al. 2020).

Increased complexity on the surfaces of coastal man-made structures such as the addition of rockpools, crevices, and cracks provides refuges for organisms, thereby increasing biodiversity and modifying community structure (Moreira et al. 2007; Chapman \& Blockley 2009; Loke et al. 2014; Loke \& Todd 2016; Morris et al. 2019). Addition of overhangs or flowerpots increased species assemblage by $65 \%$ out of which 25 species were not previously observed (Browne \& Chapman 2011). Engineering of cost-effective hybrid structures such as revetments, tetra-pods, and geo-tubes can provide substrata where natural habitats have declined (Moschella et al. 2005; Chapman \& Underwood 2011; Browne \& Chapman 2014; Firth et al. 2014; Loke et al. 2014). For example, the endangered seahorse, Hippocampus whitei inhabits specially designed eco-engineered artificial habitats' Seahorse Hotels' in Port Stephens, New South Wales, Australia due to significant decline in natural habitats (Simpson et al. 2019). The field of eco-engineering requires stakeholders, engineers and scientists to work together and produce new strategies for the design and deployment of coastal structures that will reduce the opportunities for non-native species (Dafforn et al. 2009; O'Shaughnessy et al. 2019).

To summarise, it is well established that marine built systems have a negative impact on marine biodiversity and facilitate non-native species ( Bulleri \& Chapman 2010; Airoldi \& Bulleri 2011; Chapman \& Underwood 2011; Clark \& Johnston 2011; Firth et al. 2011, 2015; Dafforn et al. 2012; Airoldi et al. 2015; Firth et al. 2016; Dafforn et al. 2017; Bishop et al. 2017; Pastro et al. 2017). High introduction rates of non-native species at port areas through marine traffic have resulted in the spread of non-native species from port to port, and also to natural (i.e., not modified by human activities) areas. International and domestic shipping plays 
a vital role in transporting non-native species at regional to national scales (Hewitt, 2002; Lockwood et al. 2005; Clark \& Johnston 2009; Johnston et al. 2009; Ruiz et al. 2011; Lo et al. 2012). For example, the economies of Australia and New Zealand are dependent on international maritime trade (Piola \& McDonald 2012). With their unique coastlines and given the high levels of endemism amongst Australia and New Zealand's marine biota, many preventive marine biosecurity and management strategies have been developed and implemented by both countries to control marine invasion risks (Hewitt \& Campbell 2007; DoE 2015; DAWR 2017, 2019; MPI 2018). However, there is no infallible solution to the invasion problem.

The first major step before attempting to control the introduction and spread of nonnative species is to determine the current distribution and abundance of non-native species (Hewitt \& Campbell 2007; Coutts \& Forrest 2007; Kaiser \& Burnett 2010; Simberloff et al. 2013). Surveys at heavily disturbed and modified port areas help keep a record of the native species present and to detect non-native species so that further action (e.g., eradication or containment) may be carried out. It is necessary to understand better how such non-native species may respond to challenges raised by the ongoing development of the built environment at local, regional and national scales. Baseline monitoring surveys are critical to answer such questions, which will help planners and managers better understand how built structures in heavily developed areas such as ports influence native biodiversity, contribute to bioinvasions and modify the health of the marine environment. Increased maritime traffic with the proliferation of construction of marine harbours, ports, seawalls, and breakwaters along the coasts raise the risk of bioinvasions and its subsequent spread (Floerl et al. 2009; Seebens et al. 2013). Bioinvasions can lead to devastating and unforeseen impacts on new environments. The effect of marine built systems on marine biodiversity and determining the influence on native and invasive species is increasingly important. In this thesis, I will investigate the ports and harbours as man-made environments, their impacts on the marine biodiversity with regard to the species status - native, non-native and cryptogenic - and the factors facilitating the spread of non-native species. 


\subsection{Thesis aim and objectives}

The general aim of this thesis is to determine the influence of man-made structures on ecosystem structure and function in natural and man-made habitats with regard to native and non-native species. Whilst there has been quite a bit of this sort of work done around the world, there has been very little done in New Zealand. This study focusses on marine biology and invasion ecology but extends into biosecurity and conservation. The potential impact of this thesis will be as a contribution to new knowledge about the marine built environment, thereby supporting management decisions to improve marine coastal environmental health and ecoengineering of modified habitats.

The following objectives were developed to provide a more specific indication of the purpose of this research:

1) To assess community composition with regard to species status - native, non-native and cryptogenic species in Australian ports and New Zealand ports, and how this varies between ports as a function port type (major vs minor ports) and latitudinal groups.

2) To evaluate the effect of natural and man-made substrata (PVC vs slate tiles) and habitat type (marina vs reef) on the ecological successional patterns (temporal variation of species) and presence of native, non-native and cryptogenic species.

3) To assess if/how natural and man-made habitats influence energy allocation to reproductive output and reproduction patterns by two closely related congeneric blue mussels, native (SHMg) and non-native ( $\mathrm{NHMg}$ ) lineages. 


\subsection{Chapter outline and hypothesis testing}

Chapter 1 is a general literature review, to help set the scene, and to make clear the state of knowledge. As such, there is no hypothesis testing in this chapter.

Chapter 2 focusses on two large nationwide datasets to observe and interpret patterns of distribution of species status - native, non-native and cryptogenic species. Also, to understand the potential impacts on the marine biodiversity as a correspondence between ports, port types (major vs minor ports), latitudinal and longitudinal groups. The analyses were performed on presence/absence data for community composition and frequency data for species status (i.e. tally of the presence of species as per their status-native, non-native and cryptogenic). The data was analysed to observe patterns of species composition and species status as a function of ports, port type and latitudinal groups. The results obtained in this chapter will help highlight the patterns of distribution of species status and help understand the impacts on the marine biodiversity as a correspondence between ports, port types (major vs minor ports), and latitudinal and longitudinal groups. The patterns observed in this study among ports, port types and latitudinal groups will help managers to take cost-effective measures to analyse the impacts of the target (i.e. high occurring/contributing) non-native species and their spread with respect to the above-stated factors.

A. Australian port survey - a national port survey program commissioned by the Australian Association of Port and Marine Authorities (AAPMA) and carried out by the CSIRO Centre for Research on Introduced Marine Pests (CRIMP) in 1995. This program aimed to report the occurrences of non-native species in Australian ports. Identification of non-native species at the national level will help understand the spread of the non-native species from port-to-port at a local, regional and national scale.

I hypothesised that;

$\mathrm{H}_{1}$ : Occurrences of non-native and cryptogenic species will be relatively greater at major commercial ports than at minor ports because of increased international marine traffic at the major ports.

$\mathrm{H}_{2}$ : Frequencies of non-native and cryptogenic species increases with an increase in latitude $\left(15-40^{\circ} \mathrm{S}\right)$ as there is evidence of high invasibility at temperate climates compared to tropical climates. 
B. New Zealand Port Biological Baseline Survey (NZPS), New Zealand Government initiated a nationwide biological baseline survey in 2000 at 13 international shipping ports and 3 marinas in New Zealand. The principle aim of this survey was to record the native, nonnative and cryptogenic species in New Zealand port areas and to identify new invasions.

I hypothesised that;

$\mathrm{H}_{1}$ : Occurrences of non-native and cryptogenic species will be relatively greater at major commercial ports than at minor ports because of increased international marine traffic at the major ports.

$\mathrm{H}_{2}$ : Frequencies of non-native and cryptogenic species increases with an increase in latitude $\left(35-45^{\circ} \mathrm{S}\right)$ because there is evidence of high invasibility at temperate climates compared to tropical climates.

Chapter 3 aimed to compare the ecological successional patterns (temporal variation of species), community composition and species status (native, non-native, cryptogenic) in both natural and man-made habitats (marinas vs reefs) using natural and man-made substrata, i.e., settlement tiles (PVC vs slate). This study was carried out in Wellington Harbour at 3 marinas (man-made habitat) and 3 neighbouring rocky reef sites (natural habitat). The data of this experimental study compares the differences in community structure and status of the species, at the natural and man-made habitats/substrata. Results highlight the settlement preferences of native, non-native and cryptogenic species for habitat and substratum types, and differences in community structure on natural and man-made substrata/habitats.

I hypothesised that;

$\mathrm{H}_{1}$ : Community composition at man-made habitat (marina) is less diverse than at adjacent natural habitat (rocky reef).

$\mathrm{H}_{2}$ : Community composition on the man-made substratum (PVC) is less diverse than that on the natural substratum (slate).

$\mathrm{H}_{3}$ : Non-native species are more abundant at the man-made habitat and on man-made substratum relative to natural habitat and substratum.

Chapter 4 aimed to compare the reproductive timing and output of the closely related native and non-native blue mussels, Mytilus galloprovincialis (invasive North hemisphere lineage; native Southern hemisphere lineage) by analysing the gonadosomatic index (GSI) of mussels 
to determine the energy expenditure and changes in reproductive patterns at natural (reef) and man-made habitats (marinas). I also measured mussel shell length (size), Molecular assays were employed to distinguish the native and non-native species, and estimates of GSI helped determine the timing of gametogenesis and spawning events, as well as the energy invested into reproduction, for the two lineages. This study was carried out for a year to examine an entire reproduction cycle. Fieldwork was conducted at 3 marina sites (man-made) and 3 neighbouring rocky reef sites (natural) in Wellington Harbour, which is a semi-enclosed harbour receiving high volumes of commercial shipping traffic and highly developed coastline. The output of this chapter will help understand the impact of man-made structures on the performance of native and non-native species and if these structures facilitate the non-native species.

I hypothesised that;

$\mathrm{H}_{1}$ : Mussels on natural habitat will have a greater reproductive output (GSI) than those on manmade habitat

$\mathrm{H}_{2}$ : NHMg will have greater reproductive output on man-made habitat than on natural habitats.

$\mathrm{H}_{3}$ : SHMg will have greater reproductive output than $\mathrm{NH} M g$ on natural habitats.

Finally, Chapter 5 summarises the thesis findings and the analyses carried out for this study whilst answering the research objectives. I further explain the significance of my findings, the contribution my work makes to biosecurity science and management decision making, and I present specific recommendations to improve the changing habitat which impact the marine biodiversity. I conclude by addressing the limitations of this study and by reviewing future research that may build on my research. 


\section{CHAPTER 2}

\section{PORT AREAS AS INTRODUCTION FOCI FOR NON-NATIVE SPECIES}

\subsection{Background}

\subsubsection{Marine shipping and port pressures}

The $21^{\text {st }}$ century is known as the era of globalisation (Ehrenfeld 2003). Global interactions facilitating marine trade has transported thousands of species from their native regions around the world has immensely increased, and a future rise is expected (UNCTAD 2014), this raises the risk for a high volume of marine introductions. Transport of marine organisms associated with ships' hull and ballast water is the primary source of vessel-based introduction of nonnative species (Hewitt \& Campbell 2007; Hewitt et al. 2009; Seebens et al. 2016; Ziako et al. 2016; O’Brien et al. 2017). Inglis et al. (2016) reported that more than $65 \%$ of 187 non-native species in New Zealand arrived as biofouling on international vessels.

Furthermore, regional domestic trade, cargo vessels or pleasure crafts 'intra-coastal shipping' transfer the non-native species from major shipping port areas to minor port/marinas (Forrest et al. 2009; Clarke \& Johnston 2011; Hänfling et al. 2011). The ports are classified into major and minor ports as per the annual cargo volumes. Major commercial ports manage at least 1 million tonnes whilst minor ports operate annual cargo volume of fewer than 1 million tonnes (Department for Transport Statistics United Kingdom 2016). There is evidence of relatively higher densities of non-native species at major commercial ports (e.g. San Francisco and Los Angeles) (Foss et al. 2007). With major ports being the focal point of entry for international vessels, it is also a focal point of transfer of non-native species to minor ports and marinas (Floerl et al. 2009; Firth et al. 2016; Olenin et al. 2016; Johnston et al. 2017).

The disturbed environment and modified substrata that harbours provide might be less attractive for native species; however, it provides opportunities for the non-native species to settle on 'unoccupied spaces' and proliferate (Johnston \& Keough 2002; Dafforn et al. 2015; Olenin et al. 2016). The high supply of introductions, i.e. propagule pressure at port areas due to receiving marine traffic results in a high probability of successful establishment of nonnative species in port areas (Lockwood et al. 2005; Johnston et al. 2009; Clark \& Johnston 2011; Lo et al. 2012; Seebens et al. 2016; O’Brien et al. 2017). 
Another aspect to consider the successful invasion is the suitability of environmental conditions of the receiving habitat (Lockwood et al. 2005; Petes et al. 2008; Piola et al. 2009; van de Koppel et al. 2015; Fava et al. 2016; Firth et al. 2017; Purroy et al. 2019). There is evidence of anti-equatorial and latitudinal shifts in species' distributions due to changing global climate (Herbert et al. 2007; Keith et al. 2011; Poloczanska et al. 2016). For example, Occhipinti-Ambrogi (2007) highlighted the range expansion of non-native species due to increasing water temperatures. It is evident from early studies that the tropics have a greater level of species diversity than temperate or polar climates 'Latitudinal diversity groups' (Darwin 1860). Diverse species interactions may reduce invasion success into species-rich compared to species-poor areas (e.g., Sax 2001; Freestone et al. 2013). However, this is not the case in higher latitudes, where studies have indicated relatively lower species diversity (Sax 2001). Thus, marine shipping carrying trade from lower to higher latitudinal regions may pose more risk of bioinvasion at high latitudes (Hewitt, 2002; Ruiz et al. 2011). However, the success of invaders also depends on their life-history traits and species interactions (Shea \& Chesson 2002; Jeschke et al. 2012; Marraffini \& Geller 2015; Papacostas et al. 2017).

\subsubsection{Biosecurity strategies}

Management of spread of non-native species is problematic due to the complex marine ecosystems (Rilov \& Crooks 2009). Once the non-native species have established, it is challenging to eradicate the invader (Kaiser \& Burnett 2010). Early detection and timely eradication measures prove as a successful management approach (Ricciardi et al. 2017). Numerous international, national and regional agreements and regulations have been adopted by many countries to minimise the spread of non-native species (Lehtiniemi et al. 2015). Australia and New Zealand, for example, have established among the world's strongest biosecurity and management measures, i.e. a comprehensive pre-border, at-border and postborder management responses (Hewitt \& Campbell 2007; Ojaveer et al. 2015). Australia and New Zealand Environment and Conservation Council (ANZECC), reported introduced nonnative species as one of the key threats to the biodiversity. The International Maritime Organisation (IMO), introduced many policies and management guidelines to avoid the introduction of non-native species through ballast waters and biofouling on shipping vessels (IMO 2017).

Ballast water loaded in other countries are not allowed to discharge waters in national territorial waters without permissions and permissions are granted to those vessels which have evidence of the mid-ocean ballast exchange and should follow guidelines to manage ballast 
water under the Biosecurity Act. New Zealand is one of the few countries in the world to have specific topics of legal legislation for biosecurity control "an act to restate and reform the law relating to the exclusion, eradication, and effective management of pests and unwanted organisms" known as the 'Biosecurity Act 1993'. Regarding Australia, 'Biosecurity Act 2015, replaced the Quarantine Act 1908 and aims to strengthen and manage the existing framework for biosecurity risks "managing diseases and pests that may cause harm to human, animal or plant health or the environment" in Australia. Therefore, to eradicate the biofouling issue, frequent hull maintenance and cleaning are required, and vessels with evidence of biofouling maintenance and record books are allowed into national-territorial regions (Ministry of Primary Industries 2018; Australian Government Department of Agriculture and Water Resources 2019). Recreational vessels posing risks on intra-coastal species transfer are required to follow Craft Risk Management Standard (CRMS) and IMO guidelines (i.e. Biofouling Management Plan and BioFouling Record Book) (MPI 2014; IMO 2015).

The NZ's Ministry of Fisheries and Australian National System for the Prevention and Management of Marine Pest Incursions are a government-controlled institution which deals with rapid detection and management of non-native species with this many regional councils also hold responsibilities regarding introduction management (Wotton \& Hewitt 2004).

\subsubsection{Monitoring strategies}

To have effective biosecurity measures, it is crucial to have accurate identification of species, i.e., native, or non-native species. For example, the invasive northern Pacific seastar, Asterias amurensis, was misidentified as a native species for nearly 10 years (Wotton \& Hewitt 2004). Some introductions go unnoticed leading to cryptic invasions. Therefore, to apprehend these challenges, there is a need for extensive surveillance and monitoring for non-native species (Hewitt \& Campbell 2007; Kaiser \& Burnett 2010; Zaiko et al. 2016; Ricciardi et al. 2017). Early detection of the invasive species (non-native species which have adverse impacts on the environment) enables the managers to take effective eradication response (Hewitt \& Campbell 2007; Gardner et al. 2016; Zaiko et al. 2016). However, managers are often faced with technical and financial constraints to undertake extensive monitoring surveys (Hewitt \& Martin 2001; Campbell et al. 2007). To overcome this problem, prioritising harbours to monitor non-native species can be of great importance (Peters et al. 2017). As stated earlier, harbours as port areas (vessel berths) are 'hotspots' for bio-invaders and can serve as the perfect invasion study areas. 
The last decade has seen an immense increase in harbour surveys all around the world to record non-native species (Pollard \& Pethebridge 2002; Campbell et al. 2007; Russel et al. 2008; Inglis et al. 2016; Woods et al. 2018). Harbour surveys attempt to establish an optimal sampling design to increase the species detection ability to form baseline records of the presence of species and help monitor the spread of non-native species (Campbell et al. 2007). The baseline surveys can feed into risk assessments as a tool to monitor the introductions, whether it be species, pathway or vectors. The assessment of baseline surveys has given rise to many cost-effective nationwide surveillance programs targeting high-risk pest species whereas only a few focussed on the underlying factors influencing the introductions of non-native species (Campbell et al. 2007; Woods et al. 2018). The first step at risk assessment is speciesspecific assessments to identify the potential of the introduced species to cause harm to the environment or economy (Andersen et al. 2004; Pyšek \& Richardson 2010; Hayes et al. 2019). The species attributes such functional traits (e.g. grazers, predators) and native biodiversity may help understand the invasion success (Hayes et al. 2019). However, this is a difficult task to practice due to complex species interactions (Simberloff 2006) and are rarely explored in monitoring surveys.

The above-stated text gave an overview of human-mediated bioinvasions, and the strategies developed to manage their spread. Baseline port surveys provide a comprehensive record of the presence of non-native species on a site-by-site basis. However, the evaluated reports of port surveys have only highlighted the high-risk pest species and the need for further surveillance and eradication response (Inglis et al. 2006, 2008 MPI Technical Reports). Rarely do they consider the factors promoting invasions, whether it be the suitability of habitats or native biodiversity. For this reason, I have used Australian Port Survey (APS) and New Zealand Port Biological Baseline Survey (NZPS) as base datasets to identify the factors promoting the spread of non-native species at local, regional and national scale across the port areas. The twoport surveys (APS and NZPS) have covered numerous ports; major commercial and minor shipping ports and ports expanding across latitudinal groups. This study provides separate comparative analyses on presence/ absence data across all surveyed ports in APS and NZPS. The frequencies of species status, i.e., native, non-native and cryptogenic species will be indicated as a function of the port type (major vs minor ports) and latitudinal groups. 


\subsubsection{Port Surveys}

\section{A. Australian Port Survey}

In 1995, the Australian Association of Port and Marine Authorities (AAPMA) and the CSIRO Centre for Research on Introduced Marine Pests (CRIMP) commenced a national port survey program to collect a baseline dataset of the introduced species in Australian ports and the threat they pose. This program went on for 10 years and was conducted at 39 Australian ports to form a baseline dataset of the introduced species across Australia including Tasmania. The ports were selected based on commercial shipping facilities, non-commercial facilities and adjacent areas outside ports.

The baseline survey aimed to define the distribution of non-natives in Australia (Hewitt $\&$ Martin 1999, 2001). The results of the APS were further entered into a National Port Survey Database (Hayes et al. 2019). The survey was designed by Hewitt \& Martin, 1996, 2001 to cover most of the habitats within each port with replicated sampling. Even though this survey was designed to detect non-native species, information of native and cryptogenic species within ports was also provided. This protocol was later adopted by various other countries such as GloBallast programme undertaken countries South Africa, Brazil, China, India, Iran, Ukraine and some to form baseline surveys at a larger scale; Australia, New Zealand, USA, Scotland, Ireland, Guam and Chile (see Campbell et al. 2007). A complete list of the survey methods adopted to form 'CRIMP protocols' is given in section $\mathrm{C}$ (Table 2.1). The species were identified and categorised as native, (resident species), non-native (non-resident/ invaded invasive species) and cryptogenic (species whose status is unclear) by various specialised taxonomic experts and scientists in Australia.

The Australian Port Survey dataset the Australian dataset was provided to me by my co-supervisors Prof Chad Hewitt and Prof Marnie Campbell. However, due to some inadequacies in the dataset with regards to presence/ absence data in each port. The ports with less than 5 species listed in the dataset were eliminated. Analyses were carried out on 27 ports out of the 39 ports for my study. Individuals with only genus name and missing species name were excluded to keep the dataset consistent which resulted in $70 \%$ deletion of unknown cryptogenic species.

\section{B. New Zealand Port Biological Baseline Survey (NZPS)}

In 2000, the New Zealand Government, encouraged by the International Maritime Organisation (IMO), funded a comprehensive five-year (2000-2005) biological baseline survey programme 
called the 'New Zealand Port Biological Baseline Surveys (NZPS)' to identify non-native species in port areas. National Institute of Water and Atmospheric Research Ltd (NIWA) was commissioned to carry out the baseline surveys (and the resurveys) at commercial shipping ports (13) and marinas (2) in New Zealand (Table 2.2.2). The principal aim of the NZPS was to form an inventory of native, introduced and cryptogenic species present in New Zealand ports. In 2010, the Ministry of Primary Industries (MPI) and NIWA made the port survey dataset available to the general public. Moreover, this baseline survey provided a preliminary inventory of native and non-native species in New Zealand ports. The NZPS datasets were acquired from the Biosecurity New Zealand Technical Papers available at https://www.marinebiosecurity.org.nz/ (Inglis et al. 2006, 2008).

The sampling methods used were based on the CSIRO Centre for Research on Introduced Marine Pests (CRIMP) protocols developed by Hewitt \& Martin $(1996,2001)$ for Australian port surveys. The list of surveys methods is given in section C (Table 2.1). MAF Biosecurity New Zealand funded NIWA and Marine Invasive Taxonomic Service (MITS) to provide with species-level identification of collected species and management of the specimens. Each identified sample was further categorised as native species, non-indigenous species (NIS), cryptogenic species 1 (previously recorded as cryptogenic in New Zealand), cryptogenic species 2 (recently reported in New Zealand), and species indeterminate (not identified to species level). However, in this study, cryptogenic 1, cryptogenic 2 and species intermediate were grouped as cryptogenic species.

\section{Overview of the sampling 'CRIMP protocols'}

The 'CRIMP protocols' (Hewitt \& Martin, 1996, 2001) were first designed for Australian Port Surveys which was which were later adopted by more than 15 countries including New Zealand (Campbell et al. 2007). The surveys were designed to determine distribution and abundance of target species, baseline assessment of native, introduced and cryptogenic species. The surveys concentrated on specific sites at port areas (e.g. harbours) and adjacent harbour areas that are most likely to be invaded. Samplings were carried out by consistent qualitative and quantitative methods in marina areas, on wharf piles by scraping method $\left(0.10 \mathrm{~m}^{2}\right.$ quadrats were fixed at $0.5 \mathrm{~m},-3 \mathrm{~m}$ and $-7 \mathrm{~m}$ below the surface). Visual surveys by divers, sediment corers and cyst identification, beam trawl/benthic sledge, traps, plankton and drop nets at various habitats as explained in Table 2.1.1. (see Hewitt \& Martin, 1996, 2001 for detailed methodology). 
However, for this study, samples from 'Quadrat scrapping' were analysed to be consistent with the theme of the thesis, which is dealing with the impacts of man-made hard substrata.

Table 2.1.1. Sampling methods for port surveys as per CRIMP protocols (Hewitt \& Martin 2001).

\begin{tabular}{|l|c|c|c|c|c|c|}
\hline \multicolumn{1}{|c|}{ Sampling Technique } & \multicolumn{5}{|c|}{ Taxa } & \multicolumn{4}{c|}{ Sampled habitats } \\
\cline { 3 - 6 } & & $\begin{array}{c}\text { Soft } \\
\text { substrate }\end{array}$ & $\begin{array}{c}\text { Hard } \\
\text { substrate }\end{array}$ & $\begin{array}{c}\text { Seagrass/ } \\
\text { algal bed }\end{array}$ & $\begin{array}{c}\text { Plankton/ } \\
\text { nekton }\end{array}$ & $\begin{array}{c}\text { Beach } \\
\text { wrack }\end{array}$ \\
\hline Small core & dinoflagellate cysts & $\mathrm{X}$ & & & \\
\hline Large core & benthic infauna & $\mathrm{X}$ & & $\mathrm{X}$ & \\
\hline $20 \mu \mathrm{m}$ plankton net & dinoflagellates & & & & $\mathrm{X}$ & \\
\hline $100 \mu \mathrm{m}$ drop net & zoo/phytoplankton & & & & $\mathrm{X}$ & \\
\hline Traps & crab/shrimp & $\mathrm{X}$ & $\mathrm{X}$ & $\mathrm{X}$ & $\mathrm{X}$ & \\
\hline Qualitative visual survey & macro biota & $\mathrm{X}$ & $\mathrm{X}$ & $\mathrm{X}$ & & $\mathrm{X}$ \\
\hline Quadrat scraping & sedentary/encrusting & & $\mathrm{X}$ & & & \\
\hline Video/ photo transect & sedentary/encrusting & $\mathrm{X}$ & $\mathrm{X}$ & $\mathrm{X}$ & & \\
\hline Beam trawl/benthic sledge & mobile epifauna & $\mathrm{X}$ & & $\mathrm{X}$ & & \\
\hline Poison station & fish & $\mathrm{X}$ & $\mathrm{X}$ & $\mathrm{X}$ & $\mathrm{X}$ & \\
\hline Beach seine & fish/mobile epifauna & $\mathrm{X}$ & & $\mathrm{X}$ & $\mathrm{X}$ & \\
\hline
\end{tabular}

\subsubsection{Limitations of large surveys}

Large datasets are formed by passive surveillance strategies, i.e. quantifying single occurrences of species; however, depending on the environmental conditions and experimental strategy, the species can settle selectively. Detection, identification of small or initial stages of an organism and can lead to cryptic invasions. It is also important to consider similar sampling methods at each sampling areas to have a fair interpretation of the study.

Current surveillance programmes are conducted with preliminary taxonomic identification based on morphology instead of molecular techniques, very few taxonomic experts, time-consuming and costly (Bishop \& Hutchings 2011). Such inadequacies in surveillance and monitoring programmes can hinder the processes of well-developed biosecurity and management approaches to restrict invasions (Peters et al. 2017). Lastly, carrying out large-scale surveys and monitoring studies are a costly affair. For instance, New Zealand's species-specific survey for detection of 7 high-risk species (green alga Caulerpa taxifolia, northern Pacific seastar Asterias amurensis, Mediterranean fan worm Sabella 
spallanzanii, European green crab Carcinus maenas, Chinese mitten crab Eriocheir sinensis, Asian clam Potamocorbula amurensis and clubbed sea squirt Styela clavannually) cost annually approximately NZ \$2 million (Arthur et al. 2015).

This study aimed to examine the community composition and spatial patterns of species with regard to species status - native, non-native and cryptogenic as a function of the surveyed port, port type, and latitudinal groups. These variables act as predictor factors to describe the spread patterns of non-native species among Australia and New Zealand ports, respectively. I hypothesised that; 1) occurrences of non-native and cryptogenic species will be relatively greater at major commercial ports than at minor ports due to high levels of international marine vessels berth at commercial ports may carry invaders, and 2) frequencies of non-native and cryptogenic species increases with an increase in latitude because there is evidence of high invasibility at temperate climates compared to tropical climates.

\subsection{Methods}

\subsubsection{Data analysis}

\section{A. Australian Port Survey (APS)}

A total of 39 ports across Australia were surveyed for the Australian port baseline survey (Figure 2.2.1) with 4 major and 23 minor shipping ports. The ports used for analyses in this study are listed in Table 2.2.1. Australian latitudinal scale ranges from 43.0 to $12.46^{\circ} \mathrm{S}$, and longitudinal scale ranges from 13.66 to $153.61^{\circ} \mathrm{E}$. The dataset was assessed to observe and interpret patterns of distribution of species status - native, non-native and cryptogenic. And, to understand the potential impacts on the marine biodiversity as a correspondence between surveyed ports, port type (major vs minor ports), and latitudinal groups.

The APS surveyed a total of 39 ports; however, ports with low replicates and ports with species number less than 5 indicated in the provided dataset were rejected from the analyses to avoid underlying outliers. The data for the sampling method 'Quadrat scrapping' was used to analyse the hypotheses for this study. The presence/absence data rather than abundance were used as recommendations of severe transformations are required for species communities where rare species are present, otherwise may be lost between more common species (Clarke and Warwick 2001). Also, there were inadequacies in the abundance data of the species provided.

The data analyses were performed on 27 ports as a function of the surveyed port. The number of replicate sampling (sampling effort) varied across all surveyed ports. The dataset 
with replicates (presence/absence) was further averaged for each port to analyse the community composition and species status (native, non-native, cryptogenic) for the factors; port type (major vs minor) and longitudinal groups. This standardisation approach was undertaken to eradicate the bias caused due to the different number of replicate sampling (sampling effort) (Table 2.2.1) conducted at each port.

Table 2.2.1. Ports sampled for the Australian Port Surveys with latitudinal and longitudinal groups, port type, and replicates (sampling effort).

\begin{tabular}{|l|c|c|c|c|}
\hline \multicolumn{1}{|c|}{ Ports } & Latitude & Longitude & Port Type & Replicates \\
\hline Abbot Point & $19^{\circ} 53^{\prime} \mathrm{S}$ & $148^{\circ} 50^{\prime} \mathrm{E}$ & Minor & 16 \\
\hline Adelaide & $34^{\circ} 47^{\prime} \mathrm{S}$ & $138^{\circ} 30^{\prime} \mathrm{E}$ & Major & 66 \\
\hline Albany & $35^{\circ} 20^{\prime} \mathrm{S}$ & $117^{\circ} 54^{\prime} \mathrm{E}$ & Minor & 59 \\
\hline Bunbury & $33^{\circ} 18^{\prime} \mathrm{S}$ & $115^{\circ} 39^{\prime} \mathrm{E}$ & Minor & 52 \\
\hline Burnie & $41^{\circ} 30^{\prime} \mathrm{S}$ & $145^{\circ} 54^{\prime} \mathrm{E}$ & Minor & 44 \\
\hline Devonport & $41^{\circ} 11^{\prime} \mathrm{S}$ & $146^{\circ} 21^{\prime} \mathrm{E}$ & Minor & 22 \\
\hline Eden & $37^{\circ} 94^{\prime} \mathrm{S}$ & $149^{\circ} 56^{\prime} \mathrm{E}$ & Minor & 31 \\
\hline Esperance & $33^{\circ} 52^{\prime} \mathrm{S}$ & $121^{\circ} 53^{\prime} \mathrm{E}$ & Minor & 60 \\
\hline Fremantle & $32^{\circ} 30^{\prime} \mathrm{S}$ & $115^{\circ} 44^{\prime} \mathrm{E}$ & Major & 250 \\
\hline Geelong & $38^{\circ} 70^{\prime} \mathrm{S}$ & $144^{\circ} 23^{\prime} \mathrm{E}$ & Minor & 41 \\
\hline Geraldton & $28^{\circ} 47^{\prime} \mathrm{S}$ & $114^{\circ} 36^{\prime} \mathrm{E}$ & Minor & 21 \\
\hline Gladstone & $23^{\circ} 50^{\prime} \mathrm{S}$ & $151^{\circ} 35^{\prime} \mathrm{E}$ & Minor & 100 \\
\hline Hastings & $38^{\circ} 18^{\prime} \mathrm{S}$ & $145^{\circ} 13^{\prime} \mathrm{E}$ & Minor & 18 \\
\hline Hay Point & $21^{\circ} 13^{\prime} \mathrm{S}$ & $149^{\circ} 20^{\prime} \mathrm{E}$ & Minor & 44 \\
\hline Hobart & $42^{\circ} 52^{\prime} \mathrm{S}$ & $147^{\circ} 20^{\prime} \mathrm{E}$ & Major & 106 \\
\hline Lady Barron & $40^{\circ} 12^{\prime} \mathrm{S}$ & $148^{\circ} 14^{\prime} \mathrm{E}$ & Minor & 17 \\
\hline Launceston & $41^{\circ} 26^{\prime} \mathrm{S}$ & $147^{\circ} 80^{\prime} \mathrm{E}$ & Minor & 78 \\
\hline Lucinda & $18^{\circ} 31^{\prime} \mathrm{S}$ & $146^{\circ} 21^{\prime} \mathrm{E}$ & Minor & 18 \\
\hline Mackay & $21^{\circ} 80^{\prime} \mathrm{S}$ & $149^{\circ} 15^{\prime} \mathrm{E}$ & Minor & 25 \\
\hline Melbourne & $37^{\circ} 49^{\prime} \mathrm{S}$ & $144^{\circ} 55^{\prime} \mathrm{E}$ & Major & 135 \\
\hline Mourilyan & $17^{\circ} 37^{\prime} \mathrm{S}$ & $146^{\circ} 70^{\prime} \mathrm{E}$ & Minor & 12 \\
\hline Newcastle & $32^{\circ} 55^{\prime} \mathrm{S}$ & $151^{\circ} 47^{\prime} \mathrm{E}$ & Minor & 86 \\
\hline Port Hedland & $20^{\circ} 19^{\prime} \mathrm{S}$ & $118^{\circ} 36^{\prime} \mathrm{E}$ & Minor & 52 \\
\hline Port Lincoln & $34^{\circ} 44^{\prime} \mathrm{S}$ & $135^{\circ} 56^{\prime} \mathrm{E}$ & Minor & 45 \\
\hline Portland & $141^{\circ} 36^{\prime} \mathrm{E}$ & Minor & 15 \\
\hline Townsville & $146^{\circ} 50^{\prime} \mathrm{E}$ & Minor & 45 \\
\hline & & & Minor & 18 \\
\hline
\end{tabular}




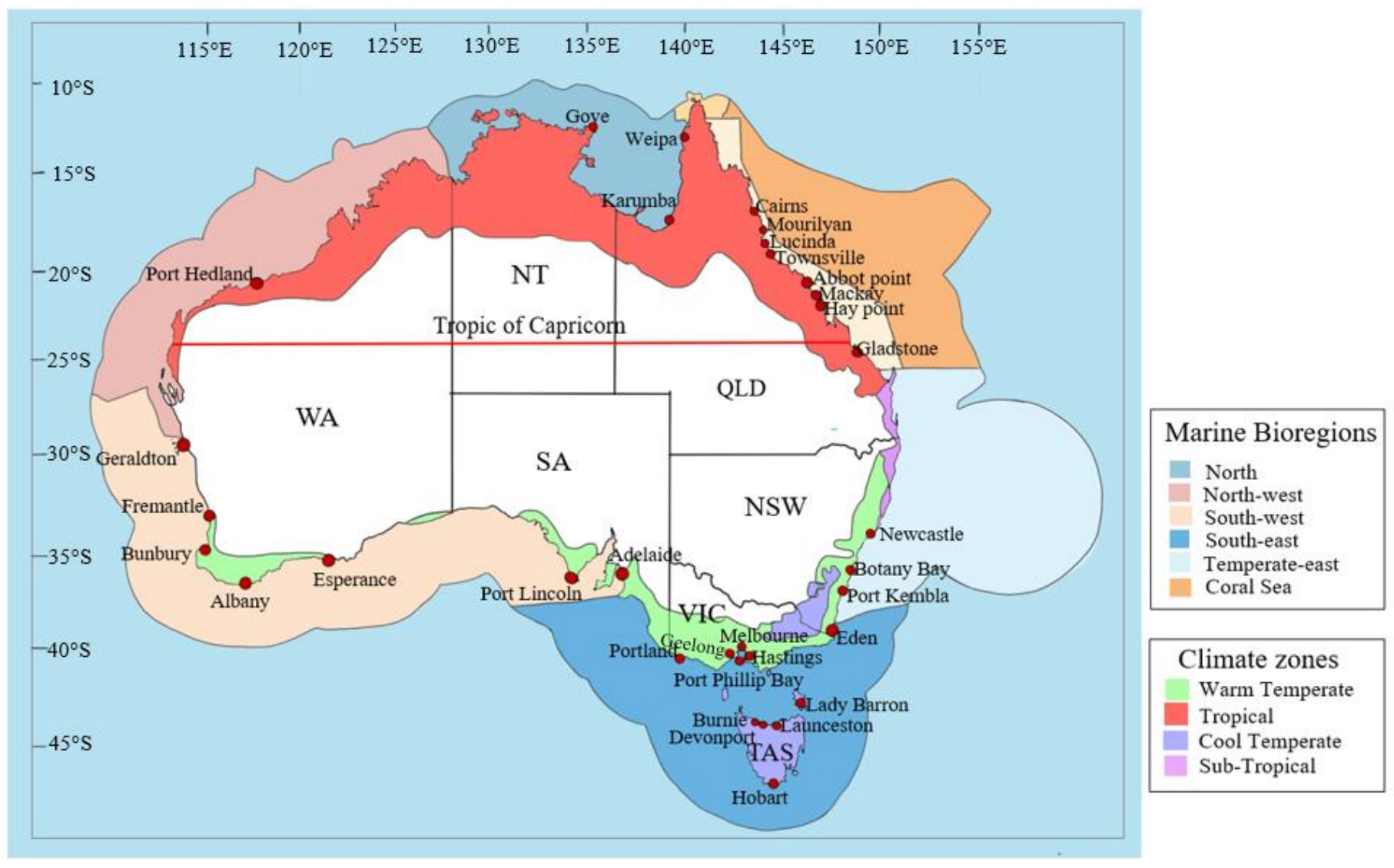

Figure 2.2.1. Map of Australia with commercial shipping ports surveyed for Australian Port Survey study. Map sourced from Hewitt \& Martin (2001) and Commonwealth of Australia (2011).

\section{B. New Zealand Port Biological Baseline Surveys (NZPS)}

The data for 'pile scrapping method' was obtained from the Biosecurity New Zealand Technical papers available at https://www.marinebiosecurity.org.nz/ (Inglis et al. 2006, 2008). This baseline survey provided a preliminary inventory of native, non-native and cryptogenic species in New Zealand ports. The baseline surveys were performed at 15 ports (13 shipping ports and 2 marinas - from here on referred to as ports) in New Zealand (Table 2.2.2). The dataset assessed: to observe and interpret patterns of distribution of species status- native, nonnative and cryptogenic, and to understand the potential impacts on the marine biodiversity as a correspondence between ports, port types (major vs minor ports) and latitudinal groups.

The data analyses were performed on 15 ports as a function of the surveyed port. The number of replicate sampling (sampling effort) varied across all the surveyed ports. The dataset with replicates was further averaged for each port to analyse the community composition and species status (native, non-native, cryptogenic) for the factors; port type (major vs minor) and longitudinal groups. The averaged dataset, i.e., the standardised dataset provided a non-bias 
approach excluding the effects of variations in the number of replicate sampling (sampling effort) (Table 2.2.2).

The dataset was transformed into presence/absence rather than abundance because; recommendations of severe transformations are required for species communities where rare species are present, otherwise may be lost between more common species (Clarke and Warwick 2001). Also, not all species were quantified at each sampling time; therefore, the presence/absence coding approach was used. The presence/absence data of the replicates (sampling effort) were averaged for each port as the sampling effort was different for each port. The averaged dataset was further analysed to examine the community composition and species status (native, non-native, cryptogenic) as a function of the port type and latitudinal groups

Table 2.2.2. Ports sampled for the New Zealand Port Biological Baseline Surveys with latitudinal and longitudinal groups, port type and replicates (sampling effort).

\begin{tabular}{|l|l|l|l|c|}
\hline Ports & Latitude & Longitude & Port type & Replicates \\
\hline Auckland & $36^{\circ} 84^{\prime} \mathrm{S}$ & $174^{\circ} 78^{\prime} \mathrm{E}$ & Major & 71 \\
\hline Bluff & $46^{\circ} 37^{\prime} \mathrm{S}$ & $168^{\circ} 18^{\prime} \mathrm{E}$ & Minor & 53 \\
\hline Dunedin Harbour & $45^{\circ} 81^{\prime} \mathrm{S}$ & $170^{\circ} 62^{\prime} \mathrm{E}$ & Minor & 47 \\
\hline Gisborne & $38^{\circ} 67^{\prime} \mathrm{S}$ & $178^{\circ} 02^{\prime} \mathrm{E}$ & Minor & 31 \\
\hline Gulf Harbour Marina & $36^{\circ} 62^{\prime} \mathrm{S}$ & $174^{\circ} 78^{\prime} \mathrm{E}$ & Minor & 58 \\
\hline Lyttelton & $43^{\circ} 61^{\prime} \mathrm{S}$ & $172^{\circ} 72^{\prime} \mathrm{E}$ & Major & 50 \\
\hline Napier & $39^{\circ} 47^{\prime} \mathrm{S}$ & $176^{\circ} 91^{\prime} \mathrm{E}$ & Major & 48 \\
\hline Nelson & $41^{\circ} 25^{\prime} \mathrm{S}$ & $173^{\circ} 17^{\prime} \mathrm{E}$ & Minor & 94 \\
\hline Opua Marina & $35^{\circ} 31^{\prime} \mathrm{S}$ & $174^{\circ} 12^{\prime} \mathrm{E}$ & Minor & 30 \\
\hline Picton & $41^{\circ} 28^{\prime} \mathrm{S}$ & $174^{\circ} 00^{\prime} \mathrm{E}$ & Minor & 35 \\
\hline Taranaki & $39^{\circ} 05^{\prime} \mathrm{S}$ & $174^{\circ} 03^{\prime} \mathrm{E}$ & Minor & 44 \\
\hline Tauranga & $37^{\circ} 64^{\prime} \mathrm{S}$ & $176^{\circ} 18^{\prime} \mathrm{E}$ & Major & 68 \\
\hline Timaru & $44^{\circ} 39^{\prime} \mathrm{S}$ & $171^{\circ} 25^{\prime} \mathrm{E}$ & Minor & 39 \\
\hline Wellington & $41^{\circ} 31^{\prime} \mathrm{S}$ & $174^{\circ} 81^{\prime} \mathrm{E}$ & Major & 73 \\
\hline Whangarei & $35^{\circ} 75^{\prime} \mathrm{S}$ & $174^{\circ} 34^{\prime} \mathrm{E}$ & Minor & 47 \\
\hline & & & & \\
\hline
\end{tabular}




\subsubsection{Statistical analysis}

The total number of species community and species status at each surveyed port was divided with replicate numbers at each port due to varying sampling replicates at each survey port. The relative number of native, non-native cryptogenic species were regressed to observe the relationship between the number of native vs non-native species, non-native vs cryptogenic species, and native vs cryptogenic species. Regressions were plotted with $95 \%$ confidence intervals using the STATISTICA v.7 (Stat Soft Inc.) software. $\mathrm{R}^{2}$ and $P$ values were calculated for each association. The significance of these tests was set at $P<0.05$.

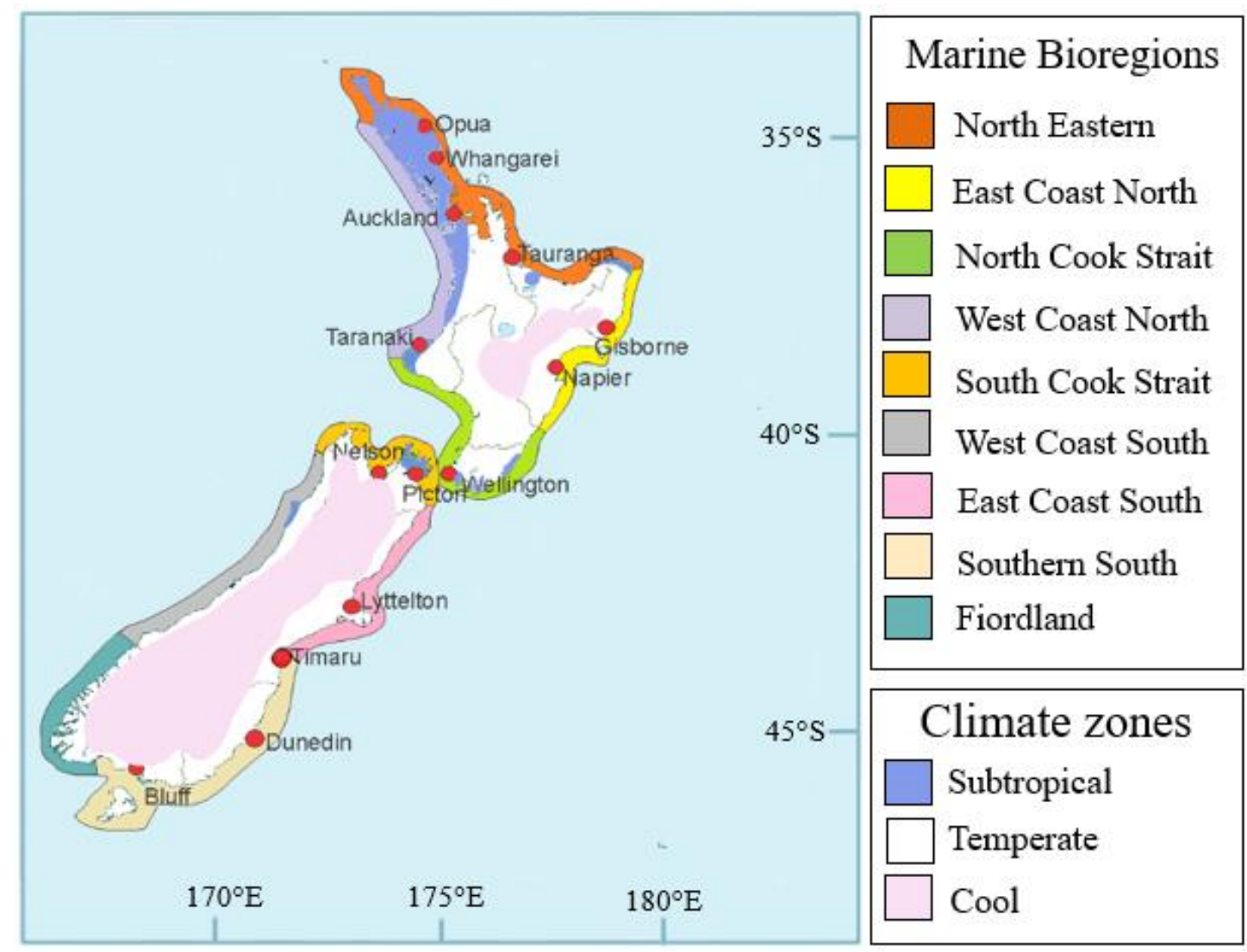

Figure 2.2.2. Map of Australia with commercial shipping ports surveyed for New Zealand Port

Biological Baseline Survey study. Map sourced from Department of Conservation and Ministry of Fisheries (2011).

An initial, two-dimensional multidimensional scaling (MDS) ordination plot was performed to visualise the similarity in community composition and species status as a function of the port type and latitudinal and longitudinal groups. In MDS, similar samples, cluster together whereas samples which are dissimilar, cluster further apart. MDS plot stress values were used to interpret the reliability of the relationships; values $<0.15=$ good representation between groups. The stress levels are also affected by the number of samples (Clarke 1993). 
Data analyses for community composition and species status were performed using the statistical package Plymouth Routines in Multivariate Ecological Research (PRIMER v.6); with permutational multivariate analysis of variance (PERMANOVA) as an add-on package (Clarke \& Gorley 2006; Anderson et al. 2008). The resemblance matrix based on Bray-Curtis similarity matrices was zero-adjusted (dummy variable) for clearer assemblages which were present across the presence/absence data. The replicates in each port were averaged and square root transformed to carry out further analyses. When species were tallied as per their status native, non-native and cryptogenic, the dataset was square-root transformed to down-weight the dominant species (Clarke \& Gorley 2006).

PERMANOVA analysis was used to determine any significant differences between surveyed ports, port type and latitudinal groups with a significance level of $P<0.05$. PERMANOVA based on 9999 permutations with Type III (partial) sums of squares was performed for each factor. The independent factors were surveyed port, port type and latitudinal groups. PERMANOVA helps statistically test the differences between two and among multiple groups, and the effects of factors on the species communities with permutations to avoid possible biases. PERMANOVA was followed with post-hoc pairwise tests between factors surveyed port, port type and latitudinal groups, respectively to indicate significant correlations between each factor group, within-group average similarity and between-group dissimilarity results

SIMPER (Similarity percentages) in PRIMER was employed to determine the species as well as species status, respectively contributing most to the overall patterns in community composition and species status (native, non-native and cryptogenic). The SIMPER analyses were restricted to top 5 species describing the location of differences leading to between-group dissimilarity. 


\subsection{Results (A)}

\section{AUSTRALIAN PORT SURVEY}

\subsubsection{Presence/absence data}

A total of 1352 species were sampled across the 27 ports for the Australian port survey study. The species were grouped in 14 phyla: Chlorophyta, Ochrophyta, Rhodophyta, Annelida, Arthropoda, Bryozoa, Chordata, Cnidaria, Echinodermata, Mollusca, Platyhelminthes, Porifera, Sipuncula and Heterokontophyta (see Appendix - Table A2 for the species list). The most represented phyla in this survey were the Mollusca (272 species) followed by Annelida (260 species) and Arthropoda (234 species). The species were further grouped according to their status; native, non-native and cryptogenic. Of the 1352 species, 1181 were native species (88\%), 126 non-native species (9\%) and 45 cryptogenic species (3\%) (Table 2.3.1).

Table 2.3.1. The total number of species noted in Australian Port Surveys grouped to Phylum and status (native, non-native and cryptogenic).

\begin{tabular}{|l|c|c|c|c|}
\hline \multicolumn{1}{|c|}{ Phylum } & Total & Native & Non-native & Cryptogenic \\
\hline Chlorophyta & 26 & 19 & 4 & 3 \\
\hline Ochrophyta & 32 & 27 & 5 & 0 \\
\hline Rhodophyta & 103 & 88 & 9 & 6 \\
\hline Annelida & 260 & 239 & 14 & 7 \\
\hline Arthropoda & 234 & 199 & 27 & 8 \\
\hline Bryozoa & 126 & 93 & 24 & 9 \\
\hline Chordata & 113 & 98 & 14 & 1 \\
\hline Cnidaria & 126 & 102 & 16 & 8 \\
\hline Echinodermata & 41 & 39 & 2 & 0 \\
\hline Mollusca & 272 & 261 & 10 & 1 \\
\hline Platyhelminthes & 1 & 1 & 0 & 0 \\
\hline Porifera & 13 & 12 & 1 & 45 \\
\hline Sipuncula & 3 & 3 & 0 & 0 \\
\hline Heterokontophyta & 2 & 0 & 126 & 0 \\
\hline Total & 1352 & 1181 & & \\
\hline
\end{tabular}




\subsubsection{Variations in the total presence of species as a function of replicates (sampling effort) at each surveyed port}

The replication of surveys varied at each surveyed port, so to have a fair comparison of the presence of species between ports, the total number of species at each port was divided by the number of replicates to obtain the relative number of species (Table 2.3.2). The relative percent of species was highest at Abbot Point (9.13\%) followed by Mourilyan (5.5\%), and Lucinda $(5.5 \%)$, and lowest relative percent of species were observed at Fremantle $(0.54 \%)$ and Melbourne (0.56\%) (Figure 2.3.1).

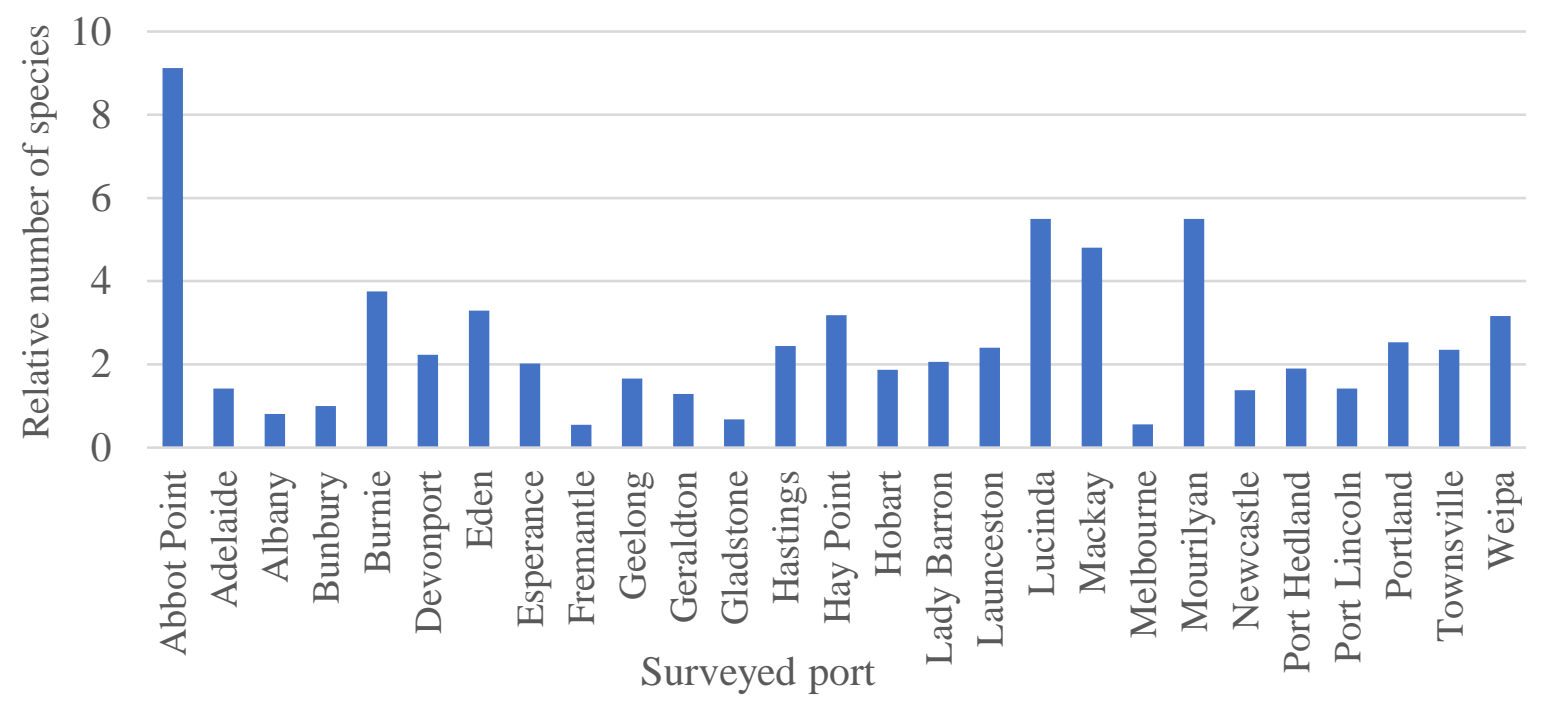

Figure 2.3.1. The total relative number of species across all 27 surveyed ports.

Table 2.3.2. The total number, sampling effort (replicates) and the relative number of species as a function of replicates at each surveyed port.

\begin{tabular}{|c|c|c|c|}
\hline Ports & Total number & Replicates & Relative number \\
\hline Abbot Point & 146 & 16 & 9.13 \\
\hline Adelaide & 94 & 66 & 1.42 \\
\hline Albany & 48 & 59 & 0.81 \\
\hline Bunbury & 52 & 52 & 1.00 \\
\hline Burnie & 165 & 44 & 3.75 \\
\hline Devonport & 49 & 22 & 2.23 \\
\hline Eden & 102 & 31 & 3.29 \\
\hline Esperance & 121 & 60 & 2.02 \\
\hline Fremantle & 136 & 250 & 0.54 \\
\hline Geelong & 68 & 41 & 1.66 \\
\hline Geraldton & 27 & 21 & 1.29 \\
\hline
\end{tabular}




\begin{tabular}{|c|c|c|c|}
\hline Gladstone & 68 & 100 & 0.68 \\
\hline Hastings & 44 & 18 & 2.44 \\
\hline Hay Point & 140 & 44 & 3.18 \\
\hline Hobart & 198 & 106 & 1.87 \\
\hline Lady Barron & 35 & 17 & 2.06 \\
\hline Launceston & 187 & 78 & 2.40 \\
\hline Lucinda & 99 & 18 & 5.50 \\
\hline Mackay & 120 & 25 & 4.80 \\
\hline Melbourne & 75 & 135 & 0.56 \\
\hline Mourilyan & 66 & 12 & 5.50 \\
\hline Newcastle & 119 & 86 & 1.38 \\
\hline Port Hedland & 99 & 52 & 1.90 \\
\hline Port Lincoln & 64 & 45 & 1.42 \\
\hline Portland & 38 & 15 & 2.53 \\
\hline Townsville & 106 & 45 & 2.36 \\
\hline Weipa & 57 & 18 & 3.17 \\
\hline & & & \\
\hline
\end{tabular}

\subsubsection{Variations in the community composition as a function of the surveyed port, port}

\section{type and latitudinal groups}

a) Surveyed ports

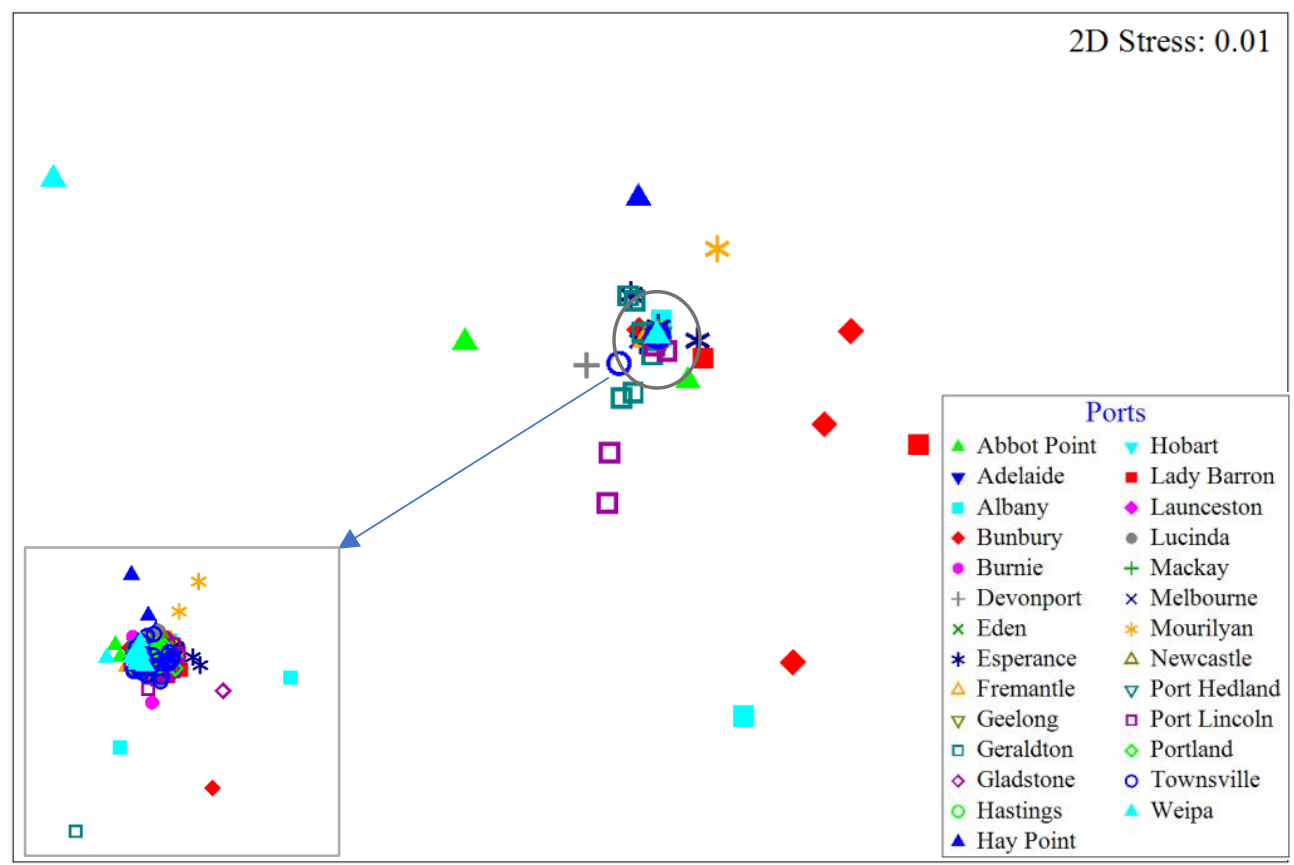

Figure 2.3.2. Multidimensional Scaling (MDS) plot. The proximity of surveyed ports to each other indicates similarity in species (based on presence/absence data). 
The graphical representation of the MDS ordination of the presence of species (presence/absence data) as a function of surveyed port showed some patterns in clustering of ports with similar species. However, the patterns are not clear enough to state the groupings (Figure 2.3.2). The 2D stress result of 0.01 indicates that the MDS is an excellent representation of the data.

Multivariate analyses were carried out to observe patterns of community composition among/between ports. PERMANOVA based on presence/absence data as a function of surveyed ports indicates significant differences in community composition among 27 surveyed ports $(P<0.001$; Table 2.3.3).

Table 2.3.3. Results of the PERMANOVA test performed on the presence/absence of species as a function of the surveyed port. Significance marked in bold $(P<0.05)$.

\begin{tabular}{|l|c|c|c|c|c|c|}
\hline & df & SS & MS & Pseudo- & P (perm) & Unique \\
perms
\end{tabular}

Pairwise comparisons also showed a high significance in community composition between surveyed ports $(P<0.001)$. The within-group similarity was relatively more robust at Port Geelong (40.69\%) followed by Hobart (40.16\%), and Esperance had the least withingroup similarity $(9.23 \%$ ) (Table 2.3 .4$)$. The between-ports dissimilarity ranged from 75.86 $100 \%$, indicating high dissimilarity in the community composition between ports. The paired ports that showed less than $90 \%$ dissimilarity are; Geelong vs Melbourne (75.86\%), Hastings vs Portland (85.95\%), Fremantle vs Melbourne (86.02\%), Eden vs Melbourne (87.21\%), Geelong vs Hobart (88.09\%), Geelong vs Portland (88.36\%), Adelaide vs Melbourne (88.73\%), Fremantle vs Newcastle (89.20\%), Fremantle vs Geelong (89.71\%) and Hay point vs Mackay (89.84\%). Further, observing these paired ports, the between-ports dissimilarity is relatively low for ports at proximity.

Table 2.3.4. The average similarity of the presence/absence of species as a function of the surveyed port.

\begin{tabular}{|c|c|c|c|c|c|}
\hline Ports & Avg. sim. (\%) & Ports & Avg. sim. (\%) & Ports & Avg. sim. (\%) \\
\hline Abbot Point & 13.07 & Devonport & 19.68 & Geraldton & 27.66 \\
\hline Adelaide & 28.34 & Eden & 25.48 & Gladstone & 28.27 \\
\hline
\end{tabular}




\begin{tabular}{|c|c|c|c|c|c|}
\hline Albany & 13.81 & Esperance & 9.23 & Hastings & 38.67 \\
\hline Bunbury & 13.50 & Fremantle & 24.87 & Hay Point & 21.26 \\
\hline Burnie & 15.77 & Geelong & 40.69 & Hobart & 40.16 \\
\hline Lady Barron & 11.22 & Mackay & 19.66 & Newcastle & 24.25 \\
\hline Launceston & 35.17 & Melbourne & 34.38 & Port Hedland & 28.91 \\
\hline Lucinda & 11.98 & Mourilyan & 15.15 & Port Lincoln & 15.68 \\
\hline Portland & 32.76 & Townsville & 11.92 & Weipa & 9.65 \\
\hline
\end{tabular}

SIMPER (similarity percentage) analysis was applied to identify the top 5 contributing and discriminating species between surveyed ports. It is important to note that red alga, Jania adhaerens, contributed $94.68 \%$ to the average similarity within Port Geraldton explaining the port as an outlier (Table 2.3.5). The SIMPER results indicated that the species contributing to the within-ports similarity also contributed to the between-ports dissimilarity (considering the top 5 species). There was no specific trend observed in terms of species contribution between surveyed ports highlighting the dissimilarities. However, the dissimilarity between ports was dependent on the average abundance of the species at each port. 
Table 2.3.5. SIMPER analysis: average similarity in the presence/absence of species as a function of the surveyed port.

\begin{tabular}{|c|c|c|c|c|c|c|c|c|c|c|c|}
\hline \multicolumn{4}{|c|}{$\begin{array}{c}\text { Abbot Point } \\
\text { Average similarity: } 13.07 \%\end{array}$} & \multicolumn{4}{|c|}{$\begin{array}{c}\text { Adelaide } \\
\text { Average similarity: } 28.34 \%\end{array}$} & \multicolumn{4}{|c|}{$\begin{array}{c}\text { Burnie } \\
\text { Average similarity: } 15.77 \%\end{array}$} \\
\hline Species & $\begin{array}{l}\text { Avg. } \\
\text { Abund }\end{array}$ & $\mathrm{C} \%$ & Cum.\% & Species & $\begin{array}{l}\text { Avg. } \\
\text { Abund }\end{array}$ & $\mathrm{C} \%$ & Cum.\% & Species & $\begin{array}{l}\text { Avg. } \\
\text { Abund }\end{array}$ & $\mathrm{C} \%$ & Cum.\% \\
\hline Ophiactis cf. savignyi & 0.69 & 15.49 & 15.49 & Sabella spallanzanii & 0.67 & 12.69 & 12.69 & Xenostrobus pulex & 0.45 & 10.83 & 10.83 \\
\hline Chama fibula & 0.56 & 11.86 & 27.35 & Hydroides elegans & 0.65 & 11.24 & 23.94 & Lasaea australis & 0.48 & 9.29 & 20.12 \\
\hline Pinctada sugillata & 0.56 & 10.85 & 38.21 & Styela plicata & 0.56 & 8.85 & 32.78 & Celleporaria foliata & 0.45 & 7.82 & 27.94 \\
\hline Dendostrea folium & 0.5 & 9.55 & 47.76 & Harmothoe waahli & 0.58 & 8.02 & 40.8 & Hiatella australis & 0.45 & 7.51 & 35.45 \\
\hline Pyura stolonifera & 0.5 & 8.83 & 56.59 & Botryllus schlosseri & 0.47 & 7.13 & 47.94 & Paradexamine churinga & 0.43 & 6.99 & 42.44 \\
\hline \multicolumn{4}{|c|}{ Albany } & \multicolumn{4}{|c|}{ Bunbury } & \multicolumn{4}{|c|}{ Devonport } \\
\hline Species & $\begin{array}{l}\text { Avg. } \\
\text { Abund }\end{array}$ & $\mathrm{C} \%$ & Cum.\% & Species & $\begin{array}{l}\text { Avg. } \\
\text { Abund }\end{array}$ & $\mathrm{C} \%$ & Cum.\% & Species & $\begin{array}{l}\text { Avg. } \\
\text { Abund }\end{array}$ & $\mathrm{C} \%$ & Cum.\% \\
\hline Bugula stolonifera & 0.32 & 15.28 & 15.28 & Paracerceis sculpta & 0.46 & 56.77 & 56.77 & Thelepus extensus & 0.59 & 24.78 & 24.78 \\
\hline Sabella spallanzanii & 0.34 & 14.21 & 29.49 & Sabella spallanzanii & 0.27 & 18.47 & 75.24 & Sertularella cf. robusta & 0.5 & 19.15 & 43.93 \\
\hline Watersipora subtorquata & 0.29 & 13.55 & 43.03 & Leptochiton liratus & 0.21 & 9.32 & 84.56 & Tubularia cf. crocea & 0.45 & 15.73 & 59.66 \\
\hline Bugula neritina & 0.27 & 8.42 & 51.46 & Herpetopoma aspersa & 0.17 & 4.51 & 89.07 & Bimeria australis & 0.36 & 8.81 & 68.47 \\
\hline Cryptosula pallasiana & 0.24 & 7.73 & 59.19 & Hiatella australis & 0.13 & 3.03 & 92.1 & Sarsia cf. eximia & 0.32 & 6.04 & 74.5 \\
\hline \multicolumn{4}{|c|}{$\begin{array}{c}\text { Eden } \\
\text { Average similarity: } \mathbf{2 5 . 4 8 \%}\end{array}$} & \multicolumn{4}{|c|}{$\begin{array}{c}\text { Esperance } \\
\text { Average similarity: } 9.23 \%\end{array}$} & \multicolumn{4}{|c|}{$\begin{array}{c}\text { Fremantle } \\
\text { Average similarity: } 24.87 \%\end{array}$} \\
\hline Species & $\begin{array}{l}\text { Avg. } \\
\text { Abund }\end{array}$ & $\mathrm{C} \%$ & Cum.\% & Species & $\begin{array}{l}\text { Avg. } \\
\text { Abund }\end{array}$ & $\mathrm{C} \%$ & Cum.\% & Species & $\begin{array}{l}\text { Avg. } \\
\text { Abund }\end{array}$ & $\mathrm{C} \%$ & Cum.\% \\
\hline Balanus trigonus & 0.71 & 23.01 & 23.01 & Hiatella australis & 0.45 & 26.42 & 26.42 & Balanus trigonus & 0.84 & 37.13 & 37.13 \\
\hline Podarkeopsis galangaui & 0.74 & 21.7 & 44.71 & Pilumnus acer & 0.27 & 14.25 & 40.67 & Hiatella australis & 0.48 & 8.91 & 46.03 \\
\hline Mytilus edulis planulatus & 0.61 & 14.29 & 58.99 & Halicarcinus ovatus & 0.28 & 11.23 & 51.91 & Pilumnus fissifrons & 0.45 & 8.83 & 54.87 \\
\hline Hiatella australis & 0.48 & 6.9 & 65.89 & Alpheus socialis & 0.22 & 5.83 & 57.73 & Mytilus edulis planulatus & 0.46 & 8.06 & 62.93 \\
\hline Watersipora subtorquata & 0.42 & 6 & 71.89 & Musculus cf. nanus & 0.23 & 5.02 & 62.76 & Celleporaria cf. nodulosa & 0.33 & 5.86 & 68.79 \\
\hline
\end{tabular}




\begin{tabular}{|c|c|c|c|c|c|c|c|c|c|c|c|}
\hline \multicolumn{4}{|c|}{$\begin{array}{c}\text { Geelong } \\
\text { Average similarity: } \mathbf{4 0 . 6 9 \%}\end{array}$} & \multicolumn{4}{|c|}{$\begin{array}{c}\text { Gladstone } \\
\text { Average similarity: } 28.27 \%\end{array}$} & \multicolumn{4}{|c|}{$\begin{array}{c}\text { Hastings } \\
\text { Average similarity: } \mathbf{3 8 . 6 7 \%}\end{array}$} \\
\hline Species & $\begin{array}{l}\text { Avg. } \\
\text { Abund }\end{array}$ & $\mathrm{C} \%$ & Cum. $\%$ & Species & $\begin{array}{l}\text { Avg. } \\
\text { Abund }\end{array}$ & $\mathrm{C} \%$ & Cum.\% & Species & $\begin{array}{l}\text { Avg. } \\
\text { Abund }\end{array}$ & $\mathrm{C} \%$ & Cum.\% \\
\hline Mytilus galloprovincialis & 0.85 & 16.44 & 16.44 & Pisidia gordoni & 0.78 & 38.14 & 38.14 & Stolonica australis & 0.83 & 20.34 & 20.34 \\
\hline Balanus trigonus & 0.83 & 15.24 & 31.68 & Sphaeroma sculpta & 0.56 & 21.22 & 59.36 & Bugula dentata & 0.72 & 16.1 & 36.44 \\
\hline Pyura stolonifera & 0.83 & 14.66 & 46.35 & Hiatella arctica & 0.39 & 8.03 & 67.39 & $\begin{array}{l}\text { Triphyllozoon } c f . \\
\text { moniliferum }\end{array}$ & 0.72 & 15.5 & 51.95 \\
\hline Ascidiella aspersa & 0.66 & 9.04 & 55.39 & Scruparia ambigua & 0.33 & 6.81 & 74.2 & Amastigia cf. texta & 0.72 & 15.19 & 67.14 \\
\hline Platynereis antipoda & 0.66 & 8.67 & 64.06 & Aora maculata & 0.36 & 6.16 & 80.36 & Cryptosula pallasiana & 0.56 & 8.95 & 76.09 \\
\hline \multicolumn{4}{|c|}{$\begin{array}{l}\text { Lady Barron } \\
\text { Average similarity: } 11.22 \%\end{array}$} & \multicolumn{4}{|c|}{$\begin{array}{c}\text { Hay Point } \\
\text { Average similarity: } 21.26 \%\end{array}$} & \multicolumn{4}{|c|}{$\begin{array}{c}\text { Hobart } \\
\text { Average similarity: } \mathbf{4 0 . 1 6 \%}\end{array}$} \\
\hline Species & $\begin{array}{l}\text { Avg. } \\
\text { Abund }\end{array}$ & $\mathrm{C} \%$ & Cum. $\%$ & Species & $\begin{array}{l}\text { Avg. } \\
\text { Abund }\end{array}$ & $\mathrm{C} \%$ & Cum. $\%$ & Species & $\begin{array}{l}\text { Avg. } \\
\text { Abund }\end{array}$ & $\mathrm{C} \%$ & Cum. $\%$ \\
\hline Bugula dentata & 0.41 & 46.7 & 46.7 & Chama lazarus & 0.64 & 15.06 & 15.06 & $\begin{array}{l}\text { Monocorophium } \\
\text { acherusicum }\end{array}$ & 0.92 & 9.81 & 9.81 \\
\hline Herdmania momus & 0.35 & 18.34 & 65.04 & Pilumnus cf. tomentosus & 0.64 & 14.67 & 29.73 & Hiatella australis & 0.81 & 7.36 & 17.16 \\
\hline Amathia distans & 0.29 & 11.98 & 77.01 & Striatobalanus amaryllis & 0.64 & 12 & 41.73 & Watersipora subtorquata & 0.79 & 6.87 & 24.03 \\
\hline Celleporaria fusca & 0.18 & 4.25 & 81.26 & Lumbrineris coccinea & 0.45 & 5.29 & 47.02 & Mytilus galloprovincialis & 0.79 & 6.83 & 30.86 \\
\hline Stolonica australis & 0.18 & 3.82 & 85.08 & Hyastenus cf. convexus & 0.43 & 5.12 & 52.13 & Crassostrea gigas & 0.79 & 6.77 & 37.63 \\
\hline \multicolumn{4}{|c|}{$\begin{array}{c}\text { Launceston } \\
\text { Average similarity: } \mathbf{3 5 . 1 7 \%}\end{array}$} & \multicolumn{4}{|c|}{$\begin{array}{l}\text { Lucinda } \\
\text { Average similarity: } 11.98 \%\end{array}$} & \multicolumn{4}{|c|}{$\begin{array}{c}\text { Mackay } \\
\text { Average similarity: } 19.66 \%\end{array}$} \\
\hline Species & $\begin{array}{l}\text { Avg. } \\
\text { Abund }\end{array}$ & $\mathrm{C} \%$ & Cum. $\%$ & Species & $\begin{array}{l}\text { Avg. } \\
\text { Abund }\end{array}$ & $\mathrm{C} \%$ & Cum.\% & Species & $\begin{array}{l}\text { Avg. } \\
\text { Abund }\end{array}$ & $\mathrm{C} \%$ & Cum.\% \\
\hline Balanus trigonus & 0.87 & 9.2 & 9.2 & Balanus reticulatus & 0.28 & 29.07 & 29.07 & Amathia distans & 0.72 & 16.78 & 16.78 \\
\hline Halicarcinus ovatus & 0.76 & 6.46 & 15.66 & Isognomon nucleus & 0.5 & 15.35 & 44.42 & Eupolymnia koorangia & 0.64 & 11.57 & 28.36 \\
\hline Balanus variegatus & 0.69 & 5.47 & 21.12 & Chama fibula & 0.44 & 9.98 & 54.4 & Thelepus robustus & 0.56 & 10.83 & 39.19 \\
\hline Achelia assimilis & 0.69 & 5.13 & 26.25 & Brachidontes maritimus & 0.33 & 7.48 & 61.88 & Lumbrineris coccinea & 0.48 & 6.96 & 46.15 \\
\hline Molgula ficus & 0.64 & 4.99 & 31.24 & Balanus amphitrite & 0.28 & 4.74 & 66.61 & Lumbrineris inflata & 0.44 & 5.59 & 51.75 \\
\hline
\end{tabular}




\begin{tabular}{|c|c|c|c|c|c|c|c|c|c|c|c|}
\hline \multicolumn{4}{|c|}{$\begin{array}{c}\text { Melbourne } \\
\text { Average similarity: } \mathbf{3 4 . 3 8 \%}\end{array}$} & \multicolumn{4}{|c|}{$\begin{array}{c}\text { Mourilyan } \\
\text { Average similarity: } 15.14 \%\end{array}$} & \multicolumn{4}{|c|}{$\begin{array}{c}\text { Newcastle } \\
\text { Average similarity: } \mathbf{2 4 . 2 5 \%}\end{array}$} \\
\hline Species & $\begin{array}{l}\text { Avg. } \\
\text { Abund }\end{array}$ & $\mathrm{C} \%$ & Cum. $\%$ & Species & $\begin{array}{l}\text { Avg. } \\
\text { Abund }\end{array}$ & $\mathrm{C} \%$ & Cum.\% & Species & $\begin{array}{l}\text { Avg. } \\
\text { Abund }\end{array}$ & $\mathrm{C} \%$ & Cum.\% \\
\hline Balanus trigonus & 0.7 & 28.86 & 28.86 & $\begin{array}{l}\text { Dendostrea } \\
\text { sandvichensis }\end{array}$ & 0.5 & 15.13 & 15.13 & Balanus variegatus & 0.67 & 29.1 & 29.1 \\
\hline Sabella spallanzanii & 0.59 & 20.55 & 49.4 & Balanus amphitrite & 0.42 & 10.28 & 25.41 & Balanus trigonus & 0.62 & 15.52 & 44.62 \\
\hline Pyura stolonifera & 0.52 & 13.84 & 63.24 & Leonnates decipens & 0.42 & 9.25 & 34.66 & Irus crebrelamellatus & 0.43 & 7.91 & 52.53 \\
\hline Mytilus edulis planulatus & 0.48 & 13.16 & 76.4 & Chama fibula & 0.42 & 9.14 & 43.8 & Augeneria verdis & 0.38 & 5.54 & 58.07 \\
\hline Ascidiella aspersa & 0.37 & 6.94 & 83.34 & Striostrea mytiloides & 0.33 & 7.13 & 50.93 & Bugula neritina & 0.34 & 4.61 & 62.68 \\
\hline \multicolumn{4}{|c|}{$\begin{array}{c}\text { Port Hedland } \\
\text { Average similarity: } 28.91 \%\end{array}$} & \multicolumn{4}{|c|}{$\begin{array}{c}\text { Port Lincoln } \\
\text { Average similarity: } 15.68 \%\end{array}$} & \multicolumn{4}{|c|}{$\begin{array}{c}\text { Portland } \\
\text { Average similarity: } 32.76 \%\end{array}$} \\
\hline Species & $\begin{array}{l}\text { Avg. } \\
\text { Abund }\end{array}$ & $\mathrm{C} \%$ & Cum. $\%$ & Species & $\begin{array}{l}\text { Avg. } \\
\text { Abund }\end{array}$ & $\mathrm{C} \%$ & Cum.\% & Species & $\begin{array}{l}\text { Avg. } \\
\text { Abund }\end{array}$ & $\mathrm{C} \%$ & Cum.\% \\
\hline Lumbrineris inflata & 0.73 & 19.23 & 19.23 & Hiatella australis & 0.56 & 36.63 & 36.63 & Bugula dentata & 0.8 & 24.58 & 24.58 \\
\hline Crisia cf. acropora & 0.69 & 17.53 & 36.76 & Musculus impactus & 0.36 & 11.33 & 47.96 & Paratanais ignotus & 0.53 & 10.6 & 35.18 \\
\hline Syllis australiensis & 0.52 & 9.92 & 46.68 & Ophiactis resiliens & 0.29 & 8.39 & 56.35 & Halicarcinus ovatus & 0.53 & 9.38 & 44.56 \\
\hline Microcosmus helleri & 0.54 & 9.55 & 56.22 & Lasaea australis & 0.27 & 8.29 & 64.64 & Eucoelium mariae & 0.53 & 9.01 & 53.56 \\
\hline Pomatostegus stellatus & 0.54 & 9.49 & 65.71 & Trichomusculus barbatus & 0.29 & 5.88 & 70.51 & Watersipora subtorquata & 0.53 & 8.52 & 62.09 \\
\hline \multicolumn{4}{|c|}{$\begin{array}{c}\text { Townsville } \\
\text { Average similarity: } 11.92 \%\end{array}$} & \multicolumn{4}{|c|}{$\begin{array}{c}\text { Weipa } \\
\text { Average similarity: } 9.65 \%\end{array}$} & \multicolumn{4}{|c|}{$\begin{array}{c}\text { Geraldton } \\
\text { Average similarity: } 27.66 \%\end{array}$} \\
\hline Species & $\begin{array}{l}\text { Avg. } \\
\text { Abund }\end{array}$ & $\mathrm{C} \%$ & Cum. $\%$ & Species & $\begin{array}{l}\text { Avg. } \\
\text { Abund }\end{array}$ & $\mathrm{C} \%$ & Cum.\% & Species & $\begin{array}{l}\text { Avg. } \\
\text { Abund }\end{array}$ & $\mathrm{C} \%$ & Cum.\% \\
\hline Branchiomma nigromaculata & 0.44 & 14.45 & 14.45 & Thelepus robustus & 0.44 & 28.23 & 28.23 & Jania adhaerens & 0.52 & 94.68 & 94.68 \\
\hline Lepidonotus carinulatus & 0.4 & 9.02 & 23.46 & Striostrea mytiloides & 0.28 & 17.04 & 45.27 & & & & \\
\hline Lumbrineris cf. coccinea & 0.38 & 8.28 & 31.75 & Balanus amphitrite & 0.22 & 10.85 & 56.12 & & & & \\
\hline Pseudopotamilla cf. laciniosa & 0.36 & 7.54 & 39.29 & Lysidice collaris & 0.28 & 8.15 & 64.27 & & & & \\
\hline Lysidice collaris & 0.33 & 5.88 & 45.17 & Striatobalanus amaryllis & 0.28 & 6.9 & 71.17 & & & & \\
\hline
\end{tabular}

$\mathrm{C} \%$ - Percent contribution; Cum.\%- cumulative percentage 


\section{b) Port type (major and minor ports)}

The graphical representation of the MDS ordination of the presence/absence data showed no distinct groupings of similar species composition as a function of port type, 4 major commercial shipping ports and 23 minor shipping ports ( $2 \mathrm{D}$ stress $=0.11$; Figure 2.3.3).

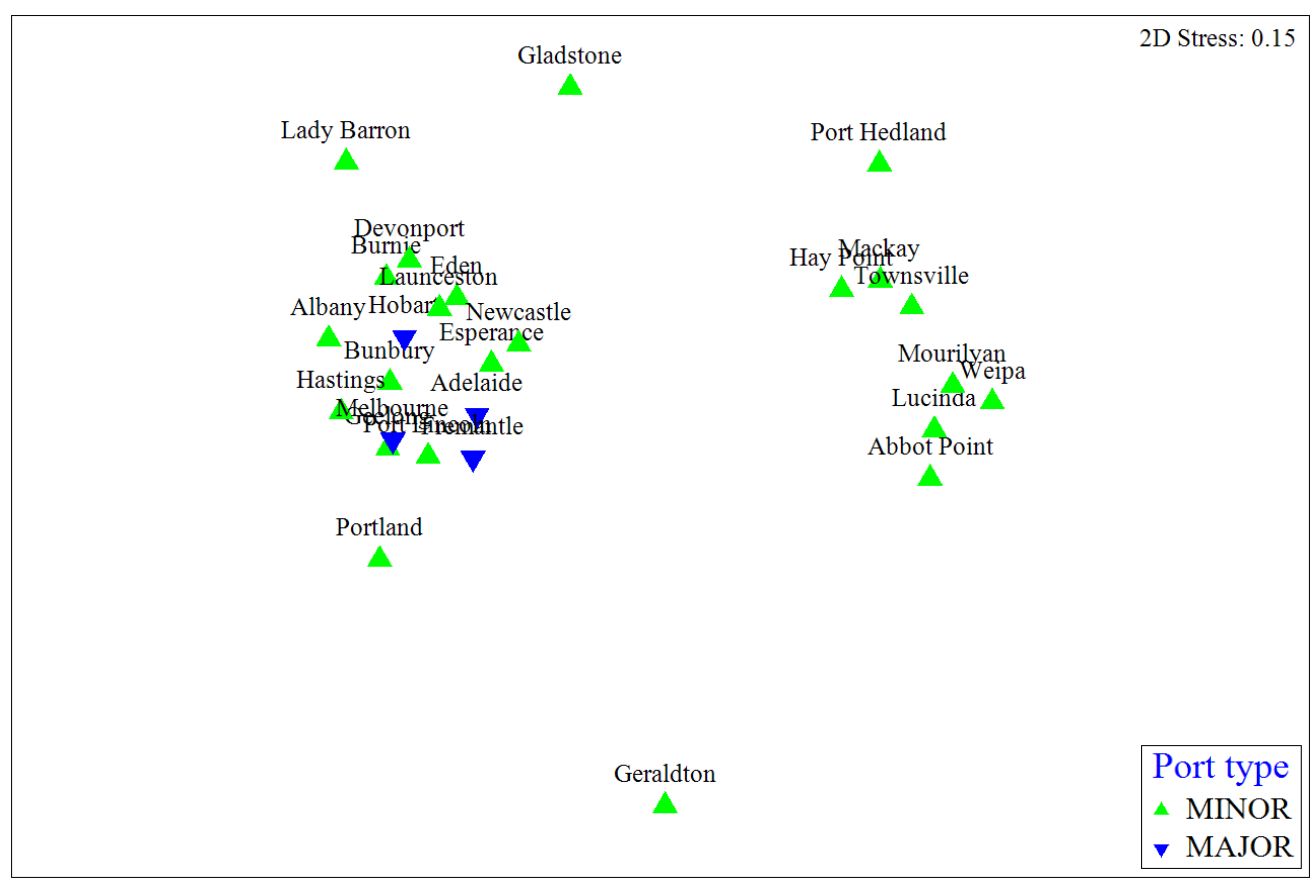

Figure 2.3.3. Multidimensional Scaling (MDS) Map. The proximity of surveyed ports to each other indicates similarity in community composition as a function of port type.

Further, multivariate analyses, PERMANOVA showed a significant difference in species community composition as a function of port type $(P=0.047$; Table 2.3.6). Pairwise comparison, however, showed relatively more similar species composition at major ports $(18.42 \%)$ than minor ports $(6.84 \%)$ (Table 2.3.6).

Table 2.3.6. Results of the PERMANOVA and pairwise test performed as a function of port type (2 levels). Significance marked in bold $(P<0.05)$.

\begin{tabular}{|c|c|c|c|c|c|c|c|c|c|}
\hline Source & df & SS & MS & $\begin{array}{c}\text { Pseudo- } \\
\boldsymbol{F}\end{array}$ & $\begin{array}{c}\boldsymbol{P} \\
\text { (perm) }\end{array}$ & $\begin{array}{c}\text { Unique } \\
\text { perms }\end{array}$ & $\begin{array}{c}\text { t } \\
\text { value }\end{array}$ & \multicolumn{2}{|c|}{ Avg. similarity } \\
\hline Port type & 1 & 5666.7 & 5666.7 & 1.3364 & $\mathbf{0 . 0 4 7}$ & 7541 & 1.156 & 18.42 & 6.84 \\
\hline Residual & 25 & $1.06 \mathrm{E}+05$ & 4240.2 & & & & & & \\
\hline Total & 26 & $1.116 \mathrm{E}+05$ & & & & & & & \\
\hline
\end{tabular}


SIMPER analysis showed 154 species contributing to the $50 \%$ dissimilarity between major and minor ports. The top 5 species contributing to the differences were: cryptogenic Balanus trigonus (1.44\%), native Mytilus edulis planulatus (1.06\%), non-native Sabella spallanzanii (1.05\%), non-native Ciona intestinalis (0.89\%) and native Pyura stolonifera $(0.85 \%)$. The species at major ports were better discriminators (Table 2.3.7).

Table 2.3.7. SIMPER analysis: average similarity in the community composition as a function of port type. Species status, i.e., native $(\mathrm{N})$, non-native $(\mathrm{NN})$ and cryptogenic $(\mathrm{C})$, is noted.

\begin{tabular}{|c|c|c|c|c|c|c|c|}
\hline \multicolumn{2}{|c|}{$\begin{array}{c}\text { Minor ports } \\
\text { Average similarity }=6.84 \%\end{array}$} & \multicolumn{2}{|c|}{$\begin{array}{c}\text { Major ports } \\
\text { Average similarity }=18.42 \%\end{array}$} & \multicolumn{4}{|c|}{$\begin{array}{c}\text { Minor \& Major ports } \\
\text { Average dissimilarity }=90.99 \%\end{array}$} \\
\hline Species & $\mathrm{C} \%$ & Species & $\mathrm{C} \%$ & Species & Minor & Major & $\mathrm{C} \%$ \\
\hline Hiatella australis $(\mathrm{N})$ & 8.07 & Balanus trigonus $(\mathrm{C})$ & 12.91 & Balanus trigonus $(\mathrm{C})$ & 0.18 & 0.75 & 1.44 \\
\hline $\begin{array}{l}\text { Watersipora } \\
\text { subtorquata }(\mathrm{NN})\end{array}$ & 3.33 & Ciona intestinalis (NN) & 7.25 & $\begin{array}{l}\text { Mytilus edulis } \\
\text { planulatus }(\mathrm{N})\end{array}$ & 0.05 & 0.43 & 1.06 \\
\hline Bugula neritina $(\mathrm{NN})$ & 2.52 & $\begin{array}{l}\text { Mytilus edulis } \\
\text { planulatus }(\mathrm{N})\end{array}$ & 5.63 & $\begin{array}{l}\text { Sabella spallanzanii } \\
(\mathrm{NN})\end{array}$ & 0.1 & 0.45 & 1.05 \\
\hline $\begin{array}{l}\text { Eupolymnia koorangia } \\
\text { (N) }\end{array}$ & 2.10 & $\begin{array}{l}\text { Halicarcinus ovatus } \\
(\mathrm{N})\end{array}$ & 5.07 & $\begin{array}{l}\text { Ciona intestinalis } \\
(\mathrm{NN})\end{array}$ & 0.02 & 0.42 & 0.89 \\
\hline Balanus amphitrite $(\mathrm{C})$ & 2.05 & $\begin{array}{l}\text { Sabella spallanzanii } \\
(\mathrm{NN})\end{array}$ & 4.92 & Pyura stolonifera $(\mathrm{N})$ & 0.14 & 0.39 & 0.85 \\
\hline
\end{tabular}

$\mathrm{C} \%=$ percent contribution

\section{c) Latitudinal groups}

The surveyed ports were grouped as a function of their latitude forming 6 latitude groups ranging from $15^{\circ} \mathrm{S}$ to $40^{\circ} \mathrm{S}$. The MDS plot is displayed in Figure 2.3.4; $2 \mathrm{D}$ stress $=0.15$, showing the ordination patterns and overlaps between ports as a function of latitudinal groups. The ports at each latitudinal group clustered together but the ports at high $\left(30^{\circ} \mathrm{S}, 35^{\circ} \mathrm{S}\right.$ and $\left.40^{\circ} \mathrm{S}\right)$ and low $\left(15^{\circ} \mathrm{S}\right.$ and $\left.20^{\circ} \mathrm{S}\right)$ latitudinal groups showed distinct separation. Port Geraldton at latitude $25^{\circ} \mathrm{S}$ was an outlier and only port sampled from that latitude. 


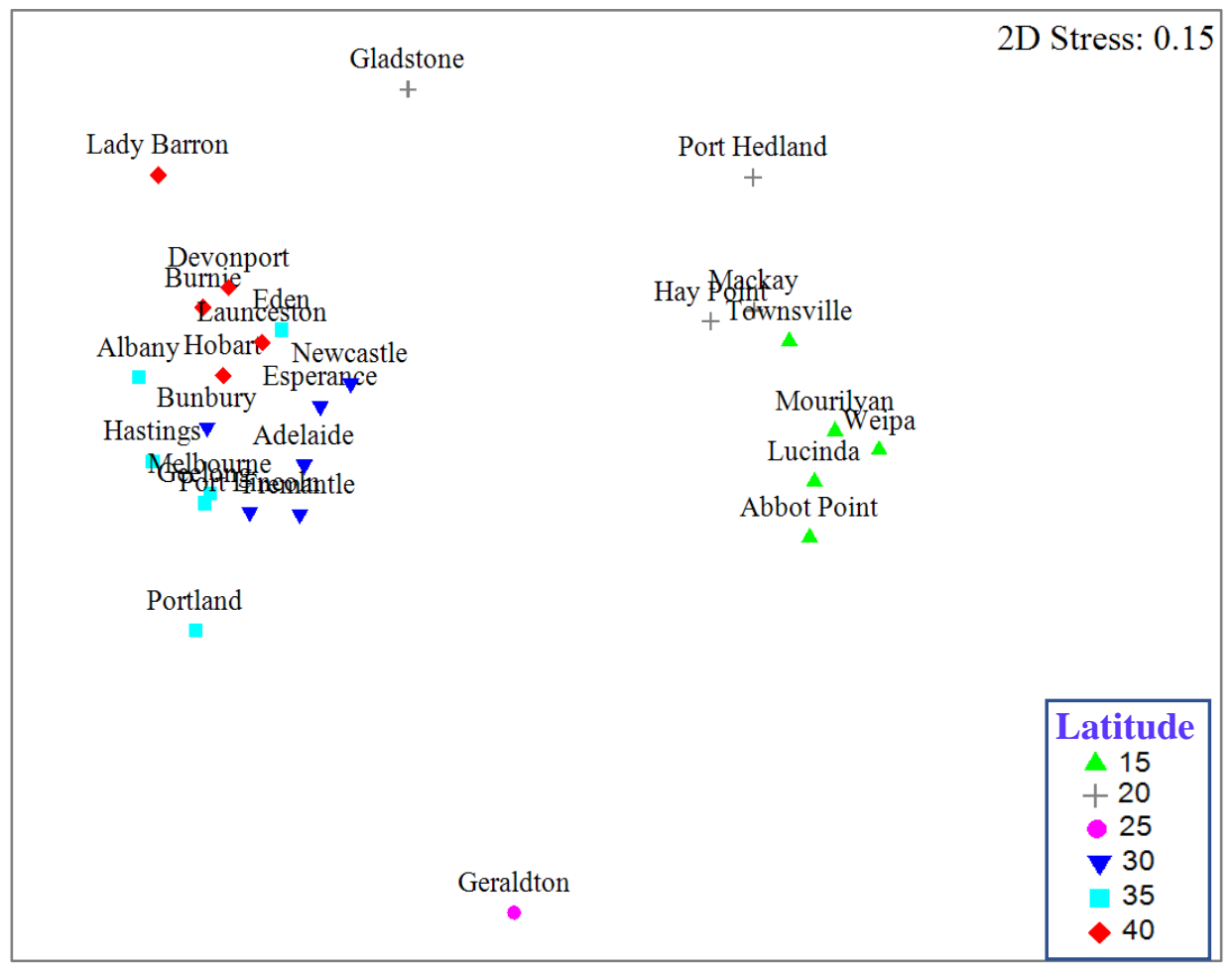

Figure 2.3.4. Multidimensional Scaling (MDS) plot. The proximity of surveyed ports to each other indicates similarity in community composition as a function of latitudinal groups.

The results of the PERMANOVA analysis showed a statistical significance in community composition as a function of latitude $(P<0.001$; Table 2.3.8) indicating variations in community composition for ports at each latitudinal group. Pairwise tests indicated significance $(P<0.05)$ between latitudes $\left(15,20,30,35,40^{\circ} \mathrm{S}\right)$ except for $25^{\circ} \mathrm{S}$, i.e. Port Geraldton, which is an outlier (Table 2.3.9).

Table 2.3.8. Results of the PERMANOVA test performed as a function of latitude (7 levels). Significance $(P<0.05)$ marked in bold.

\begin{tabular}{|c|c|c|c|c|c|c|}
\hline & df & SS & MS & Pseudo-F & $\boldsymbol{P}($ perm) & Unique perms \\
\hline Latitude & 6 & 42473 & 7078.8 & 2.046 & $\mathbf{0 . 0 0 0 1}$ & 9661 \\
\hline Residual & 20 & 69201 & 3460 & & & \\
\hline Total & 26 & $1.1167 \mathrm{E}+05$ & & & & \\
\hline
\end{tabular}


Table 2.3.9. Results of pairwise PERMANOVA test performed as a function of latitudinal groups with only significant paired latitudes. Significance $(P<0.05)$ marked in bold.

\begin{tabular}{|c|c|c|c|}
\hline Latitude $\left({ }^{\circ} \mathrm{S}\right)$ & $\mathbf{t}$ & $\boldsymbol{P}(\mathbf{p e r m})$ & Unique perms \\
\hline 15 vs 30 & 1.6903 & $\mathbf{0 . 0 0 5 2}$ & 210 \\
\hline 15 vs 35 & 1.7544 & $\mathbf{0 . 0 0 4 9}$ & 210 \\
\hline 15 vs 40 & 1.7009 & $\mathbf{0 . 0 0 8 1}$ & 126 \\
\hline 15 vs 20 & 1.3609 & $\mathbf{0 . 0 3 0 9}$ & 35 \\
\hline 30 vs 35 & 1.2686 & $\mathbf{0 . 0 1 7 9}$ & 462 \\
\hline 30 vs 40 & 1.3786 & $\mathbf{0 . 0 0 2 6}$ & 461 \\
\hline 30 vs 20 & 1.5535 & $\mathbf{0 . 0 0 6 2}$ & 210 \\
\hline 35 vs 40 & 1.3431 & $\mathbf{0 . 0 0 6 5}$ & 462 \\
\hline 35 vs 20 & 1.6481 & $\mathbf{0 . 0 0 4 3}$ & 210 \\
\hline 40 vs 20 & 1.5486 & $\mathbf{0 . 0 0 8 9}$ & 126 \\
\hline
\end{tabular}

SIMPER was performed to identify the species (top 5) that contributed to the significant dissimilarity between paired latitudes (Table 2.3.11). The species at $15^{\circ} \mathrm{S}$ were better discriminators leading to the dissimilarity between latitude $15^{\circ} \mathrm{S}$ and other latitudes, i.e., 20 , $30,35,40^{\circ} \mathrm{S}$. The top species contributing to the dissimilarity are; Chama fibula (NN), Ophiactis cf. savignyi (N), Dendostrea folium (N) and Eunice tubifex (N). Species that explained the dissimilarity between latitude $20^{\circ} \mathrm{S}$ and latitudes 30,35 and $40^{\circ} \mathrm{S}$ are; Lumbrineris inflata $(N)$, Chama lazarus $(N)$ and Thelepus robustus $(N)$. The species at latitude $20^{\circ} \mathrm{S}$ were the better discriminators. The dissimilarity for latitudinal groups $30^{\circ} \mathrm{S}$ vs $35^{\circ} \mathrm{S}$ was contributed by species; Balanus trigonus $(\mathrm{C})$, Bugula dentata $(\mathrm{N})$, Cryptosula pallasiana $(\mathrm{NN})$ and Watersipora subtorquata (NN) with species at $35^{\circ} \mathrm{S}$ being the better discriminators. Lastly, the dissimilarity between latitudes $30^{\circ} \mathrm{S}$ and $40^{\circ} \mathrm{S}$ were explained by species; Pomatoceros taeniata $(\mathrm{N})$, Balanus trigonus (C), Crassotrea gigas $(\mathrm{NN})$, Bimeria australis $(\mathrm{N})$ and Bugula dentata $(\mathrm{N})$. The species at $40^{\circ} \mathrm{S}$ latitude being the better discriminators (Table 2.3.10).

To summarize, the percentage contribution $(\mathrm{C} \%)$ of each species to the dissimilarities between the latitudes was less than $2 \%$. Also, the results indicated no specific trend in species contribution between latitudinal groups. However, the species at lower latitudes, i.e., $15^{\circ} \mathrm{S}$ and $20^{\circ} \mathrm{S}$ were better discriminators compared to higher latitudes, i.e., $30^{\circ} \mathrm{S}, 35^{\circ} \mathrm{S}, 40^{\circ} \mathrm{S}$. 
Table 2.3.10. SIMPER analysis: average dissimilarity for the community composition as a function of latitude with only significant paired latitudes.

Species status, i.e., native $(\mathrm{N})$, non-native $(\mathrm{NN})$ and cryptogenic $(\mathrm{C})$, is noted.

\begin{tabular}{|c|c|c|c|c|c|c|c|c|c|}
\hline \multicolumn{5}{|c|}{$\begin{array}{c}15 \& 30^{\circ} \mathrm{S} \\
\text { Average dissimilarity }=97.48 \%\end{array}$} & \multicolumn{5}{|c|}{$\begin{array}{c}15 \& 35^{\circ} \mathrm{S} \\
\text { Average dissimilarity }=98.40 \%\end{array}$} \\
\hline & 15 & 30 & & & & 15 & 35 & & \\
\hline Species & Avg. Abund. & Avg. Abund & $\mathrm{C} \%$ & Cum.\% & Species & Avg. Abund. & Avg. Abund & $\mathrm{C} \%$ & Cum. $\%$ \\
\hline Chama fibula (NN) & 0.52 & 0 & 0.97 & 0.97 & Watersipora subtorquata $(\mathrm{NN})$ & 0 & 0.52 & 1.03 & 1.03 \\
\hline Ophiactis cf. savignyi $(\mathrm{N})$ & 0.51 & 0 & 0.96 & 1.93 & Chama fibula (NN) & 0.52 & 0 & 1.02 & 2.04 \\
\hline Hiatella australis $(\mathrm{N})$ & 0.06 & 0.56 & 0.95 & 2.88 & Ophiactis cf. savignyi $(\mathrm{N})$ & 0.51 & 0 & 1 & 3.04 \\
\hline Dendostrea folium $(\mathrm{N})$ & 0.49 & 0.01 & 0.89 & 3.77 & Dendostrea folium $(\mathrm{N})$ & 0.49 & 0 & 0.95 & 3.99 \\
\hline Eunice tubifex $(\mathrm{N})$ & 0.45 & 0 & 0.87 & 4.64 & Eunice tubifex $(\mathrm{N})$ & 0.45 & 0 & 0.90 & 4.89 \\
\hline \multicolumn{5}{|c|}{$\begin{array}{c}15 \& 40^{\circ} \mathrm{S} \\
\text { Average dissimilarity }=98.21 \%\end{array}$} & \multicolumn{5}{|c|}{$\begin{array}{c}15 \& 20^{\circ} \mathrm{S} \\
\text { Average dissimilarity }=92.19 \%\end{array}$} \\
\hline & 15 & 40 & & & & 15 & 20 & & \\
\hline Species & Avg. Abund. & Avg. Abund & $\mathrm{C} \%$ & Cum.\% & Species & Avg. Abund. & Avg. Abund & $\mathrm{C} \%$ & Cum.\% \\
\hline Chama fibula (NN) & 0.52 & 0 & 0.83 & 0.83 & Chama fibula $(\mathrm{NN})$ & 0.52 & 0 & 0.91 & 0.91 \\
\hline Ophiactis cf. savignyi $(\mathrm{N})$ & 0.51 & 0 & 0.82 & 1.65 & Ophiactis cf. savignyi $(\mathrm{N})$ & 0.51 & 0 & 0.9 & 1.81 \\
\hline Dendostrea folium $(\mathrm{N})$ & 0.49 & 0 & 0.78 & 2.43 & Lumbrineris inflata $(\mathrm{N})$ & 0 & 0.53 & 0.88 & 2.70 \\
\hline Eunice tubifex $(\mathrm{N})$ & 0.45 & 0 & 0.74 & 3.16 & Eunice tubifex $(\mathrm{N})$ & 0.45 & 0 & 0.81 & 3.51 \\
\hline Pomatoceros taeniata $(\mathrm{N})$ & 0 & 0.47 & 0.73 & 3.89 & Dendostrea folium $(\mathrm{N})$ & 0.49 & 0.04 & 0.8 & 4.3 \\
\hline \multicolumn{5}{|c|}{$\begin{array}{c}35 \& 20^{\circ} \mathrm{S} \\
\text { Average dissimilarity }=97.79 \%\end{array}$} & \multicolumn{5}{|c|}{$\begin{array}{c}30 \& 20^{\circ} \mathrm{S} \\
\text { Average dissimilarity }=96.13 \%\end{array}$} \\
\hline & 35 & 20 & & & & 30 & 20 & & \\
\hline Species & Avg. Abund. & Avg. Abund & $\mathrm{C} \%$ & Cum. $\%$ & Species & Avg. Abund. & Avg. Abund & $\mathrm{C} \%$ & Cum.\% \\
\hline Watersipora subtorquata $(\mathrm{NN})$ & 0.52 & 0 & 1.15 & 1.15 & Hiatella australis $(\mathrm{N})$ & 0.56 & 0.07 & 1.08 & 1.08 \\
\hline Lumbrineris inflata $(\mathrm{N})$ & 0 & 0.53 & 1.07 & 2.22 & Lumbrineris inflata $(\mathrm{N})$ & 0 & 0.53 & 1.04 & 2.12 \\
\hline Chama lazarus $(\mathrm{N})$ & 0 & 0.47 & 0.98 & 3.19 & Chama lazarus $(\mathrm{N})$ & 0 & 0.47 & 0.94 & 3.06 \\
\hline Cryptosula pallasiana $(\mathrm{NN})$ & 0.43 & 0 & 0.96 & 4.15 & Balanus trigonus $(\mathrm{C})$ & 0.45 & 0 & 0.91 & 3.97 \\
\hline Thelepus robustus $(\mathrm{N})$ & 0 & 0.45 & 0.92 & 5.07 & Thelepus robustus $(\mathrm{N})$ & 0 & 0.45 & 0.89 & 4.85 \\
\hline
\end{tabular}




\begin{tabular}{|c|c|c|c|c|c|c|c|c|c|}
\hline \multicolumn{5}{|c|}{$\begin{array}{c}40 \& 20^{\circ} \mathrm{S} \\
\text { Average dissimilarity }=96.40 \%\end{array}$} & \multicolumn{5}{|c|}{$\begin{array}{c}35 \& 40^{\circ} \mathrm{S} \\
\text { Average dissimilarity }=88.37 \%\end{array}$} \\
\hline & 40 & 20 & & & & 35 & 40 & & \\
\hline Species & Avg. Abund. & Avg. Abund & $\mathrm{C} \%$ & Cum.\% & Species & Avg. Abund. & Avg. Abund & $\mathrm{C} \%$ & Cum.\% \\
\hline Lumbrineris inflata $(\mathrm{N})$ & 0 & 0.53 & 0.89 & 0.89 & Balanus trigonus $(\mathrm{C})$ & 0.43 & 0.35 & 1.04 & 1.04 \\
\hline Pomatoceros taeniata $(\mathrm{N})$ & 0.47 & 0 & 0.81 & 1.69 & Cryptosula pallasiana (NN) & 0.43 & 0.13 & 0.99 & 2.03 \\
\hline Chama lazarus $(\mathrm{N})$ & 0 & 0.47 & 0.80 & 2.49 & Pomatoceros taeniata $(\mathrm{N})$ & 0.07 & 0.47 & 0.97 & 2.99 \\
\hline Thelepus robustus $(\mathrm{N})$ & 0 & 0.45 & 0.76 & 3.25 & Bugula dentata $(\mathrm{N})$ & 0.41 & 0.31 & 0.93 & 3.92 \\
\hline Hiatella australis $(\mathrm{N})$ & 0.53 & 0.07 & 0.75 & 4 & Sabella spallanzanii (NN) & 0.36 & 0 & 0.91 & 4.83 \\
\hline \multicolumn{5}{|c|}{$\begin{array}{c}30 \& 40^{\circ} \mathrm{S} \\
\text { Average dissimilarity }=89.63 \%\end{array}$} & \multicolumn{5}{|c|}{$\begin{array}{c}30 \& 35^{\circ} \mathrm{S} \\
\text { Average dissimilarity }=86.99 \%\end{array}$} \\
\hline & 30 & 40 & & & & 30 & 35 & & \\
\hline Species & Avg. Abund. & Avg. Abund & $\mathrm{C} \%$ & Cum.\% & Species & Avg. Abund. & Avg. Abund & $\mathrm{C} \%$ & Cum.\% \\
\hline Pomatoceros taeniata $(\mathrm{N})$ & 0 & 0.47 & 0.99 & 0.99 & Balanus trigonus $(\mathrm{C})$ & 0.45 & 0.43 & 1.29 & 1.29 \\
\hline Balanus trigonus $(\mathrm{C})$ & 0.45 & 0.35 & 0.86 & 1.85 & Bugula dentata $(\mathrm{N})$ & 0 & 0.41 & 1.20 & 2.49 \\
\hline Crassotrea gigas (NN) & 0 & 0.43 & 0.78 & 2.63 & Cryptosula pallasiana $(\mathrm{NN})$ & 0.04 & 0.43 & 1.17 & 3.67 \\
\hline Bimeria australis $(\mathrm{N})$ & 0 & 0.29 & 0.77 & 3.40 & Watersipora subtorquata (NN) & 0.17 & 0.52 & 1.14 & 4.80 \\
\hline Bugula dentata $(\mathrm{N})$ & 0 & 0.31 & 0.75 & 4.15 & Sabella spallanzanii (NN) & 0.31 & 0.36 & 1.10 & 5.90 \\
\hline
\end{tabular}

$\mathrm{C} \%=$ Per cent Contribution, $\mathrm{Cum} . \%=$ Cumulative percentage 
In summary, statistically significant differences in the presence of species were observed as a function of the surveyed port. The average dissimilarities between ports was more than $75 \%$. The results indicated no specific trend in species contribution to the dissimilarities between ports; except for, Port Geraldton where the red alga, Jania adhaerens, contributed $94.68 \%$. The community composition as a function of port type (major vs minor ports) indicated significant differences. The minor ports had relatively diverse species when compared to major ports. However, this could be because of 4 major and 23 minor ports in the dataset. The latitudinal groups indicated significance between latitude groups, except for $25^{\circ} \mathrm{S}$, i.e., Port Geraldton. The species at lower latitudes, i.e., $15^{\circ} \mathrm{S}$ and $20^{\circ} \mathrm{S}$ were better discriminators compared to species at higher latitudes $\left(30,35,40^{\circ} \mathrm{S}\right)$. The top species are contributing to the between-group dissimilarities for the factors, port type and latitudinal groupsare listed below; Table 2.3.11.

Table 2.3.11. The list of species that indicated variations as a function of the port type and latitudinal groups.

\begin{tabular}{|c|c|c|}
\hline Species & Phyla & Species status \\
\hline Balanus trigonus & Arthropoda & Cryptogenic \\
\hline Bugula dentata & Bryozoa & Native \\
\hline Bugula neritina & Bryozoa & Non-native \\
\hline Chama fibula & Mollusca & Non-native \\
\hline Chama lazarus & Mollusca & Native \\
\hline Ciona intestinalis & Chordata & Non-native \\
\hline Crassotrea gigas & Mollusca & Non-native \\
\hline Cryptosula pallasiana & Bryozoa & Non-native \\
\hline Dendostrea folium & Mollusca & Native \\
\hline Eunice tubifex & Annelida & Native \\
\hline Hiatella australis & Mollusca & Native \\
\hline Jania adhaerens & Rhodophyta & Native \\
\hline Lumbrineris inflata & Annelida & Native \\
\hline Mytilus edulis planulatus & Mollusca & Native \\
\hline Ophiactis cf. savignyi & Echinodermata & Native \\
\hline Pomatoceros taeniata & Annelida & Native \\
\hline Sabella spallanzanii & Annelida & Native \\
\hline Thelepus extensus & Annelida & Native \\
\hline Watersipora subtorquata & Bryozoa & Non-native \\
\hline
\end{tabular}




\subsubsection{Variations in species status - native, non-native and cryptogenic species as a function of the surveyed port, port type and latitudinal groups}

\section{a) Surveyed ports}

To eliminate the bias due to differences in the replicates (sampling effort) at each port; the total number of species status (native, non-native and cryptogenic) was divided by the number of replicates at each surveyed port. The total relative number of species (total number/number of replicates) at each surveyed port showed relatively higher percentages of native species, followed by non-native and cryptogenic species (Figure 2.3.5). The relative number of native species was highest at Abbot point (8.44), and lowest at Melbourne (0.33) whereas the nonnative species were highest at Lucinda $(0.5 \%)$ and lowest at Port Gladstone. The number of cryptogenic species was relatively lower compared to native and non-native species (Table 2.3.12).

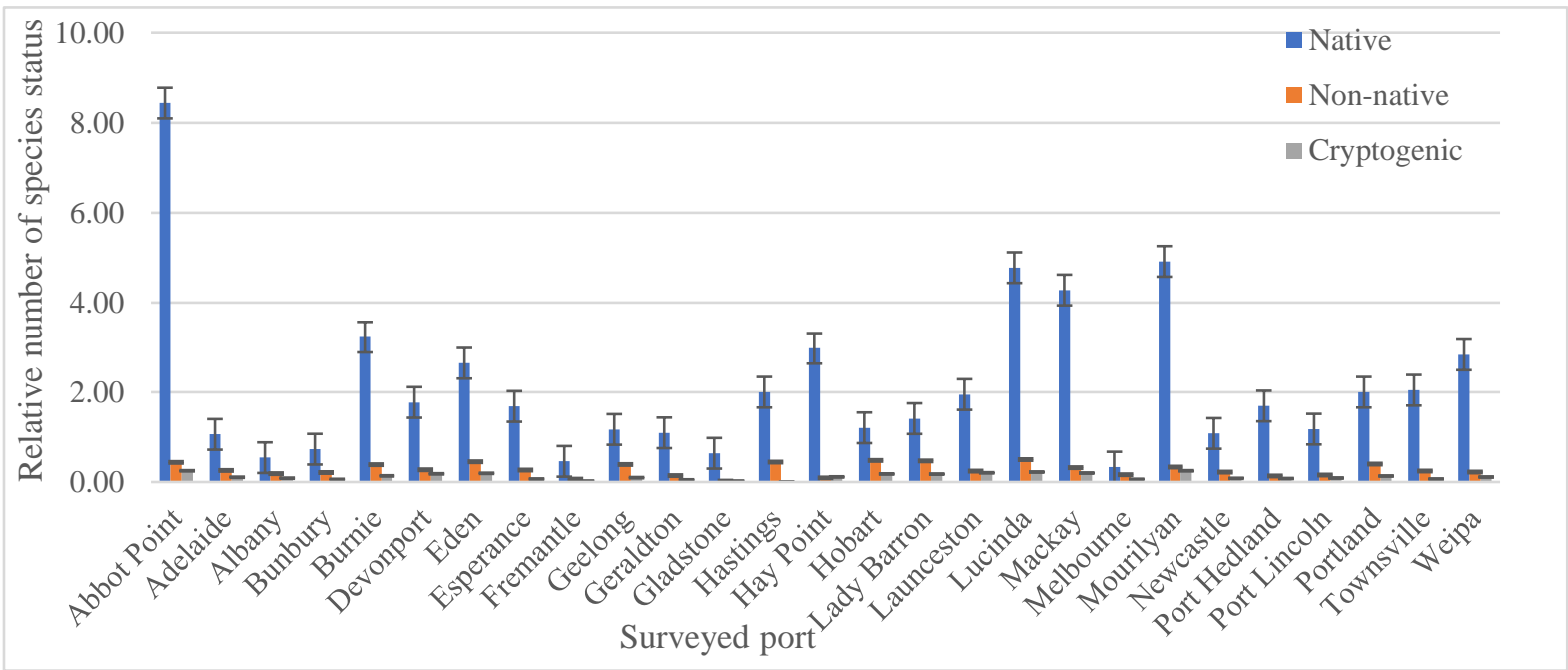

Figure 2.3.5. The total relative number of species status - native (blue), non-native (orange) and cryptogenic (grey) species across 27 surveyed ports.

Table 2.3.12. The total number of species, species status, replicates (sampling effort) and the relative number of native, non-native and cryptogenic species - across 27 surveyed ports.

\begin{tabular}{|l|c|c|c|c|c|c|c|}
\hline Surveyed port & $\begin{array}{c}\text { Native } \\
\text { species }\end{array}$ & $\begin{array}{c}\text { Non-native } \\
\text { species }\end{array}$ & $\begin{array}{c}\text { Cryptogenic } \\
\text { species }\end{array}$ & $\begin{array}{c}\text { Survey } \\
\text { Replicates }\end{array}$ & $\begin{array}{c}\text { Relative } \\
\text { Native }\end{array}$ & $\begin{array}{c}\text { Relative } \\
\text { Non-native }\end{array}$ & $\begin{array}{c}\text { Relative } \\
\text { Cryptogenic }\end{array}$ \\
\hline Abbot Point & 135 & 7 & 4 & 16 & 8.44 & 0.44 & 0.25 \\
\hline Adelaide & 70 & 17 & 7 & 66 & 1.06 & 0.26 & 0.11 \\
\hline Albany & 31 & 10 & 7 & 59 & 0.54 & 0.19 & 0.08 \\
\hline Bunbury & 37 & 11 & 4 & 52 & 0.73 & 0.21 & 0.06 \\
\hline
\end{tabular}




\begin{tabular}{|c|c|c|c|c|c|c|c|}
\hline Burnie & 140 & 19 & 6 & 44 & 3.23 & 0.39 & 0.14 \\
\hline Devonport & 39 & 7 & 3 & 22 & 1.77 & 0.27 & 0.18 \\
\hline Eden & 82 & 14 & 6 & 31 & 2.65 & 0.45 & 0.19 \\
\hline Esperance & 103 & 14 & 4 & 60 & 1.68 & 0.27 & 0.07 \\
\hline Fremantle & 116 & 16 & 4 & 250 & 0.46 & 0.06 & 0.02 \\
\hline Geelong & 49 & 16 & 3 & 41 & 1.17 & 0.39 & 0.10 \\
\hline Geraldton & 23 & 3 & 1 & 21 & 1.10 & 0.14 & 0.05 \\
\hline Gladstone & 62 & 2 & 4 & 100 & 0.64 & 0.02 & 0.02 \\
\hline Hastings & 37 & 7 & 0 & 18 & 2.00 & 0.44 & 0.00 \\
\hline Hay Point & 131 & 6 & 3 & 44 & 2.98 & 0.09 & 0.11 \\
\hline Hobart & 129 & 50 & 19 & 106 & 1.21 & 0.48 & 0.18 \\
\hline Lady Barron & 25 & 7 & 3 & 17 & 1.41 & 0.47 & 0.18 \\
\hline Launceston & 153 & 22 & 12 & 78 & 1.95 & 0.24 & 0.21 \\
\hline Lucinda & 85 & 11 & 3 & 18 & 4.78 & 0.50 & 0.22 \\
\hline Mackay & 109 & 8 & 3 & 25 & 4.28 & 0.32 & 0.20 \\
\hline Melbourne & 50 & 17 & 8 & 135 & 0.33 & 0.16 & 0.06 \\
\hline Mourilyan & 60 & 4 & 2 & 12 & 4.92 & 0.33 & 0.25 \\
\hline Newcastle & 92 & 22 & 5 & 86 & 1.08 & 0.22 & 0.08 \\
\hline Port Hedland & 89 & 7 & 3 & 52 & 1.69 & 0.13 & 0.08 \\
\hline Port Lincoln & 53 & 9 & 2 & 45 & 1.18 & 0.16 & 0.09 \\
\hline Portland & 31 & 5 & 2 & 15 & 2.00 & 0.40 & 0.13 \\
\hline Townsville & 96 & 8 & 2 & 45 & 2.04 & 0.24 & 0.07 \\
\hline Weipa & 51 & 4 & 2 & 18 & 2.83 & 0.22 & 0.11 \\
\hline
\end{tabular}

Furthermore, the number of species status was correlated against each other to observe the interaction between the number of native, non-native and cryptogenic species across all surveyed ports. The results revealed high significance and a strong positive relationship between species status (Figure 2.3.6). The correlation between the number of native and cryptogenic $\left(\mathrm{R}^{2}=0.50 ; P<0.0001\right)$ (Figure 2.3.6 a) species was relatively stronger compared to correlation of the number of cryptogenic and non-native $\left(\mathrm{R}^{2}=0.37 ; P<0.0001\right)$ (Figure 2.3.6 b) species and number of native and non-native species $\left(\mathrm{R}^{2}=0.22 ; P<0.05\right)$ (Figure 2.3.6 c). 
a)

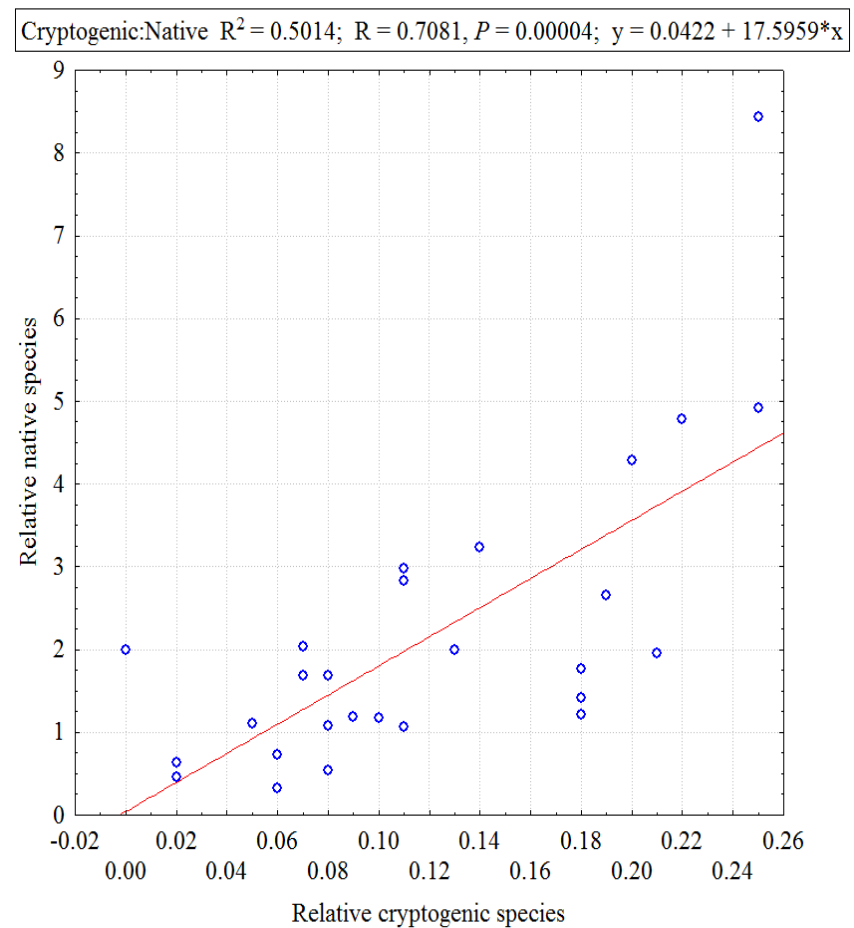

b)

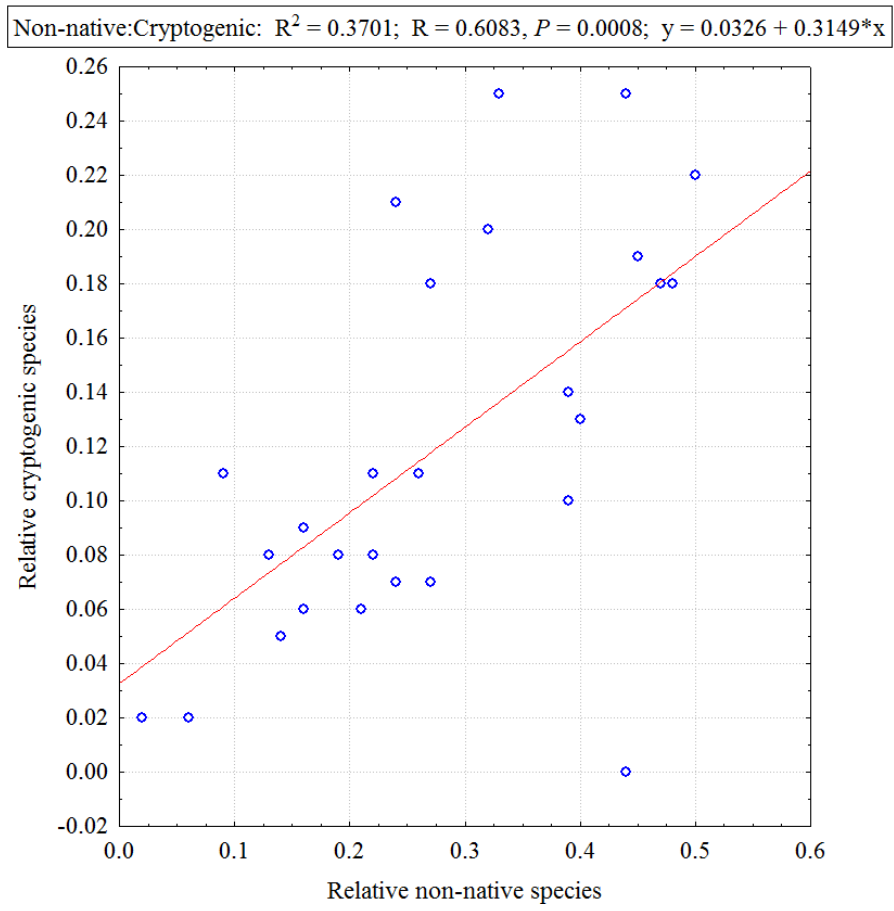

c)

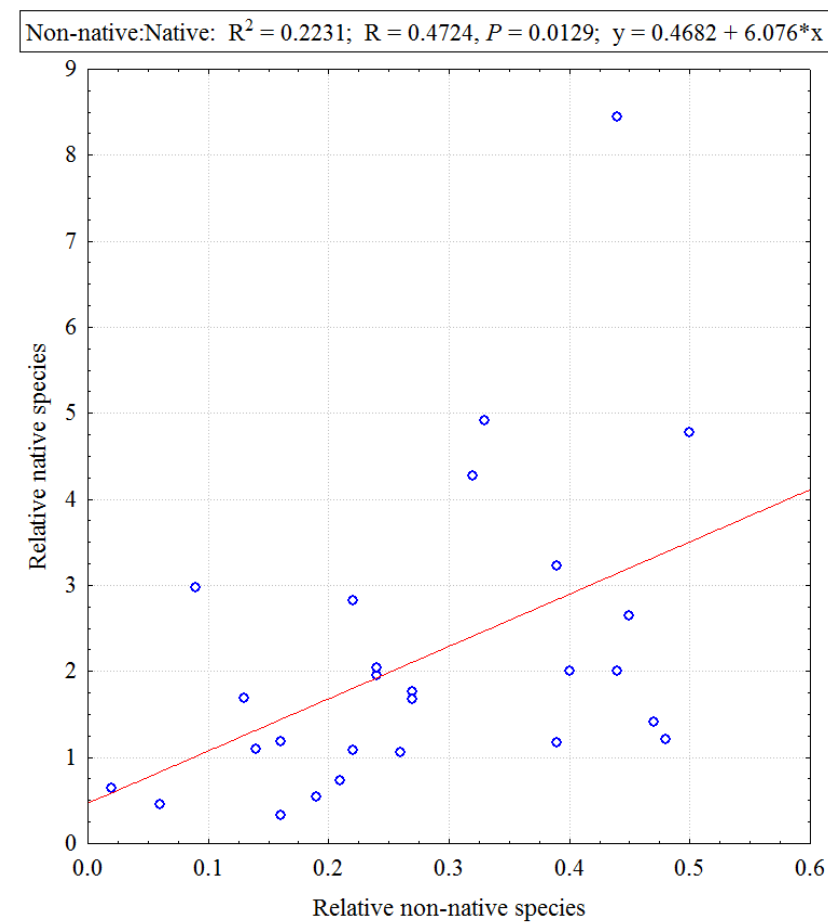

Figure 2.3.6. Regression between relative native and non-native species across 27 surveyed ports; a) Native vs Cryptogenic species, b) Cryptogenic vs Non-native species and c) Native vs Non-native species. 
Multivariate analysis, PERMANOVA was performed to indicate variations in the species status (native, non-native and cryptogenic) as a function of the surveyed port. The species status varied significantly among surveyed ports (PERMANOVA; $P<0.0001$; Table 2.3.13). The pairwise tests revealed significance between most of the ports with more than $50 \%$ average similarities.

Table 2.3.13. Results of the PERMANOVA test performed on the species status as a function of the surveyed port. Significant value in bold $(P<0.05)$.

\begin{tabular}{|l|c|c|c|c|c|c|}
\hline & df & SS & MS & Pseudo-F & $\boldsymbol{P}($ perm) & Unique perms \\
\hline Surveyed port & 26 & $5.43 \mathrm{E}+05$ & 20878 & 33.983 & $\mathbf{0 . 0 0 0 1}$ & 9845 \\
\hline Residuals & 1449 & $8.90 \mathrm{E}+05$ & 614.36 & & & \\
\hline Total & 1475 & $1.43 \mathrm{E}+06$ & & & & \\
\hline
\end{tabular}

SIMPER results revealed more than 50\% average similarity at all ports, with native species to be the highest contributing species status (Table 2.3.19; Figure 2.3.7). At ports such as Hobart, Geelong, Albany and Melbourne, the difference in percent contribution of native and non-native species was significantly similar. To note, native red alga, Jania adherens was the only contributor to the average similarity at Port Geraldton (Table A1). The between-group dissimilarities were mostly contributed by native species followed by non-native and cryptogenic species, except for ports Eden, Fremantle, Launceston and Weipa where cryptogenic species contributed more than non-native species (Figure 2.3.7).

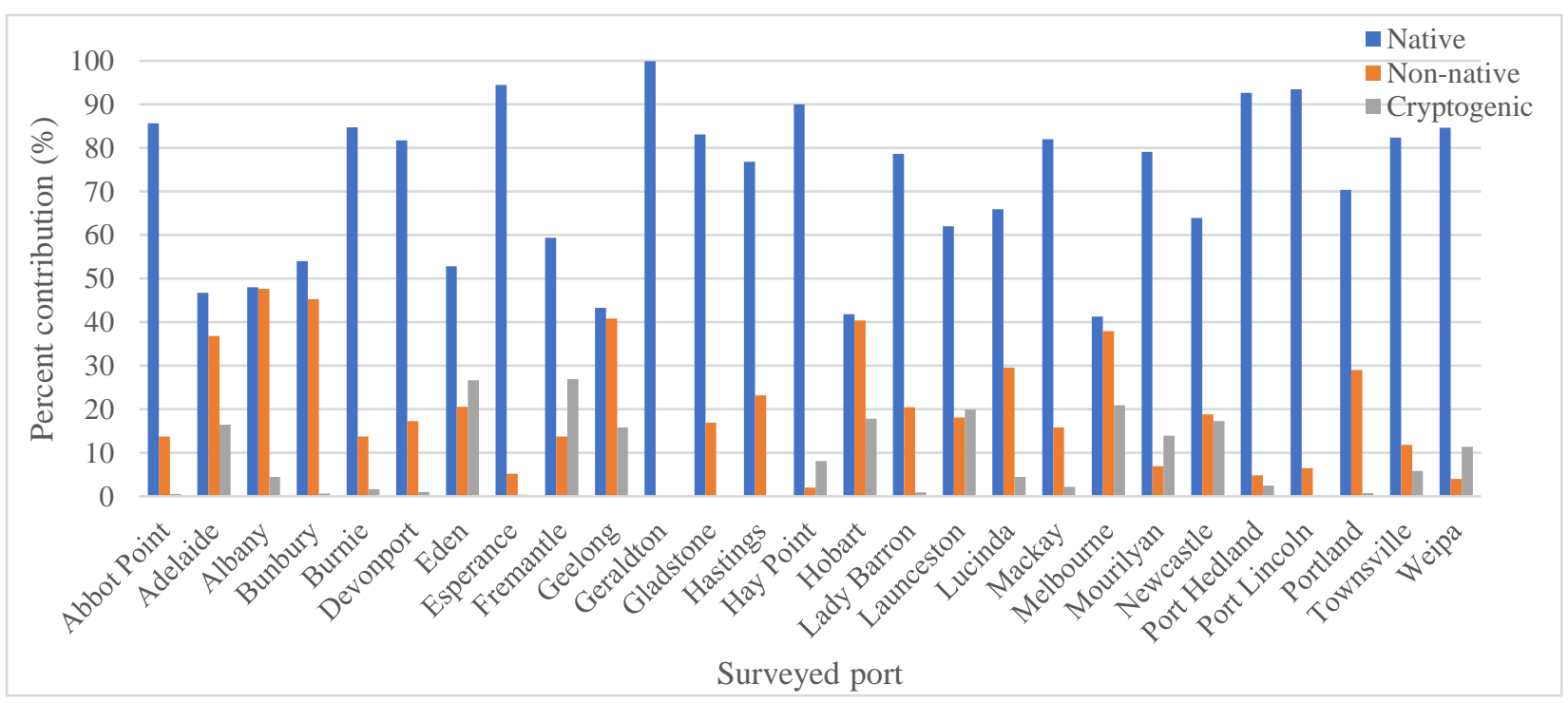

Figure 2.3.7. SIMPER analysis: Percent contribution of species status - native, non-native, cryptogenic to the average similarity as a function of surveyed port. 


\section{b) Port type}

The graphical representation of the MDS ordination of the species status- native, non-native and cryptogenic show no distinct groupings between major and minor ports $(2 \mathrm{D}$ stress $=$ 0.17; Figure 2.3.8).

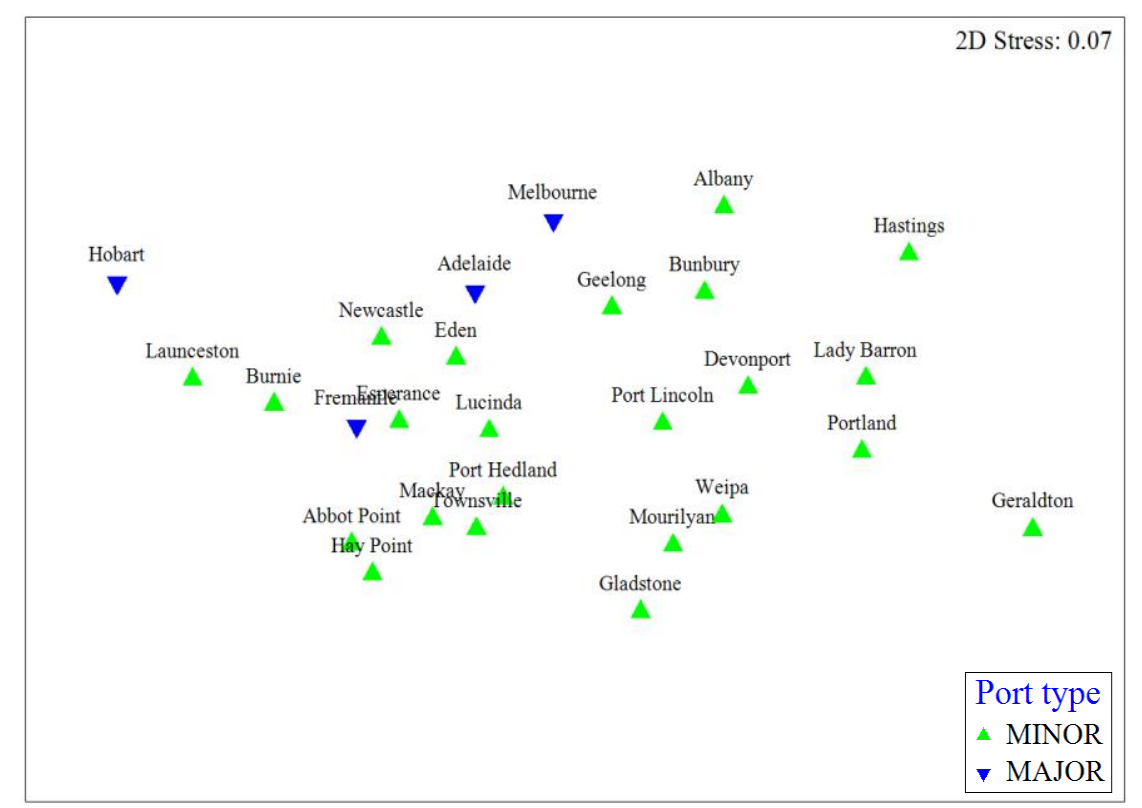

Figure 2.3.8. Multidimensional Scaling (MDS) plot. The proximity of surveyed ports to each other indicates similarity in species status (native, non-native, cryptogenic) as a function of port type.

The PERMANOVA tests were carried out to reveal significant differences in the number of species status as a function of port type. The results showed significant differences $(P<0.05$; Table 2.3 .14$)$ with relatively higher within-group similarity at major ports $(85.11 \%)$ than the major ports $(82.87 \%)$. However, the high average similarity $(80.96 \%)$ between contribution percent of species status at major and minor ports indicates not many variations in terms of species status as a function of port type (Table 2.3.14).

Table 2.3.14. Results of the PERMANOVA and pairwise test performed on the species status as a function of port type (2 levels). Significance marked in bold $(P<0.05)$.

\begin{tabular}{|c|c|c|c|c|c|c|c|c|c|}
\hline & df & SS & MS & $\begin{array}{c}\text { Pseudo- } \\
\boldsymbol{F}\end{array}$ & $\begin{array}{c}\boldsymbol{P} \\
\text { (perm) }\end{array}$ & $\begin{array}{c}\text { Unique } \\
\text { perms }\end{array}$ & \multicolumn{2}{|c|}{ Average similarity (\%) } \\
\hline Port type & 1 & 647.89 & 647.89 & 3.6703 & $\mathbf{0 . 0 4 4}$ & 7637 & Major & Minor & Minor x Major \\
\hline Residual & 25 & 4413.1 & 176.52 & & & & 85.114 & 82.867 & 80.96 \\
\hline Total & 26 & 5060.9 & & & & & & & \\
\hline
\end{tabular}


SIMPER analyses indicate the native species to be the most contributing species status within-group similarity (Minor port $=63.31 \%$; Major $=55.59 \%)$ followed by non-native $($ Minor port $=22.94 \%$; Major $=28.14 \%)$ and cryptogenic species $($ Minor port $=13.35 \%$; Major $=16.27 \%$ ). The species at major ports were better discriminators between major and minor ports $(19.04 \%)$. The native species contributed the highest $(45.13 \%)$ followed by non-native (33.13\%) and cryptogenic species $(21.74 \%)$ to the differences between major and minor ports (Table 2.3.15).

Table 2.3.15. SIMPER analysis: percent contribution of species status as a function of the port type.

\begin{tabular}{|c|c|c|c|c|c|c|c|}
\hline \multirow{3}{*}{\begin{tabular}{|c|} 
Port type \\
Species \\
status
\end{tabular}} & \multirow{2}{*}{\multicolumn{2}{|c|}{$\begin{array}{c}\text { Minor ports } \\
\text { Average similarity }= \\
82.87 \%\end{array}$}} & \multirow{2}{*}{\multicolumn{2}{|c|}{$\begin{array}{c}\text { Major ports } \\
\text { Average similarity }= \\
85.11 \%\end{array}$}} & \multirow{2}{*}{\multicolumn{3}{|c|}{$\begin{array}{c}\text { Minor \& Major ports } \\
\text { Average dissimilarity }=19.04 \%\end{array}$}} \\
\hline & & & & & & & \\
\hline & $\mathrm{C} \%$ & Cum.\% & $\mathrm{C} \%$ & Cum.\% & $\begin{array}{l}\text { Minor ports } \\
\text { Av. Abund. }\end{array}$ & $\begin{array}{l}\text { Major ports } \\
\text { Av. Abund. }\end{array}$ & $\mathrm{C} \%$ \\
\hline Native & 63.71 & 63.71 & 55.59 & 55.59 & 8.32 & 9.39 & 45.13 \\
\hline Non-native & 22.94 & 86.65 & 28.14 & 83.73 & 2.99 & 4.83 & 33.13 \\
\hline Cryptogenic & 13.35 & 100 & 16.27 & 100 & 1.8 & 2.96 & 21.74 \\
\hline
\end{tabular}

$\mathrm{C} \%=$ Per cent Contribution .

\section{c) Latitudinal groups}

The surveyed ports were grouped as a function of their latitude forming 6 latitude groups ranging from $15^{\circ} \mathrm{S}$ to $40^{\circ} \mathrm{S}$. The MDS plot is displayed in Figure 2.3.9; 2D stress $=0.07$, showing the ordination patterns and overlaps between ports as a function of latitudinal groups. Ports at $30^{\circ} \mathrm{S}, 35^{\circ} \mathrm{S}$ and $40^{\circ} \mathrm{S}$ latitudinal groups showed patterns of grouping and ports at $15^{\circ} \mathrm{S}$ and $20^{\circ} \mathrm{S}$ formed another group. This indicates variations in a number of species status between low $\left(15^{\circ} \mathrm{S}\right.$ and $\left.20^{\circ} \mathrm{S}\right)$ and high $\left(30^{\circ} \mathrm{S}, 35^{\circ} \mathrm{S}\right.$ and $\left.40^{\circ} \mathrm{S}\right)$ latitudinal groups. Port Geraldton at latitude $25^{\circ} \mathrm{S}$, the only port sampled from that latitude is an outlier. 


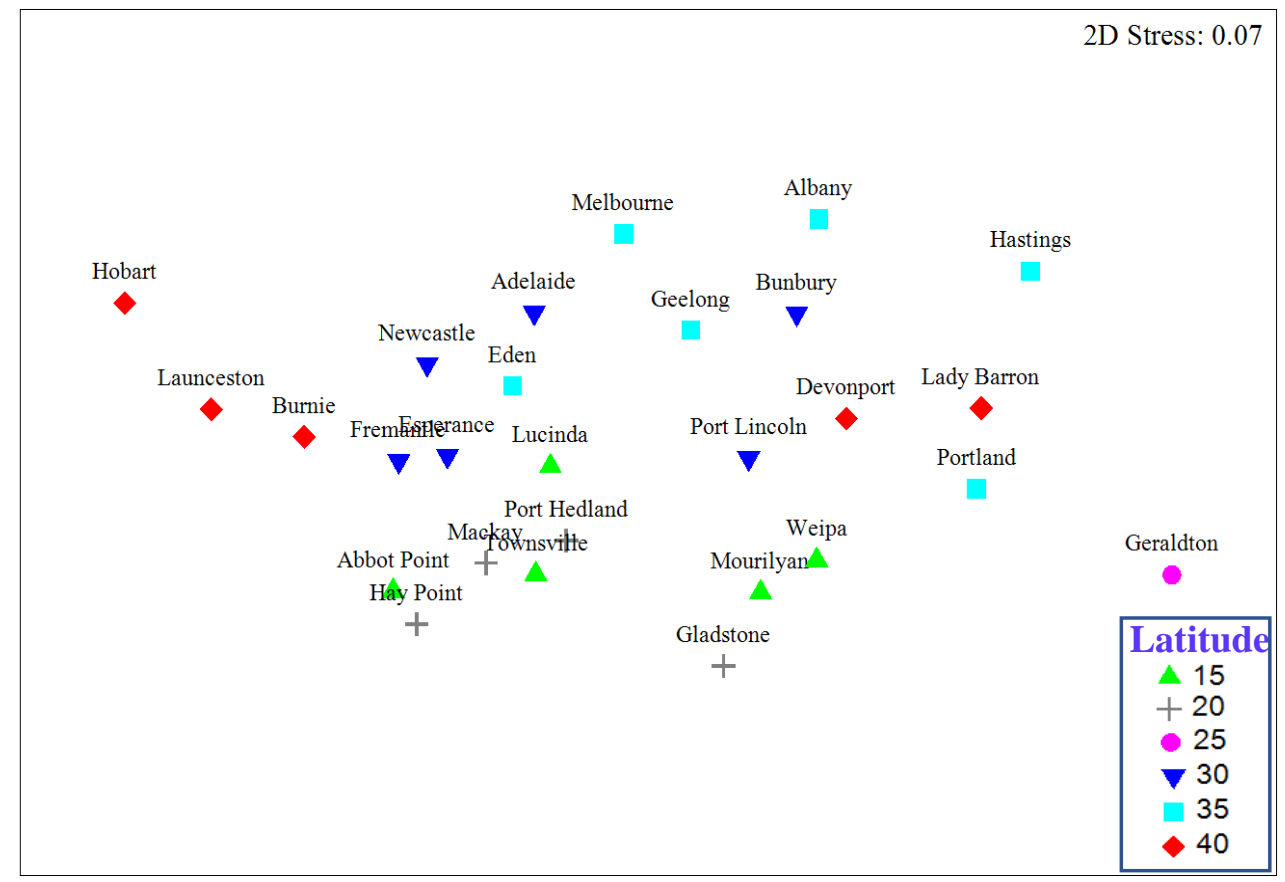

Figure 2.3.9. Multidimensional Scaling (MDS) plot. The proximity of surveyed ports to each other indicates similarity in species status (native, non-native, cryptogenic) as a function of latitudinal groups.

The multivariate PERMANOVA tests revealed statistical significance $(P<0.05)$ in the number of species status as a function of the latitudinal groups (Table 2.3.16). The pairwise PERMANOVA indicated significance $(P<0.05)$ between only $15^{\circ} \mathrm{S}$ vs $35^{\circ} \mathrm{S}$ and $35^{\circ} \mathrm{S}$ vs $20^{\circ} \mathrm{S}$ latitudinal groups (Table 2.3.17).

Table 2.3.16. Results of the PERMANOVA test performed on the status of the species as a function of latitude (6 levels), Significant value in bold $(P<0.05)$.

\begin{tabular}{|c|c|c|c|c|c|c|}
\hline & df & SS & MS & Pseudo-F & $\boldsymbol{P}($ perm) & Unique perm \\
\hline Latitudinal group & 5 & 1839.6 & 367.92 & 2.3984 & $\mathbf{0 . 0 3 4 2}$ & 9945 \\
\hline Residuals & 21 & 3221.4 & 153.4 & & & \\
\hline Total & 26 & 5060.9 & & & & \\
\hline
\end{tabular}

Table 2.3.17. Results of pairwise PERMANOVA test performed on status of the species as a function of latitude, Significant value in bold $(P<0.05)$.

\begin{tabular}{|c|c|c|c|c|}
\hline Latitude $^{\circ} \mathbf{S}$ & $\mathbf{t}$ & $\boldsymbol{P}(\mathbf{p e r m})$ & Unique perms & Average similarity (\%) \\
\hline 15 vs 30 & 1.4962 & 0.1139 & 462 & 86.604 \\
\hline 15 vs 35 & 1.9003 & $\mathbf{0 . 0 3 2 6}$ & 462 & 82.375 \\
\hline 15 vs 40 & 1.0301 & 0.331 & 126 & 79.657 \\
\hline 15 vs 25 & 2.6089 & 0.1678 & 6 & 73.196 \\
\hline
\end{tabular}




\begin{tabular}{|c|c|c|c|c|}
\hline 15 vs 20 & 0.57764 & 0.6894 & 126 & 89.853 \\
\hline 30 vs 35 & 1.7398 & 0.0865 & 462 & 84.548 \\
\hline 30 vs 40 & 0.44573 & 0.7151 & 462 & 81.929 \\
\hline 30 vs 25 & 3.0893 & 0.147 & 7 & 68.861 \\
\hline 30 vs 20 & 1.5833 & 0.0975 & 210 & 86.519 \\
\hline 35 vs 40 & 1.3764 & 0.1796 & 462 & 78.154 \\
\hline 35 vs 25 & 1.7008 & 0.1423 & 7 & 76.691 \\
\hline 35 vs 20 & 2.2963 & $\mathbf{0 . 0 1 9 3}$ & 210 & 80.101 \\
\hline 40 vs 25 & 1.5328 & 0.1654 & 6 & 86.575 \\
\hline 40 vs 20 & 0.73562 & 0.4962 & 126 & 69.52 \\
\hline 25 vs 20 & 3.1916 & 0.195 & 5 & 6.76 \\
\hline
\end{tabular}

SIMPER results revealed the native species to be the highest contributor to the withingroup average similarity followed by non-native and cryptogenic species as a function of the latitudinal group (Table 2.3.18). The between-group dissimilarity between latitudes 15 vs $35^{\circ} \mathrm{S}$ and 35 vs $20^{\circ} \mathrm{S}$ was explained by the high contribution of native species followed by nonnative and cryptogenic species (Table 2.3.19).

Table 2.3.18. SIMPER analysis: percent contribution $(\mathrm{C} \%)$ of species status to average similarity as a function of the latitudinal groups.

\begin{tabular}{|l|c|c|c|c|c|}
\hline Latitude & $\mathbf{1 5}^{\circ} \mathbf{S}$ & $\mathbf{2 0}^{\circ} \mathbf{S}$ & $\mathbf{3 0}^{\circ} \mathbf{S}$ & $\mathbf{3 5}^{\circ} \mathbf{S}$ & $\mathbf{4 0}^{\circ} \mathbf{S}$ \\
\hline Average similarity & $\mathbf{8 9 . 5 7 \%}$ & $\mathbf{7 2 . 9 7 \%}$ & $\mathbf{8 7 . 9 8 \%}$ & $\mathbf{8 4 . 2 1 \%}$ & $\mathbf{7 5 . 9 1 \%}^{\circ} \%$ \\
\hline Species status & $\mathbf{C \%}$ & $\mathbf{C \%}$ & $\mathbf{C \%}$ & $\mathbf{C \%}$ & $\mathbf{C \%}$ \\
\hline Native & 70.51 & 71.53 & 58.95 & 60.1 & 57.71 \\
\hline Non-native & 15.55 & 14.62 & 26.85 & 28.34 & 25.73 \\
\hline Cryptogenic & 13.95 & 13.85 & 14.2 & 11.56 & 16.56 \\
\hline
\end{tabular}


Table 2.3.19. SIMPER analysis: species status contributing $(\mathrm{C} \%)$ to the average dissimilarity as a function of the latitude that indicated significant differences.

\begin{tabular}{|l|c|c|c|c|c|c|}
\hline Latitude $^{\circ} \mathbf{S}$ & \multicolumn{3}{|c|}{$\mathbf{1 5 ~ \& ~ 3 5}^{\circ} \mathbf{S}$} & \multicolumn{3}{c|}{$\mathbf{3 5 ~ \& ~ 2 0}^{\circ} \mathbf{S}$} \\
\hline Avg. dissimilarity (\%) & \multicolumn{3}{|c|}{$17.62 \%$} & & $19.90 \%$ \\
\hline Avg. Abundance & $\mathbf{1 5}$ & $\mathbf{3 5}$ & $\mathbf{C \%}$ & $\mathbf{3 5}$ & $\mathbf{2 0}$ & $\mathbf{C \%}$ \\
\hline Native & 9.1 & 6.72 & 58.43 & 6.72 & 9.8 & 62.56 \\
\hline Non-native & 2.56 & 3.32 & 21.75 & 3.32 & 2.33 & 21.34 \\
\hline Cryptogenic & 1.59 & 1.84 & 19.82 & 1.84 & 1.8 & 16.1 \\
\hline
\end{tabular}

To summarise, the number of species status, i.e., native, non-native and cryptogenic species significantly varied across surveyed ports. The native species were the most contributing species status across all surveyed ports. However, a high percentage of non-native species was observed at ports; Hobart, Geelong, Albany and Melbourne and cryptogenic species at ports; Eden, Fremantle, Launceston and Weipa. Native red alga, Jania adherens was the only contributor at Port Geraldton. The species status as a function of port type significantly varied between major and minor ports with a relatively high percentage of native species at minor ports than major ports. But, non-native and cryptogenic species had relatively higher percentages at major ports than at minor ports. Therefore, accepting the hypothesis that occurrences of non-native and cryptogenic species will be relatively greater at major commercial ports than at minor ports because of increased international marine traffic at the major ports. Lastly, species status significantly varied as a function of latitudinal groups. The native species had a relatively high percentage across all latitudinal groups. However, when comparing the non-native and cryptogenic across the latitudinal groups; the results are in coherence with my hypothesis that frequencies of non-native and cryptogenic species increase with the increase in latitude $\left(15-40^{\circ} \mathrm{S}\right)$. 


\subsection{Results (B)}

\section{New Zealand Port Biological Baseline survey (NZPS)}

\subsubsection{Presence/absence data}

A total of 585 species were identified across the 15 surveyed ports. The species were grouped in 11 phyla groups: Chlorophyta, Ochrophyta, Rhodophyta, Annelida, Arthropoda, Bryozoa, Chordata, Cnidaria, Echinodermata, Mollusca and Porifera (see Appendix - Table A3) for the species list). The most represented phyla in this survey were Arthropoda (128 species) followed by Annelida ( 84 species) and Mollusca ( 73 species). The species were further grouped as per their species status; native, non-native and cryptogenic. Of the 585 species, 461 were native species $(78.80 \%), 65$ non-native species $(11.11 \%)$ and 59 cryptogenic species $(10.09 \%)$ (Table 2.4.1).

Table 2.4.1. The total number of species noted in New Zealand port surveys grouped as per their Phyla and species status (native, non-native and cryptogenic).

\begin{tabular}{|l|c|c|c|c|}
\hline \multicolumn{1}{|c|}{ Phyla } & Total & Native & Non-native & Cryptogenic \\
\hline Chlorophyta & 7 & 7 & 0 & 0 \\
\hline Ochrophyta & 16 & 14 & 2 & 0 \\
\hline Rhodophyta & 65 & 56 & 4 & 5 \\
\hline Annelida & 84 & 74 & 8 & 2 \\
\hline Arthropoda & 128 & 100 & 13 & 15 \\
\hline Bryozoa & 51 & 34 & 14 & 3 \\
\hline Chordata & 56 & 43 & 3 & 10 \\
\hline Cnidaria & 35 & 19 & 9 & 7 \\
\hline Echinodermata & 11 & 9 & 1 & 1 \\
\hline Mollusca & 73 & 68 & 3 & 2 \\
\hline Porifera & 59 & 37 & 8 & 14 \\
\hline Total & 585 & 461 & 65 & 59 \\
\hline
\end{tabular}




\subsubsection{Variations in total presence of species as a function of replicates (sampling effort) at each surveyed port}

The total number of species at each port was divided with the number of replicates to obtain the relative number of species (Table 2.4.2). The relative number of species excludes the bias caused due to the differences in replicates (sampling effort). The relative total number of species was relatively highest at Picton 2005 (10.76\%) followed by Timaru 2005 (8.29\%), and lowest at Gulf Harbour Marina (3.73\%) (Figure 2.4.1).

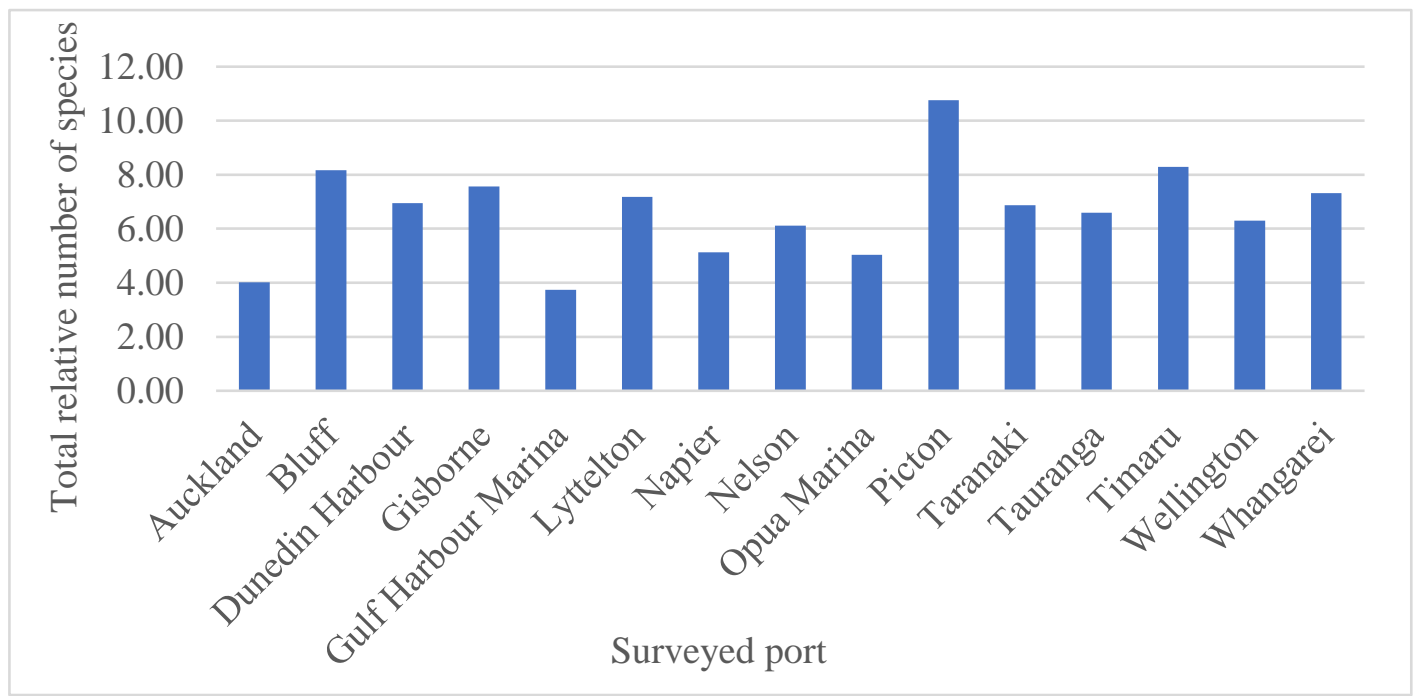

Figure 2.4.1. The total relative number of species across 15 surveyed ports.

Table 2.4.2. The total relative number of species as a function of replicates (sampling effort) at each surveyed port.

\begin{tabular}{|l|c|c|c|c|}
\hline Surveyed ports & Total number & Replicates & Relative Total & Total percent (\%) \\
\hline Auckland & 96 & 71 & 1.35 & 4.01 \\
\hline Bluff & 146 & 53 & 2.75 & 8.17 \\
\hline Dunedin Harbour & 110 & 47 & 2.34 & 6.94 \\
\hline Gisborne & 79 & 31 & 2.55 & 7.56 \\
\hline Gulf Harbour Marina & 73 & 58 & 1.26 & 3.73 \\
\hline Lyttelton & 121 & 50 & 2.42 & 7.18 \\
\hline Napier & 83 & 48 & 1.73 & 5.13 \\
\hline Nelson & 194 & 94 & 2.06 & 6.12 \\
\hline Opua Marina & 51 & 30 & 1.70 & 5.04 \\
\hline Picton & 127 & 35 & 3.63 & 10.76 \\
\hline Taranaki & 102 & 44 & 2.32 & 6.87 \\
\hline Tauranga & 151 & 68 & 2.22 & 6.59 \\
\hline Timaru & 109 & 39 & 2.79 & 8.29 \\
\hline Wellington & 155 & 73 & 2.12 & 6.30 \\
\hline Whangarei & 116 & 47 & 2.47 & 7.32 \\
\hline
\end{tabular}




\subsubsection{Occurrences of species}

The presence of each species was calculated across all surveyed ports to observe the high occurring species in the New Zealand port survey (NZPS). The cryptogenic tunicates, Asterocarpa cerea and Corella eumyota occurred at all surveyed ports. The top 10 species occurring in most of the surveyed ports are listed in Table 2.4.3.

Table 2.4.3. Total occurrences of top 10 species across 15 surveyed ports.

\begin{tabular}{|l|c|c|c|}
\hline \multicolumn{1}{|c|}{ Species } & Phyla & Species status & $\begin{array}{c}\text { Total port } \\
\text { occurrences }\end{array}$ \\
\hline Asterocarpa cerea & Chordata & Cryptogenic & 15 \\
\hline Corella eumyota & Chordata & Cryptogenic & 15 \\
\hline Notomithrax minor & Arthropoda & Native & 14 \\
\hline Austrominius modestus & Arthropoda & Native & 13 \\
\hline Bugula flabellata & Bryozoa & Non-native & 13 \\
\hline Cnemidocarpa bicornuta & Chordata & Native & 13 \\
\hline Cnemidocarpa nisiotus & Chordata & Native & 13 \\
\hline Molgula mortenseni & Chordata & Native & 13 \\
\hline Lepidonotus polychromus & Annelida & Native & 12 \\
\hline Modiolarca impacta & Mollusca & Native & 12 \\
\hline
\end{tabular}




\subsubsection{Variations in the community composition as a function of the surveyed port, port type and latitudinal groups}

\section{a) Surveyed ports}

The multivariate PERMANOVA was performed to indicate patterns in species composition as a function of the surveyed port. The results revealed high significance $(P<0.0001$; Table 2.4.4) as a function of the surveyed port. The pairwise PERMANOVA also revealed high significance between the ports $(P<0.0001)$. The ports; Picton $(26.45 \%)$ had the most similar species followed by Opua Marina (26.11\%) and least within-group similarity at Port Nelson (8.88\%) (Table 2.4.5). The between-group dissimilarity in species composition between surveyed ports ranged from $80.05 \%$ (Picton vs Wellington) to $98.37 \%$ (Dunedin vs Gisborne).

Table 2.4.4. Results of the PERMANOVA test performed on the presence/absence of species as a function of the surveyed port. Significance marked in bold $(P<0.05)$.

\begin{tabular}{|l|c|c|c|c|c|c|}
\hline & df & SS & MS & Pseudo- & $\boldsymbol{P}$ (perm) & $\begin{array}{l}\text { Unique } \\
\text { perms }\end{array}$ \\
\hline Surveyed port & 14 & $6.49 \mathrm{E}+05$ & 46329 & 12.862 & $\mathbf{0 . 0 0 0 1}$ & 9606 \\
\hline Residual & 773 & $2.78 \mathrm{E}+06$ & 3602 & & & \\
\hline Total & 787 & $3.43 \mathrm{E}+06$ & & & & \\
\hline
\end{tabular}

SIMPER results revealed the top 5 species to contribute to more than $50 \%$ average within-group similarity as a function of surveyed ports (Table 2.4.5). Native barnacle, Austrominius modestus was observed to be the highest contributing species at ports, Auckland (21.57\%), Bluff (22.59\%), Dunedin (19.54\%), Nelson (27.54\%), Opua Marina (58.6\%) and Tauranga (20.48\%). The non-native bryozoan, Bugula neritina contributed relatively highest at ports Gisborne (25.11\%), Napier (19.04\%) and Whangarei (17.70\%). The non-native bryozoan, Watersipora subtorquata contributed highest at ports, Timaru (24.79\%) and Lyttelton (22.04\%). The average between-group dissimilarities ranged from $80.05 \%$ (Picton vs Wellington) to $98.37 \%$ (Dunedin vs Gisborne). SIMPER results revealed that the species that contributed to the within-group similarity also contributed to the between-group similarity, but the average abundance contribution from each port varied, leading to the dissimilarities in community composition between surveyed ports. 
Table 2.4.5. SIMPER analysis: average similarity in the presence/absence of species as a function of the surveyed port.

\begin{tabular}{|c|c|c|c|c|c|c|c|c|c|c|c|}
\hline \multicolumn{4}{|c|}{$\begin{array}{c}\text { Auckland } \\
\text { Average similarity: } 17.69\end{array}$} & \multicolumn{4}{|c|}{$\begin{array}{c}\text { Bluff } \\
\text { Average similarity: } 11.84\end{array}$} & \multicolumn{4}{|c|}{$\begin{array}{c}\text { Dunedin Habour } \\
\text { Average similarity: } 14.95\end{array}$} \\
\hline Species & $\begin{array}{l}\text { Avg. } \\
\text { Abund }\end{array}$ & $\mathrm{C} \%$ & Cum. $\%$ & Species & $\begin{array}{l}\text { Avg. } \\
\text { Abund }\end{array}$ & $\mathrm{C} \%$ & Cum. $\%$ & Species & $\begin{array}{l}\text { Avg. } \\
\text { Abund }\end{array}$ & $\mathrm{C} \%$ & Cum. $\%$ \\
\hline Austrominius modestus & 0.42 & 21.57 & 21.57 & Austrominius modestus & 0.28 & 22.59 & 22.59 & Austrominius modestus & 0.38 & 19.54 & 19.54 \\
\hline Caberea rostrata & 0.52 & 15.58 & 37.15 & Corella eumyota & 0.47 & 15.21 & 37.8 & Haplocheira barbimana & 0.53 & 16.21 & 35.75 \\
\hline Crassostrea gigas & 0.46 & 13.72 & 50.87 & Phycodrys quercifolia & 0.36 & 7.72 & 45.52 & Nereis falcaria & 0.4 & 9.06 & 44.81 \\
\hline Ostrea chilensis & 0.37 & 6.5 & 57.38 & Galeolaria hystrix & 0.32 & 6.22 & 51.74 & Asterocarpa cerea & 0.34 & 5.92 & 50.74 \\
\hline Pyura picta & 0.34 & 5.39 & 62.77 & Nereis falcaria & 0.3 & 5.3 & 57.04 & Aplidium adamsi & 0.3 & 4.55 & 55.28 \\
\hline \multicolumn{4}{|c|}{ Gisborne } & \multicolumn{4}{|c|}{$\begin{array}{c}\text { Gulf Harbour Marina } \\
\text { Average similarity: } 16.16\end{array}$} & \multicolumn{4}{|c|}{$\begin{array}{c}\text { Lyttelton } \\
\text { age similarity: } 23.89\end{array}$} \\
\hline Species & $\begin{array}{l}\text { Avg. } \\
\text { Abund }\end{array}$ & $\mathrm{C} \%$ & Cum.\% & Species & $\begin{array}{l}\text { Avg. } \\
\text { Abund }\end{array}$ & $\mathrm{C} \%$ & Cum. $\%$ & Species & $\begin{array}{l}\text { Avg. } \\
\text { Abund }\end{array}$ & $\mathrm{C} \%$ & Cum. $\%$ \\
\hline Bugula neritina & 0.55 & 25.11 & 25.11 & Styela plicata & 0.4 & 12.48 & 12.48 & Watersipora subtorquata & 0.76 & 22.04 & 22.04 \\
\hline Scrupocellaria ornithorhyncus & 0.45 & 14.41 & 39.51 & Balanus trigonus & 0.36 & 11.31 & 23.79 & Branchiomma curta & 0.6 & 10.62 & 32.66 \\
\hline Leptograpsus variegatus & 0.26 & 5.85 & 45.36 & Schizoporella errata & 0.29 & 9.07 & 32.86 & Austrominius modestus & 0.44 & 9.03 & 41.69 \\
\hline Cnemidocarpa nisiotus & 0.29 & 5.43 & 50.8 & Dictyota dichotoma & 0.36 & 8.1 & 40.97 & Asterocarpa cerea & 0.52 & 7.83 & 49.52 \\
\hline Paguristes setosus & 0.29 & 5.34 & 56.14 & Asterocarpa cerea & 0.34 & 7.78 & 48.75 & Leucothoe trailli & 0.46 & 5.65 & 55.18 \\
\hline \multicolumn{4}{|c|}{$\begin{array}{c}\text { Napier } \\
\text { Average similarity: } 13.15\end{array}$} & \multicolumn{4}{|c|}{$\begin{array}{c}\text { Nelson } \\
\text { Average similarity: } 8.92\end{array}$} & \multicolumn{4}{|c|}{$\begin{array}{c}\text { Opua Marina } \\
\text { Average similarity: } 26.11\end{array}$} \\
\hline Species & $\begin{array}{l}\text { Avg. } \\
\text { Abund }\end{array}$ & $\mathrm{C} \%$ & Cum. $\%$ & Species & $\begin{array}{l}\text { Avg. } \\
\text { Abund }\end{array}$ & $\mathrm{C} \%$ & Cum. $\%$ & Species & $\begin{array}{l}\text { Avg. } \\
\text { Abund }\end{array}$ & $\mathrm{C} \%$ & Cum. $\%$ \\
\hline Bugula neritina & 0.44 & 19.04 & 19.04 & Austrominius modestus & 0.38 & 27.54 & 27.54 & Austrominius modestus & 0.53 & 58.6 & 58.6 \\
\hline Bugula flabellata & 0.4 & 12.89 & 31.93 & Asterocarpa cerea & 0.35 & 10.8 & 38.35 & Asterocarpa cerea & 0.43 & 6.41 & 65 \\
\hline Proscoloplos bondi & 0.31 & 7.39 & 39.32 & $\begin{array}{l}\text { Petrolisthes } \\
\text { novaezealandiae }\end{array}$ & 0.3 & 9.07 & 47.42 & Balanus trigonus & 0.4 & 6.2 & 71.2 \\
\hline Austrominius modestus & 0.25 & 7.23 & 46.55 & Haplocheira barbimana & 0.24 & 5.93 & 53.35 & Neanthes kerguelensis & 0.4 & 6.18 & 77.38 \\
\hline Pterocirrus brevicornis & 0.29 & 6.73 & 53.27 & Xenostrobus pulex & 0.15 & 3.69 & 57.04 & Halicarcinus varius & 0.33 & 3.68 & 81.06 \\
\hline
\end{tabular}




\begin{tabular}{|c|c|c|c|c|c|c|c|c|c|c|c|}
\hline \multicolumn{4}{|c|}{$\begin{array}{c}\text { Picton } \\
\text { Average similarity: } 26.45\end{array}$} & \multicolumn{4}{|c|}{$\begin{array}{c}\text { Taranaki } \\
\text { Average similarity: } 19.71\end{array}$} & \multicolumn{4}{|c|}{$\begin{array}{c}\text { Tauranga } \\
\text { Average similarity: } 18.95\end{array}$} \\
\hline Species & $\begin{array}{l}\text { Avg. } \\
\text { Abund }\end{array}$ & $\mathrm{C} \%$ & Cum. $\%$ & Species & $\begin{array}{l}\text { Avg. } \\
\text { Abund }\end{array}$ & $\mathrm{C} \%$ & Cum. $\%$ & Species & $\begin{array}{l}\text { Avg. } \\
\text { Abund }\end{array}$ & $\mathrm{C} \%$ & Cum.\% \\
\hline Aulacomya atra maoriana & 0.86 & 15.27 & 15.27 & Chaemosipho columna & 0.66 & 31.49 & 31.49 & Molgula mortenseni & 0.59 & 10.5 & 10.5 \\
\hline Ostrea chilensis & 0.71 & 10.38 & 25.66 & Xenostrobus pulex & 0.57 & 23.27 & 54.76 & Austrominius modestus & 0.29 & 9.99 & 20.48 \\
\hline Petrolisthes elongatus & 0.66 & 8.16 & 33.82 & Austrominius modestus & 0.3 & 7.34 & 62.1 & Balanus trigonus & 0.51 & 8.18 & 28.66 \\
\hline Perna canaliculus & 0.57 & 6.01 & 39.83 & Watersipora subtorquata & 0.36 & 7.01 & 69.11 & Lepidonotus polychromus & 0.46 & 6.49 & 35.15 \\
\hline Nicolea armilla & 0.54 & 5.14 & 44.97 & $\begin{array}{l}\text { Lumbrineris } \\
\text { sphaerocephala }\end{array}$ & 0.25 & 2.15 & 71.26 & Maoricrypta costata & 0.47 & 6.45 & 41.6 \\
\hline \multicolumn{4}{|c|}{$\begin{array}{c}\text { Timaru } \\
\text { Average similarity: } 22.15\end{array}$} & \multicolumn{4}{|c|}{$\begin{array}{c}\text { Wellington } \\
\text { Average similarity: } 21.72\end{array}$} & \multicolumn{4}{|c|}{$\begin{array}{c}\text { Whangarei } \\
\text { Average similarity: } 12.91\end{array}$} \\
\hline Species & $\begin{array}{l}\text { Avg. } \\
\text { Abund }\end{array}$ & $\mathrm{C} \%$ & Cum. $\%$ & Species & $\begin{array}{l}\text { Avg. } \\
\text { Abund }\end{array}$ & $\mathrm{C} \%$ & Cum. $\%$ & Species & $\begin{array}{l}\text { Avg. } \\
\text { Abund }\end{array}$ & $\mathrm{C} \%$ & Cum. $\%$ \\
\hline Watersipora subtorquata & 0.74 & 24.79 & 24.79 & Petrolisthes elongatus & 0.63 & 9.18 & 9.18 & Bugula neritina & 0.45 & 17.7 & 17.7 \\
\hline Branchiomma curta & 0.59 & 11.54 & 36.32 & Mytilus galloprovincialis & 0.6 & 8.34 & 17.53 & Austrominius modestus & 0.28 & 12.31 & 30.01 \\
\hline Austrominius modestus & 0.44 & 9.94 & 46.27 & Aulacomya atra maoriana & 0.6 & 7.56 & 25.09 & Ostrea aupouria & 0.45 & 12.03 & 42.03 \\
\hline Cryptosula pallasiana & 0.41 & 7.58 & 53.85 & Ostrea chilensis & 0.53 & 5.75 & 30.84 & Balanus trigonus & 0.43 & 11.36 & 53.39 \\
\hline $\begin{array}{l}\text { Pseudosphaeroma } \\
\text { campbellense }\end{array}$ & 0.33 & 6.88 & 60.73 & $\begin{array}{l}\text { Petrolisthes } \\
\text { novaezealandiae }\end{array}$ & 0.49 & 5.14 & 35.99 & Bugula flabellata & 0.3 & 4.83 & 58.22 \\
\hline
\end{tabular}




\section{b) Port type (major and minor ports)}

The graphical representation of the MDS ordination of the presence/absence data showed no groupings of similar species composition as a function of port type, 5 major commercial shipping ports and 10 minor shipping ports $(2 \mathrm{D}$ stress $=0.13$; Figure 2.4.2). The PERMANOVA tests results were in coherence with the MDS ordination and indicated no significant $(P=0.96)$ variations in community composition as a function of port type (Table 2.4.6).

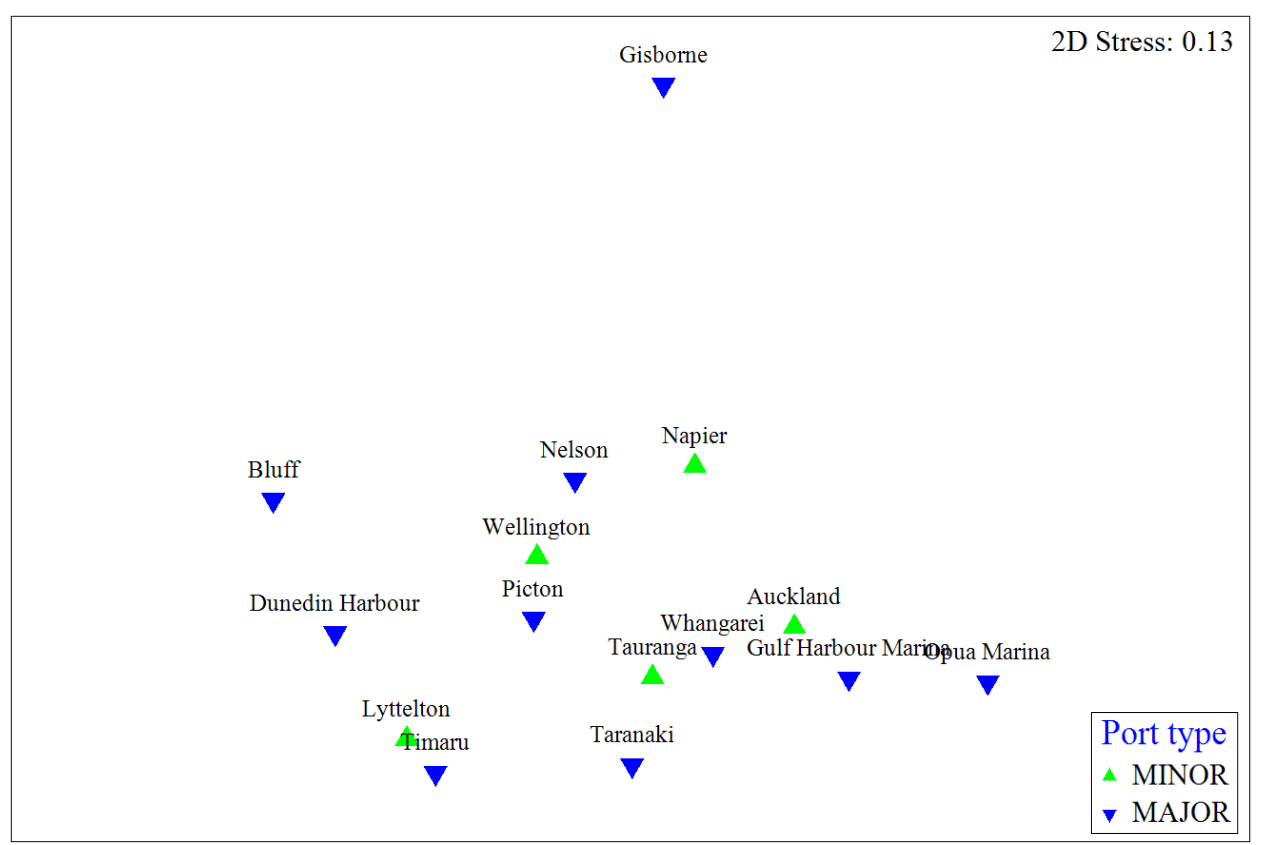

Figure 2.4.2 Multidimensional Scaling (MDS) plot. The proximity of surveyed ports to each other indicates similarity in community composition as a function of port type.

Table 2.4.6. Results of the PERMANOVA analysis and pairwise test performed on the presence of species as a function of port type ( 2 levels). Significance marked in bold $(P<0.05)$.

\begin{tabular}{|c|c|c|c|c|c|c|c|c|c|}
\hline Source & df & SS & MS & Pseudo-F & $\boldsymbol{P}$ (perm) & $\begin{array}{c}\text { Unique } \\
\text { perms }\end{array}$ & \multicolumn{2}{|c|}{ Average similarity (\%) } \\
\hline Port type & 1 & 1500.1 & 1500.1 & 0.63315 & 0.967 & 2889 & Major & Minor & Minor x Major \\
\hline Residual & 13 & 30799 & 2369.2 & & & & 35.53 & 29.84 & 34.47 \\
\hline Total & 14 & 32300 & & & & & & & \\
\hline
\end{tabular}




\section{c) Latitudinal groups}

The surveyed ports at each latitude were grouped, forming 3 latitudinal groups; $35^{\circ} \mathrm{S}, 40^{\circ} \mathrm{S}$ and $45^{\circ} \mathrm{S}$. The MDS plot showed the ordination patterns as a function of the latitudinal groups (35, $40,45^{\circ} \mathrm{S}$ ) (Figure 2.4.3; 2D stress $=0.13$ ).

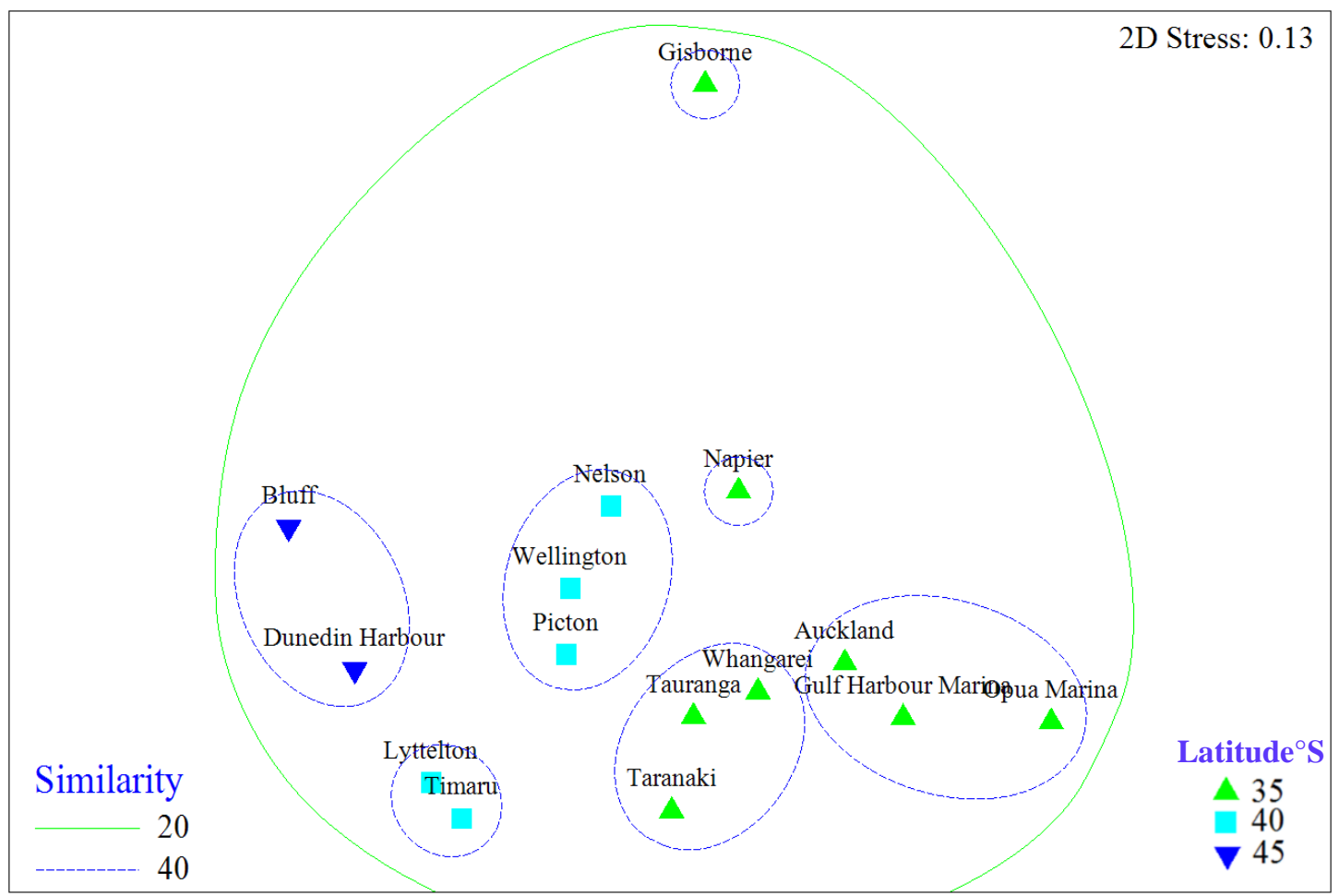

Figure 2.4.3. Multidimensional Scaling (MDS) plot. The proximity of latitudes to each other indicates similarity in the community composition.

The PERMANOVA tests, as a function of latitude, revealed high significance $(P<$ 0.0001) (Table 2.4.7). The pairwise PERMANOVA test revealed significant differences between 35 vs $45^{\circ} \mathrm{S}(P=0.02)$ and 35 vs $40^{\circ} \mathrm{S}(P=0.002)$ but not between 40 vs $45^{\circ} \mathrm{S}(P=$ 0.14) (Table 2.4.8).

Table 2.4.7. Results of the PERMANOVA test performed as a function of latitude (3 levels). Significance $(P<0.05)$ marked in bold.

\begin{tabular}{|l|c|c|c|c|c|c|}
\hline & df & SS & MS & Pseudo- $\boldsymbol{P}$ & $\boldsymbol{P}($ perm) & Unique perms \\
\hline Latitude & 2 & 8279.5 & 4139.7 & 2.0681 & $\mathbf{0 . 0 0 0 1}$ & 9499 \\
\hline Residual & 12 & 24020 & 2001.7 & & & \\
\hline Total & 14 & 32300 & & & & \\
\hline
\end{tabular}


Table 2.4.8. Results of the PERMANOVA and pairwise test as a function of port type (2 levels). Significance marked in bold $(P<0.05)$.

\begin{tabular}{|c|c|c|c|}
\hline Latitude & $\mathbf{t}$ & $\mathbf{P}(\mathbf{p e r m})$ & Unique perms \\
\hline $\mathbf{3 5} \mathbf{\text { vs 45 }}{ }^{\circ} \mathbf{S}$ & 1.48 & $\mathbf{0 . 0 2 2}$ & 45 \\
\hline $\mathbf{3 5} \mathbf{\text { vs 40 }}{ }^{\circ} \mathbf{S}$ & 1.45 & $\mathbf{0 . 0 0 3}$ & 1282 \\
\hline $\mathbf{4 5}_{\mathbf{v s}}^{\mathbf{4 0}}{ }^{\circ} \mathbf{S}$ & 1.32 & 0.139 & 21 \\
\hline
\end{tabular}

SIMPER analysis for latitudinal groups indicated latitudes $35 \mathrm{vs} 45^{\circ} \mathrm{S}$ to have the highest average dissimilarity (76.09\%). The species that indicated the dissimilarities are; Bugula flabellata (NN), Forsterygion lapillum (N), Nereiphylla castanea (N), Halisarca dujardini $(\mathrm{NN})$ and Leuconopsis obsoleta $(\mathrm{N})$. The species at latitude $45^{\circ} \mathrm{S}$ were better discriminators. The species indicating dissimilarities between latitudes 35 vs $40^{\circ} \mathrm{S}(71.28 \%)$ are; Petrolisthes elongatus (N), Asterocarpa coerulea (N), Watersipora subtorquata (NN), Undaria pinnatifida (NN) and Bougainvillia muscus (C) (Table 2.4.9).

Table 2.4.9. SIMPER analysis: average dissimilarity of community composition as a function of latitude. Species status - native (N), non-native (NN) and cryptogenic (C).

\begin{tabular}{|c|c|c|c|c|c|c|c|}
\hline \multicolumn{3}{|c|}{35 \& 45 } & \multicolumn{5}{c|}{$\mathbf{3 5 ~ \& ~ 4 0}{ }^{\circ} \mathbf{S}$} \\
Average dissimilarity $=76.09 \%$ & \multicolumn{4}{c|}{ Average dissimilarity =71.28\% } \\
\hline Species & $\mathbf{3 5}$ & $\mathbf{4 5}$ & $\mathbf{C \%}$ & Species & $\mathbf{3 5}$ & $\mathbf{4 0}$ & $\mathbf{C \%}$ \\
\hline Bugula flabellata $(\mathrm{NN})$ & 0.47 & 0 & 1.14 & Petrolisthes elongatus $(\mathrm{N})$ & 0.07 & 0.5 & 0.99 \\
\hline Forsterygion lapillum $(\mathrm{N})$ & 0.06 & 0.5 & 1.06 & Asterocarpa coerulea $(\mathrm{N})$ & 0.03 & 0.43 & 0.94 \\
\hline Nereiphylla castanea $(\mathrm{N})$ & 0.2 & 0.59 & 0.98 & Watersipora subtorquata $(\mathrm{NN})$ & 0.24 & 0.52 & 0.94 \\
\hline Halisarca dujardini $(\mathrm{NN})$ & 0.2 & 0.55 & 0.97 & Undaria pinnatifida $(\mathrm{NN})$ & 0 & 0.35 & 0.81 \\
\hline Leuconopsis obsoleta $(\mathrm{N})$ & 0 & 0.41 & 0.97 & Bougainvillia muscus $(\mathrm{C})$ & 0.1 & 0.31 & 0.80 \\
\hline
\end{tabular}

$\mathrm{C} \%=$ Per cent Contribution.

In summary, the presence of species as a function of surveyed ports showed significance; however, the community composition as a function of port type did not show the significance. The latitudinal groups indicated significant differences for groups; $35 \mathrm{vs} 40^{\circ} \mathrm{S}$ and $35 \mathrm{vs} 45^{\circ} \mathrm{S}$. The species at higher latitudes $\left(40,45^{\circ} \mathrm{S}\right)$ being better discriminators explaining the differences. A strong association in the community composition between ports; i) Auckland, Gulf Harbour and Opua Marina (native barnacle Austrominius modestus, cryptogenic tunicate Asterocarpa cerea, cryptogenic barnacle Balanus trigonus), ii) Tauranga, 
Whangarei, Taranaki and Napier (native barnacle Austrominius modestus, cryptogenic barnacle Balanus trigonus), iii) Wellington, Picton and Nelson (native mollusc Aulacomya atra maoriana, native false crab Petrolisthes elongatus and native molluscs Ostrea chilensis) iv) Lyttelton and Timaru (non-native bryozoan Watersipora subtorquata, native polychaete Branchiomma curta and native barnacle Austrominius modestus, v) Bluff and Dunedin (native barnacle Austrominius modestus and cryptogenic tunicate Corella eumyota), was observed. The results indicated similar high contributing species at proximity ports. The species showing variations as a function of surveyed ports and latitudinal groups are stated in Table 2.4.10.

Table 2.4.10. The list of species that indicated variations as a function of surveyed ports and latitudinal groups.

\begin{tabular}{|c|c|c|}
\hline Species & Phyla & Species status \\
\hline Asterocarpa cerea & Chordata & Cryptogenic \\
\hline Aulacomya atra maoriana & Mollusca & Native \\
\hline Austrominius modestus & Arthropoda & Native \\
\hline Balanus trigonus & Arthropoda & Native \\
\hline Bougainvillia muscus & Cnidaria & Cryptogenic \\
\hline Bugula flabellata & Bryozoa & Non-native \\
\hline Bugula neritina & Bryozoa & Non-native \\
\hline Chaemosipho columna & Arthropoda & Native \\
\hline Corella eumyota & Chordata & Cryptogenic \\
\hline Halisarca dujardini & Porifera & Non-native \\
\hline Molgula mortenseni & Chordata & Native \\
\hline Mytilus galloprovincialis & Mollusca & Cryptogenic \\
\hline Nereiphylla castanea & Annelida & Native \\
\hline Ostrea chilensis & Mollusca & Native \\
\hline Petrolisthes elongatus & Arthropoda & Native \\
\hline Petrolisthes novaezealandiae & Arthropoda & Native \\
\hline Styela plicata & Chordata & Cryptogenic \\
\hline Watersipora subtorquata & Bryozoa & Non-native \\
\hline Xenostrobus pulex & Mollusca & Native \\
\hline
\end{tabular}




\subsubsection{Variations in the species status - native, non-native and cryptogenic species as a function of surveyed ports, port type and latitudinal groups}

\section{a) Surveyed ports}

The total number of species at each port was divided with the number of replicates to obtain the relative number of species (Table 2.4.11). The native species were relatively observed in higher percentages, followed by non-native and cryptogenic species (Figure 2.4.4). The relatively high levels of native species were highest at Port Picton (15.20) and lowest at Melbourne $(0.33 \%)$. In contrast, the non-native species were highest at Lyttelton $(2.62 \%)$, Timaru $(2.51 \%)$ and lowest at Port Picton (0.51). The cryptogenic species were relatively in high levels at Wellington (2.11) and lowest at Port Taranaki (0.45) (Table 2.4.11).

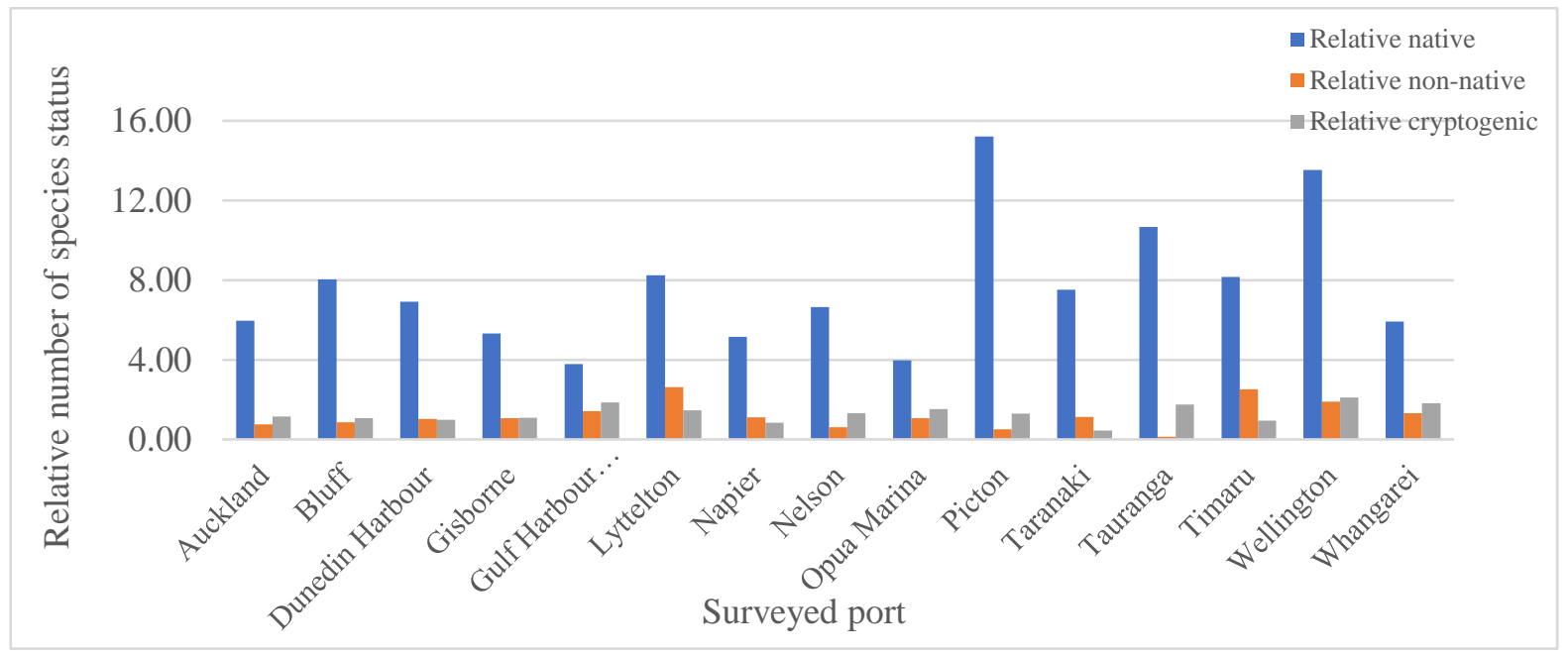

Figure 2.4.4. The total relative number of species status - native (blue), non-native (orange) and cryptogenic (grey) species across 15 surveyed ports.

Table 2.4.11. The total number of species as a function of status - native, non-native and cryptogenic species - across 15 surveyed ports.

\begin{tabular}{|c|c|c|c|c|c|c|c|}
\hline Surveyed port & $\begin{array}{c}\text { Total } \\
\text { Native }\end{array}$ & $\begin{array}{c}\text { Total } \\
\text { Non-native }\end{array}$ & $\begin{array}{c}\text { Total } \\
\text { Cryptogenic }\end{array}$ & Replicates & $\begin{array}{c}\text { Relative } \\
\text { native }\end{array}$ & $\begin{array}{c}\text { Relative } \\
\text { non-native }\end{array}$ & $\begin{array}{c}\text { Relative } \\
\text { cryptogenic }\end{array}$ \\
\hline Auckland & 423 & 53 & 81 & 71 & 5.96 & 0.75 & 1.14 \\
\hline Bluff & 426 & 46 & 57 & 53 & 8.04 & 0.87 & 1.08 \\
\hline Dunedin Harbour & 325 & 48 & 46 & 47 & 6.91 & 1.02 & 0.98 \\
\hline Gisborne & 165 & 33 & 34 & 31 & 5.32 & 1.06 & 1.10 \\
\hline Gulf Harbour Marina & 219 & 82 & 108 & 58 & 3.78 & 1.41 & 1.86 \\
\hline Lyttelton & 412 & 131 & 73 & 50 & 8.24 & 2.62 & 1.46 \\
\hline Napier & 247 & 53 & 40 & 48 & 5.15 & 1.10 & 0.83 \\
\hline Nelson & 625 & 58 & 123 & 94 & 6.65 & 0.62 & 1.31 \\
\hline
\end{tabular}




\begin{tabular}{|c|c|c|c|c|c|c|c|}
\hline Opua Marina & 119 & 32 & 46 & 30 & 3.97 & 1.07 & 1.53 \\
\hline Picton & 532 & 18 & 45 & 35 & 15.20 & 0.51 & 1.29 \\
\hline Taranaki & 331 & 50 & 20 & 44 & 7.52 & 1.14 & 0.45 \\
\hline Tauranga & 725 & 9 & 119 & 68 & 10.66 & 0.13 & 1.75 \\
\hline Timaru & 318 & 98 & 37 & 39 & 8.15 & 2.51 & 0.95 \\
\hline Wellington & 987 & 138 & 154 & 73 & 13.52 & 1.89 & 2.11 \\
\hline Whangarei & 278 & 62 & 85 & 47 & 5.91 & 1.32 & 1.81 \\
\hline
\end{tabular}

Furthermore, the species status, i.e., native, non-native and cryptogenic, were regressed to observe the relationship between species status across all surveyed ports. However, no significant relationship was observed between native vs non-native $(P=0.08)$, cryptogenic vs non-native $(P=0.47)$, and cryptogenic vs non-native $(P=0.79)$ (Table 2.4.12).

Table 2.4.12. Results for regression for species status - native, non-native and cryptogenic species (significance $=P<0.05$, marked in bold).

\begin{tabular}{|c|c|c|c|c|}
\hline Species status & $\mathrm{R}^{2}$ & $\mathrm{R}$ & $P$ & $\mathrm{y}$ \\
\hline Native vs Non-native & 0.002 & -0.046 & 0.0868 & $7.9319+0.2216^{*} \mathrm{x}$ \\
\hline Cryptogenic vs Non-native & 0.042 & 0.204 & 0.466 & $5.7133+1.4906^{*} \mathrm{x}$ \\
\hline Cryptogenic vs Non-native & 0.006 & 0.076 & 0.788 & $1.2501+0.0497^{*} \mathrm{x}$ \\
\hline
\end{tabular}

Multivariate analysis, PERMANOVA was performed to indicate variations in the number of species status as a function of the surveyed port. The number of species (native, non-native and cryptogenic) was found to vary significantly among surveyed ports (PERMANOVA; $P<0.0001$; Table 2.4.13).

Table 2.4.13. Results of the PERMANOVA test performed on the species status as a function of surveyed port (15 levels). Significance marked in bold $(P<0.05)$.

\begin{tabular}{|c|c|c|c|c|c|c|}
\hline Source & df & SS & MS & Pseudo- $F$ & $\boldsymbol{P}($ perm) & Unique perms \\
\hline Port & 14 & 89881 & 6420.1 & 5.6423 & $\mathbf{0 . 0 0 0 1}$ & 9839 \\
\hline Residual & 773 & $8.80 \mathrm{E}+05$ & 1137.8 & & & \\
\hline Total & 787 & $9.69 \mathrm{E}+05$ & & & & \\
\hline
\end{tabular}

The pairwise tests revealed significance $(P<0.05)$ between most of the ports with more than $50 \%$ average similarities. The native species contributed the most to the within-port similarity and between-port dissimilarity followed by non-native species (Table 2.4.14). 
However, a relatively high percent of cryptogenic species was observed at ports; Nelson, Wellington, Tauranga and Picton.

Table 2.4.14. SIMPER analysis: percent contribution of species status - native, non-native and cryptogenic species, as a function of the surveyed port.

\begin{tabular}{|c|c|c|c|c|}
\hline Surveyed port & $\begin{array}{c}\text { Avg. similarity } \\
(\%)\end{array}$ & $\begin{array}{c}\text { Native } \\
(\%)\end{array}$ & $\begin{array}{c}\text { Non-native } \\
(\%)\end{array}$ & $\begin{array}{c}\text { Cryptogenic } \\
(\%)\end{array}$ \\
\hline Auckland & 56.95 & 72.56 & 16.3 & 11.13 \\
\hline Bluff & 61.52 & 76.97 & 12.19 & 10.83 \\
\hline Dunedin Harbour & 65.63 & 71.3 & 14.98 & 13.72 \\
\hline Gisborne & 62.96 & 61.76 & 21.54 & 16.7 \\
\hline Gulf Harbour Marina & 51.35 & 50.34 & 26.98 & 22.68 \\
\hline Lyttelton & 76.17 & 58.18 & 30.59 & 11.23 \\
\hline Napier & 53.49 & 71.45 & 17.2 & 11.35 \\
\hline Nelson & 56.71 & 78.98 & 4.76 & 16.26 \\
\hline Opua Marina & 55.85 & 77.91 & 12.98 & 9.11 \\
\hline Picton & 72.3 & 75.9 & 8.84 & 15.27 \\
\hline Taranaki & 70.74 & 87.1 & 12.14 & 0.76 \\
\hline Tauranga & 65.61 & 80.36 & 3.11 & 16.53 \\
\hline Timaru & 72.09 & 65.45 & 27.87 & 6.69 \\
\hline Wellington & 58.92 & 57.29 & 19.22 & 23.49 \\
\hline Whangarei & 55.43 & 57.5 & 22.88 & 19.62 \\
\hline
\end{tabular}

\section{b) Port type}

The PERMANOVA results for species status revealed no statistical significance $(P=0.09)$ as a function of port type (Table 2.4.15). Therefore, rejecting my hypothesis that occurrences of non-native and cryptogenic species will be relatively greater at major commercial ports than at minor ports.

Table 2.4.15. The PERMANOVA analysis used to determine differences in the species status as a function of port type ( 2 levels), Significant value in bold $(P<0.05)$.

\begin{tabular}{|c|c|c|c|c|c|c|}
\hline Source & df & SS & MS & Pseudo- $\boldsymbol{F}$ & $\boldsymbol{P}($ perm) & Unique perms \\
\hline Port type & 1 & 76.872 & 76.872 & 2.514 & 0.091 & 2881 \\
\hline Residual & 13 & 397.51 & 30.578 & & & \\
\hline Total & 14 & 474.38 & & & & \\
\hline
\end{tabular}




\section{c) Latitudinal groups}

PERMANOVA results revealed no significance $(P=0.37)$ between the number of the status of the species as a function of latitude (Table 2.4.16). Therefore, rejecting my hypothesis that frequencies of non-native and cryptogenic species increase with increase in latitude.

Table 2.4.16. The PERMANOVA analysis used to determine differences in the species status as a function of latitude (3 levels), Significant value in bold $(P<0.05)$.

\begin{tabular}{|l|c|c|c|c|c|c|}
\hline Source & df & SS & MS & Pseudo- $\boldsymbol{F}$ & $\boldsymbol{P}($ perm) & Unique perm \\
\hline Latitude & 2 & 74.818 & 37.409 & 1.1235 & 0.3681 & 9593 \\
\hline Residuals & 12 & 399.56 & 33.297 & & & \\
\hline Total & 14 & 474.38 & & & & \\
\hline
\end{tabular}

To summarise, the species status - native, non-native and cryptogenic species showed significance as a function of surveyed ports. The relatively high percentages of native species compared to non-native and cryptogenic species were observed at all ports. However, no significance was observed as a function of the port type and latitudinal groups. For NZPS, I reject both my hypotheses based on the factors; port type and latitudinal groups.

\subsection{Discussion}

\subsubsection{Background}

Marine organisms have spread from their native range to another through human transport such as shipping (ballast water exchange, hull fouling, dry ballast, etc.), aquaculture (intentional or unintentional), trade escape and man-made canals where species move from one place to another (Ruiz et al. 2000; Hewitt \& Hayes 2002). The rate of bioinvasions has immensely increased during the last decade and most likely be increasing due to accelerated global trade, transport and tourism. Marine traffic plays a key role as transport hubs facilitating the spread of species through hitchhiking on cargo ships (Hulme 2009; Seebens et al. 2013). Although not all species survive the range expansion, some die during transit whilst some cannot withstand the new environmental conditions. However, the species that survive and establish can cause immense impacts on ecological and socio-economic ecosystems. Therefore, understanding the pathway and predicting potential invasive species' entry point is likely to be the first step towards strategising any rapid management and eradication plans. This chapter, for this reason, analysed two large national-scale baseline port surveys (the Australian Port Survey dataset [APS] and the New Zealand Port Biological Baseline Survey dataset [NZPS]) to determine the 
community structure and the species status - native, non-native and cryptogenic - at the surveyed ports and tested factors of port type (major vs minor ports) and latitudinal groups explain the occurrence of non-native species. The results of this study highlighted the major commercial shipping ports being the hotspots for non-native species and latitudinal separation with regard to occurrences of non-native species.

\subsubsection{Australian Port Surveys (APS)}

The extensive sampling of Australian port surveys indicated $88 \%$ native species, $9 \%$ non-native and 3\% cryptogenic species. The species composition amongst surveyed ports significantly differed, with relatively stronger species composition (within-group similarity) at Port Geelong (40.69\%) followed by Hobart (40.16\%) whereas weak species composition among Port Esperance (9.23\%). Port Geraldton sat as an outlier as a native red alga, Jania adherens was the only species contributing to its within-group similarity. This led to high dissimilarities between Port Geraldton and other surveyed ports. Port Geelong and Port Melbourne however, had the average lead dissimilarity indicating a similar set of species contributing at each port.

It is interesting to observe that ports in the southern region of Australia such as Geelong, Melbourne, Hobart, Portland, Fremantle, Newcastle, Eden, Adelaide and two ports in the north region of Australia, Port Hay point and Mackay had relatively low between ports dissimilarity. These ports are located within close proximity to each other and experience immense domestic traffic which may likely be the reason for the sharing of species. These results for the factor latitudinal groups supported these assumptions. The ports in the north of Australia at $15^{\circ} \mathrm{S}$ and $20^{\circ} \mathrm{S}$ formed one group whereas ports at $30^{\circ} \mathrm{S}, 35^{\circ} \mathrm{S}$ and $40^{\circ} \mathrm{S}$ formed another (MDS plot). A strong separation between northern (low latitudes) and southern (high latitudes) of Australia was observed with regards to species composition. Similarly, the species status- native, nonnative and cryptogenic significantly varied among latitude groups with a strong association between species status at high latitudes and low latitudes. Although native species were the main species status explaining similarity and dissimilarity among and between latitude groups, the non-native species were relatively abundant at higher latitudes. These results were explained by the top 5 species explaining similarity for low latitudes are cryptogenic barnacle Balanus amphitrite, native barnacle Striatobalanus amaryllis, native polychaete Thelepus robustus, cryptogenic polychaete Lysidice collaris and native oyster Dendostrea folium. In contrast, species such as native clam Hiatella australis, non-native bryozoan Watersipora 
subtorquata, native sea spider Halicarcinus ovatus, non-native bryozoan Bugula neritina and cryptogenic barnacle Balanus trigonus at higher latitudes.

The species, however, did not show significance, but pairwise tests showed a difference in species composition between major and minor ports. The species at major ports had stronger within-group similarity than at minor ports (SIMPER). Similarly, the species status significantly differed between port types with native species as the main species contributing to within-group and between-group similarity. For non-native species, the major ports had high levels of non-native species compared to minor ports. The species (top 5) explaining the similarities within minor ports are native clam Hiatella australis, non-native bryozoan Watersipora subtorquata, cryptogenic barnacle Balanus amphitrite, non-native bryozoan Bugula neritina and native tunicate Pyura stolonifera whereas species such as cryptogenic barnacle Balanus trigonus, non-native tunicate Ciona intestinalis, native sea spider Halicarcinus ovatus, native brittle star Amphipholis squamata and non-native mussel Musculista senhousia at major ports.

Given these results, the major ports analysed - Adelaide, Fremantle, Hobart and Melbourne are in the south of Australia explaining a high number of non-native species at high latitudes. These results highlight several on-going challenges such as major commercial ports being hotspots for marine invasions and the role of shipping as the main pathway for introductions and thereby spread of species (especially non-native species) through regional transport connecting ports for domestic trade or recreational activities.

\subsubsection{New Zealand Port Biological Baseline survey (NZPS)}

The analysis of the NZPS dataset identified $78.80 \%$ native species, $11.11 \%$ non-native species and $10.09 \%$ cryptogenic species. The species composition significantly differed amongst 15 surveyed ports. The MDS plots, in this study, indicated close species interaction between ports forming groups such as; i) Nelson, Wellington and Picton, ii) Bluff and Dunedin Harbour, iii) Lyttelton and Timaru, iv) Whangarei, Tauranga and Taranaki, v) Auckland, Gulf Harbour Marina and Opua Marina. The major ports Auckland, Lyttelton, Napier, Tauranga and Wellington grouped with minor ports. The multivariate analyses supported the MDS patterns, the species composition and species status did not vary as a function of major and minor port types. The port groups observed are located at proximity distance. These results indicate the domestic transfer of species presumably due to local or regional marine traffic with hull fouling 
being the important pathway for the spread of species at regional scales (Coutts \& Taylor 2004; Floerl et al. 2004; Floerl \& Inglis 2005).

Considering the factor; latitudinal groups $\left(35^{\circ} \mathrm{S}, 40^{\circ} \mathrm{S}\right.$ and $\left.45^{\circ} \mathrm{S}\right)$ of New Zealand, the species composition significantly differed amongst latitudinal groups with high similarity in species composition between higher latitudes (33.39\%) $\left(40^{\circ} \mathrm{S}\right.$ vs $\left.45^{\circ} \mathrm{S}\right)$ than between low latitudes $\left(35^{\circ} \mathrm{S}\right.$ vs $40^{\circ} \mathrm{S}=31.51 \% ; 35^{\circ} \mathrm{S}$ vs $\left.45^{\circ} \mathrm{S}=25.58 \%\right)$. Considering the species status analyses, species status did not show a significant difference between latitudinal groups. As seen above, with the species contributing to the similarity among each latitudinal group, the native species were the main species representing latitude groups followed by cryptogenic and lastly the non-native species. These results were explained by the top 5 species explaining similarity with $35^{\circ} \mathrm{S}$ latitudes were cryptogenic tunicate Asterocarpa cerea, non-native bryozoan Bugula neritina, cryptogenic tunicate Corella eumyota, native sea spider Halicarcinus cookii and native sea spider Notomithrax minor. At $40^{\circ} \mathrm{S}$ latitude, species contributing to the within-group similarity are cryptogenic tunicate Asterocarpa cerea, native barnacle Austrominius modestus, non-native bryozoan Bugula flabellata, native tunicate Cnemidocarpa bicornuta and native tunicate Cnemidocarpa nisiotus. In contrast, species such as native red algae Adamsiella chauvinii, native amphipod Amaryllis macrophthalma, native tunicate Aplidium adamsi, cryptogenic tunicate Aplidium phortax and cryptogenic tunicate Asterocarpa cerea explained similarity at $45^{\circ} \mathrm{S}$ latitude. These species consist of biofouling species which commonly encrust on the hull of the ships, engine or port equipment that may result in the domestic transfer of species. These results highlight the complexity of humanmediated transfer of species from one port to another or even port to marinas (Floerl et al. 2004).

\subsubsection{Defining pathways}

Marine traffic has been highlighted as the potential vector to transfer non-native marine species across the world (Hewitt et al. 2009; Seebens et al. 2016; Ziako et al. 2016; O'Brien et al. 2017). Marine traffic arriving at major international shipping ports are the main access points (Campbell \& Hewitt 2007). The marine vessels dock at ports and harbours for extended periods and are a substantial time for fouling to occur (Hewitt et al. 2009). Regarding invasion success at major ports, the commercial ports receiving large volumes of international trade as well as propagules of non-native species. The release of a large number of propagules will increase the chance of non-native species to survive and reproduction at new environments, i.e. ports. Therefore, the heavily invaded areas may serve as hubs for the transfer of species from 
major ports to nearby minor ports (Lockwood et al. 2009; Firth et al. 2016; Olenin et al. 2016; Johnston et al. 2017). This is in consistence with the results of this study indicating similar species between major ports and nearby minor ports where the marine vessels frequently travel to and from. With an increase in human activities over the past 50 years, maritime traffic has increased risks of transfer of species from one region to another.

Recent changes to the climatic conditions with increasing global warming, the species from warm regions (low latitudes) spread to colder regions (high latitudes) consequently changing their geographical ranges thereby affecting the ecological ecosystems (Walther et al. 2002, 2009). There a climate-mediated invasion process follows a classic invasion process (Walther et al. 2009). Human mediated vectors and climate change are the two most prevalent problems impacting marine biodiversity (Rahel \& Olden 2008). The altered habitats put stress on the native species to adapt new conditions; in contrast, the non-native species are excellent in adapting, establishing and spreading. Combination of the number of major ports at high latitudes increases invasion pressure.

The ports and marinas receiving a high frequency of marine traffic are the focal point of entry for marine bioinvasions (Firth et al. 2016; Olenin et al. 2016; Johnston et al. 2017). Commercial shipping vessels have also been associated with non-native species in other studies (Hopkins and Forrest 2010; Lo et al. 2012). As such, major shipping ports supporting a high number of non-native species was not surprising, especially in the south of Australia where the shipping traffic is relatively high (Commonwealth of Australia 2015). Domestic marine traffic poses a threat to the intra-regional transfer of non-native species from port to port within a region (Forrest et al. 2009; Clarke Murray 2011; Hänfling et al. 2011). Domestic trade vessels, fishing vessels, pleasure boats and tour boats move extensively among harbours connecting the major port to other harbours or marinas. The southern regions of Australia are home to some of Australia's busiest shipping routes including Bass Strait, east-west and west-east international shipping routes (Commonwealth of Australia 2015). The marine traffic comprises of international and coastal cargo trading ships, passenger shipping, and ferry services across the Bass Strait. These regions are also productive for fisheries, and commercial fishing is concentrated in inshore coastal waters, and most of the recreational fishing occurs inland, near the coasts and bays. Major ports and adjacent marinas in these areas have numerous marinebased industries and are connected to various minor ports through commercial and recreational fishing, yachts or pleasure crafts. 
The main shipping routes for international and domestic marine traffic in New Zealand and the frequency of marine vessels increase the risk of inter-port transfer of non-native species. However, the frequency of vessels is not the only factor facilitating invasions; the marine vessels carrying high volumes of ballast water - non-native discharge species. For instance, Auckland is the busiest port in New Zealand; however, Port Taranaki receives high volumes of bulk carriers and tankers carrying petroleum. Coutts \& Taylor (2004) examined 30 merchant ships arriving New Zealand and concluded that hulls of the ships are more susceptible to fouling and spread of species on vessels. Biosecurity New Zealand and Cawthron Institute have developed a database to record international cargo vessels and ballast water operations (Dodgshun et al. 2007). However, domestic vessels operating exclusively between NZ domestic ports are not required to report the ballast water discharge, the introduction of nonnative species via ballast water is most likely.

Domestic vessels and local crafts such as fishing vessels and pleasure crafts put a significant pressure of transfer of non-native species through hull fouling (Forrest et al. 2009; Clarke \& Johnston 2011; Hänfling et al. 2011). A report on eradication measures of Undaria pinnatifida, spread from Wellington to South Island revealed fishing vessels to be the primary vector for the transfer of the seaweed (Department of Conservation 2005). Facilities such as marinas, harbours and berths are exposed to frequent movements of recreational and fishing vessels along the coastline. Additionally, these pleasure boats dock in marinas and harbours for a long period - become heavily exposed to hull fouling and being potential vectors for nonnative species. For example, about $47 \%$ yachts and $30 \%$ of launches in ports between Timaru and Bluff, New Zealand were heavily fouled by non-native seaweed, Undaria pinnatifida (Department of Conservation 2005). New Zealand in recent years has implemented regulations for recreational vessels posing risks on intra-coastal species transfer are required to follow Craft Risk Management Standard (CRMS) and IMO guidelines (i.e. Biofouling Management Plan and BioFouling Record Book), provide evidence of records of non-permanent ballast water, vessel hull cleaning and use of appropriate antifouling treatment (MPI 2014; IMO 2015).

\subsubsection{Management implications}

As outlined in this study, human-mediated pathways at a regional scale also indicate as highrisk pathways linking major and minor ports (Coutts \& Forrest 2007). Connectivity between ports has increased in recent years - increasing the possibility of introduction of non-native species. Progress has recently been made by Australia and New Zealand to develop region-based surveillance programmes for the spread of non-native species. Examples include Marine High- 
Risk Site Surveillance (MHRSS, NZ) (Woods et al. 2015), Australian State government and Commonwealth government department led regional surveillance and legislation with regard to non-native species (DAFF 2015).

With changing environments, significant new path risks may emerge for specific nonnative species even where the introduction of species is managed. The propagule pressure primarily correlate to invasion success (Ruiz et al. 2000; Floerl \& Inglis 2005; Lockwood et al. 2005). Many scientists have explained the importance of propagule pressure with regard to non-native species and its management measures; however, it is hard to predict parameter (Johnston et al. 2009). For example, evaluation in Port Phillip Bay, Australia indicates a new introduction every 41.5 weeks (Thresher et al. 1999). The issues of non-native species have grown in recent years - controlling and eradication are quite complicated. Government around the world have taken up national priorities to establish programs and management protocols for prevention (pre and post borders), early detection and management of non-native species. Examples include EU Biodiversity Strategy and the Marine Strategy Framework Directive (Lehtiniemi et al. 2015), Australian National System for the Prevention and Management of Marine Pest Incursions (DAFF 2015), Marine Biosecurity Programme of New Zealand, Aquatic Nuisance Species Task Force (ANSTF) in the United States.

Prevention, early detection and rapid management response reduce the potential introduction of non-native species and their impacts on ecosystems. Australia and New Zealand have established some of the world's strongest biosecurity and management measures, i.e. a comprehensive pre-border, at-border and post-border management responses (Hewitt \& Campbell 2007; Commonwealth of Australia 2013; Ojaveer et al. 2015). Both countries have adopted and implemented international pre-border measures for ballast water management, i.e. the International Maritime Organization, the Ballast Water Management Convention, to control and minimise the spread of non-native species. The Biosecurity Act, NZ (1993) and the Biosecurity Act, AUS (2015), are oriented towards the management of the unintentional introduction of non-native species and post-border incursion measures and long-term management. Ballast water management following the International Maritime Organisation (IMO) protocols and ballast water treatment in the mid-ocean measures are undertaken to reduce the risks of invasions (Hewitt and Campbell 2007; Tamelander et al. 2010; IMO 2017). Recent measures have been focussed on biofouling management; IMO proposed protocols to clean marine vessels, using appropriate anti-fouling agents, evidence of biofouling maintenance and record books (Ministry of Primary Industries 2018; Australian Government 
Department of Agriculture and Water Resources 2019). These countries have also undertaken long term management plans of non-native species conducted by regional councils for baseline evaluations. Australia and New Zealand led many countries across the world in establishing management strategies for non-native species (Hayes et al. 2005; Hewitt and Campbell 2007).

\subsubsection{Pros and cons of large-scale studies}

The passive sampling devices used in APS and NZPS includes dive surveys, fouling panels traps settlement trays for sediment infauna (Hewitt \& Martin 2001). Such sampling designs provide the opportunity to sample biofouling species at large scale locations; however, there are still drawbacks for such sampling designs. The 'snapshot' data capture only provides realtime information; organisms may settle selectively depending on design flaws or environmental conditions such as temperature or wave exposure. Advantage of such passive sampling is that it can acquire samples of species at larval/juvenile stages which thereby impacts the development of species structure. However, the success of such samples depends on taxonomic expertise; the identification of species plays an important role for such large datasets with numerous species collection. Poor identification of species may lead to confusion between congeners or identifying non-native species as native species (Ponchon et al. 2013). Lastly, such large datasets (APS and NZPS) are time consuming and expensive task. Resurveys may be an option to observe the effectiveness of management plans or identify new introductions, but it highly depends on the funding on such large-scale projects.

While the usefulness of large-scale datasets for a broad sense of potential vectors of the introduction of non-native species to aid with rapid management measures is undeniable, this study provides an overall perspective of major commercial shipping ports being the hotspots for non-native species. Ports as entry points for invaders is established, but the second key result indicates the regional transfer of non-native species through domestic vectors. Nonetheless, marine traffic being transport hubs of non-native species is evident. Increased maritime traffic leads to continuous transfer of non-native species. Another factor considered for this study was latitude groups. Relatively abundant non-native species were observed at high latitudes $\left(35^{\circ} \mathrm{S}, 40^{\circ} \mathrm{S}, 45^{\circ} \mathrm{S}\right)$ but these results are in an argument with the locations of major ports at high latitudes. Most of the species observed were biofouling species which further indicate strict management plans towards the eradication of non-native biofouling species. Such species easily attach on vessels' hulls, engines or crevices of the ship which is not easily visible. Australia and New Zealand have developed several guidelines for biofouling 
considering IMO Biofouling Management Plan 2011 (MEPC.207[62]) and are in the process of considering biofouling regulations.

The Australian Port surveys and New Zealand Port Biological Baseline Surveys offered as good datasets to identify the potential factors, i.e. major ports and high latitudes facilitating occurrences of non-native species. While I encourage in using this general applicability of this observed pattern; these results also suggest that port characteristics such as disturbed physicochemical environments, new structures, structure maintenance should be prioritised whilst monitoring for non-native species which will aid with early detection. 


\section{CHAPTER 3}

\section{COMMUNITY DEVELOPMENT AND STRUCTURE ON NATURAL AND MAN-MADE SUBSTRATA IN NATURAL AND MAN-MADE ENVIRONMENTS}

\subsection{Background}

Natural coasts around the world have been heavily degraded and replaced by man-made structures such as seawalls, groynes, marinas, jetties and so on (Lam et al. 2009; Airoldi \& Bulleri 2011; Scyphers et al. 2015; Cacabelos et al. 2016). Although these man-made structures are mostly built to protect the coastlines from erosion and act as defence structures, such manmade structures do provide novel habitats for marine communities (Burt et al. 2009, 2011; Cacabelos et al. 2016; Heery et al. 2017). These man-made structures are expected to proliferate in the future owing to the migration of humans to the coasts and alteration of coastlines as per human needs (Hinkel et al. 2014; Bulleri \& Chapman 2015; Dafforn et al. 2015; Neumann et al. 2015; Dangendorf et al. 2017). The building of continuous coastal defences on the natural coastline can cause habitat loss and habitat fragmentation of natural coastlines having local and regional impacts on marine biodiversity (Airoldi et al. 2008, 2009; Chapman 2012; Scyphers et al. 2015; Perkol-Finkel et al. 2018; Macura et al., 2019). Measures to rectify the negative impacts of the man-made structures by coming up with conservation strategies have only begun relatively recently (Thompson et al. 2002; Airoldi et al. 2005; Chapman \& Underwood 2011; Kueffer \& Kaiser-Bunbury 2014).

Natural coastal shores are heterogeneous environments with a range of microhabitats providing refuge to many intertidal species from predation and desiccation (Thompson et al., 2002; Waltham \& Dafforn, 2018; Bulger et al. 2019). The correlation between heterogeneous habitats and biodiversity has been observed across all ecosystems, be it land such as rainforests or sea such as coral reefs (Simberloff \& Von Holle 1999; Tews et al. 2004; Davies et al. 2005; Hansen \& Clevenger 2005). This can even be observed at small scales with increased microbiota communities on rough surfaces rather than on smooth surfaces (Lam et al. 2009; (Pister 2009; Cacabelos et al. 2016). Unlike natural habitats, the man-made structures have smooth surfaces, i.e. low structural complexity, with no rockpools or crevices, making it difficult for the species to colonise or find refuge from desiccation, predation or wave action (Chapman \& Clynick, 2006; Von Holle, 2011). Therefore, the building of man-made structures 
tends to homogenise natural coastlines, having a negative impact on the native marine biodiversity (Mack et al. 2000; Braby \& Somero 2006; Brandl et al. 2017; Pastro et al. 2017; Perkol-Finkel et al. 2018). Once coastlines are modified, it is difficult to re-establish diverse communities as there would be competition over limited resources such as food and space (Simberloff \& Von Holle 1999; Levine 2000; Bruno et al. 2003; Rius \& McQuaid 2009; Branch et al. 2010).

Man-made coastal structures are built using materials such as granite, concrete, plastic, or wood, which are usually not observed in natural coastal habitats (Bulleri \& Chapman 2010; Loke \& Todd 2016). There has been evidence that some marine organisms are selective of chemical cues provided by substrata (Pawlik 1992; Dobretsov \& Wahl 2001; Tamburri et al. 2008). Therefore, species-specific preference for settle on certain substrata (material types) is possible. Experiments using different materials to test for species community comparisons have yielded contradictory results. Some studies indicated similar species richness, but low abundances of species on artificial materials such as ceramic, glass, granite, concrete, steel, aluminium, wood, brick, rubber compared to natural reefs (Anderson \& Underwood 1994; Creed \& De Paula 2007; Field et al. 2007; Tyrrell \& Byers 2007; Loke \& Todd 2016; Kennedy et al. 2017; Mallela et al. 2017). Whilst some studies in estuaries showed increased species abundances on artificial structures (tyres, wood, metal) due to additional substrata for the organisms to settlement on (Chapman \& Bulleri 2003; Chapman \& Clynick 2006; Smith et al. 2014), and still, other studies showed differences in species diversity and abundances as an effect of different habitat type rather than the material type (Burt et al. 2009; Cacabelos et al. 2016). For instance, even when the seawalls along the Sydney coast were built with sandstone to mimic natural reefs, the structures did not support similar communities (Chapman \& Bulleri 2003). Therefore, man-made structures on its own cannot replace natural habitats (Bulleri \& Chapman 2004; Bulleri \& Chapman 2010; Carvalho et al. 2013; Cacabelos et al. 2016). However, eco-engineered man-made structures can act as surrogates for natural habitats.

The orientation of man-made structures is usually vertical and steep, providing reduced settlement opportunity, whilst most natural habitats are horizontal or gently sloping, supporting relatively more species (Chapman \& Clynick 2006; Spagnolo et al. 2014; Kennedy et al. 2017). The steep man-made structures act as a barrier for larval dispersal, movement of mobile species, alter recruitment patterns and reduce water flow causing impacts on ecological connectivity (Bulleri \& Chapman 2004; Moreira et al. 2006; Rivero et al. 2013 Bishop et al. 2017). This further impacts the gene flow and trophic transfer along coastlines (Branch \& 
Steffani 2004; Trussell et al. 2004; Burlakova et al. 2012; Inglis \& Seaward 2016; Bishop et al. 2017). Thus, low genetic diversity is one of the factors that may be observed amongst species on man-made structures (Fauvelot et al. 2009; Sammarco et al. 2012). Subsequently, some species may develop interspecific and intraspecific relationships amongst the community which are not seen at natural habitats ( Chapman 2006, 2013; Tyrrell \& Byers 2007; Chapman \& Underwood 2009; Quinn et al. 2012). For instance, some invertebrates had a smaller sized body and less reproductive output as a response to increased community density (Moreira et al. 2006).

Recent re-assessments of man-made coastal structures have concluded that it is important to redefine the design features of the structures. Engineering structures with multifunctional use, i.e. for coastal defence as well as providing habitat for marine organisms, have been considered. Addition of rockpools, crevices forming tide pools or even addition of overhangs can promote biodiversity (Bulleri \& Chapman, 2010; Chapman \& Underwood 2011; Loke \& Todd, 2016). For instance, the addition of flowerpots over the vertical seawalls led to an increase in species assemblage diversity by $62 \%$, with 25 species which were not previously found on the seawall (Browne \& Chapman 2011). Cost-effective hybrid structures such as revetments, tetra-pods and geo-tubes can be multifunctional, especially in areas where the natural habitats are lost (Moschella et al. 2005; Chapman \& Underwood 2011; Browne \& Chapman 2014; Firth et al. 2014; Loke et al. 2014). Additionally, precautionary policies regarding the placement of coastal structures had been implemented more towards the beach to protect intertidal marine communities (Dethier et al. 2017).

Man-made habitats such as marinas and ports are usually enclosed areas with limited water/wave action, as well as increased sedimentation rates leading to high turbidity and reduced photosynthesis, thereby degrading the natural habitat and reducing the resident biodiversity (Guerra-García \& García-Gómez 2004; Perkol-Finkel \& Benayahu 2007; Rivero et al. 2013; Pastro et al. 2017). Levels of disturbance are also thought to vary between manmade and natural habitats (e.g., via strong waves or predation) (Moschella et al. 2005). However, anthropogenic disturbances such as maintenance of man-made structures or overharvesting of resident species tend to dislodge competitively dominant and settled species, thereby providing bare space for colonisation of opportunistic species (Airoldi et al. 2005; Airoldi \& Bulleri 2011; Bracewell et al. 2013; Oricchio et al. 2016). The community structure often varies between different habitats, for example, sessile species composition greatly differed among complex habitats compared to the bare substrate (Burlakova et al. 2012) and 
even the microbial communities differed between man-made structures and natural rocky reefs (Tan et al. 2015).

Studies comparing the community composition on natural and man-made structures have observed similar species richness but different relative abundances on both structures (Connell \& Glasby 1999; Thompson et al. 2002; Chapman 2003; Bulleri \& Chapman 2004; Pister 2009; Carvalho et al. 2013). However, many recent studies have highlighted the two habitats, natural and man-made to support different species assemblages (Moschella et al. 2005; Perkol-Finkel et al. 2006; Clynick et al. 2007; Lam et al. 2009; Bulleri \& Chapman 2015; Lai et al. 2018). Whilst some studies have observed the man-made structures to support species that are not generally observed in natural habitats (Goodsell et al. 2007; Browne \& Chapman 2011). Man-made structures may act as novel habitat for various benthic communities, especially in sedimentary habitats, providing additional habitat where they support greater species diversity compared to natural habitats (Bulleri \& Chapman 2010; Airoldi et al. 2015; Heery et al. 2017). In some instances, species richness was relatively lower at man-made structures than natural habitats (Connell \& Glasby 1999; Moschella et al. 2005; Pister 2009; Firth et al. 2013; Aguilera et al. 2014; Munsch et al. 2014). Species richness and effects on ecosystem functioning are dependent on specific functions of species (Chapman 2003; Rius \& McQuaid 2006; Stachowicz et al. 2008; Pister 2009; Mineur et al. 2012; Albano \& Obenat 2019). Besides, the composition of assemblages is also an important factor as the changes in the diversity of the species (Creed \& De Paula 2007; Field et al. 2007).

Ecosystem functions are influenced by 'keystone species' as they strongly affect the energy pathways, and by 'ecosystem engineers' which create or modify habitats. Additionally, species such as sessile organisms that usually facilitate a positive relationship with other species by providing refuge, especially for mobile species and larger predators; are economically significant (Borthagaray \& Carranza 2007; Sousa et al. 2009; Green et al. 2013; Martins et al. 2016; O'Shaughnessy et al. 2019). The habitat-forming species or the early recruiters help with the development of a community by providing refuge or acting as a food source. Overgrowth of these initial recruits due to the absence of grazers and plenty of space can have adverse effects on late settlers by blocking the surfaces (Connell 1961; Sousa 1979; Bracewell et al. 2013; Aguilera et al. 2014). However, recognising which species can withstand anthropogenic disturbances and how such disturbance can impact the overall ecosystem structure is essential (Liversage et al. 2014). For instance, habitat-forming sessile species such as ascidians, bivalves, bryozoans, cnidarians, corals, and sponges that are permanently fixed 
on substrata may be majorly affected by anthropogenic disturbances that lead to their dislodgment, thereby disrupting the ecosystem structure (Lockwood et al. 2007).

An important change to the community composition is conferred by invasive species (Bulleri et al., 2016). It is universally accepted that bioinvasions are a major threat to marine biodiversity as well as the global economy (Ojaveer et al. 2015; Gestoso et al. 2017; Olenin et al. 2017; Simpson et al. 2017). Invasive species are ubiquitous and can degrade habitats in many ecosystems (Wonham 1999; Pauchard \& Shea 2006; Bellard et al. 2016; Bulleri et al. 2016). Consequently, there has been a surge in studies of invasive species all around the world. Frequently, the invasive species have been seen to establish in regions with heavy anthropogenic activities (Thompson et al. 2002; Ruiz et al. 2009; Johnston et al. 2017). Disturbance and maintenance along the coastlines for urbanisation and coastal development are ubiquitous, and provision of non-native species are such sites is typical (Clark \& Johnston 2009; Piola et al. 2009; Bulleri \& Chapman 2010; Dumont et al. 2011; Rivero et al. 2013). For example, maintenance of breakwaters leads to displacement of dominant space occupiers, mussels and oysters, leading to the growth of opportunistic and invasive biofilms and macroalgae (Airoldi \& Bulleri 2011; Ceccherelli et al. 2014).

Ports and bays are sites where ships' ballast water discharge and hull fouling communities may contribute to the introductions of non-native species (Ruiz et al. 1997; Hewitt et al. 2004; Chapman \& Underwood 2011; Mineur et al. 2012; Choi et al. 2016; Foster et al. 2016; Olenin et al. 2017). Coastal habitats are vulnerable to invasions due to the changing of natural habitats, local biodiversity and propagule pressure from non-native species (Johnston et al. 2009; Simberloff 2009; Simpson et al. 2017; Epstein \& Smale 2018; Riera et al. 2018). Many studies suggest that non-native species are less successful at natural habitats as compared to man-made structures (Chapman \& Carlton 1991; Dafforn et al. 2012). There is evidence of non-native species being strongly related to disturbed areas with high turbidity and wave exposure (James \& Shears 2016). Man-made structures act as 'stepping stones' for the spread of non-native species and support a high number of non-native species (Dumont et al. 2011; Mineur et al. 2012; Saura et al. 2014; Dong et al. 2016).

Not all non-native species can successfully establish due to unsuitable climatic conditions, diseases, predation and competition by native species through species-specific interactions or invasion resistance by the diverse native community (Elton 1958; Tilman et al. 1994; Mack et al. 2000; Stachowicz et al. 2002; Dumont et al. 2011; Firth et al. 2013; 
Henriksson et al. 2016; Leclerc \& Viard 2018). The successful non-native species may be highly competitive in terms of their high reproductive/growth rates and phenotypic plasticity, which aids their introduction and establishment success in a new environment (Petes et al. 2008; Piola et al. 2009; MacKie et al. 2012; Fava et al. 2016; Purroy et al. 2019). Once established, the non-native species disperse further from the introductory areas (Tyrrell \& Byers 2007; Forrest et al. 2009).

Invasive species can cause changes to community structure and impact ecosystem functioning (Firth et al. 2016), including the loss of native species and a decrease in diversity, thereby leading to a homogenous community (Browne \& Chapman 2014; Airoldi et al. 2015; Ferrario et al. 2017). Invasive species, when established in an environment, can co-exist with native species if they have similar ecosystem functions: however, if their functioning is different, it may lead to modified habitats and cascading effects on the other species (Crooks 2002; Trussell et al. 2004; Babarro \& Abad 2013; Saura et al. 2014). It is therefore essential to understand the ecological functioning of an invasive species in its new habitat and its relationships with other species (Airoldi \& Bulleri 2011; Perkol-Finkel et al. 2012; Zwerschke et al. 2016; Leclerc \& Viard 2018; Mayer-pinto et al. 2018). For example, the predatory European green crab (Carcinus maenas) in California, established and altered the community structure and reduced the number of native species through predation (Grosholz et al. 2000). Predation by the invasive crab, Carcinus maenas, led to the decrease of a grazer, Littorina littorea, which in turn resulted in the proliferation of ephemeral algae in rocky reefs (Trussell et al. 2004). Some studies have also highlighted the replacement of native species by nonnative species (Geller 1999, Byers 2000; Ojaveer et al. 2002; Rodriguez 2006; Tan et al. 2015).

Spatial, temporal and environmental heterogeneity determine ecological diversityfunction relationships (Stachowicz et al. 2008). Ecological succession in community structure helps identify patterns or interactions in abundances and diversity over time (Connell \& Slatyer 1977; Loke et al. 2016; Johnston et al. 2017; Chang \& Turner 2019). Ecological succession is the study of patterns of colonisation and resilience of species after a disturbance (Connell \& Slatyer 1977). In recent times, the two main factors that disturb ecological succession are human activities and climate change (Bishop et al. 2017; Firth et al. 2016). Anthropogenic disturbances causing newly exposed habitats have a significant effect on ecological succession, especially the first succession being highly driven by stochastic processes and colonisation is variable and patchy (Chapman \& Underwood 2009; Clark \& Johnston 2009; Chapman 2012; Spagnolo et al. 2014). Pioneer species first colonise new barren habitats as they can withstand 
extreme conditions - 'primary autogenic succession' but are short-lived. Bacteria and biofilms, and other settlers such as diatoms, form an initial layer over the bare substrata. Chemical cues emitted by the initial larval colonists and even the associated substratum are known to influence changes in the recruitment of other species (Pawlik 1992; Dobretsov \& Wahl 2001; Tamburri et al. 2008). Over time, new species colonise - 'secondary succession' - and may tend to stabilise - 'climax community' (Connell \& Slatyer 1977; Chang \& Turner 2019). The 'climax community' is mature and is dominated by a few species (Berlow 1997). In the marine environment, the sequence of recruitment and settlement of species have a strong influence on the diversity as well as the structure of the climax community (Bulleri 2005; Lu \& Wu 2007; Becker et al. 2018; Gouezo et al. 2019). Various factors, such as the level of disturbances or prey-predator interaction, can lead to alternative stable states with different community structure (Petraitis \& Latham, 1999).

Nevertheless, we cannot assume that similar community structure and sequence of succession observed at natural habitats will be seen on man-made habitats. Another question arises in terms of species status (native vs non-native species), the competitive traits of nonnative species could displace native species. This displacement of species can produce changes in community structure found in natural successions (Pandolfi 2008). Thus, comparative studies across a variety of ecosystems can help us to understand the main factors facilitating the succession of both native and non-native species (Chang \& Turner 2019). Whilst there is some research done on the succession of species, but no similar studies have been conducted comparing natural and artificial habitats/ substrata in the context of species status.

Studies investigating the community structure, species abundances and diversity as well as the status of the species - native and non-native - with a focus on natural vs man-made structures have been performed all over the world, especially in temperate regions (Connell \& Glasby 1999; Connell 2001; Hewitt 2002; Airoldi 2003; Bacchiocchi \& Airoldi 2003; Chapman \& Bulleri 2003; Airoldi et al. 2005; Bulleri \& Airoldi 2005; Wyatt et al. 2005; Airoldi \& Beck 2007; Parsons et al. 2016; Mayer-Pinto et al. 2018). The proliferation of built structures along with New Zealand's (NZ) coastline and an increase of $10 \%$ non-native species since 2009 has been outlined by New Zealand's Environmental Reporting Series (Ministry for the Environment \& Stats NZ, 2016). However, to the best of my knowledge, no research has been carried out in New Zealand to examine the effects of man-made built structures and natural rocky reefs on marine community composition and species' abundances over a period of time, 
and that also examines preference of native and non-native species in terms of habitat type (Natural reef vs Man-made habitat).

Many previous studies have acknowledged the impacts of man-made structures on community composition and species' abundances, as well as the facilitation of non-native species. Therefore, this chapter attempts to quantify species diversity and community composition at the rocky reef (natural) and marina habitats (built) using slate (natural) and PVC (polyvinylchloride) (man-made) tiles in Wellington Harbour. The successional pathways from the initial bare surface to final community composition have been examined to observe the effects of man-made habitats/substratum for 2 years. This study also analysed the impact of habitat type and substratum type on the recruitment of fouling species with respect to their status; native, non-native and cryptogenic (species which could not be identified or the status could not be determined) and tested if there is a preference by non-native species for a particular habitat or substratum. The variability in the association of native and non-native (positive, i.e. increase in the number of native and non-native species; negative, i.e. increase in non-native abundance with a decrease in the number of native species) may help determine a positive or negative relationship between native and non-native species. The hypotheses investigated in this chapter are: 1) community composition at man-made habitat (3 replicated marinas) is less diverse than at neighbouring natural rocky reefs; 2) community composition on the man-made substratum (PVC) is less diverse than that on a natural substratum (slate), and 3) non-native species are more abundant at the artificial habitats and on artificial substratum relative to natural habitats and substratum. 


\subsection{Methods}

\subsubsection{Study sites}

Six study sites (3 paired sites) were selected in Wellington Harbour to examine if the marinas (man-made habitats) support similar or different communities to the adjacent natural rocky reefs. The three marina sites were; Chaffers Marina (CM), Evans Bay Marina (EB) and Seaview Marina (SM) and three natural reef sites were; Oriental Bay (OB), Shelly Bay (SB) and Sorrento Bay (SR) (Figure 3.2.1; Table 3.2.1). The three paired sites were; Chaffers Marina - Oriental Bay; Evans Bay Marina - Shell Bay; Seaview Marina - Sorrento Bay which was at 200 m distance between each marina and reef site.



Figure 3.2.1. Map of Wellington Harbour, New Zealand, indicating natural reef and man-made habitats (marinas) as sampling sites for the study.

Table 3.2.1. List of sampling sites with habitat types, codes, latitude and longitudes.

\begin{tabular}{|c|c|c|c|c|}
\hline Site & Site code & Habitat & Latitude & Longitude \\
\hline Chaffers Marina & $\mathrm{CM}$ & Marina & S $41^{\circ} 17.194^{\prime}$ & E $174^{\circ} 48.165^{\prime}$ \\
\hline Oriental Bay & OB & Reef & $\mathrm{S} 41^{\circ} 17.377^{\prime}$ & E $174^{\circ} 47.340^{\prime}$ \\
\hline Evans Bay Marina & EB & Marina & $\mathrm{S} 41^{\circ} 17.983^{\prime}$ & E $174^{\circ} 49.028^{\prime}$ \\
\hline Shelly Bay & SB & Reef & $\mathrm{S} 41^{\circ} 18.100^{\prime}$ & E $174^{\circ} 49.049^{\prime}$ \\
\hline Seaview Marina & SM & Marina & $\mathrm{S} 41^{\circ} 24.765^{\prime}$ & E $174^{\circ} 90.299^{\prime}$ \\
\hline Sorrento Bay & SR & Reef & $\mathrm{S} 41^{\circ} 15.278^{\prime}$ & E $174^{\circ} 54.188^{\prime}$ \\
\hline
\end{tabular}




\subsubsection{Substratum}

To study the fouling community composition on tiles of different substrata (material), PVC as man-made and slate as natural substrata were used. PVC as a man-made material has been previously used in many settlement arrays studies whilst, slate is a natural material and is not chemically treated. Each tile was cut into $0.0225 \mathrm{~m}^{2}(0.15 \times 0.15 \mathrm{~m})$ and was $10 \mathrm{~mm}$ in thickness. Four holes were drilled at $2 \mathrm{~cm}$ from the edge of the tiles in the four corners. The tiles were secured back to back (PVC to slate) with cable ties through the four holes exposing only one side of each tile for settlement, i.e. front view of the tiles (Figure 3.2.2 c \& d). The surface of the PVC tiles was lightly scraped with sandpaper to remove the industrial smoothness, to help with species attachment. The slate tile was left untreated because it is naturally slightly rough.

\subsubsection{Experimental design}

In marinas, wooden wharf pilings were a perfect set-up for the experimental design from which to suspend the settlement tiles, whilst natural reefs had no such set-up. Therefore, different experimental set-ups were designed for the marina (man-made habitat) and reef sites (natural habitat).

\section{a) Marina (Man-made habitat)}

At each of the three marina sites, the settlement tiles were hung between two wharf pilings with ropes at $2 \mathrm{~m}$ below the sea surface estimated at low tide considering the Mean Low Water Springs (MLWS). Eight sets of PVC and slate paired tiles were tied to a rope with cable ties at equal intervals (Figure 3.2.2 a). In total, 5 such rope set-ups were deployed on 5 different sets of wharf pilings. Eight paired tiles were attached equidistant from each other and were constantly submerged. Hence, for the 2-year study period, 1 marina site had 5 replicate set-ups with 8 paired tiles $(1$ marina site $\times 5$ replicates $\times 8$ paired tiles $=40$ paired tiles at 1 marina site [40 PVC +40 slate]). At 3 marina sites $\times 5$ replicates $\times 8$ paired tiles $=120$ paired tiles $[120$ $\mathrm{PVC}+120$ slate $]$.

\section{b) Reef (Natural habitat)}

Galvanised steel frames were constructed $(1.6 \times 0.25 \mathrm{~m})$, from which the tiles were hung across the frames with ropes. The frames were maintained in position underwater with the help of cement-filled tyres used as weights and subsurface buoys to help the frame stay vertical (Figure 3.2.2 b). The frames were placed perpendicular to the coast so that the surfaces of both the tiles are exposed to the waves. Similar to the tile set-up at marina sites, 5 replicates of the frame set- 
up were placed at each natural reef site. For the 2-year study period, 1 reef site had 5 replicate set-ups with 8 paired tiles $(1$ reef site $\times 5$ replicates $\times 8$ paired tiles $=40$ paired tiles at 1 reef site $[40 \mathrm{PVC}+40$ slate]). At 3 reef sites $\times 5$ replicates $\times 8$ paired tiles $=120$ paired tiles $[120$ PVC + 120 slate $]$.

\subsubsection{Field sampling and sampling intervals}

The placement of the set-ups and the sampling (retrieval) of the tiles was carried out by SCUBA divers. Whilst field sampling, the cable ties were cut, and pairs of tiles (PVC and slate) were placed in pre-labelled plastic bags. Once the tiles were retrieved from the water, they were placed in an icebox and then transferred to a freezer $\left(-18^{\circ} \mathrm{C}\right)$ in the laboratory until they were processed. At every sampling interval (see below), 30 paired tiles (PVC and slate) were collected from the six study sites (marina and reef): in total, 60 tiles (30 PVC +30 slate) were processed at anyone sampling period. Hence, for 8 sampling intervals, a total of 480 tiles were collected by the end of the 2-year study. The tiles were sampled randomly for every sample interval, for example, at time 1 (Nov 2017) number 6 tiles from all the experimental set-ups were retrieved.

This study was designed to compare the fouling community on PVC and slate substrata from the first time they were deployed in the water (August 2017 - austral winter) to the end of the 2 years (August 2019). Sampling interval after the first deployment in August 2017 was every three months until the final retrieval in August 2019 (Table 3.2.2).

Table 3.2.2. List of sampling intervals, months, seasons and sampling year examined in this study, following set-up and deployment in August 2017.

\begin{tabular}{|c|l|c|c|}
\hline $\begin{array}{c}\text { Sampling } \\
\text { interval }\end{array}$ & \multicolumn{1}{|c|}{ Month } & $\begin{array}{c}\text { Season } \\
\text { (Austral) }\end{array}$ & Sampling year \\
\hline 1 & November 2017 & Spring & Year 1 \\
\hline 2 & February 2018 & Summer & \\
\hline 3 & May 2018 & Autumn & \\
\hline 4 & August 2018 & Winter & \\
\hline 5 & November 2018 & Spring & Year 2 \\
\hline 6 & February 2019 & Summer & \\
\hline 7 & May 2019 & Autumn & \\
\hline 8 & August 2019 & Winter & \\
\hline
\end{tabular}




\section{a) Set-up in marinas}

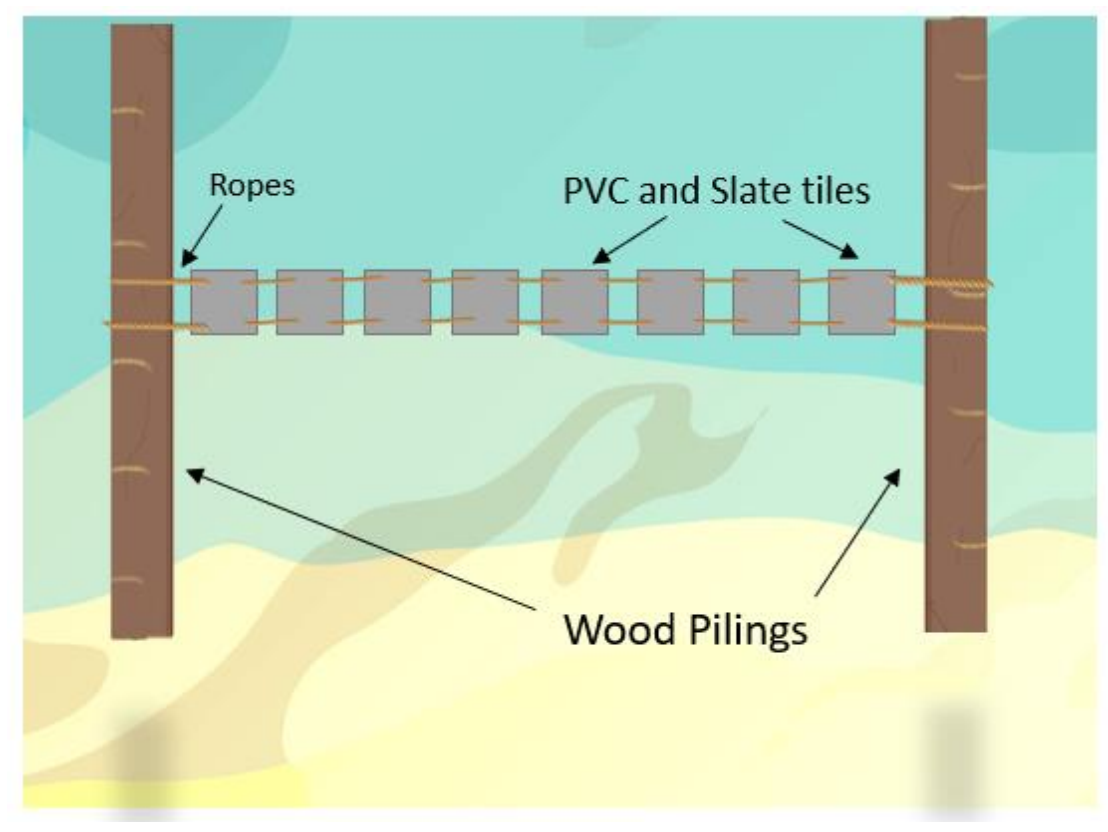

c) Front view

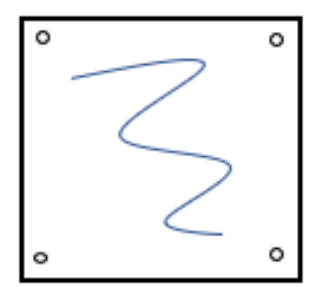

$15 \times 15 \mathrm{~cm}$ b) Set-up at natural reef sites

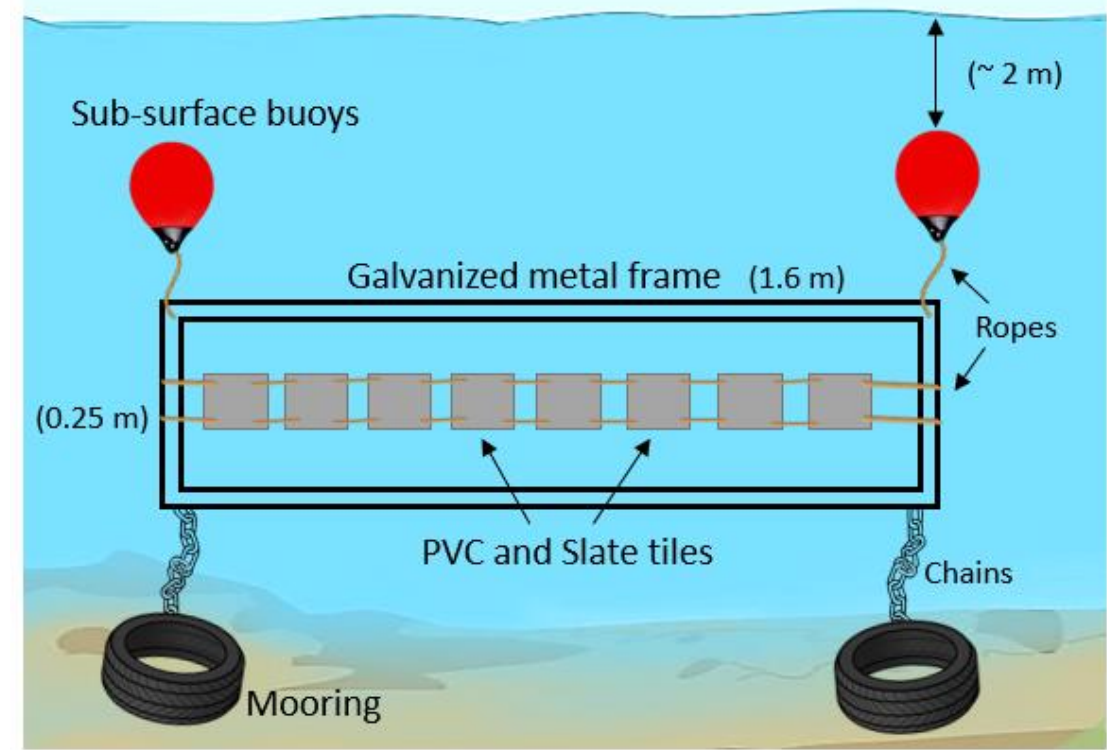

d) Side view

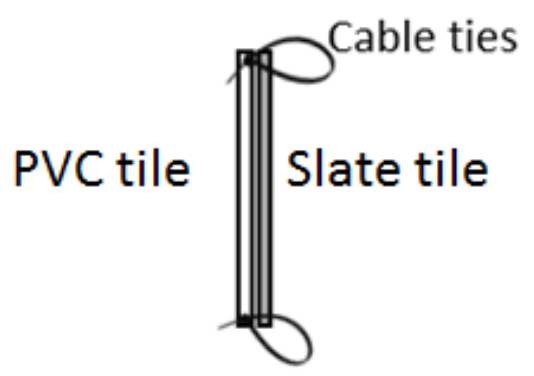

Figure 3.2.2. Set-up of settlement tiles deployed in the a) marinas and at b) natural reef sites; c) front view and d) side view of the PVC and slate substrata. 


\subsubsection{Tile processing}

The fouling community on each tile was thawed and gently patted dry before processing. Subsequently, to have a 2D view of the community on the tiles, high-resolution digital images were taken of the front of the tiles (the side exposed for settlement). At each sampling interval, these images were then analysed using Coral Point Count with Excel extensions (CPCe) to record the community composition over a 2-year study period (Kohler \& Gill 2006). A 100point random grid within $14 \times 14 \mathrm{~cm}$ was generated (for each tile, a $1 \mathrm{~cm}$ border was not included to avoid edge effects). The number of points (100) that overlaid on the image was determined using Lenth's power test as suggested in CPCe manual (Power $=0.998$ for 100 points). The species cover at each point was determined for each plate at each time interval for all sites. Similarly, points on the bare space on the tiles were also noted to assess the availability of bare space for settlement through the study period.

Species were identified using field guides for common intertidal and shallow subtidal species of New Zealand, including known non-native species. Species were identified to the lowest possible taxonomic level (most usually to species) and then placed in major systematic groups. The organisms which could not be identified to species were identified to genus or family level and coded as sp. 1 or sp. 2, for example, Ulva sp. 1 (see Table 3.3.1).

'Biofilm', herein coded as Biofilm type 1, was classified as a single major group as it is biologically important as an early coloniser, is highly variable in time and space in its exact content and could not be accurately identified to any meaningful taxonomic level. An unknown black-dotted biofilm that was visually different from the clear biofilm (Biofilm type 1) was observed in the initial stages of sampling herein and was labelled 'Biofilm type 2'. An unidentified green moss-like structure (Chlorophyta) was labelled as Green sp. 1; the sheetlike green alga was labelled as 'Ulva lactuca', the green ribbon-like alga was labelled as 'Ulva sp. 1', the beige sheet-like tunicate as 'Tunicate sp. 1' and the mustard sheet-like tunicate as 'Tunicate sp. 2'.

\subsubsection{Data analyses}

\section{a) Preliminary analyses}

Data were analysed using the statistical package Plymouth Routines in Multivariate Ecological Research (PRIMER v.6) (Clarke \& Gorley 2006). The DIVERSE routine was used to calculate the total number of 'species' occurrences (total species richness) and the total number of 'individuals' as represented by point counts (total individuals); at marina sites (man-made 
habitat) on PVC and slate settlement tiles (man-made and natural substrata) as well as for natural reef sites (natural habitat) on PVC and slate settlement tiles. Species accumulation curves were plotted across all 480 samples to determine if the sampling effort was sufficient to discover all likely (expected) taxonomic diversity in Wellington Harbour over 2 years. The metric $S_{\text {obs }}$ showed the observed total number of species with the increase in the number of samples (the asymptotic value of the species accumulation curve). The non-parametric estimators used for plots were; Chao1, Jacknife1 and Bootstrap. Chao1 and Jacknife1 estimate richness from single samples (abundance-based)

\section{b) Bare space availability}

Multivariate analyses were performed using PRIMER v.6 with permutational multivariate analysis of variance (PERMANOVA) as an add-on package (Anderson et al. 2008). PERMANOVA helps statistically test the differences between two groups and among a group, and the effects of factors on communities using a permutation approach to avoid possible biases and problems associated with regular parametric testing.

Availability of bare space (expressed as a percentage) as a function of habitat and substratum through the tri-monthly sampling periods was tested using permutational multivariate analysis of variance (PERMANOVA). As the units for bare space and species community composition were similar, the bare space data were square-root transformed. The data were square-root transformed based on Bray-Curtis similarity matrices with 9999 permutations of the raw data. PERMANOVA was run with Type III (partial) sums of squares with relevant factors. The main independent factors were substratum (fixed), sample interval (fixed), habitat (fixed) and sites nested within habitat (fixed) and available bare space (point count) was the dependent variable. Factor, sites nested within the habitat, in the PERMANOVA model resulted in no tests. Therefore, a PERMANOVA model with factors habitat, substratum and sample interval were considered. CPCe points for bare space at each sampling time were also plotted on a graph to observe the variations in availability of bare space over time.

\section{c) Fouling community composition}

The multivariate analyses based on Bray-Curtis similarity matrices were run after the data were square-root transformed to reduce the effects of abundant species, with 9999 unrestricted permutations of the raw data with Type III sum of squares. A two-dimensional multidimensional scaling (MDS) ordination plot was performed to visualise the similarity in samples for 3 factors; habitat type, substratum and sample intervals (12 months). Additionally, 
MDS with the temporal variations displayed as an overlay connecting each sampling interval to visualise the trajectory of change across all 6 sites, respectively. MDS helps visualise the multivariate patterns in fouling community change over time between the habitat types and the substrata. In MDS, samples that are similar cluster together whereas samples which are dissimilar cluster further apart. MDS plot stress values were used to interpret the reliability of the relationships; values $<0.15=$ good representation between groups. The stress levels are also affected by the number of samples (Clarke 1993).

The variations in fouling community composition as a function of; habitat type, site (habitat), substratum type and sample interval (given as sampling sequence in the order from the first to the eighth) with their relevant interaction terms were analysed using multi-factorial PERMANOVA. Pairwise PERMANOVA tests were employed to test for the location of the differences (equivalent to standard post-hoc tests).

Species contributing to the similarities and dissimilarities between the two groups as a function of Habitat, Substratum and Time were identified using the routine similarity percentages (SIMPER) at a 50\% contribution cut-off. The PERMANOVA results were mostly significant $(P<0.001)$, the SIMPER analyses were performed only for major factors (Habitat, Sites, Substratum and Time).

\section{d) Species status (native, non-native and cryptogenic) within the fouling community}

The species within the fouling community sampled on the tiles were classified with respect to their status, i.e., native, non-native and cryptogenic species with the help of Word Register of Marine Species (WoRMS). The species whose status could not be identified were classified as a cryptogenic status group. A multivariate PERMANOVA was performed with the species status as the dependent factor whilst habitat, site (habitat), substratum and sample interval as the independent variables. This test helped indicate if the factors of; habitat, site (habitat), substratum and sample interval had any effects on the abundance of native, non-native or cryptogenic species. SIMPER indicated similarity of the presence of species with respect to their status within each factor as well as the dissimilarity between the groups. 


\section{Natural Habitat}
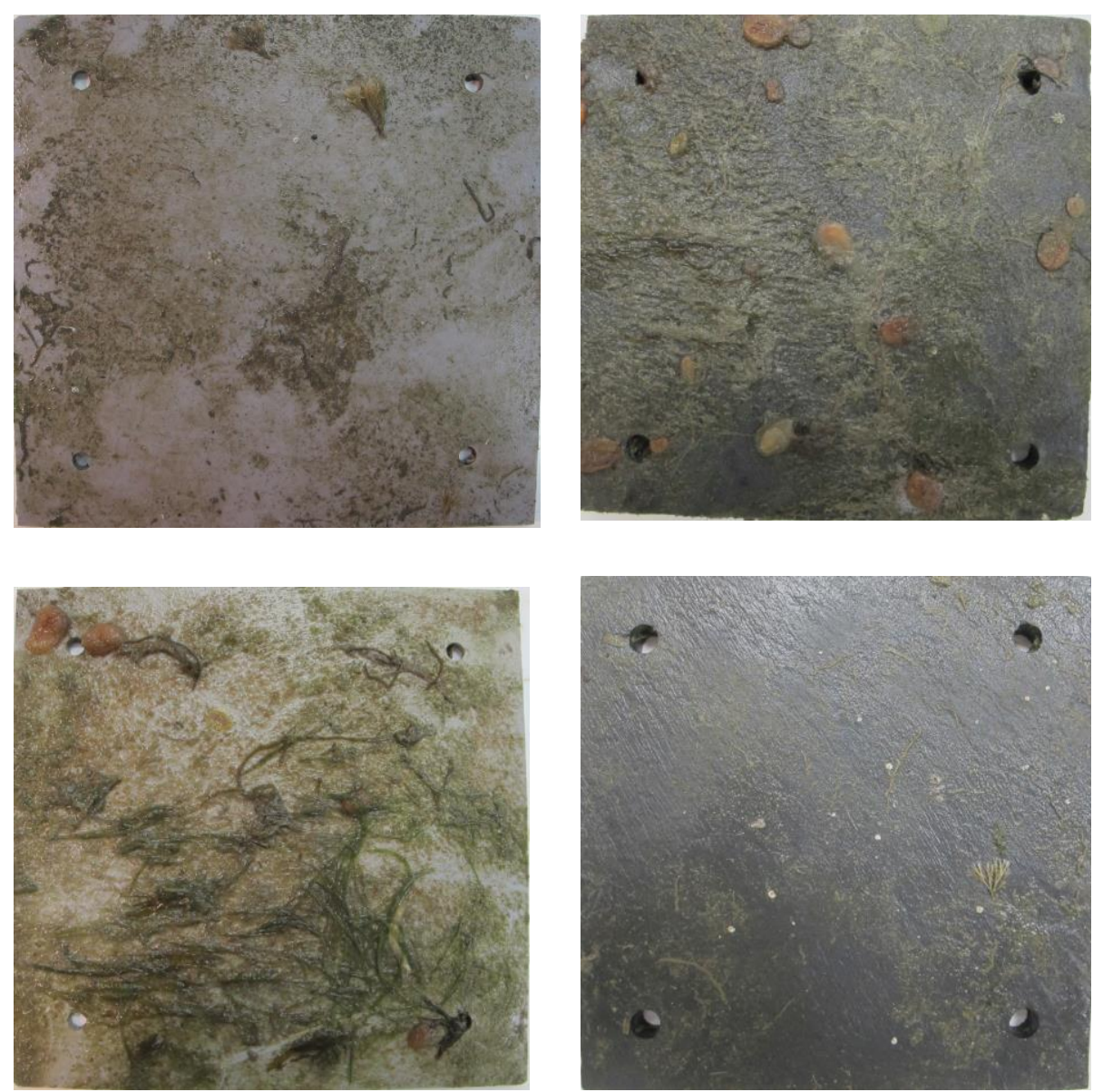

Substratum type

\section{Man-made Habitat}

PVC
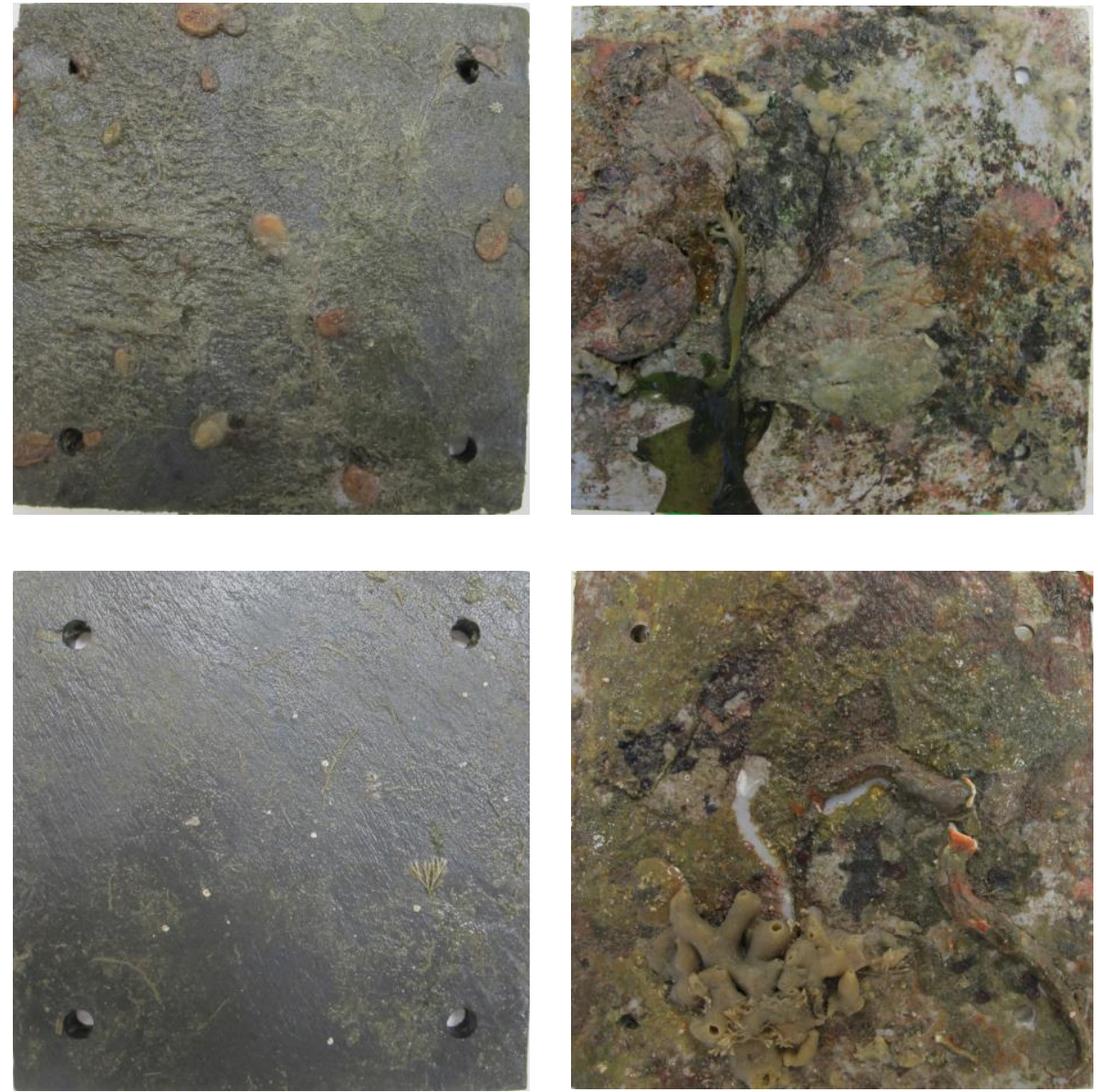

Slate

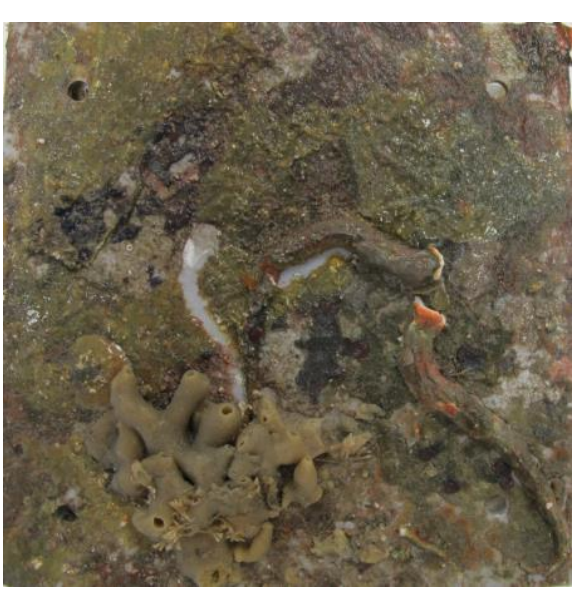

PVC
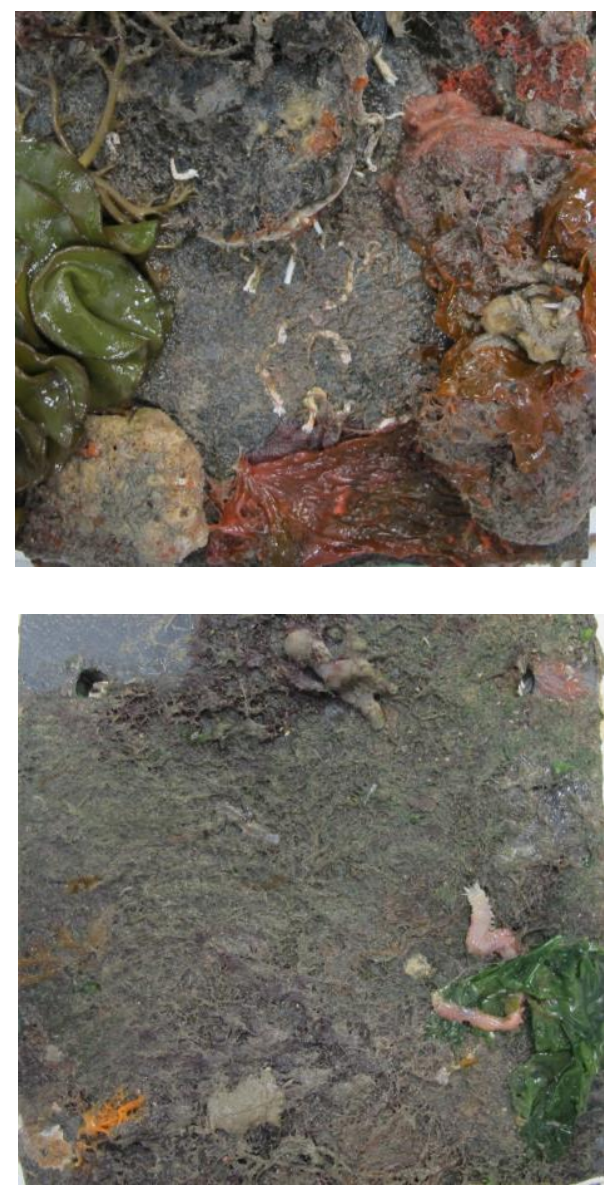

Slate

$1^{\text {st }}$ sampling interval (Nov 2017)

$8^{\text {th }}$ sampling interval (Aug 2019)

Figure 3.2.3. Representative PVC and slate tiles collected in the study, showing the community growth at first sampling interval (November 2017) and last sampling interval (August 2019) 


\subsection{Results}

\subsubsection{Diversity of the fouling community}

In total, 47 putative species were identified from 480 experimental tiles. The species were pooled to form 12 major groups; Annelida, Arthropoda, Biofilm, Bryozoa, Chlorophyta, Chordata, Echinodermata, Mollusca, Nemertea, Phaeophyta, Porifera and Rhodophyta (Table 3.3.1).

Table 3.3.1. List of species and major groups recorded at the 6 sampling sites for all 8-time periods in Wellington Harbour, with $S=$ total number of species richness on 480 settlement tiles and $\mathrm{N}=$ total number of individuals as represented by point counts.

\begin{tabular}{|c|c|c|c|c|c|c|c|c|c|}
\hline \multirow{3}{*}{\begin{tabular}{|c|} 
Habitat type \\
\\
Substratum \\
Species / Major group
\end{tabular}} & \multirow{3}{*}{$\begin{array}{l}\text { Species } \\
\text { Status }\end{array}$} & \multicolumn{4}{|c|}{ Reef } & \multicolumn{4}{|c|}{ Marina } \\
\hline & & \multicolumn{2}{|c|}{ PVC } & \multicolumn{2}{|c|}{ Slate } & \multicolumn{2}{|c|}{ PVC } & \multicolumn{2}{|c|}{ Slate } \\
\hline & & $\mathbf{S}$ & $\mathbf{N}$ & $\mathbf{S}$ & $\mathbf{N}$ & $\mathbf{S}$ & $\mathbf{N}$ & $\mathbf{S}$ & $\mathbf{N}$ \\
\hline \multicolumn{10}{|l|}{ Annelida } \\
\hline Galeolaria hystrix & Native & 7 & 14 & 11 & 14 & 7 & 16 & 6 & 20 \\
\hline Nereid sp. 1 & Cryptogenic & 3 & 3 & 10 & 15 & 3 & 5 & 0 & 0 \\
\hline Serpula vermicularis & Native & 0 & 0 & 0 & 0 & 5 & 10 & 41 & 90 \\
\hline Spirobranchus cariniferus & Native & 67 & 358 & 79 & 475 & 31 & 77 & 4 & 23 \\
\hline Spirorbis spirorbis & Native & 28 & 52 & 38 & 80 & 33 & 72 & 20 & 164 \\
\hline \multicolumn{10}{|l|}{ Arthropoda } \\
\hline Amphibalanus amphitrite & Non-native & 1 & 1 & 6 & 7 & 2 & 2 & 42 & 92 \\
\hline Amphipod sp. 1 & Cryptogenic & 3 & 5 & 3 & 3 & 0 & 0 & 0 & 0 \\
\hline Crab sp. 1 & Cryptogenic & 1 & 2 & 2 & 3 & 0 & 0 & 0 & 0 \\
\hline Elminius modestus & Non-native & 16 & 60 & 23 & 64 & 3 & 5 & 1 & 1 \\
\hline Isopod sp. 1 & Cryptogenic & 0 & 0 & 0 & 0 & 1 & 1 & 8 & 91 \\
\hline \multicolumn{10}{|l|}{ Biofilm } \\
\hline Biofilm type 1 & Cryptogenic & 96 & 2608 & 83 & 1543 & 99 & 2952 & 3 & 75 \\
\hline Biofilm type 2 & Cryptogenic & 6 & 263 & 12 & 517 & 9 & 102 & 0 & 0 \\
\hline \multicolumn{10}{|l|}{ Bryozoa } \\
\hline Bugula flabellata & Non-native & 17 & 247 & 13 & 126 & 27 & 132 & 0 & 0 \\
\hline Bugula neritina & Non-native & 0 & 0 & 0 & 0 & 4 & 205 & 30 & 466 \\
\hline Bugula stolonifera & Non-native & 14 & 164 & 9 & 85 & 21 & 171 & 46 & 239 \\
\hline Membranipora membranacea & Native & 60 & 803 & 57 & 718 & 33 & 153 & 17 & 111 \\
\hline Rhynchozoon larreyi & Native & 4 & 25 & 3 & 23 & 6 & 58 & 23 & 157 \\
\hline Schizoporella errata & Non-native & 17 & 58 & 15 & 65 & 12 & 84 & 44 & 183 \\
\hline Watersipora subtorquata & Non-native & 70 & 945 & 59 & 742 & 43 & 230 & 41 & 291 \\
\hline
\end{tabular}




\begin{tabular}{|c|c|c|c|c|c|c|c|c|c|}
\hline \multicolumn{10}{|l|}{ Chlorophyta } \\
\hline Codium fragile & Non-native & 3 & 47 & 1 & 7 & 0 & 0 & 4 & 16 \\
\hline Green sp. 1 & Cryptogenic & 68 & 1826 & 62 & 1426 & 61 & 1662 & 36 & 413 \\
\hline Ulva lactuca & Native & 11 & 119 & 8 & 53 & 16 & 111 & 2 & 61 \\
\hline Cladophora & Native & 26 & 196 & 22 & 129 & 43 & 613 & 9 & 17 \\
\hline Ulva sp. 1 & Cryptogenic & 4 & 7 & 10 & 58 & 10 & 94 & 28 & 138 \\
\hline \multicolumn{10}{|l|}{ Chordata } \\
\hline Aplidium stellatum & Native & 0 & 0 & 2 & 8 & 4 & 31 & 19 & 181 \\
\hline Asterocarpa humilis & Native & 31 & 313 & 45 & 1108 & 27 & 425 & 60 & 613 \\
\hline Botrylloides leachii & Non-native & 1 & 2 & 2 & 5 & 16 & 194 & 4 & 59 \\
\hline Corella eumyota & Native & 6 & 13 & 8 & 18 & 7 & 31 & 16 & 128 \\
\hline Tunicate sp. 1 & Cryptogenic & 20 & 195 & 20 & 255 & 37 & 340 & 3 & 3 \\
\hline Tunicate sp. 2 & Cryptogenic & 7 & 145 & 8 & 236 & 6 & 67 & 0 & 0 \\
\hline Tunicate sp. 3 & Cryptogenic & 0 & 0 & 1 & 7 & 0 & 0 & 0 & 0 \\
\hline \multicolumn{10}{|l|}{ Echinodermata } \\
\hline Patiriella regularis & Native & 0 & 0 & 1 & 1 & 0 & 0 & 35 & 391 \\
\hline \multicolumn{10}{|l|}{ Mollusca } \\
\hline Anomia trigonopsis & Native & 0 & 0 & 0 & 0 & 4 & 50 & 3 & 5 \\
\hline Mytilus galloprovincialis & Non-native & 5 & 15 & 3 & 19 & 1 & 2 & 0 & 0 \\
\hline Ostrea chilensis & Native & 12 & 83 & 25 & 166 & 40 & 429 & 11 & 25 \\
\hline Perna canaliculus & Native & 4 & 25 & 3 & 24 & 1 & 1 & 64 & 946 \\
\hline \multicolumn{10}{|l|}{ Nemertea } \\
\hline Nemertine sp. 1 & Cryptogenic & 3 & 3 & 10 & 20 & 2 & 12 & 9 & 15 \\
\hline \multicolumn{10}{|l|}{ Phaeophyta } \\
\hline Colpomenia peregrina & Non-native & 7 & 16 & 7 & 87 & 2 & 6 & 66 & 1400 \\
\hline Ralfsia verrucosa & Native & 91 & 1444 & 66 & 508 & 60 & 560 & 1 & 1 \\
\hline Undaria pinnatifida & Non-native & 1 & 6 & 6 & 118 & 3 & 46 & 56 & 800 \\
\hline \multicolumn{10}{|l|}{ Porifera } \\
\hline Clathrina sp. 1 & Cryptogenic & 24 & 382 & 29 & 355 & 21 & 197 & 0 & 0 \\
\hline Cliona sp. 1 & Cryptogenic & 1 & 1 & 2 & 10 & 1 & 1 & 67 & 799 \\
\hline \multicolumn{10}{|l|}{ Rhodophyta } \\
\hline Apophlaea lyallii & Native & 1 & 9 & 0 & 0 & 1 & 2 & 7 & 18 \\
\hline Bangia atropurpurea & Non-native & 39 & 345 & 34 & 315 & 73 & 1094 & 9 & 60 \\
\hline Coralline algae & Native & 13 & 41 & 11 & 24 & 21 & 138 & 0 & 0 \\
\hline Gigartina circumcincta & Native & 4 & 9 & 10 & 80 & 8 & 57 & 2 & 14 \\
\hline Rhodymenia dichotoma & Non-native & 0 & 0 & 2 & 7 & 0 & 0 & 0 & 0 \\
\hline
\end{tabular}




\subsubsection{Species accumulation}

Species accumulation curves across all 480 samples for the two-year study period indicated a rapid initial increase in species count and then stabilised (Figure 3.3.1). Species count estimators (Chao1, Jacknife1, Bootstrap) did not vary much from the observed species count (S $\mathrm{S}_{\text {obs}}$ ). Within the first 100 samples, the accumulation of new species had flattened off, such that $\geq 90 \%$ of all species had been recorded. However, the results indicated that approximately 400 samples were required to observe all the species sampled (i.e., to reach the asymptotic value of each curve at approx. 50 species). Overall, these results support the contention that the sampling effort was adequate and sufficient to reasonably represent the diversity of the fouling community in Wellington Harbour.

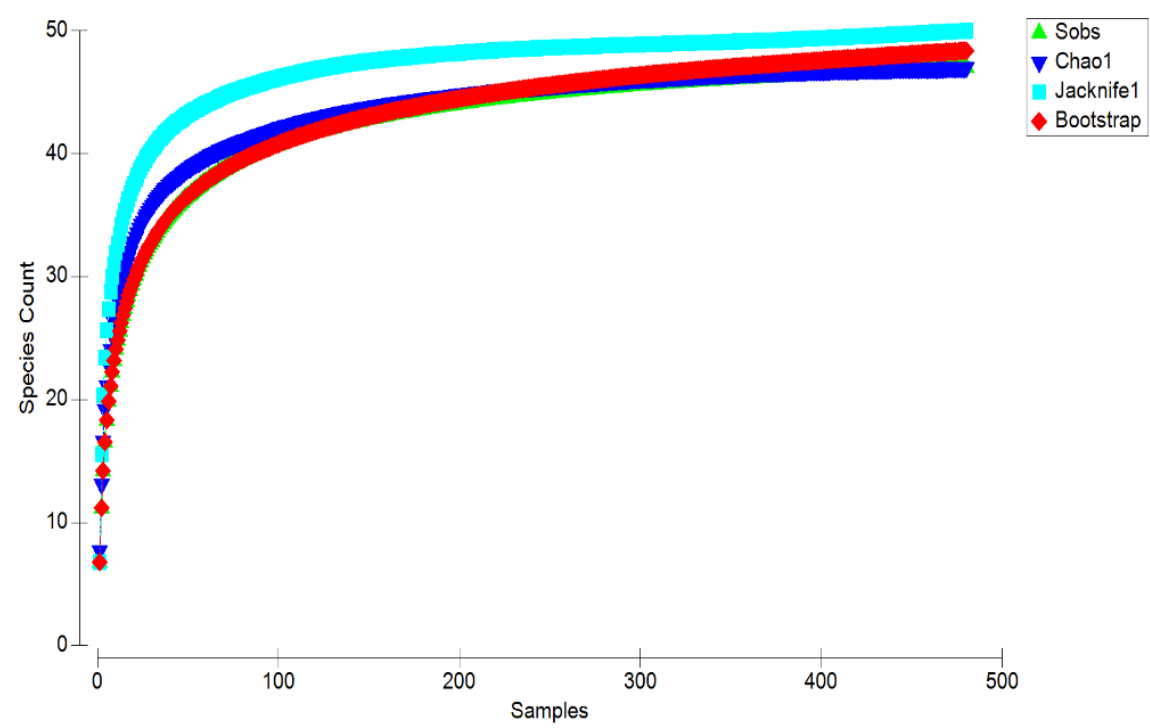

Figure 3.3.1. Species accumulation curves for observed species $\left(\mathrm{S}_{\mathrm{obs}}\right)$ and for nonparametric estimators of species count richness (Chao1, Jacknife1, Bootstrap).

\subsubsection{Bare space availability}

The multivariate PERMANOVA showed no significant differences in the availability of bare space considering the interaction of all factors; Habitat, Substratum and Time (Habitat $\times$ Substratum $\times$ Time; $P=0.48$ ). However, the bare space availability significantly differed with the Habitat $\times$ Time interaction $(P<0.05)$. The availability of bare space differed as a function of Habitat, Substratum and Time, respectively $(P<0.001)$ (Table 3.3.2).

Pairwise tests for main factors indicated significantly $(P<0.001)$ more available bare space at the marina (73.78\%) than reef habitats (72.48\%). In terms of substratum, Slate vs PVC indicated a significant difference with significantly $(P<0.001)$ more available bare space on the slate $(78.49 \%)$ than PVC $(72.15 \%)$ (Table 3.3.3). The factor, habitat $\times$ sample interval 
indicated significant results $(P<0.05)$ for sample interval 2, 3 and 7 (Table 3.3.3), with relatively higher bare space availability at reef sites for time 2 and 7, whilst the bare space availability was higher at marina sites for time 3.

Table 3.3.2. Results for PERMANOVA to determine the availability of bare space as a function of habitat, substratum and sample interval with their interactions.

\begin{tabular}{|l|c|c|c|c|c|}
\hline Source & df & \multicolumn{1}{|c|}{ SS } & MS & Pseudo- $\boldsymbol{F}$ & $P(\mathbf{p e r m})$ \\
\hline HABITAT $\times$ SUBSTRATUM $\times$ SAMPLE INTERVAL & & & \\
\hline Habitat & 1 & 8403.9 & 8403.9 & 20.168 & $\mathbf{0 . 0 0 0 1}$ \\
\hline Substratum & 1 & 34121 & 34121 & 81.885 & $\mathbf{0 . 0 0 0 1}$ \\
\hline Time & 7 & 9759.7 & 1394.2 & 3.3459 & $\mathbf{0 . 0 0 0 7}$ \\
\hline Habitat $\times$ Substratum & 1 & 312.97 & 312.97 & 0.75108 & 0.4094 \\
\hline Habitat $\times$ Sample interval & 7 & 8135.1 & 1162.2 & 2.789 & $\mathbf{0 . 0 0 3 7}$ \\
\hline Substratum $\times$ Sample interval & 7 & 2871.4 & 410.2 & 0.98441 & 0.4456 \\
\hline Habitat $\times$ Substratum $\times$ Sample interval & 7 & 2768.4 & 395.48 & 0.94909 & 0.4778 \\
\hline Residuals & 448 & $1.8668 E 5$ & 416.7 & & \\
\hline Total & 479 & $2.6641 \mathrm{E} 5$ & & & \\
\hline
\end{tabular}

Table 3.3.3. Results of pairwise PERMANOVA test for bare space as a function of habitat type, substratum type and habitat $\times$ sample interval. Significance marked in bold $(P<0.05)$.

\begin{tabular}{|c|c|c|c|c|c|}
\hline \multirow{2}{*}{ Groups } & $\mathbf{t}$ & $\boldsymbol{P}(\mathbf{p e r m})$ & \multicolumn{3}{|c|}{ Avg. similarities } \\
\hline Habitat (Reef vs Marina) & 4.49 & $\mathbf{0 . 0 0 0 1}$ & 72.48 & 73.78 & 72.10 \\
\hline Substratum (PVC vs Slate) & 9.05 & $\mathbf{0 . 0 0 0 1}$ & PVC & Slate & PVC $\times$ Slate \\
\hline Habitat $\times$ Sample interval & & & 72.15 & 78.49 & 69.91 \\
\hline Time 1 & & & Reef & Marina & Reef $\times$ Marina \\
\hline Time 2 & 1.666 & 0.084 & 69.55 & 72.43 & 67.99 \\
\hline Time 3 & 2.557 & $\mathbf{0 . 0 1 1}$ & 73.42 & 73.20 & 73.75 \\
\hline Time 4 & 4.058 & $\mathbf{0 . 0 0 1}$ & 72.54 & 74.03 & 58.99 \\
\hline Time 5 & 0.889 & 0.423 & 75.12 & 72.83 & 74.51 \\
\hline Time 6 & 0.924 & 0.385 & 80.88 & 73.11 & 76.70 \\
\hline Time 7 & 1.258 & 0.162 & 66.24 & 80.81 & 70.91 \\
\hline Time 8 & 2.602 & $\mathbf{0 . 0 0 7}$ & 78.10 & 77.39 & 73.30 \\
\hline & 0.793 & 0.483 & 79.72 & 74.78 & 77.23 \\
\hline
\end{tabular}


Figure 3.3.2 indicates the temporal variation in available bare space observed in this study. The tiles at the time of deployment (Time 0) were barren, i.e. 100\% bare space availability with nearly $64 \%$ bare space availability within 3 months. Settlement of species led to variations in bare space availability over time, indicating rapid settlement within 3 months (Time 1). Throughout the study, there was always $20 \%$ available bare space for settlement and species cover did not reach its limit ( $0 \%$ bare space). However, a clear trend of an increasing number of species indicated the variations in recruitment and settlement of fouling community over time, with rapid settlement within the first 3 months (Time 1) of deployment of the bare tiles (PVC and slate).

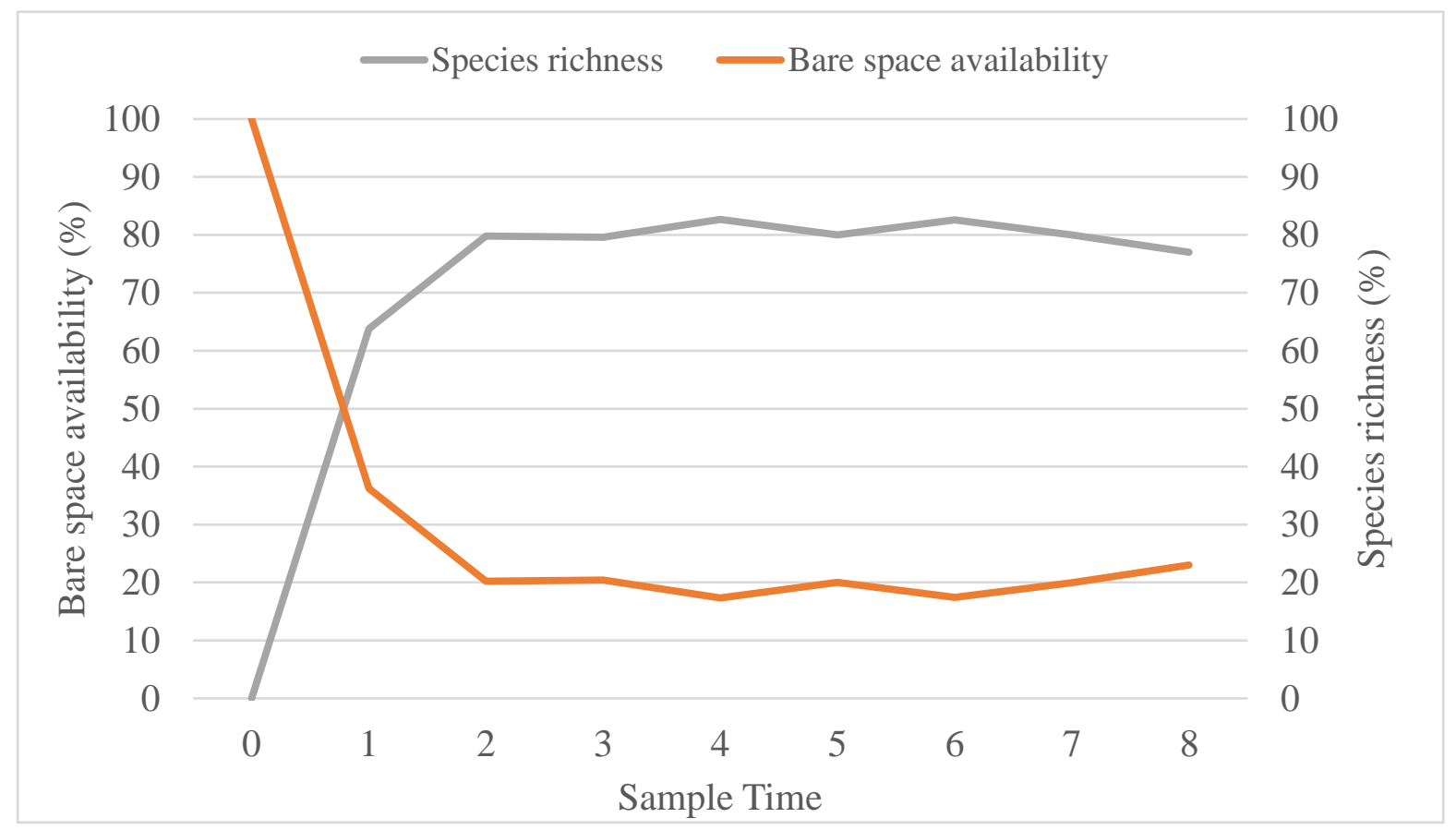

Figure 3.3.2. Temporal variation of average bare space availability (\%) and species richness (\%) by point counts (100-point grid) for the 2-year study (irrespective to habitat type and substratum type). 


\subsubsection{Fouling community ordination}

Two-dimensional MDS ordination plots to see if the communities varied as a function of habitat type, substratum and time showed a cluster of points in the centre with no distinct separation between habitat type, substratum and sampling time. However, the high-stress level of the plot (2D Stress: 0.28) indicated that the 2-D plot could not represent well the multidimensional nature of the data set (Figure 3.3.3 a, b \& c). Examination of the 3-D plot revealed a stress level of 0.20 , which is the generally accepted upper limit for such a plot (Clarke 1993). The 3-D plots based on habitat type (marina vs reef) and substratum type (PVC vs slate), showed evidence of segregation in the communities for each group, but both the groups clustered in the centre. In terms of sampling intervals, the communities showed some evidence of distinct clusters for each sampling interval, although there was still a level of cluster overlap (Figure 3.3.3 c).
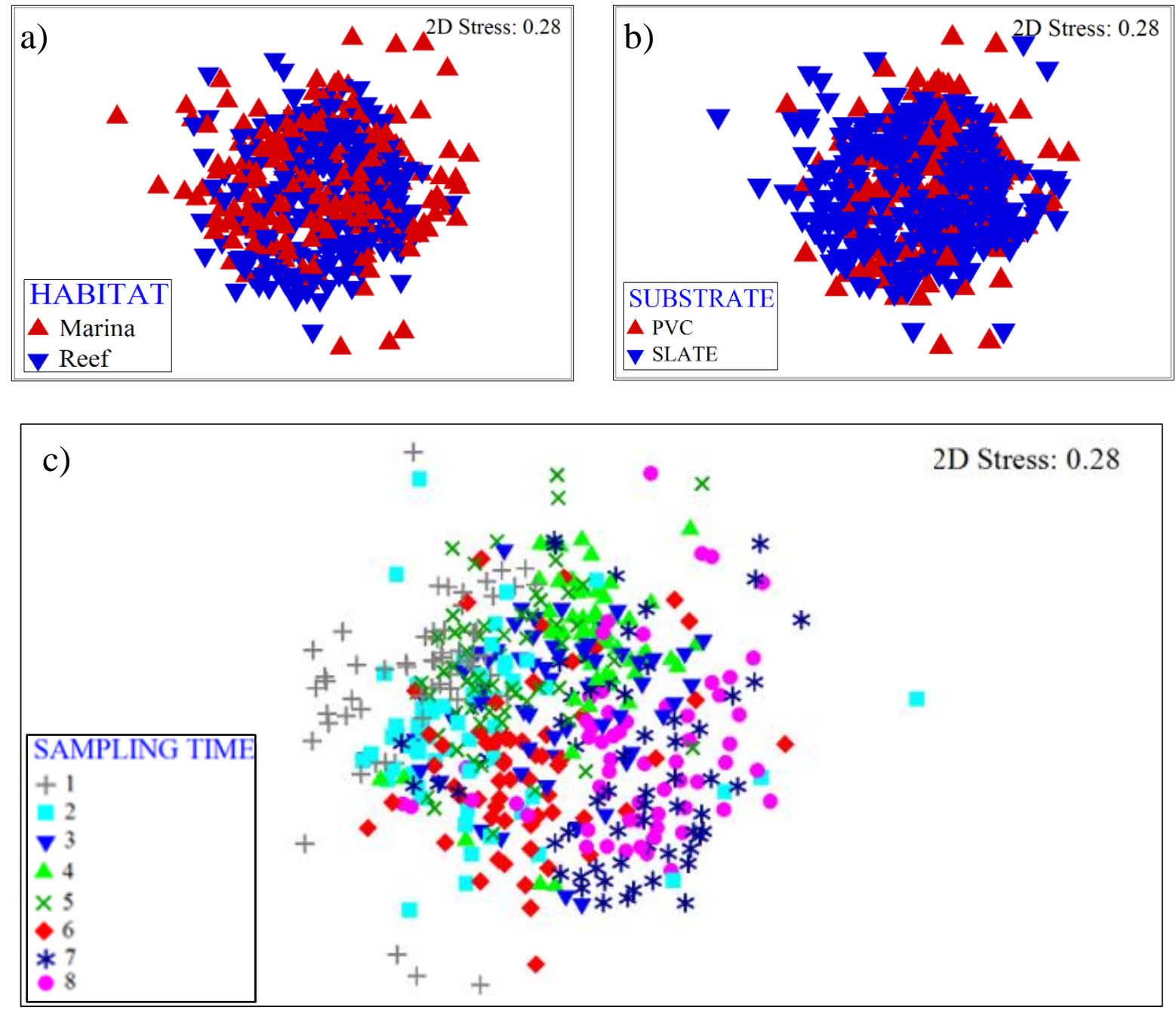

Figure 3.3.3. Two-dimensional MDS plot based on community composition between a) habitat type (marina and reef) b) substratum type (PVC and slate) and c) sampling interval (1-8). 
The dataset was averaged for each sampling interval (1-8), and substratum type (PVC and slate) for each study site. MDS plots were generated for each site (6 sites) to examine the change in community composition over time. The paired tiles (PVC and slate) for each sampling time tended to group (Figure 3.3.4) with the clear transitions between sampling times (time intervals 1-8), indicating that the fouling communities changed continuously between consecutive sampling times. As expected, all six site-specific plots showed a trajectory of change, from the initial colonisation community (sample interval 1) through to the final community (sample interval 8).
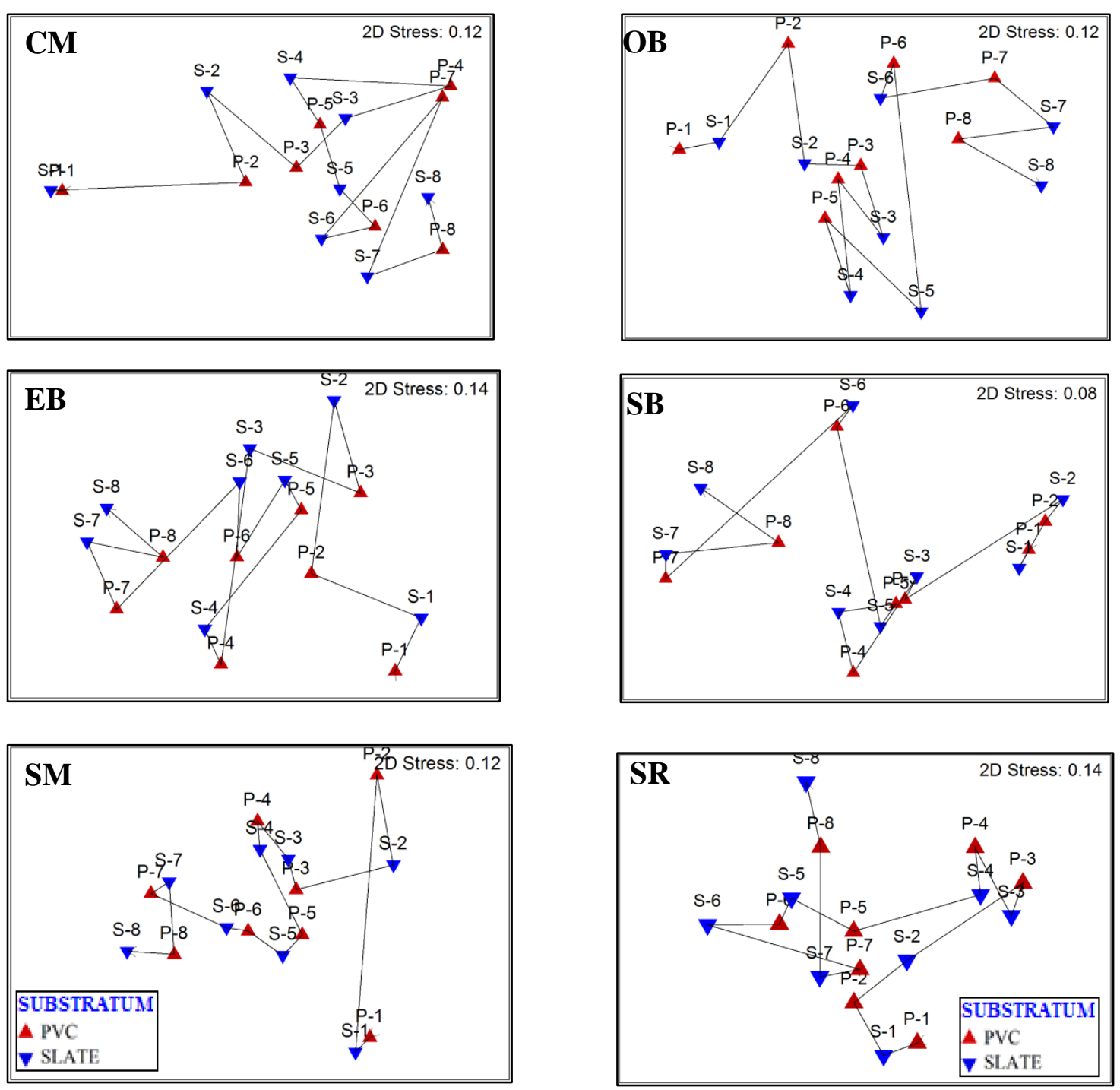

Figure 3.3.4. MDS ordination of temporal variation of the fouling community on three marina sites $(\mathrm{CM}=$ Chaffers marina, $\mathrm{EB}=$ Evans Bay marina, $\mathrm{SM}=$ Seaview marina $)$ and three reef sites $(\mathrm{OB}=$ Oriental Bay, $\mathrm{SB}=$ Shelly Bay, $\mathrm{SR}=$ Sorrento Bay). Sample labelling: $\mathrm{P}=\mathrm{PVC}$ substratum and $\mathrm{S}=$ Slate substratum; numbers denoted sampling intervals: 1= November 2017, 2= February 2018, 3= May 2018, 4= August 2018, 5= November 2018, 6= February 2018, 7= May 2018 and 8= August 2018. 
3.3.5. Variations in the fouling community composition as a function of habitat, site (habitat), substratum and sample intervals

Multivariate PERMANOVA of the fouling community composition revealed that all terms were statistically significant $(P<0.05)$ and that most were highly significant $(P<0.001)$ (Table 3.3.4).

Table 3.3.4. Permutational ANOVA (PERMANOVA) analysis used to determine differences in community composition between factors: habitat type (2 levels), site (habitat) (6 levels), substratum type (2 levels) and sampling intervals (8 levels), Significant value in bold $(P<$ $0.05)$.

\begin{tabular}{|l|c|c|c|c|c|}
\hline Source of variation & df & SS & MS & Pseudo-F & P (perm) \\
\hline Habitat & 1 & 53993 & 53993 & 37.112 & $\mathbf{0 . 0 0 0 1}$ \\
\hline Substratum & 1 & 25917 & 25917 & 17.814 & $\mathbf{0 . 0 0 0 1}$ \\
\hline Sample interval & 7 & $2.69 \mathrm{E}+05$ & 38385 & 26.384 & $\mathbf{0 . 0 0 0 1}$ \\
\hline Sites (Habitat) & 4 & $1.15 \mathrm{E}+05$ & 28668 & 19.705 & $\mathbf{0 . 0 0 0 1}$ \\
\hline Habitat $\times$ Substratum & 1 & 6990.7 & 6990.7 & 4.805 & $\mathbf{0 . 0 0 0 1}$ \\
\hline Habitat $\times$ Sample interval & 7 & 56417 & 8059.6 & 5.5397 & $\mathbf{0 . 0 0 0 1}$ \\
\hline Substratum $\times$ Sample interval & 7 & 22258 & 3179.7 & 2.1856 & $\mathbf{0 . 0 0 0 1}$ \\
\hline Sites (Habitat) $\times$ Substratum & 4 & 8925.2 & 2231.3 & 1.5337 & $\mathbf{0 . 0 1 7 3}$ \\
\hline Sites (Habitat) $\times$ Sample interval & 28 & $1.77 \mathrm{E}+05$ & 6331.1 & 4.3517 & $\mathbf{0 . 0 0 0 1}$ \\
\hline Habitat $\times$ Substratum $\times$ Sample interval & 7 & 17342 & 2477.4 & 1.7028 & $\mathbf{0 . 0 0 0 5}$ \\
\hline Sites $($ Habitat) $\times$ Substratum $\times$ Sample & 28 & 57669 & 2059.6 & 1.4157 & $\mathbf{0 . 0 0 0 1}$ \\
\hline interval & & & & & \\
\hline Residuals & 384 & $5.59 \mathrm{E}+05$ & 1454.9 & & \\
\hline Total & 479 & $1.37 \mathrm{E}+06$ & & & \\
\hline
\end{tabular}

\section{i. Habitat type}

The pairwise PERMANOVA revealed that the reef sites exhibited slightly more within-group community similarity $(29.35 \%)$ than the marina sites $(26.12 \%)$ and that this difference was significant $(P<0.001)$ (Table 3.3.5). At both the habitat types, the same suite of species was observed. However, the difference in abundances of species explained the dissimilarity between habitat type (Table 3.3.6 \& Table 3.3.7). For instance, overall, Biofilm type 1 and Green sp. 1 were the dominant contributors for average similarity and dissimilarity between habitat type. A subset of 7 species for marina and reef habitats explained most patterns of 
similarity and dissimilarity; Biofilm type 1, Green sp. 1, Ralfsia verrucosa, Bangia atropurpurea, Watersipora subtorquata, Asterocarpa humilis and Membranipora membranacea (Table 3.3.7).

\section{ii. Substratum type}

The pairwise PERMANOVA revealed that the PVC substratum exhibited more within-group community similarity (29.89\%) than the slate substratum (23.80\%) and that this difference was significant $(P<0.001)$ (Table 3.3.5). Similar to habitats, a similar suite of species was observed. However, the differences in abundances of species explained the dissimilarity between substratum type (Table 3.3.6 \& Table 3.3.7). Biofilm type 1 and Green sp. 1 were the main contributors among PVC vs slate substratum similarity and between PVC vs slate substratum dissimilarity. A subset of 7 species for PVC and slate substratum explained the most patterns of similarity and dissimilarity; Biofilm type 1, Green sp. 1, Ralfsia verrucosa, Bangia atropurpurea, Watersipora subtorquata, Asterocarpa humilis and Membranipora membranacea (Table 3.3.7).

Table 3.3.5. Results of pairwise PERMANOVA test performed on fouling communities as a function of habitat and substratum with the average similarities between groups.

\begin{tabular}{|l|c|c|c|c|c|c|}
\hline Groups & $\mathbf{t}$ & $\boldsymbol{P}($ perm) & Unique perms & \multicolumn{3}{|c|}{ Average similarity (\%) } \\
\hline Habitats & 6.09 & $\mathbf{0 . 0 0 0 1}$ & 9940 & Marina & Reef & Marina x Reef \\
Marina vs Reef & & & & $(26.12)$ & $(29.35)$ & $(24.55)$ \\
\hline Substratum & 4.22 & $\mathbf{0 . 0 0 0 1}$ & 9921 & PVC & Slate & PVC x Slate \\
PVC vs Slate & & & & $(29.89)$ & $(23.80)$ & $(25.43)$ \\
\hline
\end{tabular}


Table 3.3.6. SIMPER results for major species contributing to the average similarity between habitat type and substratum type.

Marina = Average similarity: 26.12

Reef = Average similarity: 29.35

\begin{tabular}{|c|c|c|c|c|c|c|c|}
\hline Species & Avg. Abund. & Contrib \% & Cum. \% & Species & Avg. Abund & Contrib\% & Cum.\% \\
\hline Biofilm type 1 & 2.93 & 27.33 & 27.33 & Biofilm type 1 & 3.11 & 27.49 & 27.49 \\
\hline Green sp. 1 & 2.27 & 17.55 & 44.88 & Ralfsia verrucosa & 2.04 & 16.23 & 43.71 \\
\hline Bangia atropurpurea & 1.88 & 14.19 & 59.07 & Green sp. 1 & 2.35 & 15.58 & 59.29 \\
\hline Ostrea chilensis & 1.27 & 6.63 & 65.7 & Watersipora subtorquata & 1.69 & 9.95 & 69.24 \\
\hline Ralfsia verrucosa & 1.01 & 5.11 & 70.81 & Spirobranchus cariniferus & 1.22 & 8.62 & 77.86 \\
\hline Tunicate sp. 1 & 1.05 & 4.97 & 75.78 & Membranipora membranacea & 1.39 & 6.79 & 84.65 \\
\hline Cladophora & 1 & 4.42 & 80.2 & Asterocarpa humilis & 1.16 & 4.11 & 88.77 \\
\hline Watersipora subtorquata & 0.68 & 3.2 & 83.41 & Bangia atropurpurea & 0.76 & 2.5 & 91.27 \\
\hline Membranipora membranacea & 0.64 & 2.77 & 86.17 & & & & \\
\hline Asterocarpa humilis & 0.8 & 2.45 & 88.63 & & & & \\
\hline Spirorbis spirorbis & 0.44 & 2.23 & 90.86 & & & & \\
\hline \multicolumn{4}{|c|}{ PVC = Average similarity: 29.89} & \multicolumn{4}{|c|}{ Slate $=$ Average similarity: 25.43} \\
\hline Species & Avg. Abund. & Contrib \% & Cum. \% & Species & Avg. Abund & Contrib\% & Cum.\% \\
\hline Biofilm type 1 & 3.87 & 37.78 & 37.78 & Biofilm type 1 & 2.17 & 20.02 & 20.02 \\
\hline Green sp. 1 & 2.44 & 15.63 & 53.41 & Green sp. 1 & 2.19 & 18.91 & 38.93 \\
\hline Ralfsia verrucosa & 1.98 & 13.58 & 66.99 & Ralfsia verrucosa & 1.07 & 7.32 & 46.25 \\
\hline Bangia atropurpurea & 1.44 & 7.19 & 74.18 & Bangia atropurpurea & 1.2 & 7.16 & 53.41 \\
\hline Watersipora subtorquata & 1.29 & 6.13 & 80.31 & Spirobranchus cariniferus & 0.91 & 6.9 & 60.31 \\
\hline Membranipora membranacea & 0.99 & 3.67 & 83.98 & Watersipora subtorquata & 1.09 & 6.32 & 66.63 \\
\hline Spirobranchus cariniferus & 0.73 & 3.25 & 87.23 & Membranipora membranacea & 1.05 & 6.01 & 72.65 \\
\hline Cladophora & 0.84 & 2.76 & 89.99 & Asterocarpa humilis & 1.21 & 5.52 & 78.16 \\
\hline \multirow[t]{3}{*}{ Asterocarpa humilis } & 0.75 & 1.91 & 91.90 & Ostrea chilensis & 1.05 & 5.27 & 83.44 \\
\hline & & & & Tunicate sp. 1 & 0.94 & 4.26 & 87.69 \\
\hline & & & & Spirorbis spirorbis & 0.46 & 2.97 & 90.66 \\
\hline
\end{tabular}


Table 3.3.7. Results for SIMPER analysis. Average similarities within groups and average dissimilarities in fouling communities between habitat type and substratum type.

\begin{tabular}{|c|c|c|c|c|c|c|c|c|}
\hline \multirow[b]{2}{*}{ Species } & \multicolumn{4}{|c|}{ Marina $\&$ Reef $=$ Average dissimilarity $=\mathbf{7 4 . 4 5}$} & \multicolumn{4}{|c|}{ PVC \& Slate $=$ Average dissimilarity $=74.57$} \\
\hline & $\begin{array}{c}\text { Marina } \\
\text { Avg. Abund. }\end{array}$ & $\begin{array}{c}\text { Reef } \\
\text { Avg. Abund. }\end{array}$ & Contrib \% & Cum. \% & $\begin{array}{c}\text { PVC } \\
\text { Avg. Abund. }\end{array}$ & $\begin{array}{c}\text { Slate } \\
\text { Avg. Abund. }\end{array}$ & Contrib \% & Cum. \% \\
\hline Biofilm type 1 & 2.93 & 3.11 & 11.16 & 11.16 & 3.87 & 2.17 & 11.96 & 11.96 \\
\hline Green sp. 1 & 2.27 & 2.35 & 10.68 & 21.84 & 2.44 & 2.19 & 10.82 & 22.79 \\
\hline Ralfsia verrucosa & 1.01 & 2.04 & 7.25 & 29.09 & 1.98 & 1.07 & 7.15 & 29.94 \\
\hline Bangia atropurpurea & 1.88 & 0.76 & 6.83 & 35.92 & 1.44 & 1.2 & 6.57 & 36.51 \\
\hline Watersipora subtorquata & 0.68 & 1.69 & 6.01 & 41.93 & 1.29 & 1.09 & 5.77 & 42.28 \\
\hline Asterocarpa humilis & 0.8 & 1.16 & 5.61 & 47.54 & 0.75 & 1.21 & 5.65 & 47.93 \\
\hline Membranipora membranacea & 0.64 & 1.39 & 5.38 & 52.93 & 0.99 & 1.05 & 5.28 & 53.21 \\
\hline Ostrea chilensis & 1.27 & 0.37 & 4.72 & 57.64 & 0.59 & 1.05 & 4.59 & 57.8 \\
\hline Cladophora & 1 & 0.46 & 4.39 & 62.03 & 0.84 & 0.62 & 4.4 & 62.2 \\
\hline Tunicate sp. 1 & 1.05 & 0.5 & 4.33 & 66.37 & 0.61 & 0.94 & 4.29 & 66.49 \\
\hline Spirobranchus cariniferus & 0.42 & 1.22 & 4.19 & 70.55 & 0.73 & 0.91 & 3.93 & 70.42 \\
\hline Clathrina sp. & 0.45 & 0.69 & 3.42 & 73.97 & 0.59 & 0.56 & 3.44 & 73.85 \\
\hline Bugula stolonifera & 0.62 & 0.25 & 2.75 & 76.72 & 0.38 & 0.49 & 2.74 & 76.59 \\
\hline Bugula flabellata & 0.44 & 0.35 & 2.35 & 79.07 & 0.43 & 0.36 & 2.37 & 78.95 \\
\hline Spirorbis spirorbis & 0.44 & 0.36 & 2.16 & 81.23 & 0.34 & 0.46 & 2.19 & 81.15 \\
\hline Biofilm type 2 & 0.15 & 0.47 & 2.14 & 83.37 & 0.26 & 0.36 & 2.13 & 83.28 \\
\hline Coralline algae & 0.41 & 0.15 & 1.74 & 85.11 & 0.28 & 0.27 & 1.74 & 85.02 \\
\hline Ulva lactuca & 0.35 & 0.19 & 1.69 & 86.8 & 0.25 & 0.29 & 1.7 & 86.72 \\
\hline Schizoporella errata & 0.27 & 0.24 & 1.49 & 88.29 & 0.24 & 0.27 & 1.5 & 88.22 \\
\hline Tunicate sp. 2 & 0.18 & 0.28 & 1.42 & 89.71 & 0.19 & 0.26 & 1.43 & 89.65 \\
\hline Botrylloides leachii & 0.35 & 0.02 & 1.15 & 90.86 & 0.2 & 0.17 & 1.14 & 90.79 \\
\hline
\end{tabular}




\section{iii. Habitat $\times$ Substratum}

Fouling community composition as a function of habitat and substratum $(P<0.001)$ exhibited relatively more within-group similarity on PVC than on slate at both marina and reef habitats (pairwise PERMANOVA tests; Table 3.3.8).

Table 3.3.8. Results of pairwise PERMANOVA test performed on fouling communities as a function of the interaction between habitat $\times$ substratum with the average similarities between groups.

\begin{tabular}{|l|c|c|c|c|c|c|}
\hline Groups & t & \multicolumn{1}{|c|}{$\boldsymbol{P}$ (perm) } & Unique perms & \multicolumn{3}{|c|}{ Average similarity (\%) } \\
\hline Habitat x Substratum & \multicolumn{7}{|c|}{} & & & \\
\hline Marina & 3.65 & $\mathbf{0 . 0 0 0 1}$ & 9930 & PVC & Slate & PVC x Slate \\
PVC vs Slate & & & & $(30.04)$ & $(24.49)$ & $(24.99)$ \\
\hline $\begin{array}{l}\text { Reef } \\
\text { PVC vs Slate }\end{array}$ & 2.97 & $\mathbf{0 . 0 0 0 1}$ & 9953 & PVC & Slate & PVC x Slate \\
\hline
\end{tabular}

In summary, the fouling community composition as a function of habitat and substratum and their interactions indicated statistically significant results (PERMANOVA; $P$ $<$ 0.001). Pairwise PERMANOVA indicated relatively more within-group community similarity at reef sites than at marina sites and on PVC substratum than on slate substratum. However, when comparing the fouling community composition between substrata at each habitat, PVC substratum had more within-group similarity than that on slate substratum at both reef and marina habitats. SIMPER results also revealed a similar suite of 2 species contributing to $>50 \%$ within-group similarity and 7 species $>50 \%$ between-group dissimilarity [Habitat (Marina vs Reef); Substratum (PVC vs Slate)] in the relative abundance of the community.

\section{iv. Sample interval}

The fouling community composition differed significantly between sample intervals $(P<$ 0.001). As expected, Time 1 (41.19\%) had relatively fewer species contributing to its withingroup similarity, with an increase in fouling community species diversity over time resulting in a decrease in within-group similarity over time (Table 3.3.9). However, most of the betweengroup community dissimilarity was explained by the slight differences in abundances of the observed species.

SIMPER analysis showed that Biofilm type 1 and Green sp. 1 were the first recruits that appeared on the tiles (they were present within 3 months, by Time 1) suggesting these two 
species to be opportunistic species which rapidly dominated much of the available bare space. Biofilm type 1 and Green sp. 1 also consistently contributed the most to the within-group community similarity and between-group community dissimilarities for all sample intervals. Biofilm type 1 increased with time (Time 1; Biofilm type $1=29.97 \%$ ) and was the highest at Time $4(60.08 \%)$ and decreased thereafter, suggesting Biofilm type 1 may be an ephemeral species, i.e. short-lived species. Additionally, Green sp. 1 showed a bimodal trend, with a decrease at Time 4, which marks the austral winter, suggesting that abundance of Green sp. 1 may be seasonally dependent (Figure 3.3.5). As observed, the dominance of Biofilm type 1 and Green sp. 1 changed over time and was replaced by the dominance of the red alga, Bangia atropurpurea at Time 8, i.e. the end of the 2-year study. Other contributors to top-ranked abundance included Asterocarpa humilis, Membranipora membranacea, Ostrea chilensis, Ralfsia verrucosa and Watersipora subtorquata. Increase in the abundance of these aforementioned species was gradual with no interaction observed between these species, suggesting varied patterns of succession for each species (Table 3.3.9).

The interaction factor, Habitat $\times$ Sample interval, the community composition indicated significant $(P<0.005)$ results between habitat type (marina vs reef) for all sampling intervals. The community composition for the interaction factor Substratum $\times$ Sample interval showed significant results $(P<0.05)$ each sample interval except for time $1(P=0.54)$ (Table A4). When comparing the temporal variation of the top 8 species between habitat type and substratum type (SIMPER, Figure 3.3.5), the species showed a similar overall trend of percentage cover. The species between habitat type (marina vs reef) indicated a relatively high abundance of; native tunicate Asterocarpa humilis, cryptogenic Biofilm type 1, native bryozoan Membranipora membranacea, native crustose brown seaweed Ralfsia verrucosa and non-native bryozoa Watersipora subtorquata in reef habitat than at marina habitat. Whilst, nonnative red alga Bangia atropurpurea, native oyster Ostrea chilensis, cryptogenic Tunicate sp. 1 and cryptogenic Ulva sp. 1 had relatively high abundances at marina habitat than at reef habitat. 
Table 3.3.9. SIMPER results for 10 major consistent species contributing to the average similarity within each sampling interval. $\mathrm{A}=\mathrm{Avg}$. Abundance, $\mathrm{C} \%=$ Per cent Contribution.

\begin{tabular}{|c|c|c|c|c|c|c|c|c|c|c|c|c|c|c|c|c|}
\hline & \multicolumn{2}{|c|}{ Time 1} & \multicolumn{2}{|c|}{ Time 2} & \multicolumn{2}{|c|}{ Time 3} & \multicolumn{2}{|c|}{ Time 4} & \multicolumn{2}{|c|}{ Time 5} & \multicolumn{2}{|c|}{ Time 6} & \multicolumn{2}{|c|}{ Time 7} & \multicolumn{2}{|c|}{ Time 8} \\
\hline Avg. similarity & & $9 \%$ & & & & & & $8 \%$ & & & & $9 \%$ & & & & \\
\hline Species & $\mathbf{A}$ & $\mathrm{C} \%$ & $\mathbf{A}$ & $\mathrm{C} \%$ & $\mathbf{A}$ & $\mathrm{C} \%$ & $\mathbf{A}$ & $\mathrm{C} \%$ & $\mathbf{A}$ & $\mathrm{C} \%$ & $\mathbf{A}$ & $\mathrm{C} \%$ & $\mathbf{A}$ & $\mathrm{C} \%$ & $\mathbf{A}$ & $\mathrm{C} \%$ \\
\hline Asterocarpa humilis & 0.23 & 0.49 & 0.52 & 0.74 & 1.26 & 4.21 & 1.4 & 3.78 & 1.25 & 4.3 & 0.91 & 2.77 & 0.77 & 2.14 & 1.51 & 5.57 \\
\hline Bangia atropurpurea & 0.1 & 0.06 & 0.45 & 0.54 & 1.00 & 4.82 & 1.53 & 7.11 & 0.83 & 2.29 & 1.42 & 7.19 & 2.22 & 18.42 & 3.02 & 29.9 \\
\hline Biofilm type 1 & 3.34 & 29.97 & 2.04 & 13.3 & 3.77 & 35.47 & 6.13 & 60.08 & 4.09 & 41.11 & 1.97 & 14.63 & 1.68 & 7.54 & 1.15 & 4.37 \\
\hline Green sp. 1 & 3.84 & 44.23 & 4.76 & 43.96 & 1.86 & 8.96 & 0.37 & 0.24 & 3.55 & 27.14 & 2.83 & 21.64 & 0.72 & 1.28 & 0.59 & 0.79 \\
\hline Membranipora membranacea & 0.34 & 0.78 & 0.59 & 1.23 & 1.37 & 4.37 & 1.12 & 5.23 & 1.1 & 2.87 & 0.84 & 3.27 & 1.59 & 11.95 & 1.21 & 5.92 \\
\hline Ostrea chilensis & - & - & 0.12 & 0.11 & 0.77 & 2.4 & 0.83 & 2.73 & 1.07 & 3.36 & 0.9 & 2.26 & 1.32 & 7.39 & 1.52 & 7.89 \\
\hline Ralfsia verrucosa & 0.77 & 2.41 & 2.62 & 22.37 & 1.65 & 11.66 & 0.69 & 1.75 & 0.68 & 2.14 & 1.88 & 10.8 & 1.96 & 13.92 & 1.94 & 13.65 \\
\hline Watersipora subtorquata & 0.09 & 0.11 & 0.99 & 4.08 & 1.75 & 8.92 & 1.09 & 3.67 & 0.92 & 3.3 & 1.49 & 8.46 & 1.7 & 11.91 & 1.46 & 7.47 \\
\hline
\end{tabular}




\section{a) Man-made habitat}

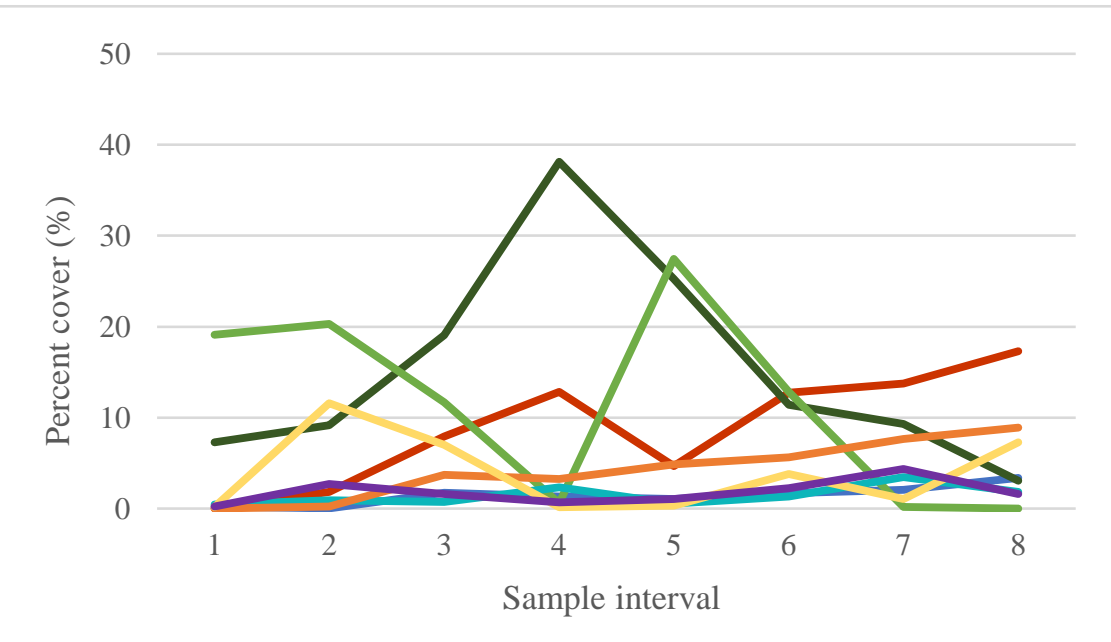

c) Man-made substratum

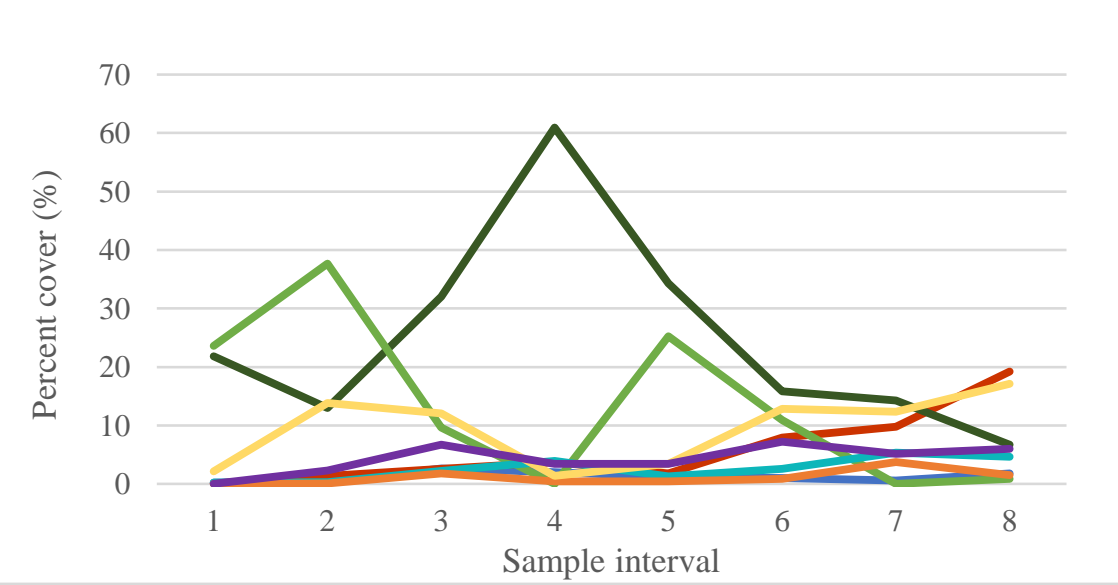

b) Natural habitat

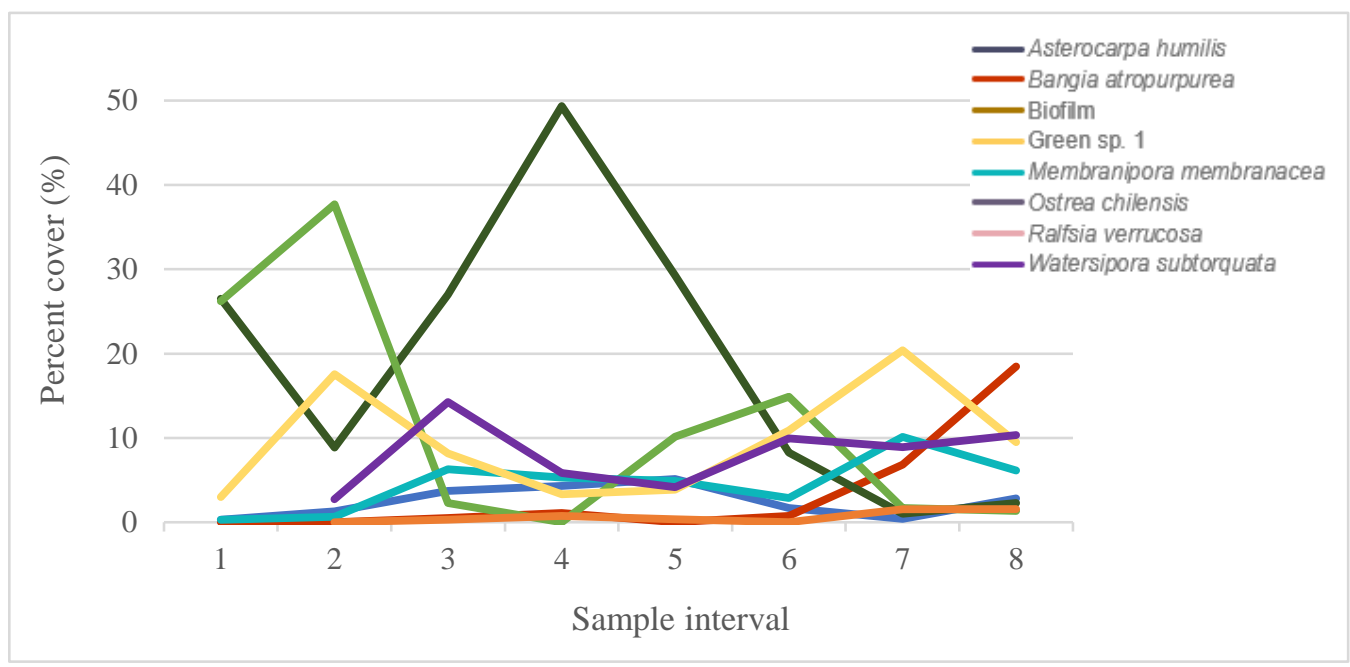

\section{d) Natural substratum}

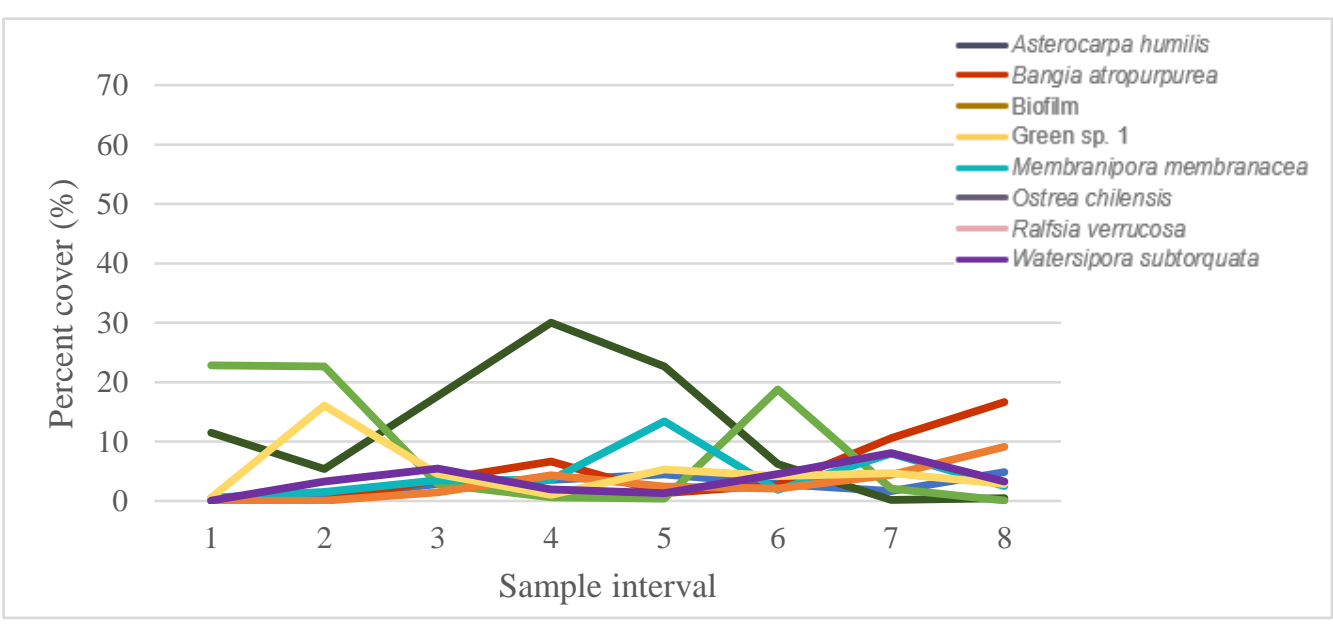

Figure 3.3.5. The percent cover (SIMPER) of top 8 major consistent species contributing to within-group similarity for each sample interval indicating variations over time at a) man-made habitat b) natural habitat c) man-made substratum and d) natural substratum 


\subsubsection{Species status (native, non-native and cryptogenic) within the fouling community}

\section{a) Species status and their occurrences}

The 47 putative species were classed according to their status as native, non-native and cryptogenic. There were 19 native species, 12 non-natives and 16 cryptogenic species (Table 3.3.1).

\section{b) Species status as a function of habitat, site, substratum and sample interval}

Multivariate PERMANOVA for the species status revealed that all main factors were statistically significant $(P<0.001)$, with significant interaction between Habitat $\times$ Sample interval and Site (Habitat) $\times$ Sample interval $(P<0.001)$, indicating variations in the species status between habitat type/site (habitat) over time. Other interaction terms were not significant (Table 3.3.10).

Table 3.3.10. Permutational ANOVA (PERMANOVA) analysis used to determine differences in the status of the species between factors: habitat type (2 levels), site (habitat) (6 levels), substratum type (2 levels) and sampling time ( 8 levels), Significant value in bold $(P<0.05)$.

\begin{tabular}{|l|c|c|c|c|c|c|}
\hline Source & df & SS & MS & Pseudo- & $\begin{array}{r}\text { Unique } \\
(\mathbf{p e r m})\end{array}$ & \begin{tabular}{c} 
perms \\
\hline Habitat
\end{tabular} \\
\hline Substratum & 1 & 2759.6 & 2759.6 & 8.1738 & $\mathbf{0 . 0 0 0 3}$ & 9966 \\
\hline Time & 1 & 4920 & 4920 & 14.573 & $\mathbf{0 . 0 0 0 1}$ & 9961 \\
\hline Site $($ Habitat) & 7 & 43896 & 6270.9 & 18.574 & $\mathbf{0 . 0 0 0 1}$ & 9914 \\
\hline Habitat $\times$ Substratum & 4 & 20889 & 5222.2 & 15.468 & $\mathbf{0 . 0 0 0 1}$ & 9942 \\
\hline Habitat $\times$ Time & 1 & 807.32 & 807.32 & 2.3913 & 0.0911 & 9952 \\
\hline Substratum $\times$ Time & 7 & 19211 & 2744.5 & 8.1291 & $\mathbf{0 . 0 0 0 1}$ & 9913 \\
\hline Site $($ Habitat) $\times$ Substratum & 7 & 4158.6 & 594.08 & 1.7597 & $\mathbf{0 . 0 4}$ & 9918 \\
\hline Site $($ Habitat) $\times$ Time & 4 & 2302.6 & 575.65 & 1.7051 & 0.089 & 9931 \\
\hline Habitat $\times$ Substratum $\times$ Time & 28 & 53135 & 1897.7 & 5.6208 & $\mathbf{0 . 0 0 0 1}$ & 9871 \\
\hline Site $($ Habitat) $\times$ Substratum $\times$ Time & 28 & 11276 & 402.72 & 1.1928 & 0.164 & 9828 \\
\hline Residuals & 384 & $1.30 \mathrm{E}+05$ & 337.61 & & & \\
\hline Total & 479 & $2.95 \mathrm{E}+05$ & & & & \\
\hline
\end{tabular}




\section{i. Habitat type}

Numbers of occurrences as a function of the status of the species - native, non-native and cryptogenic- were similar as a function of time at reef and marina habitats (Figure 3.3.6). However, PERMANOVA revealed a significant difference $(P<0.001)$ between the reef and marina habitats, but the within-group similarity was very similar $($ Reef $=70.09 \%$; Marina $=$ 69.01\%; Table 3.3.11). SIMPER analysis further revealed that the cryptogenic species contributed most to similarity at both reef (47.44\%) and marina sites $(47.33 \%)$ followed by native species $($ Reef $=37.15 \%$; Marina $=31.70 \%)$. The non-native species were abundant significantly $(P<0.05$; Table 3.3 .12$)$ at marina sites $(20.97 \%)$ than reef sites $(15.41 \%)$. The cryptogenic species contributed most to the between-group dissimilarity (Table 3.3.13 a).

a) Reef habitat

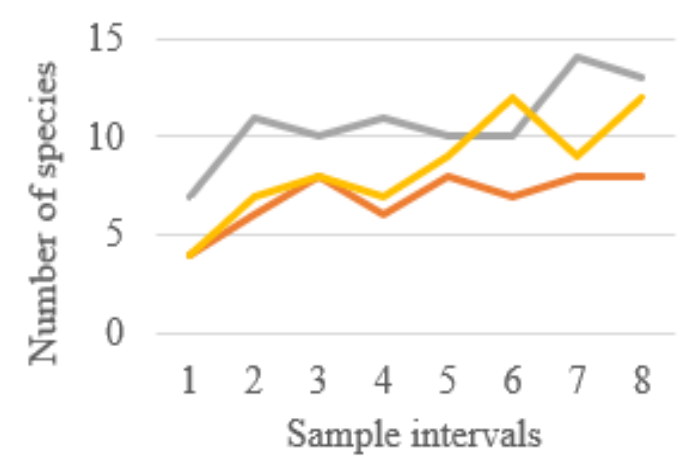

b) Marina habitat

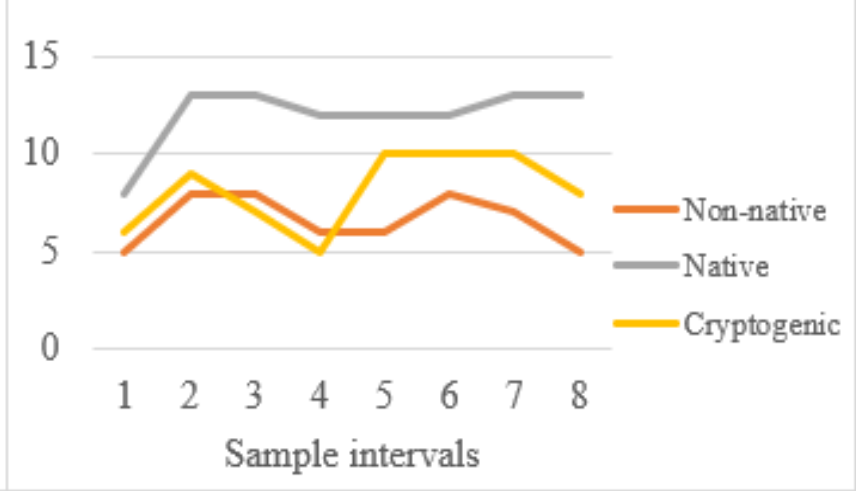

Figure 3.3.6. Temporal change in the number of species with respect to species status (native, nonnative and cryptogenic) as a function of habitat type (Reef vs Marina)

Table 3.3.11. Results of pairwise PERMANOVA test performed on species status as a function of habitat type and substratum type with the average similarities between groups.

\begin{tabular}{|c|c|c|c|c|c|}
\hline \multirow[t]{2}{*}{ Groups } & \multirow[t]{2}{*}{$\mathbf{t}$} & \multirow[t]{2}{*}{$P($ perm $)$} & \multicolumn{3}{|c|}{ Avg. similarities } \\
\hline & & & Reef & Marina & Reef $\times$ Marina \\
\hline $\begin{array}{l}\text { Habitat } \\
\text { (Reef vs Marina) }\end{array}$ & 2.88 & 0.0004 & 70.09 & 69.01 & 69.29 \\
\hline Substratum & 3.83 & 0.0001 & PVC & Slate & PVC $\times$ Slate \\
\hline (PVC vs Slate) & & & 71.53 & 67.86 & 69.14 \\
\hline
\end{tabular}


Table 3.3.12. Results of pairwise PERMANOVA test performed for non-native species as a function of habitat type and substratum type.

\begin{tabular}{|c|c|c|c|}
\hline Groups & $\mathbf{t}$ & $\boldsymbol{P}($ perm) & Unique perms \\
\hline $\begin{array}{c}\text { Habitat } \\
\text { (Reef vs Marina) }\end{array}$ & 1.53 & $\mathbf{0 . 0 3}$ & 9923 \\
\hline $\begin{array}{c}\text { Substratum } \\
\text { (PVC vs Slate) }\end{array}$ & 0.88 & 0.56 & 9924 \\
\hline
\end{tabular}

\section{ii. Substratum type}

The number of native, non-native and cryptogenic species as a function of time on PVC and slate substrata were similar (Figure 3.3.7). However, PERMANOVA revealed a significant difference $(P<0.001)$ between PVC and slate substrata, with PVC exhibiting greater withingroup similarity (71.53\%) than the slate substratum (67.86\%) (Table 3.3.11). SIMPER analyses revealed that cryptogenic species followed by native species contributed most to the withingroup similarities and between-group dissimilarities for both substrata. (Table 3.3.13 b). The non-native species observed to contribute more on slate substratum than PVC; however, their difference was not significant (Table 3.3.12).
a) Slate substratum
b) PVC substratum
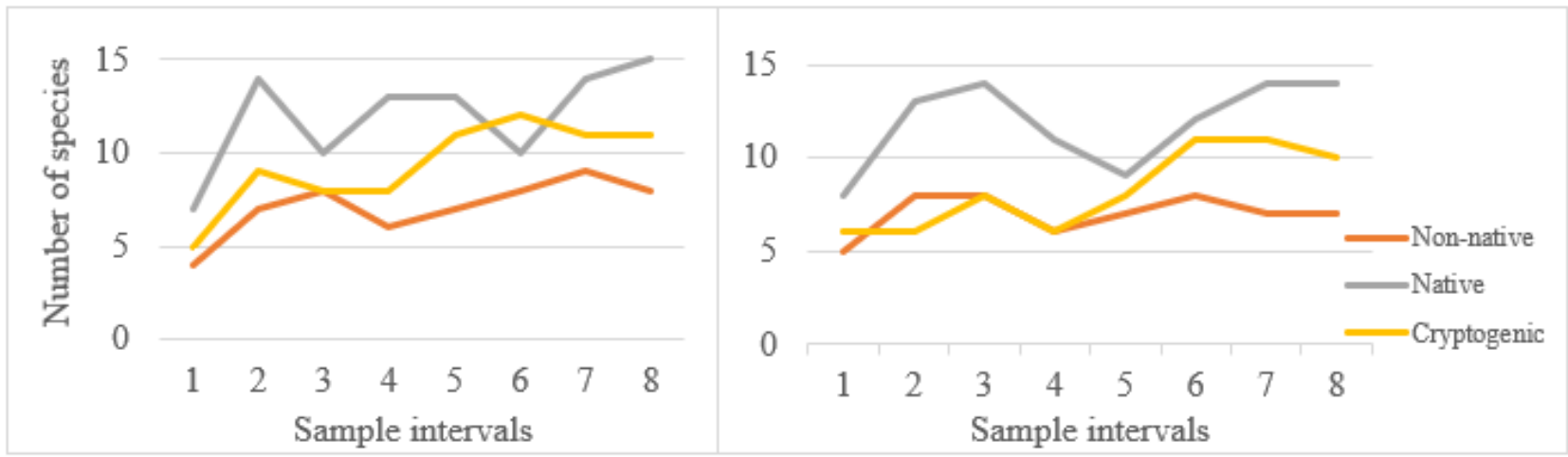

Figure 3.3.7. Temporal change in the number of species with respect to species status (native, nonnative and cryptogenic) as a function of substratum type (PVC vs Slate) 
Table 3.3.13. SIMPER results for species status contributing to the average within-group similarity and dissimilarity between a) habitat type (Reef vs Marina and b) substratum type (PVC vs Slate).

\begin{tabular}{|c|c|c|c|c|c|c|c|c|c|c|c|c|}
\hline \multicolumn{4}{|c|}{ Marina: Average similarity $=69.01 \%$} & \multicolumn{4}{|c|}{ Reef: Average similarity $=\mathbf{7 0 . 0 9 \%}$} & \multicolumn{5}{|c|}{$\begin{array}{c}\text { Habitat (Marina vs Reef) } \\
\text { Average dissimilarity }=\mathbf{3 0 . 7 1 \%}\end{array}$} \\
\hline $\begin{array}{l}\text { Species } \\
\text { Status }\end{array}$ & $\begin{array}{l}\text { Avg. } \\
\text { Abund. }\end{array}$ & $\begin{array}{c}\text { Contrib } \\
\%\end{array}$ & $\underset{\%}{\text { Cum. }}$ & $\begin{array}{l}\text { Species } \\
\text { Status }\end{array}$ & $\begin{array}{l}\text { Avg. } \\
\text { Abund. }\end{array}$ & $\begin{array}{c}\text { Contrib } \\
\%\end{array}$ & Cum.\% & $\begin{array}{l}\text { Species } \\
\text { Status }\end{array}$ & $\begin{array}{c}\text { Avg. } \\
\text { Abund. } \\
\text { Marina }\end{array}$ & $\begin{array}{l}\text { Avg. } \\
\text { Abund. } \\
\text { Reef }\end{array}$ & $\begin{array}{c}\text { Contrib } \\
\%\end{array}$ & $\underset{\%}{\operatorname{Cum} .}$ \\
\hline Cryptogenic & 5.69 & 62.09 & 62.09 & Cryptogenic & 5.96 & 76.27 & 76.27 & Cryptogenic & 5.69 & 5.96 & 34.50 & 34.50 \\
\hline Native & 4.27 & 29.64 & 91.73 & Native & 4.87 & 20.65 & 96.92 & Native & 4.27 & 4.87 & 32.91 & 67.40 \\
\hline Non-native & 3.28 & 8.27 & 100 & Non-native & 2.95 & 3.08 & 100 & Non-native & 3.28 & 2.95 & 32.60 & 100 \\
\hline
\end{tabular}

b)

\begin{tabular}{|c|c|c|c|c|c|c|c|c|c|c|c|c|}
\hline \multicolumn{4}{|c|}{ PVC: Average similarity $=\mathbf{7 1 . 5 3 \%}$} & \multicolumn{4}{|c|}{ Slate: Average similarity $=67.86 \%$} & \multicolumn{5}{|c|}{$\begin{array}{c}\text { Substratum (PVC vs Slate) } \\
\text { Average dissimilarity }=\mathbf{3 0 . 8 6 \%}\end{array}$} \\
\hline $\begin{array}{l}\text { Species } \\
\text { Status }\end{array}$ & $\begin{array}{l}\text { Avg. } \\
\text { Abund. }\end{array}$ & $\begin{array}{c}\text { Contrib } \\
\%\end{array}$ & $\underset{\%}{\text { Cum. }}$ & $\begin{array}{l}\text { Species } \\
\text { Status }\end{array}$ & $\begin{array}{l}\text { Avg. } \\
\text { Abund. }\end{array}$ & $\begin{array}{c}\text { Contrib } \\
\%\end{array}$ & $\underset{\%}{\operatorname{Cum} .}$ & $\begin{array}{l}\text { Species } \\
\text { Status }\end{array}$ & $\begin{array}{c}\text { Avg. } \\
\text { Abund. } \\
\text { Slate }\end{array}$ & $\begin{array}{c}\text { Avg. } \\
\text { Abund. } \\
\text { PVC }\end{array}$ & $\begin{array}{c}\text { Contrib } \\
\%\end{array}$ & $\begin{array}{c}\text { Cum. } \\
\%\end{array}$ \\
\hline Cryptogenic & 6.40 & 5.80 & 50.80 & Cryptogenic & 5.23 & 44.28 & 44.28 & Cryptogenic & 5.25 & 6.40 & 35.31 & 35.31 \\
\hline Native & 4.59 & 31.57 & 82.37 & Native & 4.55 & 37.24 & 81.53 & Native & 4.55 & 4.59 & 32.41 & 67.72 \\
\hline Non-native & 3.23 & 17.63 & 100 & Non-native & 3.00 & 18.47 & 100 & Non-native & 3.00 & 3.23 & 32.28 & 100 \\
\hline
\end{tabular}




\section{iii. Sample interval}

The PERMANOVA tests revealed that species status - native, non-native and cryptogenic species - exhibited significant variation $(P<0.001)$ between sample intervals irrespective of the effects of habitats or substratum, with $>50 \%$ within-group species status similarity for all sample intervals. SIMPER analysis of species status at each sample interval revealed that cryptogenic species were the most abundant group contributing to within-group similarity, followed by native species (Table 3.3.14). However, with time, the cryptogenic species decreased with an increase in the abundance of native and non-native species. This trend was also observed for species status as a function of sample interval at both habitat type and substratum type (Table 3.3.15).

Table 3.3.14. Major species status contributing to the average similarity within each sampling interval. $\mathrm{A}=\mathrm{Avg}$. Abundance, $\mathrm{C} \%=$ Per cent Contribution.

\begin{tabular}{|c|c|c|c|c|c|c|c|c|}
\hline & \multicolumn{2}{|c|}{ Time 1} & \multicolumn{2}{|c|}{ Time 2} & \multicolumn{2}{|c|}{ Time 3} & \multicolumn{2}{|c|}{ Time 4} \\
\hline Average similarity & \multicolumn{2}{|c|}{ 73.57\% } & \multicolumn{2}{|c|}{$70.56 \%$} & \multicolumn{2}{|c|}{$69.60 \%$} & \multicolumn{2}{|c|}{$70.86 \%$} \\
\hline Species Status & $\mathbf{A}$ & $\mathrm{C} \%$ & $\mathbf{A}$ & $\mathrm{C} \%$ & $\mathbf{A}$ & $\mathrm{C} \%$ & $\mathbf{A}$ & $\mathrm{C} \%$ \\
\hline Cryptogenic & 6.16 & 66.45 & 5.82 & 46.60 & 5.44 & 40.13 & 6.91 & 52.66 \\
\hline Native & 3.71 & 31.75 & 4.50 & 36.43 & 4.86 & 34.37 & 4.30 & 28.03 \\
\hline \multirow[t]{2}{*}{ Non-native } & 0.58 & 1.80 & 2.98 & 16.47 & 3.93 & 25.50 & 3.39 & 19.31 \\
\hline & \multicolumn{2}{|c|}{ Time 5} & \multicolumn{2}{|c|}{ Time 6} & \multicolumn{2}{|c|}{ Time 7} & \multicolumn{2}{|c|}{ Time 8} \\
\hline Average similarity & \multicolumn{2}{|c|}{$71.04 \%$} & \multicolumn{2}{|c|}{$62.62 \%$} & \multicolumn{2}{|c|}{$67.33 \%$} & \multicolumn{2}{|c|}{$67.31 \%$} \\
\hline Species Status & $\mathbf{A}$ & $\mathrm{C} \%$ & $\mathbf{A}$ & $\mathrm{C} \%$ & $\mathbf{A}$ & $\mathrm{C} \%$ & $\mathbf{A}$ & $\mathrm{C} \%$ \\
\hline Cryptogenic & 6.47 & 56.32 & 6.66 & 51.39 & 5.06 & 36.40 & 4.11 & 26.97 \\
\hline Native & 4.11 & 29.21 & 4.37 & 29.02 & 4.97 & 37.29 & 5.72 & 43.15 \\
\hline Non-native & 2.40 & 14.47 & 3.21 & 19.59 & 3.99 & 26.31 & 4.45 & 29.88 \\
\hline
\end{tabular}


Table 3.3.15. The temporal variation of species status (percent contribution) as per SIMPER results for habitat type (reef vs marina) and substratum type (slate vs PVC).

\begin{tabular}{|c|c|c|c|c|c|c|c|c|}
\hline \multicolumn{9}{|c|}{ Habitat type $\times$ Sample interval } \\
\hline \multicolumn{9}{|c|}{ Reef habitat } \\
\hline $\begin{array}{c}\text { Sampling } \\
\text { interval }\end{array}$ & 1 & 2 & 3 & 4 & 5 & 6 & 7 & 8 \\
\hline Cryptogenic & 66.73 & 51.13 & 31.05 & 53.82 & 49.12 & 59.29 & 31.66 & 28.22 \\
\hline Native & 32.63 & 40.42 & 44.3 & 30.7 & 38.8 & 25.11 & 44.25 & 33.89 \\
\hline Non-native & 0.63 & 8.46 & 24.65 & 15.47 & 12.08 & 15.6 & 24.1 & 37.89 \\
\hline \multicolumn{9}{|c|}{ Marina habitat } \\
\hline $\begin{array}{c}\text { Sampling } \\
\text { interval }\end{array}$ & 1 & 2 & 3 & 4 & 5 & 6 & 7 & 8 \\
\hline Cryptogenic & 65.22 & 39.25 & 48.57 & 51.19 & 62.49 & 43.67 & 40.82 & 24.99 \\
\hline Native & 31.25 & 30.77 & 26.25 & 25.64 & 21.19 & 32.88 & 31.17 & 52.6 \\
\hline Non-native & 3.54 & 29.97 & 25.17 & 23.18 & 16.31 & 23.45 & 28.01 & 22.41 \\
\hline \multicolumn{9}{|c|}{ Substratum type $\times$ Sample interval } \\
\hline \multicolumn{9}{|c|}{ Slate substratum } \\
\hline $\begin{array}{c}\text { Sampling } \\
\text { interval }\end{array}$ & 1 & 2 & 3 & 4 & 5 & 6 & 7 & 8 \\
\hline Cryptogenic & 65.81 & 41.17 & 34.78 & 46.53 & 48.45 & 54.95 & 35.21 & 25.18 \\
\hline Native & 32.34 & 44.1 & 35.76 & 31.66 & 36.09 & 28.31 & 36.8 & 46.03 \\
\hline Non-native & 1.85 & 14.73 & 29.46 & 21.81 & 15.46 & 16.74 & 27.99 & 28.79 \\
\hline \multicolumn{9}{|c|}{ PVC substratum } \\
\hline $\begin{array}{c}\text { Sampling } \\
\text { interval }\end{array}$ & 1 & 2 & 3 & 4 & 5 & 6 & 7 & 8 \\
\hline Cryptogenic & 67.48 & 52.09 & 46.04 & 58.81 & 64.52 & 47.65 & 37.58 & 28.97 \\
\hline Native & 30.88 & 29.33 & 32.57 & 24.47 & 22.4 & 29.63 & 37.93 & 40.24 \\
\hline Non-native & 1.65 & 18.58 & 21.39 & 16.73 & 13.09 & 22.72 & 24.5 & 30.79 \\
\hline
\end{tabular}




\subsubsection{Regression between the native and non-native species as a function of the sample interval}

The relationships of native and non-native species number were strongly positive, with significant positive relationships for all 8 sample intervals at both habitat type $\left(r^{2}=0.58, r=\right.$ $0.76, P<0.001)$ and substratum type $\left(\mathrm{r}^{2}=0.58, \mathrm{r}=0.76, P<0.001\right)$ (Figure 3.3.8). These results suggest that; an increase in the number of native species led to an increase in the number of non-native species over time.

a) Habitat

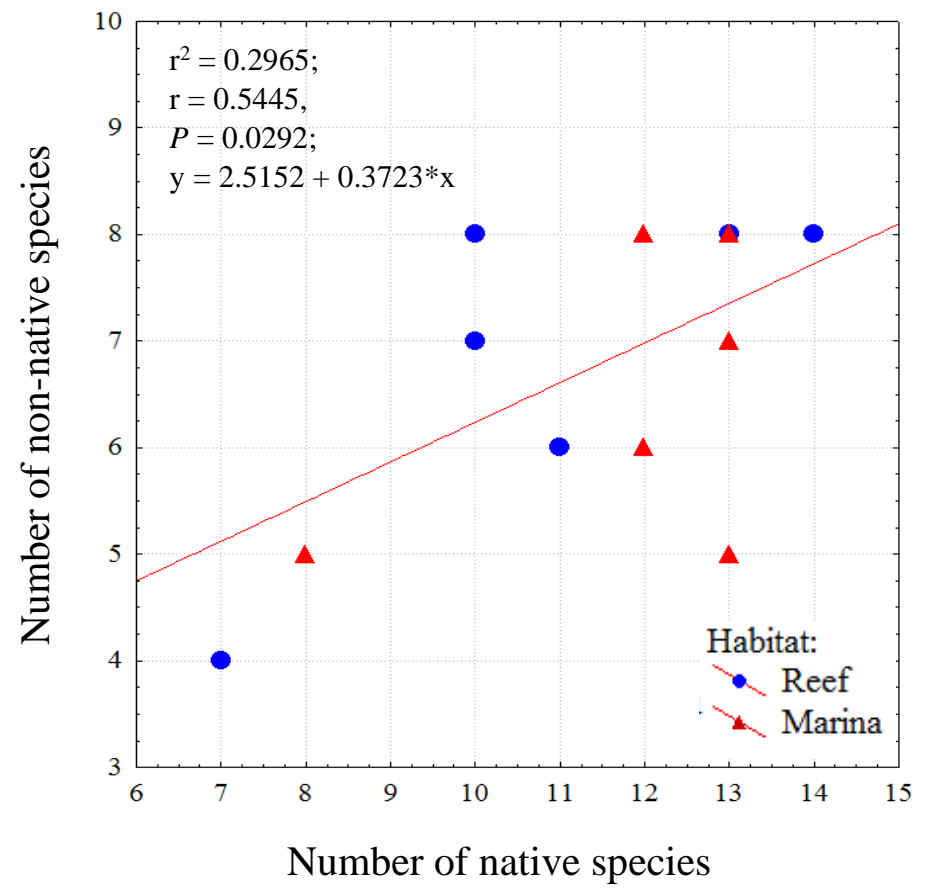

b) Substratum

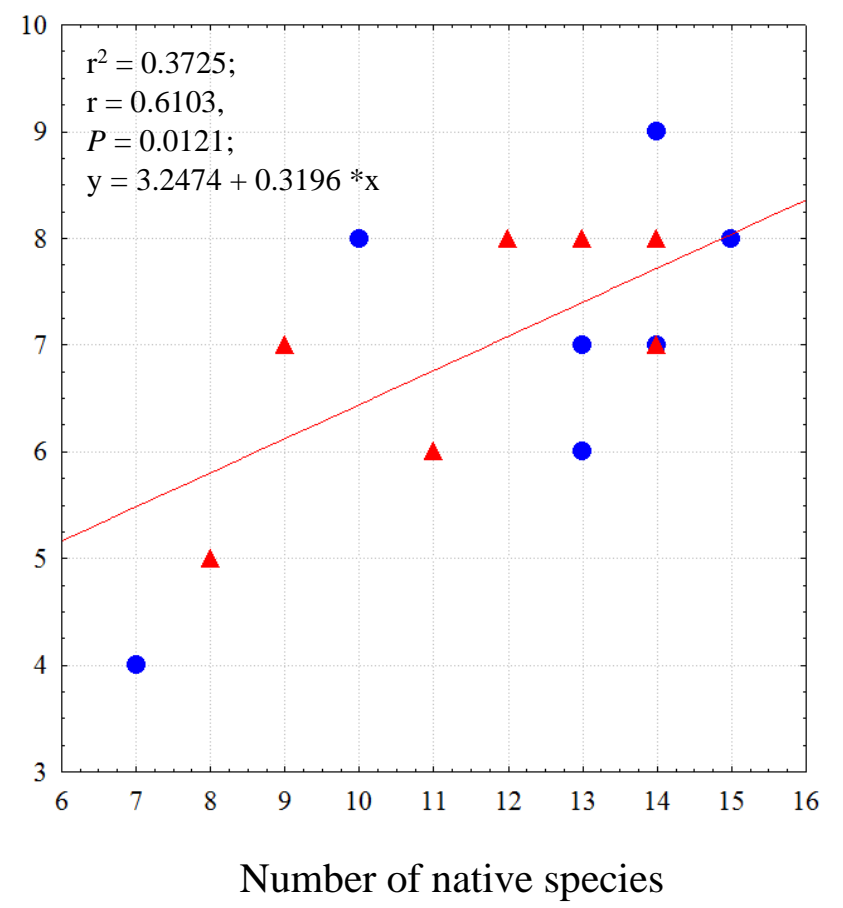

Figure 3.3.8. Correlation of number of native and non-native species as a function of time at a) habitat type (Reef vs Marina); b) substratum type (Slate vs PVC). 


\subsection{Discussion}

Humans have contributed significantly to the modification of the marine environment and the corresponding impacts of these modifications on the associated marine assemblages (Airoldi \& Beck 2007; Firth et al. 2016; Ruiz et al. 2009). This study aimed to examine the effect of natural and man-made built habitats (Reef vs Marina) and substrata (Slate vs PVC) on a fouling community. The settlement tiles (Slate \& PVC) were deployed at 3 reef sites and 3 marina sites over two years, with tri-monthly sampling. To my knowledge, this study is the first to examine and compare fouling community and species status (native, non-native, cryptogenic) using an experimental setup of slate and PVC tiles at reef and marina habitats which are analogous to natural and man-made habitats or structures in New Zealand. I observed a total of 47 species on 480 tiles, consistent with species number observed in other studies concerning artificial structures (Glasby 1999; Connell \& Glasby 1999; Bacchiocchi \& Airoldi 2003; Firth et al. 2013). The majority of the species identified were observed to have settled by $\sim 6$ months of the study period.

\subsubsection{Availability of bare space}

In this study, the bare space availability varied significantly between habitat type; however, the differences were too small to be of ecological importance. Considering the substratum type, the bare space availability significantly varied between PVC and slate tiles with relatively more available bare space on a slate tile. However, the temporal variations in the availability of bare space between substratum type were similar. The temporal and spatial changes indicate the rate of change of bare space availability varied with temporal changes in the development of species community. The rapid settlement of species covered $64 \%$ of the tile within 3 months of immersion of the bare tiles (100\% bare space). However, the percentage cover of species did not reach $100 \%$, indicating the availability of bare space for future settlements.

\subsubsection{Fouling community composition as a function of habitat type and substratum type}

Species number was observed to be similar between habitats (Reef vs Marina) and substrata (Slate vs PVC). Upon further analysis, the species abundances (i.e., not presence/absence) and per cent contributions to the group similarity differed between both habitat type and substratum type resulting in significant differences. These results are consistent with studies comparing natural rocky reefs and seawalls as artificial structures that observed similar species taxa between both habitats, even if community structure and abundances were different (Chapman 2003; Bulleri et al. 2005; Albano \& Obenat 2019). These authors speculated the differences in 
assemblages to intrinsic features of the substrates at both habitats and physical attributes such as wave-exposure. Previous studies using settlement plates have shown differences in community composition at the initial stages, but over time the community became more similar (Anderson \& Underwood 1994; Andersson et al. 2009). This highly depends on the seasons of submersion of settlement tiles and the recruitment or settlement time of the species (Anderson \& Underwood 1994). Submersion time is an essential factor in any community structure comparison study. Submersion time coinciding with reproductive periods of species can lead to high larval settlement due to the availability of free space (Anderson \& Underwood 1994; Andersson et al. 2009; Smith et al. 2014).

Upon further analysing the species composition between substratum-type and habitattype, respectively, at each sample time, a similar suite of species colonised the Slate and PVC tiles at Reef and Marina habitats but with slightly differing abundances. These results suggest that differences between Reef vs Marina habitat and Slate vs PVC substratum, although statistically significant, maybe due to small-scale temporal and spatial differences in the recruitment patterns of each species (Chang \& Turner, 2019). Ultimately, in this study, these small-scale differences that most likely reflect stochastic processes, give rise to similar patterns of ecological succession between both habitat type and substrata type in Wellington Harbour. Whilst the statistical analyses revealed highly significant differences in community composition (based on differences in abundance, not in species presence) between habitats and substrata, the importance of these highly significant differences from an ecological point of view is still not clear. The man-made habitat (marina) and substratum (PVC) do not promote or degrade species richness and community composition, although many other studies have shown this to be the case. Therefore, indicating that relative to adjacent natural reefs $(\sim 200 \mathrm{~m})$, i.e. local spatial scale, marinas do not degrade species richness. However, this might not be the case in terms of broader scale effect.

This study also revealed similar multi-species succession trajectories between habitat type and substratum type. For example, the transition of Biofilm type 1, which was the dominant species led to the dominance of red algae, Bangia atropurpurea and other encrusting species by the end of the 2-year study. Within 3 months of immersion, the initially bare settlement tiles (PVC vs Slate) $64 \%$ of all observed species were found amongst the initial colonisers (Biofilm type 1 and Green sp. 1). Early settlers are also known to modify a habitat, which may make it habitable for later recruiting species (Connell 1972; Morand \& Briand 1996; Dang \& Lovell 2000; Lewis et al. 2003; Salta et al. 2013; Lotze et al. 2020). This finding 
is consistent with earlier observations that new, barren, surfaces are more prone to be colonised by rapidly growing opportunistic species (Sousa 1979; Fletcher \& Callow 1992; Dafforn et al. 2012; Tan et al. 2015). In this study, Biofilm type 1 readily settled on both PVC and slate substratum; however, the percent contribution to the within-group similarity by Biofilm type 1 was $38 \%$ on PVC substratum whereas $20 \%$ on the slate substratum. This difference, however, did not impact the community composition or succession patterns.

Biofilm type 1 was the major space occupant, at least initially until it reached a peak of abundance (cover on the tiles) at about 1 year into the 2-year study, before declining dramatically in abundance after that. The other colonists observed in the study were encrusting species such as Ostrea chilensis, Asterocarpa humilis, Ralfsia verrucosa, Watersipora subtorquata and Membranipora membranacea which have slow growth rates and occupancy of the available space (Chapman 2012). However, it is not clear in this study if the Biofilm Type 1 facilitated the establishment of other species. Besides, the recruitment and community development may be largely dependent on local recruitment, reproduction and growth rates which are likely to vary with time, available space and nutrients (Smith et al. 2014). Presumably, the reproduction time of a given species with available bare space for settlement led to the settlement of the other species. Whether the species composition would change given a longer time for colonisation or whether the red algae, Bangia atropurpurea observed represents as 'climax state' remains unknown.

Grazers are known to influence the species distribution, abundance and diversity of algal species (Williams et al. 2013). Grazers are dependent on space availability and predation intensity (Williams et al. 2000). The grazers were not quantified in this study which may have provided more information about the algal succession and similarities in other species succession patterns. The other factor impacting patterns of colonisation are physical factors such as environmental stress, disturbance, availability of resources, space and functional characteristics like recruitment, competition, growth, dispersal and reproduction rate of a species (Sousa 1985; Menge et al. 1986; Benedetti-Cecchi 2000; Petes et al. 2007). A study conducted on a larger scale comparing intertidal species composition and biogeographic patterns between New Zealand and New South Wales, Australia, found relatively similar species composition and contribution of major taxa due to similarity in various other patterns such as temperature and latitude that regulate the communities in these areas (Schiel et al. 2019). Hence, determining the changes in physical and biological processes at specific habitats at a given time may also explain the variations in species diversity and species composition 
(Tilman et al. 1994). Unfortunately, environmental data for this study could not be processed due to failure in calibrations; however, this is one factor to be considered for future research. Wellington Harbour is one of the largest natural harbours in the Southern Hemisphere and is heavily modified by port development, indicating that it is a 'disturbed' environment. Therefore, dispersal of species from artificial structures to nearby habitats, thereby altering the developing community may be a cause-effect of disturbance (Sousa 1979; Chapman 2012).

\subsubsection{Species status - native, non-native and cryptogenic species}

Analyses of multi-species community composition (described above) provide a powerful approach by which to identify how and perhaps why built environment when compared to the natural environment influences biological diversity. Another approach, using the species status, i.e., native, non-native, cryptogenic allows for a more definitive test of if and how native and non-native biodiversity make use of natural (reef) and man-made environments in coastal regions.

Artificial structures may provide habitats for certain species that are not found on natural rocky reefs because of their low predation rates and increased availability of bare space (Bulleri \& Airoldi 2005). The native, non-native and cryptogenic species significantly differed between Reef vs Marina habitats and between PVC vs Slate substrata. The cryptogenic species were the dominant species status between habitat type and substrata type. For non-native species, the species were relatively abundant at marina sites. This confirms my hypothesis that non-native species are more abundant than native species at the man-made habitats (marina) relative to natural habitats. These results coincide with many other studies where a high number of non-native species are observed at artificial habitats (Connell 2001; Bacchiocchi \& Airoldi 2003; Airoldi et al. 2005; Bulleri \& Airoldi 2005; Airoldi \& Beck 2007; Glasby et al. 2007; Perkol-Finkel et al. 2012). However, the non-native species were abundant on PVC substratum; however, the difference of non-native species between PVC vs Slate substrata was not significant.

The number of native and non-native species were positive and strong correlated for each time at both habitat type and substratum type. However, a previous comparative study of different substratum types indicated that the non-native tunicates increased in abundance on artificial substrates, with an associated decline in other native species (Tyrrell \& Byers, 2007). Non-native species are generally seen as a threat to the native species richness. However, if a habitat is conducive to native species with sufficient resources and space, it also provides an 
opportunity for non-native species (Davis 2003). Therefore, the quality of a habitat determines the settlement of species irrespective to the species status (Sax 2002; Stohlgren et al. 2003). These results are in accordance with the ecological theory stating effective 'biotic acceptance hypothesis' (Stohlgren 2003, 2006). The 'biotic acceptance hypothesis' defined as the establishment and coexistence of introduced species despite the presence and abundance of native species (Stohlgren et al. 2006). Another ecological theory to consider for this study is the 'empty niche' hypothesis where the ecosystem is not saturated with native species, and the non-native species occupy the vacant niches and available resources (Elton 1958; Stohlgren et al. 2003). However, co-existence of native and non-native species in a habitat further raises need to analyse for 'invasional meltdown'. Invasion meltdown' hypothesis is the presence of non-native species in a habitat facilitates the invasion of other species, increasing their likelihood of survival and ecological impact (Simberloff \& Von Holle 1999). That being said, there is a need for a comprehensive study to observe if we see the same positive relationship between native and non-native species at a large spatial and temporal scale.

In summary, these results suggest that the differences between Reef vs Marina habitat and Slate vs PVC substratum, although statistically significant, maybe due to small-scale temporal and spatial differences in the recruitment patterns of each species (Chang \& Turner 2019). These small-scale differences that most likely reflect stochastic processes give rise to similar patterns of ecological succession between both habitat type and substratum type in Wellington Harbour. The present study also highlighted the importance of species statusnative, non-native and cryptogenic with different habitat types and substratum types. Although the native species were predominant, the non-native species were relatively abundant on PVC tiles and marina sites. These results indicate relatively more preference of non-native species towards man-made substratum and habitats. Besides, the native and non-native species positively correlated, indicating co-existence of the same. Given these observations, future studies should focus more on basic knowledge of the life-history traits and functioning of the species at various trophic levels, which will give a better understanding of species-specific interactions. Longer duration of experimental study will aid with acquiring complex community to have an overall knowledge of the species composition and interactions.

This study from a management point of view informs that anthropogenic alterations of natural habitats can lead to the destruction of natural habitats. Empty niches and disturbed habitats are a haven for non-native species (Airoldi et al. 2000; Guerra-García et al. 2004; Erlandsson et al. 2006; Oricchio et al. 2016; Pastro et al. 2017). It is evident from this study 
that non-native species prefer man-made habitats and substratum. Maintenance of structures or dredge along the coast can lead to the removal of intertidal species exposing it to the settlement of non-native species (Airoldi et al. 2005; Airoldi \& Bulleri 2011; Bracewell et al. 2013; Oricchio et al. 2016). Building new port infrastructures along the coast also provides additional habitats which are relatively more preferred by non-native species than native species, i.e. nonnative more in abundance (Bulleri \& Chapman 2010; Dumont et al. 2011; Rivero et al. 2013). Hardening the coastlines will degrade the quality of the habitat by obstructing the water flow bringing in nutrients thereby causing competition between native and non-native species for resources (Clark \& Johnston 2009; Piola et al. 2009).

Additionally, the vertical orientation of substrata provides relatively less surface area to colonise compared to natural reefs. Even though this study showed co-existence of native and non-native species, there is a chance of provision of other non-native species by existing non-native species. This study highlights the need for a conservation strategy to manage natural habitats along the Wellington Harbour coastline. With the increasing modification of natural habitats to artificial habitats, there is a need to have a comprehensive understanding of the novel design of structures that can facilitate more native/local species and maintain native biodiversity (Chapman 2012; Dafforn et al. 2015a, 2015b; O’Shaughnessy et al. 2019). Ecoengineering of artificial structures is still at an experimental stage and may vary at different habitats. Future studies considering this study as a baseline work in Wellington Harbour should focus on different potential designs that can enhance the native biodiversity, reduces the nonnative abundance and provide beneficial ecosystem services. 


\section{CHAPTER 4}

\section{DO NATIVE $M$. GALLOPROVINCIALIS LINEAGE, AND ITS NON- NATIVE $M$. GALLOPROVINCIALIS LINEAGE CONGENER DIFFER IN REPRODUCTIVE RESPONSE TO MAN-MADE HABITATS?}

\subsection{Introduction}

\subsubsection{Importance of habitat type}

Modified coastal environments have recently raised many ecological concerns, new challenges and opportunities for an improved understanding of the management of marine biodiversity in the modern world (Firth et al. 2016). The heterogeneous natural habitats inhabit more diverse and complex species, providing refuge from biotic and abiotic stressors (Moschella et al. 2005; Moreira et al. 2006; Chapman \& Underwood 2011; Firth et al. 2013; Firth et al. 2014; Loke et al. 2014; Aguilera et al. 2014; Oliver et al. 2015; Firth et al. 2016; Loke \& Todd 2016). Unlike natural habitats, the man-made habitats have very different physical characteristics such as the smooth surface textures, artificial materials (e.g. cement, plastic, etc.) and vertical orientation (Perkol-Finkel et al. 2006; Dafforn et al. 2012; Perkol-Finkel et al. 2012; Spagnolo et al. 2014; Cacabelos et al. 2016; Brzozowska et al. 2017; Johnston et al. 2017). The different habitat structures have a significant impact on the environment as well as the ecological functioning of the species (Glasby \& Connell 2001; Bulleri \& Chapman 2004, 2010; Bulleri 2005; Tyrrell \& Byers 2007; Chapman 2012; Tan et al. 2015; Megina et al. 2016).

Numerous studies have investigated the impacts of man-made habitats and substrata on the population and community structure (Bulleri 2005; Airoldi et al. 2005; Bulleri \& Airoldi 2005; Wyatt et al. 2005; Airoldi \& Beck 2007; Parsons et al. 2016; Mayer-Pinto et al. 2018). However, we still know very little about the effects of the man-made structures on the energy output, i.e., fitness of a species. For instance, Moreira et al. (2006) reported smaller sized limpet Siphonaria denticulata on seawalls compared to natural rocky reefs leading to reduced reproductive output. Similarly, Martins et al. (2016) reported smaller sized and low densities of barnacle Chthamalus stellatus on man-made structures compared to natural rocky reefs.

At a local scale, the physiological processes of a species are directly or indirectly affected by environment factors temperature, food quality/quantity, wave exposure and water quality (Green et al. 2011; Rivero et al. 2013; Bagley et al. 2015; Bishop et al. 2017; Heery et 
al. 2017). In case of port and marinas as man-made habitats, semi-enclosed habitats have restricted water flow, reduced nutrient availability, increase water temperatures, contaminated, turbid waters which may have an adverse effect on the physiological processes of a species (Johnston \& Keough 2002; Piola \& Johnston 2008; Vaselli et al. 2008; Piola et al. 2009). The differences in environmental conditions also influence the growth, survival and reproduction of a species. Furthermore, the inter and intraspecific interactions in a community also influence the larval dispersal, recruitment, reproduction, growth, predation, competition and co-existence (Airoldi et al. 2005; Bulleri 2006; Perkol-Finkel et al. 2006; Burt et al. 2009; Quinn et al. 2012; Munari 2013; Firth et al. 2014; Bishop et al. 2017; Mayer-Pinto et al. 2018); and are therefore important factors to study the performance of a species on the man-made structures.

\subsubsection{Impacts of man-made structures on bioinvasions}

Bioinvasions are an increasing threat to biodiversity worldwide, especially to native biodiversity (Ruiz et al. 1999; Glasby et al. 2007; Hewitt \& Campbell 2007; MacKie et al. 2012; Thomsen et al. 2014; Ojaveer et al. 2015; Cook et al. 2016; Gestoso et al. 2017; Olenin et al. 2017; Wells 2018; Albano \& Obenat 2019). There have been previous studies indicating the man-made habitats to favour low density of native species and the successful invasion of non-native species (Ruiz et al. 2000; Byers 2002; Glasby et al. 2007; Bulleri \& Chapman 2010; Airoldi \& Bulleri 2011; Airoldi et al. 2015; Marraffini \& Geller 2015; Johnston et al. 2017). Several studies have also indicated that the invasive species have a competitive edge over the native species as they have relatively high reproductive rate, high survival rate, fast growth and phenotypic plasticity (Dafforn 2017; Johnston et al. 2017; Simpson et al. 2017; Epstein \& Smale 2018; Riera et al. 2018). Ultimately, non-native species may perform better at an invaded area than at their native regions (e.g., Parker et al. 2013). Several other studies have raised concerns regarding hybridisation and introgression between native and non-native species (Seehausen 2004; Wonham 2004; Roman \& Darling 2007; Fauvelot et al. 2009; Pickett \& David 2018); leading to genetic homogeneity in a community.

However, not all non-native species cause negative impacts, and some non-native species tend to naturalise, i.e. they become established without causing any major impact on the environment (Simberloff \& Von Holle 1999; Mack et al. 2000; Branch \& Nina Steffani 2004). Such naturalised species tend to co-exist with the native species in an environment with plenty of food and space without replacing them (Rius \& McQuaid 2006; Zardi et al. 2008; Nicastro et al. 2010; Dafforn et al. 2012; Ojaveer \& Kotta 2015; Zwerschke et al. 2016; Reise et al. 2017). For example, Ruiz et al. (1999) showed that of the 196-non-native species studied 
in the Chesapeake Bay (Atlantic coast of the USA), $6 \%$ of the species had some measurable negative impact. Therefore, indicating that invasive species may promote biodiversity. Another example is that of a study in Chile which reported competition between the non-native tunicate Pyura praeputialis and native primary space occupiers. These tunicates formed massive mats along the coast, creating a new habitat for 116 invertebrates and algae, whereas the adjacent natural (non-invaded) coast had just 66 species (Castilla et al. 2004). A recent meta-analysis by Katsanevakis et al. (2014) reported that out of 63 non-native species, about 35\% species had a positive impact by increasing the diversity of other species. Therefore, non-native species do not always have a negative effect on an invaded system, and understanding why this is the case may be challenging. It is harder still to predict a priori what the outcome of an invasion maybe.

\subsubsection{Study species}

Mussels are dominant space occupiers on hard substrata, colonising the entire middle region of the intertidal zone (Paine 1966; Capelle et al. 2016; Hetherington et al. 2019). Mussels are also ecosystem engineers and play an important role in promoting other species by forming biogenic reefs and because they are a food source for predators (Crooks 2002; Borthagaray \& Carranza 2007; Sousa et al. 2009; Bertolini et al. 2017). The genus Mytilus (common blue mussels) is widely distributed, having an anti-tropical distribution around the world (Hilbish et al. 2000). The genus contains numerous species, but its taxonomy and systematics are still unresolved in many parts of the world. The widely distributed smooth-shelled Mytilus edulis species complex has three distinct lineages, Mytilus edulis (Linnaeus 1758), Mytilus galloprovincialis (Lamarck 1819) and Mytilus trossulus (Gould 1850), all of which are of Northern hemisphere origin.

Evolutionary evidence suggests allopatric speciation of Mytilus spp., with M. trossulus being the oldest of the three Northern hemisphere origin Mytilus spp. which first originated in North Pacific (Vermeij 1991). According to genomic and mitochondrial DNA analysis, $M$. edulis and M. galloprovincialis are closely related whilst M. trossulus is most distinct (Geller 1999; Hilbish et al. 2000). About 3.5 M ybp (years before present), first range expansion of $M$. trossulus into the North Atlantic via the Bering Strait gave rise to M. edulis (Cunningham \& Collins, 1994; Vermeij, 1991). By 2 M ybp, sea-level changes led to spread of north Atlantic M. edulis to Mediterranean Sea (Vermeij 1991). However, persistent sea-level fluctuations led to the separation between the North Atlantic M. edulis hindering the gene flow, which led to Mediterranean Sea M. galloprovincialis (Barsotti \& Meluzzi 1968; Riginos \& Cunningham 2005). These different lines of evidence show how natural range expansion (and associated 
invasion pressure) has led to hybridisation and introgression between the genetically similar Mytilus spp. (Seehausen 2004; Wonham 2004; Pickett \& David 2018; Gardner et al. 2020). The second wave of range expansion of North Pacific M. trossulus during the Pleistocene or Holocene period gave rise to $M$. trossulus on the Atlantic coast of North America. These two lineages varied genetically and showed a difference in physiological tolerance (e.g. salinity) (Gardner \& Thompson 2001; Braby \& Somero, 2006). Further, RFLP assays and DNA sequencing by various researchers confirmed M. trossulus, M. edulis and M. galloprovincialis of the Northern hemisphere origins (Levinton \& Koehn 1976; Gardner \& Skibinski 1991; Toro 1998; Hilbish et al. 2000; Gérard et al. 2008).

Grant \& Cherry (1985) were the first to point out that the blue mussels in South Africa are not native and are the invasive Northern hemisphere origin $M$. galloprovincialis by examining the shell morphometric and genetic variations. This study was of much importance regarding the taxonomy of blue mussels in the Southern hemisphere. Following that, McDonald et al. (1991) identified two groups of Southern hemisphere mussels, a South America groups (Chile, Argentina, the Falkland Islands and the Kerguelen Islands) which had more M. edulis-like alleles and, an Australasian group including Australia and New Zealand that had more $M$. galloprovincialis - like alleles. This has been further confirmed by Borsa et al. (2007), Pickett \& David (2018) and Malachowicz \& Wenne (2019). Additionally, Hilbish et al. (2000) and Gérard et al. (2008), both suggested two Southern hemisphere invasion events via the North Atlantic Ocean, with first expansion 1.2 M ybp in South America, i.e. Chile (Mytilus chilensis), Argentina (Mytilus platensis), the Falkland Islands (Mytilus platensis) and Kerguelen Islands (Mytilus desolationis) and a second recent expansion $0.7 \mathrm{M}$ ybp in the Australasian group i.e. Australia (Mytilus planulatus) and New Zealand (Mytilus aoteanus) (Gardner et al. 2020) . The nomenclature for these blue mussel sub-species in the Southern hemisphere has been controversial, with historical samples (i.e., pre-human arrival) being classified and described with the help of fossil and morphological data (e.g. Gardner 2004).

Recent evidence regarding the 'cryptic dispersal' of M. galloprovincialis has suggested both natural, and human mediation range expansion; together with adaptation and hybridisation events has led to the absence of distinct differences between Southern and Northern hemisphere haplotypes (Hilbish et al. 2000; Gérard et al. 2008; Westfall \& Gardner 2010; Pickett \& David 2018). Considering all these evolutionary evidences of Mytilus spp. range expansion and molecular studies relating to taxonomy, it is evident that Australasian mussels are most similar to Northern hemisphere M. galloprovincialis but are, however, native to Southern hemisphere. 
Fossil evidence indicates the presence of some form of M. galloprovincialis in the Southern hemisphere before human arrival, but which may have been displaced by, or are co-occurring with, accidentally introduced Northern hemisphere $M$. galloprovincialis in some regions (McDonald et al. 1991; Westfall \& Gardner 2013). In New Zealand, concerns about hybridisation and introgression of Southern and Northern hemisphere lineages were expressed because the invading mussel may displace the Southern hemisphere lineage $M$. aoteanus (Gardner et al. 2016; Zbawicka et al. 2019). There are still many ongoing studies (e.g. SNPsbased work) relating to the taxonomy of the aforementioned species especially the Northern vs Southern hemisphere M. galloprovincialis lineages and insights into hybridisation and introgression between the invasive and native mussel (Gardner et al., 2016; Gardner et al. 2020).

Mytilus galloprovincialis is one of the world's most successful invading species, being ranked in the Top 100 (Lowe et al. 2000). Mytilus galloprovincialis, the Mediterranean mussel, has spread from its native Mediterranean coastline to numerous locations in the world except for Antarctica, including but not limited to the Pacific coast of Canada, the California coast (Wonham 1999; Anderson \& Thompson 2002), Hong Kong (Lee \& Morton 1985), Japan (Wilkins et al. 1983), Australia and New Zealand (reviewed by Daguin \& Borsa 2000; Pickett \& David 2018), and Chile (Borsa et al. 2012; Oyarzún et al. 2016). M. galloprovincialis is cultivated as one of the most important commercial species all over the world; however, in New Zealand, this species is a pest on native green shell mussel, Perna perna, aquaculture farms (Forrest \& Atalah 2017).

The impacts of $M$. galloprovincialis on various native species and its congeners have been studied extensively throughout the years. Previous studies in South Africa have reported displacement of native species due to the dominance of invasive $M$. galloprovincialis (Griffiths et al. 1992; Branch \& Steffani 2004). Whilst, Bownes \& McQuaid 2006, reported co-existence but with niche separation for the native Perna perna and non-native M. galloprovincialis in the south coast of South Africa. Competition for habitat and hybridisation between $M$. galloprovincialis and resident dominant $M$. trossulus were observed on the Pacific coast of North America and Canada (Wonham 2004; Dutton \& Hofmann 2008; Shields et al. 2008, 2010). The M. galloprovincialis is a strong competitor, possess traits which help them acclimatise to fluctuating water temperatures due to metabolic adjustments, heat shock protein expression, high fecundity, rapid growth rate and resistance to desiccation (Hockey \& Van Erkom Schurink 1992; Erlandsson et al. 2006; Anestis et al. 2007; Shinen \& Morgan 2009). 
Subsequently, mussels observed at such varied environments experience differences in physiological processes (Bayne \& Thompson 1970). The mussels have strategies to overcome the variable environments, by maximizing the growth, reproduction and survival processes (Bayne \& Thompson 1970; Hockey \& Van Erkom Schurink 1992). Therefore, there might be differences in life-history traits such as reproduction timing (lifecycles), feeding or growth in different habitats (for example, natural vs man-made habitats).

In New Zealand, the impacts of the non-native Northern hemisphere $M$. galloprovincialis lineage on the native Southern hemisphere M. galloprovincialis lineage is not yet known. This is especially the case in the context of how man-made habitats influence the invasion success of Northern hemisphere lineage (henceforth, $\mathrm{NHMg}$ ) vs Southern hemisphere lineage (henceforth, $\mathrm{SH} M g$ ) mussels. For co-occurring mussel lineages (native vs non-native) where interspecific competition is taking place, differences in the energy utilised for reproduction, growth and byssus thread production for attachment may explain the outcome of competitive interactions (e.g., Gosling 1992; Steffani \& Branch 2003). Therefore, examining the energy invested in reproductive output (e.g. gonadosomatic index - GSI) at natural vs manmade habitats may be a pivotal way to understand the mussel's comparative physiological processes. GSI is measured by quantifying the gonad weight with respect to body/soma weight (Hickman 1979; Devlaming et al. 1982; Santos et al. 2011). The gonadosomatic index (GSI) is an important metric to study the magnitude of gametogenic events and seasonal patterns in gonad development. It has been used by Gardner \& Skibinski (1990) to study the fecundity and temporal variations in Mytilus spp. (M. edulis, M. galloprovincialis and their hybrids in southwest England). Their results showed M. galloprovincialis to have greater mean fecundity compared to congener M. edulis. Therefore, in New Zealand, it is interesting to observe two congener species that co-occur, one of which is the non-native $\mathrm{NHMg}$ lineage, and the closely related, native $\mathrm{SH} M g$ lineage.

The objective of the present study is to measure and compare the reproductive output (GSI) of the two lineages to observe if reproductive output contributes to their differences in performance (presumptive fitness) at reef vs marina sites, which are analogous to natural habitats and man-made habitats. Firstly, I hypothesised that both the blue mussel lineages ( $\mathrm{NH} M g$ and $\mathrm{SH} M g$ ) would have bigger shells on natural reefs compared to marinas. Due to the close evolutionary affinities between the non-native, $\mathrm{NHMg}$ and native, $\mathrm{SHMg}$ (McDonald et al. 1991; Hilbish et al. 2000; Gérard et al. 2008; Westfall \& Gardner 2010; Pickett \& David 2018); I hypothesised that both the blue mussel lineages would have similar reproductive 
patterns (i.e., timing and magnitude of spawning events). I further hypothesised that the mussels at the natural reef sites have a relatively higher reproductive output (GSI) than those at marina sites. Lastly, hypothesised that the non-native $\mathrm{NHMg}$ would have higher reproductive output at marina sites (man-made) compared to rocky reefs (natural).

\subsection{Methods}

\subsubsection{Study site}

The study was carried out in Wellington Harbour $\left(41^{\circ} 16^{\prime} 45.5^{\prime \prime S}, 174^{\circ} 52^{\prime} 02.3^{\prime \prime E}\right)$ which is an enclosed bay on the southernmost tip of New Zealand's North Island (Figure 4.2.1). The Harbour is one of the largest natural harbours in the Southern hemisphere, whilst most of it is heavily modified for urban and port development, some of it is still intact. Hutt River on the eastern side of the Harbour is the only source of freshwater into the catchment. Wellington Harbour serves as a significant international commercial shipping port and is one of the busiest ports in New Zealand. Hence, sites around Wellington harbour were selected to compare gonadosomatic index (GSI) as an indicator for the reproductive effort by SHMg (native) and $\mathrm{NHMg}$ (non-native) blue mussels on the reef (natural) and marina (man-made) habitats. Westfall (2011) indicated the presence of SHMg, NHMg and M. edulis/M. galloprovincialis (NHMg/Me) hybrids at different proportions at different sites in Wellington Harbour.

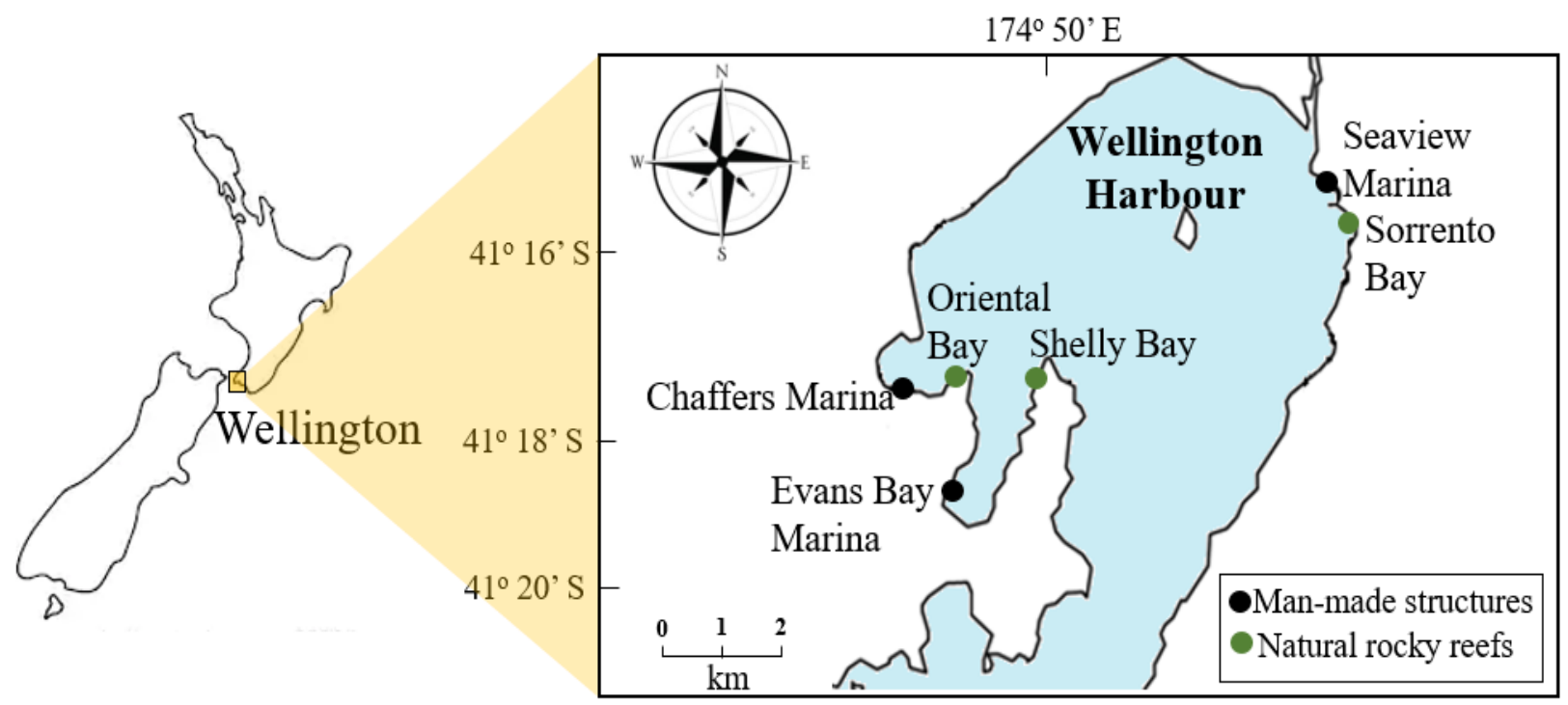

Figure 4.2.1. Map of Wellington Harbour, New Zealand. Points denoting marinas as man-made structure sites (black) and natural rocky reefs as natural sites (green) for this study. 
In my study, three paired sites (natural vs man-made) were chosen around the harbour: Oriental Bay (OB; natural) and Chaffers Marina (CM; man-made), Shelly Bay (SB; natural) and Evans Bay Marina (EB; man-made) and Sorrento Bay (SR; natural) and Seaview Marina (SM; man-made). Paired sites (natural vs man-made) were selected at a distance of $\sim 200 \mathrm{~m}$ to examine the monthly GSI of NHMg and SHMg in the marinas and at adjacent reef habitats. All sites had extensive coverage of blue mussels present through the sampling period.

\subsubsection{Field sampling}

Westfall (2011) identified $8 \mathrm{SHMg}, 1 \mathrm{NHMg}$ and $1 \mathrm{NHMg} / \mathrm{Me}$ (hybrid) with 20 unknowns out of the 30 blue mussels collected in Wellington Harbour from her study. Therefore, at each site, random collections of 40 blue mussels were carried out (irrespective of their sex) to provide what was expected to be large enough lineage-specific sample sizes per site. Mussel size was $>2 \mathrm{~cm}$ shell length to ensure that only sexually mature individuals, for which a GSI could be calculated, were sampled. The mussels were collected from the intertidal zone at each site during low tide (similar tidal elevations) every month for a year from June 2017 to May 2018 (40 mussels $\times 12$ months $\times 6$ sites; $\mathrm{N}_{\text {total }}=2880$ ). The mussels on natural sites were collected from rocky reefs and for marina sites, the mussels were collected from wharves, artificial structures or ripraps. Immediately after collection, the mussels were placed in pre-labelled bags and frozen $\left(-18{ }^{\circ} \mathrm{C}\right)$ until processing. Environmental variables such as $\mathrm{pH}$, dissolved oxygen (DO, mg. $\mathrm{l}^{-1}$ ), salinity (PSU), turbidity (NTU) and chlorophyll $\left(\mu \mathrm{g} . \mathrm{l}^{-1}\right.$ ) were measured at each site for each month. The $\mathrm{pH}, \mathrm{DO}$, and salinity measurements were taken with a handheld YSI Meter (PRO-Series, YSI) and turbidity as well as chlorophyll with a handheld fluorometer/turbidimeter (Aquafluor ${ }^{\mathrm{TM}}$, Turner Designs). Unfortunately, the data for turbidity and chlorophyll was not accurate even after cross-referencing with CTD data for the same. Therefore, environmental data were not included in this study.

\subsubsection{Shell length}

The weight of soma and gonad tissue increases as a function of shell length (Suchanek 1981). Therefore, after removal of all the flesh, each mussel was numbered. The shell length (distance from the anterior to the posterior side of the shell), height (distance from dorsal to ventral side) 
and width (maximum distance between closed valves) of the mussel shell (Gardner 2004) were measured using a vernier calliper $( \pm 0.01 \mathrm{~cm})$ (Figure 4.2.2).
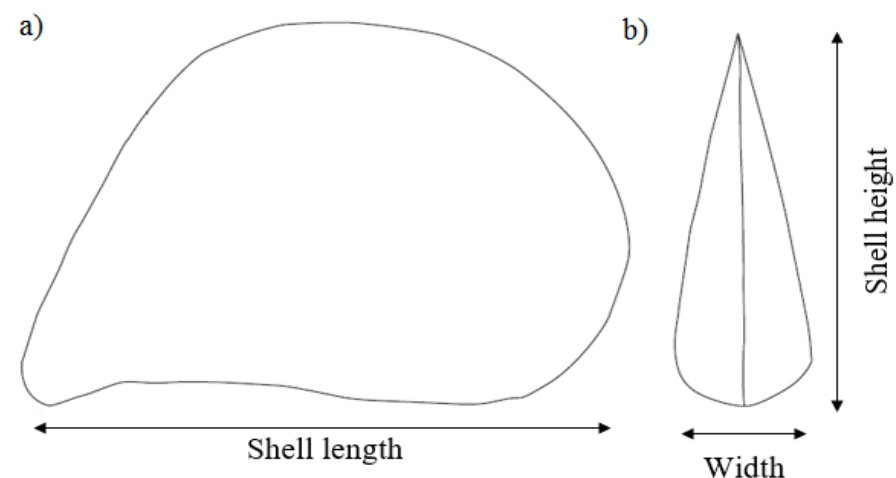

Figure 4.2.2. Illustration representing the measurements taken for shell length, height and width; a) frontal view; b) lateral view. Image sourced and modified from Gardner

\subsubsection{Laboratory analysis}

After defrosting, $30 \mathrm{mg}$ of mantle tissue was extracted from each mussel for DNA extraction (details below). Subsequently, the soma and gonad of each mussel were dissected and weighed separately $(0.001 \mathrm{~g})$ after $24 \mathrm{~h}$ at $60{ }^{\circ} \mathrm{C}$ to determine their dry weights. The gonadosomatic index (GSI = gonad mass/body mass $\times 100 \%)$ was calculated for each mussel to qualitatively determine the energy investment in gametogenesis as a function of total body weight, and also the timing of spawning events as indicated by a decrease in GSI values from one month to the next (Seed \& Suchanek 1992).

\subsubsection{Lineage identification}

\section{a) DNA extraction}

The DNA extraction was performed from the mantle tissue using Tissue Genomic DNA kits (Geneaid) following the manufacturer's recommendations. DNA concentrations were measured using a Nano-Photometer ${ }^{\mathrm{TM}}$ NP 80 (Implen, Germany) before the concentrations were standardised to a $50 \mathrm{ng} / \mu 1$ stock concentration with double distilled water to prepare a final volume of $20 \mu 1$.

\section{b) PCR}

The 16s rRNA RFLP assay (Westfall et al., 2010) was used to distinguish the lineage of SHMg (native), $\mathrm{NH} M g$ (non-native) and NHMg/Me (hybrids). The primers 16sAR/16sBR (1 $\mu 1$ each), 12.5 $\mu 1$ MyTaq Remix, $8.5 \mu 1$ double distilled water and $2 \mu 1$ template DNA (100 ng) were used to amplify the 16sRNA gene in a $25 \mu \mathrm{l}$ total solution. PCR was carried out in an Eppendorf 
Thermocycler (Master cycler ep groups S). Amplification conditions applied were 3 min at 95 ${ }^{\circ} \mathrm{C}, 30$ cycles at $95{ }^{\circ} \mathrm{C}$ for $30 \mathrm{~s}, 30$ cycles at $52{ }^{\circ} \mathrm{C}$ for $30 \mathrm{~s}, 30$ cycles at $72{ }^{\circ} \mathrm{C}$ for $45 \mathrm{~s}$ and final extension of $3 \mathrm{~min}$ at $72{ }^{\circ} \mathrm{C}$.

\section{c) DNA Digest}

A double restriction endonuclease digest was performed on the PCR product using $1 \mu \mathrm{l}$ each of the EcoRV and NheI enzymes, $1 \mu 1$ loading buffer, $2 \mu 1$ red buffer, $5 \mu l$ distilled water and $10 \mu 1$ PCR product that was incubated in the Thermocycler at $37{ }^{\circ} \mathrm{C}$ for $15 \mathrm{~min}$. The enzymes EcoRV and NheI distinguish SHMg (native) and NHMg (non-native) (Westfall et al. 2010). The enzyme SpeI enzyme used by Westfall \& Gardner (2010) to distinguish the blue mussels was not used in this study because after testing a few mussels with EcoRV and NheI enzymes, $\mathrm{SH} M g$ and $\mathrm{NH} M g$ were successfully determined.

\section{d) Gel Electrophoresis}

DNA concentrations $(5 \mu \mathrm{l})$ were run on a $2 \%$ agarose gel with an Easy Ladder 1 (band size range: 100 to $2000 \mathrm{bp}$ ) to help with fragment sizing. The gel was run at 100 volts for 30 to 40 mins. The gel was viewed under ultraviolet, and pictures were recorded using an imaging system (UVITEC, Essential V6, Cambridge, UK). The resulting bands were observed for each sample and referenced against the Easy Ladder 1 and fragment profiles of $\mathrm{NHMg}$ at $537 \mathrm{bp}$ whilst SHMg at 370 and 167 bp and NHMe/Mg (hybrid) at 370, 85 and 82 bp (Westfall et al. 2010).

\subsubsection{Statistical analyses}

Lineage distributions between reef and marina habitats were analysed using a contingency test $(\mathrm{R} \times \mathrm{C})$. Statistical tests were performed using the STATISTICA v.7 (Stat Soft Inc.) software package. Normality testing using the Kolmogorov-Smirnov (K-S) test (shell length: $d=0.05$, $P<0.01$; GSI: $\mathrm{d}=0.04, P<0.01)$ revealed that both variables were not normally distributed, whilst examination of quantile-quantile plots (Q-Q plots) showed that the data were approximately normally distributed, although some heteroscedasticity was observed. Because the violations of assumptions of normality were small in both cases, and because the parametric analysis is generally robust to such small-medium deviations, the data were not transformed.

\section{a) Shell length}

Variation in shell length was analysed using a two-way ANOVA (analysis of variance) as a function of habitat type and lineage and their interactions $(P<0.05)$. Paired $t$-tests were 
employed to test the hypothesis that shell length differs as a function of habitat type irrespective of lineage and with regard to the lineage regardless of habitat type, respectively. Cohen's ' $d$ ' effect size ' $r$ ' of shell length was tested for lineages ( $\mathrm{NH} M g$ vs SHMg) and habitat type (reef vs marina). Cohen's ' $d$ ' evaluates the size of an effect of the test statistic (observed $P$-value) because a significant effect does not necessarily mean a large effect. The evaluation relies on standard deviations instead of standard errors. Cohen's ' $d$ ' measures the size of the mean difference in terms of the standard deviation. The magnitude interpretations of the Cohen's $d$ value are; $<0.30$ is small effect size, 0.50 is moderate effect size, and $>0.80$ is a large effect size (Cohen 1992).

$$
\begin{aligned}
& \text { Cohen's } d=M_{1}-M_{2} / \mathrm{s}_{\text {pooled }} \\
& \text { where } \mathrm{s}_{\text {pooled }}=\sqrt{ }\left[\left(\mathrm{s}_{1^{2}}+\mathrm{s}_{2}{ }^{2}\right) / 2\right] \\
& \quad \mathrm{r}_{\mathrm{Yl}}=\mathrm{d} / \sqrt{ }\left(\mathrm{d}^{2}+4\right)
\end{aligned}
$$

where; $\mathrm{d}=$ Cohen value, $\mathrm{r}=$ effect-size, $M_{1}=$ Mean of group $1, M_{2}=$ Mean of group 2, $\sigma_{1}=$ Standard deviation of group 1, $\sigma_{2}=$ Standard deviation of group 2.

\section{b) Gonadosomatic index (GSI)}

Correlation and regression analyses were conducted to determine the relationship between GSI (\%) and shell length (cm) of SHMg and $\mathrm{NHMg}$ between the reef and marina habitats. Because larger (presumptive older) individuals have greater gamete production than smaller mussels (Rodhouse et al. 1986), it is important to establish that any difference in GSI between the lineages results from the genotypic background rather than a bias in the collection of larger versus smaller mussels. The regressions between GSI vs shell length were plotted with $95 \%$ confidence intervals; $\mathrm{R}^{2}$ and $P$ values were calculated for each association. The significance of these tests was set at $P<0.05$.

Analysis of covariance (ANCOVA) was performed, with shell length as co-variate, habitat-type, lineage and month as the independent variables and GSI as the dependent variable. GSI were analysed using a three-way factorial ANCOVA as a function of; the effects of the interaction of the factors; month, habitat type and lineage were analysed. The significance level was set at $P<0.05$ with $P<0.001$, indicating high significance Paired $t$-tests were also employed to test the hypothesis that GSI values differ as a function of habitat type irrespective of lineage and for lineage regardless of habitat type, respectively. Lineage-specific GSI was also tested in each habitat using a paired $t$-test. Cohen's ' $d$ ' effect-size ' $r$ ' was calculated for GSI for the habitat type (reef vs marina) to test the effect size of the significant results. 


\subsection{Results}

Of the 2880 mussels, the $16 \mathrm{~s}$ mitochondrial rDNA RFLP assay was able to identify a total of $1884 \mathrm{SHMg}$ (native), $656 \mathrm{NHMg}$ (non-native) and $273 \mathrm{NHMe} / \mathrm{Mg}$ hybrids from the monthly reef (natural) and marina (man-made) habitat collections (i.e., 2813 of 2880 mussels or $97.7 \%$ of all individuals). However, the RFLP assay failed to identify the lineage for 67 mussels which were removed from further analyses. As M. edulis/M. galloprovincialis hybrids are of Northern hemisphere origin (i.e., they are invasive in New Zealand), they were assigned as Northern hemisphere non-native lineage (NHMg). Subsequently, 1884 SHMg and 929 NHMg (2:1, native: non-native) individuals were tested in this study.

Based on the RFLP assay results, testing revealed a non-significant difference in $\mathrm{NH} M g$ and $\mathrm{SH} M g$ distributions between the reef and marina habitats $\left(\chi^{2}=0.003 \mathrm{df}=1, P=0.96\right)$. Both the habitats were dominated by native $\mathrm{SH} M g$ compared to $\mathrm{NH} M g$ (Reef: $\mathrm{SHMg}=$ $66.74 \%, \mathrm{NHMg}=33.26 \%$; Marina: $\mathrm{SH} M g=66.57 \%, \mathrm{NH} M g=33.43 \%$; Figure 4.3.1).

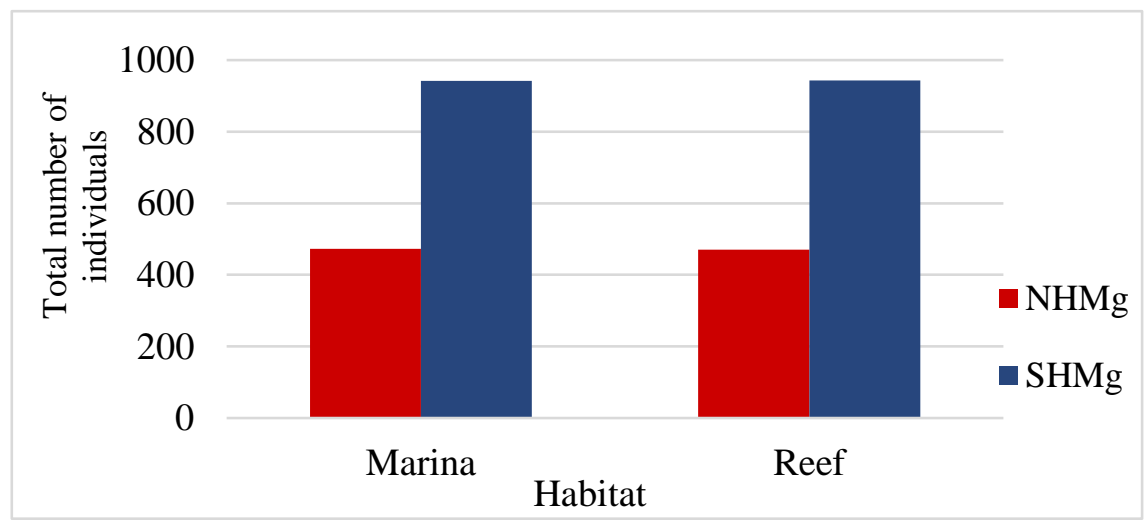

Figure 4.3.1. Total number of Northern hemisphere (NHMg-non-native) and Southern hemisphere (SHMg-native) Mytilus galloprovincialis at the marina and reef habitats.

\subsubsection{Shell length}

The shell length of the mussels ranged from $2.5-8.30 \mathrm{~cm}$ with a mean shell length of $5.23 \mathrm{~cm}$ \pm 0.85 irrespective of habitat type and lineage. Two-way ANOVA revealed that shell length differed significantly between habitat type $(P=0.008)$, but not between lineage $(P=0.19)$ and no interaction effect between Habitat $\times$ Lineage was detected $(P=0.26)$ (Table 4.3.1). Paired $t$-tests of shell length as a function of habitat type revealed a significant difference ( $t$-value $=$ 2.40, df $=2812, P<0.05$; Table 4.3.2) with larger mean shells occurring at marina $(5.27 \mathrm{~cm} \pm$ $0.9)$ than at reef $(5.20 \mathrm{~cm} \pm 0.8)$ habitats. However, such small differences in shell length (to the level of tenths of a millimetre) are not likely to have any biological significance. These results were supported by Cohen's $d$ value (habitat type: $d=0.09, \mathrm{r}=0.046$ ) which states that 
the effect size of shell length between habitat type is trivial (Table 4.3.2). A paired $t$-test of shell length as a function of lineage indicated no significant difference in shell length between NHMg and SHMg lineage $(t$-value $=1.30, \mathrm{df}=2812, P=0.19$; Table 4.3.2).

Table 4.3.1. Two-way ANOVA for shell length $(\mathrm{cm})$ as a function of habitat type and lineage (significance $=P<0.05$, marked in bold).

\begin{tabular}{|l|c|c|c|c|}
\hline Source of variation & df & MS & F & $P$ \\
\hline Habitat type & 1 & 5.00 & 6.94 & $\mathbf{0 . 0 0 8}$ \\
\hline Lineage & 1 & 1.19 & 1.65 & 0.19 \\
\hline Habitat type x Lineage & 1 & 0.90 & 1.25 & 0.26 \\
\hline Error & 2810 & 0.72 & & \\
\hline
\end{tabular}

$(\mathrm{df}=$ degree of freedom, $\mathrm{MS}=$ mean square, $\mathrm{F}=\mathrm{F}$-statistic, $P=P$-value $)$

Table 4.3.2. Paired $t$-tests for shell length (SL) as a function of habitat type and lineage (significance $=P<0.05$, marked in bold). Cohen's $d$ effect size ' $r$ ' of shell length for habitat type (reef vs marina) and lineage ( $\mathrm{NH} M g$ vs $\mathrm{SH} M g$ ).

\begin{tabular}{|l|l|c|c|c|c|c|}
\hline Variable & & Mean SL $(\mathrm{cm}) \pm$ SD & $t$-value & $P$ & Cohen's $d$ & Effect-size 'r' \\
\hline Habitat type & Marina & $5.28 \pm 0.90$ & -2.40 & $\mathbf{0 . 0 2}$ & 0.093 & 0.046 \\
\cline { 2 - 7 } & Reef & $5.20 \pm 0.80$ & & & & \\
\hline Lineage & NHMg & $5.20 \pm 0.87$ & 1.30 & 0.19 & 0.058 & 0.029 \\
\cline { 2 - 8 } & SHMg & $5.25 \pm 0.84$ & & & & \\
\hline
\end{tabular}

$\mathrm{SD}=$ Standard deviation, $t$-value $=\mathrm{t}$-statistic

\subsubsection{Regression - GSI as a function of shell length for the NHMg and SHMg lineages}

At reef sites, no significant effect $\left(\mathrm{R}^{2}=0.0009, P=0.35\right)$ was observed between shell length and GSI of NHMg and $\mathrm{SH} M g$, but there was a significant weak relation $\left(\mathrm{R}^{2}=0.01, P<0.0001\right)$ at marina sites for both lineages where shell length coincided with GSI (Table 4.3.3).

Table 4.3.3. Results for regression for Gonadosomatic index (GSI \%) as a function of shell length for $\mathrm{NH} M g$ and $\mathrm{SH} M g$ at the marina and reef habitats (significance $=P<0.05$, marked in bold).

\begin{tabular}{|c|c|c|c|c|}
\hline Habitat type & $\mathrm{R}^{2}$ & $\mathrm{R}$ & $P$ & $\mathrm{y}$ \\
\hline Reef & $<0.001$ & 0.03 & 0.35 & $13.9451+1.1855^{*} \mathrm{x}$ \\
\hline Marina & 0.011 & 0.12 & $<\mathbf{0 . 0 0 0 1}$ & $13.9451+1.185{ }^{*} \mathrm{x}$ \\
\hline
\end{tabular}




\subsubsection{GSI as a function of habitat type and lineage}

GSI values of SHMg (native) at reef sites ranged from $0-51.3 \%$ and at the marina sites from $0-60.6 \%$. GSI values of NHMg (non-native) ranged from $0-50.8 \%$ and $0-57.6 \%$ at marina sites. Three-way ANCOVA testing for GSI as a function of the month (sample intervals), lineage and habitat type with shell length as co-variate showed no significant interaction (Table 4.3.4). However, significant results were observed for factors; month, habitat type and their interaction (Month $\times$ Habitat type; $P<0.001$ ). Furthermore, Tukey HSD post hoc test indicated statistically higher GSI values of mussels at reef than at marina sites (Marina: 20.20\% \pm 10.03 ; Reef: $22.80 \% \pm 8.84)$.

Cohen's $d$ test $(d=0.275, \mathrm{r}=136)$ showed a trivial effect of the significance of GSI between habitat type (Table 4.3.5). The GSI values as a function of Habitat type $\times$ Month indicated significant results only for the months, July ( $d=0.426$, moderate effect), November ( $d=809$, large effect) and December $(d=667$, large effect) (Table 4.3.5). The GSI values of mussels were relatively higher at reef (natural) habitat than at marina (man-made) habitat (Table 4.3.5). Therefore, indicating relatively larger spawning activity in marinas, especially during November followed by quick gametogenesis in December compared to reproductive activity in reef habitat (Figure 4.3.3).

Table 4.3.4. Results of ANCOVA for GSI values and shell length (cm; Co-variate) as a function of Month $\times$ Lineage $\times$ Habitat type (significance $=P<0.05$; marked in bold).

\begin{tabular}{|l|c|c|c|c|}
\hline Source of variation & df & MS & F & $P$ \\
\hline Month $\times$ Lineage $\times$ Habitat type & \multicolumn{3}{|c|}{} \\
\hline Shell length & 1 & 6492.501 & 85.5688 & $<\mathbf{0 . 0 0 0 1}$ \\
\hline Month & 11 & 2809.963 & 37.0343 & $<\mathbf{0 . 0 0 0 1}$ \\
\hline Lineage & 1 & 13.699 & 0.1805 & 0.67 \\
\hline Habitat type & 1 & 4228.210 & 55.7263 & $<\mathbf{0 . 0 0 0 1}$ \\
\hline Month $\times$ Lineage & 11 & 92.633 & 1.2209 & 0.27 \\
\hline Month $\times$ Habitat type & 11 & 339.841 & 4.4790 & $<\mathbf{0 . 0 0 0 1}$ \\
\hline Lineage $\times$ Habitat type & 1 & 11.594 & 0.1528 & 0.69 \\
\hline Month $\times$ Lineage $\times$ Habitat type & 11 & 44.818 & 0.5907 & 0.84 \\
\hline Error & 2765 & 75.875 & & \\
\hline
\end{tabular}

$(\mathrm{df}=$ degree of freedom, $\mathrm{MS}=$ mean square, $\mathrm{F}=F$-statistic, $P=P$-value $)$ 
Table 4.3.5. Tukey HSD post hoc tests for GSI values as a function of significant factors as per ANCOVA, i.e. habitat type and month (significance $P<0.05$, marked in bold). Cohen's $d$ effect size of GSI for habitat type (reef vs marina) for significant effects.

\begin{tabular}{|c|c|c|c|c|c|c|c|}
\hline Variable & & $\begin{array}{l}\text { GSI values } \\
(\%) \pm \mathrm{SD}\end{array}$ & MS & $\mathrm{df}$ & $P$ & $\begin{array}{c}\text { Cohen's } \\
d\end{array}$ & $\begin{array}{l}\text { Effect- } \\
\text { size ' } r \text { ' }\end{array}$ \\
\hline \multirow[t]{2}{*}{ Habitat type } & Marina & $20.20 \pm 10.03$ & \multirow[t]{2}{*}{78.194} & \multirow[t]{2}{*}{2766} & $<0.0001$ & \multirow[t]{2}{*}{0.275} & \multirow[t]{2}{*}{0.136} \\
\hline & Reef & $22.80 \pm 8.84$ & & & & & \\
\hline \multirow{12}{*}{$\begin{array}{l}\text { Month } \\
\text { Habitat type } \\
\text { (Natural vs } \\
\text { Man-made) }\end{array}$} & June & & \multirow[t]{12}{*}{78.194} & \multirow[t]{12}{*}{2766} & 0.926 & & \\
\hline & July & & & & 0.011 & 0.426 & 0.208 \\
\hline & August & & & & 0.136 & & \\
\hline & September & & & & 1.00 & & \\
\hline & October & & & & 0.617 & & \\
\hline & November & & & & 0.00001 & 0.809 & 0.375 \\
\hline & December & & & & 0.00007 & 0.667 & 0.316 \\
\hline & January & & & & 0.467 & & \\
\hline & February & & & & 0.99 & & \\
\hline & March & & & & 1.00 & & \\
\hline & April & & & & 0.99 & & \\
\hline & May & & & & 0.54 & & \\
\hline
\end{tabular}

$\mathrm{SD}=$ Standard deviation, $t$-value $=\mathrm{t}$-statistic

Overall, the GSI cycles of both mussel lineages at the reef and marina sites were qualitatively very similar (Figure 4.3.2). At reef habitats, the GSI values were highest during the start of the austral winter (June) for both species ( $\mathrm{SH} M g=28.82 \% \pm 7.28, \mathrm{NHMg}=29.08 \%$ \pm 6.32 ) indicating gametogenesis had occurred earlier. GSI values decreased dramatically in August (end of winter) reaching their lowest values ( $\mathrm{SHMg}=18.76 \% \pm 6.93, \mathrm{NHMg}=18.18 \%$ \pm 7.04 ) (Figure 4.3.2 a), suggesting spawning activity. This was followed by an increase in GSI values during September-October (gametogenesis), and again a drop in GSI values (spawning) during austral spring (October-November), especially in November ( $\mathrm{SH} M g=19.39 \% \pm 10.27$, $\mathrm{NH} M g=20.55 \% \pm 8.72$ ). A gradual recovery period (increase in GSI values - gametogenesis) from December to May (Summer-Autumn) then followed (Table 4.3.6).

At the marina sites, the highest GSI values $(\mathrm{SHMg}=27.33 \% \pm 11.47, \mathrm{NH} M g=25.40 \%$ \pm 11.56 ) were observed in June (Figure 4.3.2 b), suggesting that gametogenesis occurred from May-June (austral autumn and early winter), or perhaps earlier. A sudden drop in GSI values 
in August $(\mathrm{SH} M g=14.51 \% \pm 8.54, \mathrm{NH} M g=15.51 \% \pm 6.88)$ indicated a spawning period. The GSI values were lowest in November $(\mathrm{SH} M g=12.88 \% \pm 8.27, \mathrm{NH} M g=11.24 \% \pm 8.98)$, and the gametes seemed to be spawned out (Table 4.3.6). Two spawning events were observed from June-August (austral winter) and October-November (spring) for $\mathrm{NH} M g$ and $\mathrm{SH} M g$ on both the habitats.

a) Reef habitat

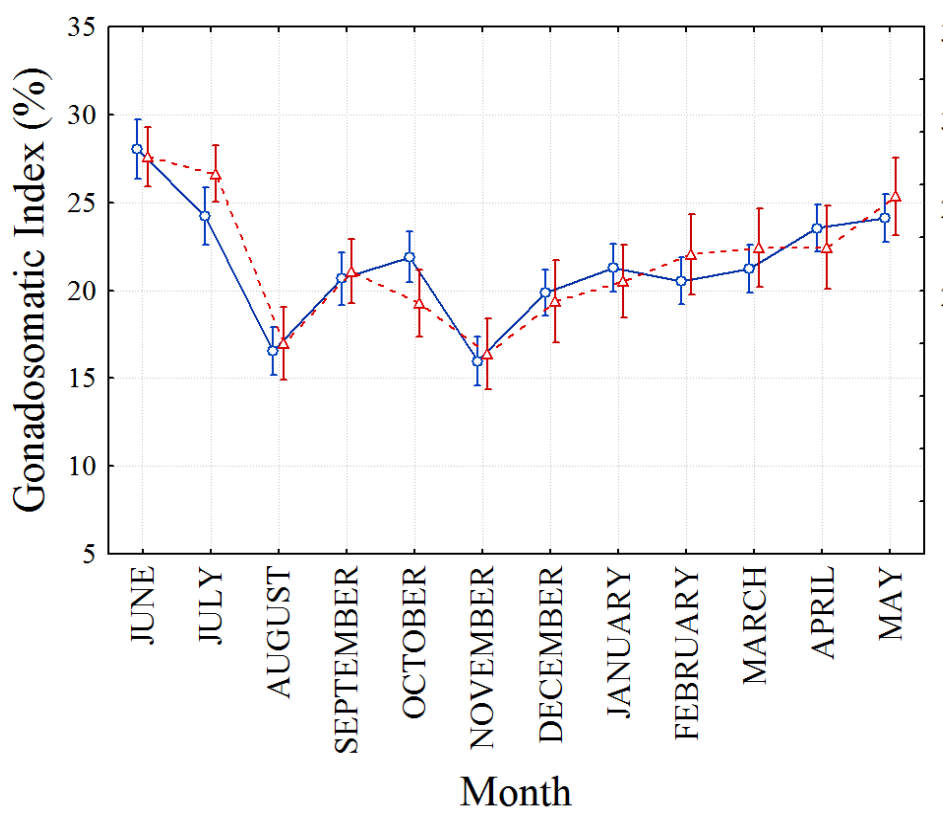

b) Marina habitat

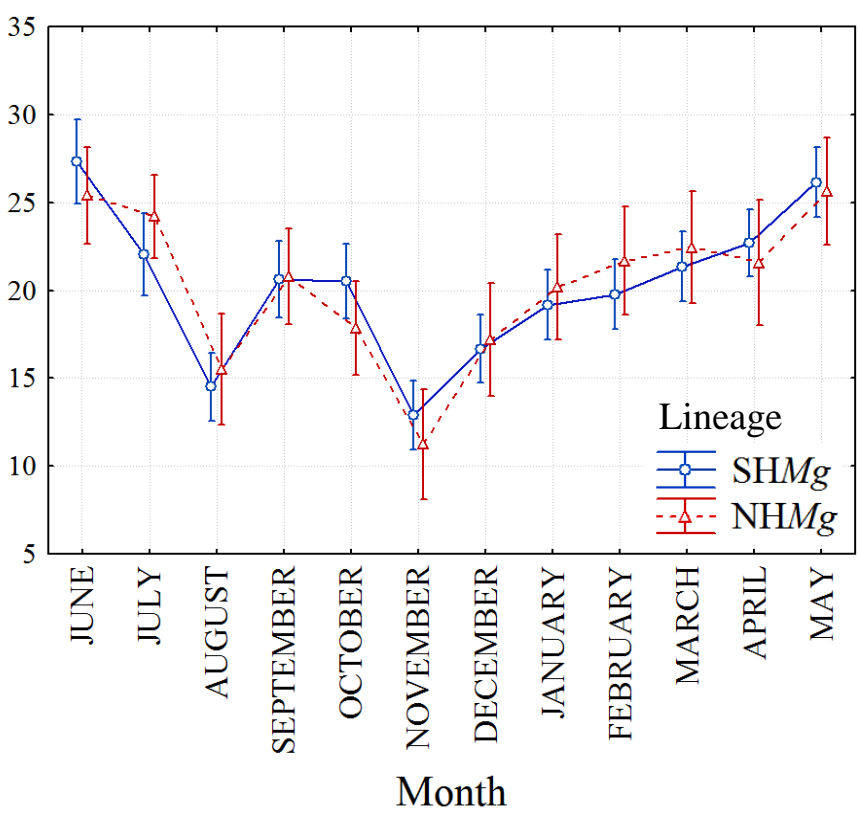

Figure 4.3.2. Monthly variations of the GSI values of SHMg (blue) and $\mathrm{NHMg}$ (red) lineages at a) marina and b) reef habitats in Wellington Harbour from June 2017-May 2018.

Table 4.3.6. Monthly variations in Gonadosomatic Index $(\%) \pm$ standard deviation (SD) of SHMg and NHMg at reef and marina habitats during June 2017-May 2018.

\begin{tabular}{|l|c|c|c|c|}
\hline \multirow{2}{*}{ Month } & \multicolumn{2}{|c|}{ Reef habitat } & \multicolumn{2}{c|}{ Marina habitat } \\
\hline June & $29.08 \pm 6.32$ & $28.82 \pm 7.28$ & $25.40 \pm 11.56$ & $27.33 \pm 11.47$ \\
\hline July & $28.98 \pm 10.64$ & $26.48 \pm 10.74$ & $24.22 \pm 11.29$ & $22.05 \pm 10.88$ \\
\hline August & $18.18 \pm 7.04$ & $18.76 \pm 6.93$ & $15.51 \pm 6.88$ & $14.51 \pm 8.54$ \\
\hline September & $21.33 \pm 6.15$ & $20.69 \pm 5.96$ & $20.80 \pm 8.67$ & $20.64 \pm 9.87$ \\
\hline October & $20.87 \pm 7.69$ & $23.29 \pm 7.37$ & $17.84 \pm 7.94$ & $20.50 \pm 9.45$ \\
\hline November & $20.55 \pm 8.72$ & $19.39 \pm 10.27$ & $11.24 \pm 8.98$ & $12.88 \pm 8.27$ \\
\hline December & $22.17 \pm 9.84$ & $22.87 \pm 8.48$ & $17.21 \pm 9.08$ & $16.66 \pm 9.03$ \\
\hline
\end{tabular}




\begin{tabular}{|l|c|c|c|c|}
\hline January & $20.90 \pm 6.88$ & $23.37 \pm 7.69$ & $20.18 \pm 7.41$ & $19.18 \pm 7.87$ \\
\hline February & $22.56 \pm 11.57$ & $21.21 \pm 10.50$ & $21.68 \pm 7.58$ & $19.77 \pm 8.47$ \\
\hline March & $22.42 \pm 5.58$ & $21.12 \pm 6.29$ & $22.45 \pm 8.71$ & $21.36 \pm 7.93$ \\
\hline April & $23.22 \pm 6.95$ & $24.46 \pm 6.06$ & $21.58 \pm 8.99$ & $22.69 \pm 9.07$ \\
\hline May & $24.99 \pm 10.39$ & $22.26 \pm 11.31$ & $25.64 \pm 11.78$ & $26.15 \pm 10.59$ \\
\hline
\end{tabular}

\subsection{Discussion}

\subsubsection{Background}

With the proliferation of man-made structures along the world's coast, there are many chances for a non-native species to establish and spread (Simberloff \& Von Holle 1999; Bulleri \& Airoldi 2005; Bulleri et al. 2006; Tyrrell \& Byers 2007; Dafforn et al. 2009, 2012; Airoldi \& Bulleri 2011; Perkol-Finkel et al. 2012; Theuerkauf et al. 2018). This is especially the case for Northern hemisphere M. galloprovincialis, which is known as one of the aggressive invaders, with competitive traits such as high growth, high reproduction rate and phenotypic plasticity that help them acclimatise to many environments (Dafforn 2017; Johnston et al. 2017; Simpson et al. 2017; Epstein \& Smale 2018; Riera et al. 2018). Having said that, M. galloprovincialis is highly used in shellfish industries for its economic value all around the world as it has successfully invaded most of the regions worldwide (Wonham 1999; Daguin \& Borsa, 2000; Hilbish et al. 2000; Anderson \& Thompson 2002; Borsa et al. 2012; Oyarzún et al. 2016; Pickett \& David 2018). Northern hemisphere M. galloprovincialis lineage has invaded $\sim 0.7 \mathrm{M}$ ybp in NZ and has observed to have spread in most of the regions, marinas, ports or natural rocky reefs (Gardner et al. 2020). These blue mussels form biogenic reefs providing refuge to various other species but competing for food and space could be a negative impact on the native habitat-forming species (Crooks 2002; Castilla et al. 2004; Borthagaray \& Carranza 2007; Sousa et al. 2009; Bertolini et al. 2017). The congeneric comparisons help to determine the attributes of invasions, to examine the performance of non-native species compared to native species and to determine if they outcompete native congeners. This chapter aimed to investigate the reproductive output (measured as GSI) of $\mathrm{NHMg}$ and $\mathrm{SH} M g$ on natural rocky reefs and marina sites as analogous to natural and man-made habitats. Patterns of abundances, shell length and GSI of the two lineages were tested for a year at natural reef and marina sites.

\subsubsection{Abundances}

In this study, the $\mathrm{NHMg}$ and $\mathrm{SH} M g$ co-occur on both natural and man-made habitats as also previously seen in Wellington Harbour (Westfall 2011; Gardner \& Westfall 2012). The two 
lineages, $\mathrm{NH} M g$ and $\mathrm{SH} M g$, were distinguished using 16s RNA RFLP assay developed by Westfall \& Gardner (2010). When considering the reproduction rate in displacing native lineage with non-native lineage, competitive traits and abundances of native species also play an important role to decide the success of non-native species. The native SHMg lineage was most abundant at both natural and man-made habitats throughout the one year of the study period. It has been widely reported that non-native species prefer man-made structures/ habitats and native habitats to promote more native species and local communities (Chapman \& Bulleri 2003; Glasby et al. 2007; Airoldi et al. 2015; Marraffini \& Geller 2015; Gestoso et al. 2017; Johnston et al. 2017; Simpson et al. 2017). However, in this case, there was no preference for habitats observed by $\mathrm{NHMg}$, but it is observed to be very well established. As seen in NW Spain, the larvae of M. galloprovincialis settled on various kinds of available substrata (Caceres Martinez et al. 1994). Native lineage SHMg was still the dominant space occupier at both habitat types and is not yet seen to be displaced by non-native $\mathrm{NHMg}$ lineage.

\subsubsection{Shell length as a function of habitat type and lineage}

The shell length of the blue mussels was examined in this study to observe if any differences exist in the shell lengths of $\mathrm{NH} M g$ and $\mathrm{SH} M g$ at natural reef sites or marina sites. Previous studies have reported smaller sized limpets (Moreira et al. 2006) and barnacles (Martins et al. 2016) on man-made structures compared to natural reefs. The shell length of the mussels collected in this study ranged from 25 to $83 \mathrm{~mm}$. The $M$. galloprovincialis observed in eastern Pacific, California was an average shell length of $60.7 \mathrm{~mm}$ (Dutton \& Hofmann 2008) whilst in Chile ranged from 32 to $70 \mathrm{~mm}$ (Díaz et al. 2019). In this study, the shell length of the two lineages collected at random from reef and marina sites were relatively similar with an average length of $52.0 \mathrm{~mm} \pm 8.7$ for $\mathrm{NH} M g$, and $52.5 \mathrm{~mm} \pm 8.4$ for SHMg. Therefore, the average shell length of the mussels collected was within a standard shell length range. The shell length showed statistically significant differences between habitats (Reef vs Marina) irrespective of the lineage; however, the difference was small and probably without any ecological significance.

Generally, an increase in reproductive output, i.e. gamete production in a mussel is directly comparable to the age or size of the mussels. Reproductive output is calculated by gonad weight divided by total body weight (i.e., gonad + soma). Older or larger mussels are expected to have higher gamete production (Gardner \& Skibinski 1990; Seed \& Suchanek 1992). In this study, $\mathrm{NH} M g$ and $\mathrm{SH} M g$ had a mean shell length of $52.0 \mathrm{~mm} \pm 8.7$ and $52.5 \mathrm{~mm}$ \pm 8.4 , respectively, and a mean GSI value of $22.07 \% \pm 9.61$ and $21.24 \% \pm 9.5$, respectively. 
M. galloprovincialis studied in Chile had an average shell length $55.0 \mathrm{~mm}$ with GSI of $\sim 28.9 \%$ (Díaz et al. 2019) therefore, a common range of size and reproductive output range was seen in this study for both M. galloprovincialis lineages. Furthermore, there was no relationship observed between shell length and GSI for both $\mathrm{NHMg}$ and SHMg at reef sites whilst, a significant but very weak relation was observed between shell length and GSI at marina sites. It is important to note that the different habitat types (Reef vs Marina) did not have any distinct impact on the relationship of shell length to GSI for NHMg and SHMg. Therefore, I reject the hypothesis that the shell lengths of both lineages are greater at natural reef sites than at marina sites. This suggests but does not prove that growth rates of the two lineages are not significantly different at both habitat types. However, a study in Chile, comparing gonad weight in similar sized (-70 mm) native Mytilus chilensis and non-native M. galloprovincialis showed relatively higher gonad weight for native $M$. chilensis due to the physical characteristics of the two blue mussels (Díaz et al. 2019).

\subsubsection{GSI as a function of habitat type and lineage}

Comparing the reproductive effort between two congeneric species helps to determine their response to different habitat types (Thompson 1984). At exposed sites (natural rocky reefs), where there is plenty of food supply, M. galloprovincialis is observed to grow faster with increased soma and gonad production than at sheltered sites (marinas), although, stronger waves at exposed areas lead to energy investment for production of byssus threads for attachment (Steffani \& Branch 2003). There is evidence of different reproductive effort between different populations, even at a local scale (Bayne et al. 1983). For instance, food quality, food availability, tidal level and sediment type influence growth and reproduction (Honkoop and Beukema 1997; Beukema et al. 2002). Elsewhere, a study comparing the reproductive output of limpets on seawalls vs natural reefs observed relatively small-sized limpets leading to low reproductive output by limpets on seawalls (Moreira et al. 2006). However, in my study, the reproductive output (GSI) as a function of habitat type showed significant differences (Marina $=20.20 \% \pm 10.03$, Reef $=22.80 \% \pm 8.84$ ), therefore accepting the hypothesis that reproductive output of both lineages is relatively higher at natural reef than at marina sites, but the differences in GSI values are very small. The ecological significance of such small differences in GSI values is yet to be determined. This study observed no significant effect of GSI values between lineages

GSI values as a function of the interaction effect of habitat type $\times$ lineage did not show significant differences. Therefore, the lineages ( $\mathrm{NHMg}$ and $\mathrm{SHMg}$ ) did not show differences 
in reproductive output at each habitat type, i.e. reef (natural) and marina (man-made) habitats, respectively. Thus, I reject my hypothesis that $\mathrm{NHMg}$ has a greater reproductive output at marina sites than at natural reef sites, as both the lineages had relatively higher GSI values at reef sites than marina sites. The reproductive output of the mussels is a function of the partitioning of energy between somatic growth and reproduction and also acts as a physiological stress response (Cáceres-Martínez \& Figueras 1998; Seed \& Suchanek 1992; Okaniwa et al. 2010). In the case of environmental stress like temperature variation, low food availability, desiccation, predation, and wave exposure, mussels may invest relatively more energy in defence against the stress than in reproduction (e.g., Gosling 1992; Steffani \& Branch 2003). In this study, the co-occurring NHMg and SHMg were sampled within environments with not very distinct variations in temperature and food availability (Gardner, pers. comm., unpublished data), which might be the reason for the similar reproductive output by the two lineages at both habitats (Reef vs Marina).

The GSI values as a function of the interaction of factors, month $\times$ habitat type indicated significance during the months - July, November and December. The GSI values were relatively higher at reef sites than at marina sites. Subsequently, these results indicate that the mussels irrespective to the lineages had a quicker first spawning response in July and a larger spawning activity during November was observed in the marina sites compared to reef sites. However, the reason for larger spawning activity by the mussels in the marina could be speculated because of the slightly warmer temperatures in enclosed marina conditions. However, there are no environmental data to support this speculation.

\subsubsection{Reproductive cycle}

Temporal variations in reproductive output is a likely result of gamete production (gametogenesis) and gamete loss (mostly spawning, but may also be resorption) (Seed \& Suchanek 1992; Cáceres-Martínez \& Figueras 1998). In this study, temporal variations (monthly) in GSI values showed significant difference as a function of habitat type (Reef vs Marina) but not as a function of lineage ( $\mathrm{NH} M g$ vs $\mathrm{SH} M g$ ). However, the reproductive patterns for both lineages ( $\mathrm{NHMg}$ vs $\mathrm{SH} M g$ ) showed a similar timing of gametogenesis and spawning at both Reef vs Marina habitats. Previous studies of mussel reproductive output have reported differences in spawning periods between other Mytilus spp. (Gardner \& Skibinski 1990; Secor et al. 2001; Toro et al. 2002). In this study, two spawning events were observed with two periods of gonad build-up (gametogenesis) observed during summer and spring. In this study, gametogenesis took place in early winter (June) and with spawning during late winter (August), 
followed by a quick gonad condition recovery in spring (October), and a second spawning during late spring (November). These events were recorded by observing the conspicuous peaks and drops in GSI values. These observations also indicate the influence of temperature on the gonad cycle of the mussels (Seed \& Suchanek 1992; Cáceres-Martínez \& Figueras 1998) as well as food availability during May leading to gametogenesis (Lachowicz 2005). For instance, Okaniwa et al. (2010) reported that the gametogenesis in M. galloprovincialis in Japan coincided with an increase in chlorophyll-a concentration as well as low sea and air temperature.

The spawning events of $\mathrm{NH} M g$ and $\mathrm{SH} M g$ lineages coincided with rising water temperatures as has been previously reported for other Mytilus spp. (Seed \& Suchanek 1992; Carrington 2002; Okaniwa et al. 2010). Warmer temperatures were observed to influence gametogenesis, but lower temperatures stimulated spawning (Ceccherelli \& Rossi 1984; Oyarzún et al. 2011). Such spawning periods were also observed in M. galloprovincialis in South Africa (Zardi et al. 2007) and NW Spain (Cáceres-Martínez \& Figueras 1998) during late spring and summer. However, M. galloprovincialis in Pacific coast (Curiel-Ramirez \& Caceres-Martinez 2004) and M. edulis and M. galloprovincialis in southwestern England (Secor et al. 2001) has previously shown a single spawning event from autumn to early spring. M. galloprovincialis in South Africa showed two spawning periods, during summer and winter (Schurink \& Griffiths 1991). Gardner \& Skibinski (1990) reported prolonged reproductive cycles and multiple spawning events in M. edulis/ M. galloprovincialis hybrids.

The NHMg and SHMg lineages show similar responses in terms of reproduction timing and output in Wellington Harbour, during this study period. Even though, in this study, difference by sex of the mussels in the GSI was not addressed. A study in southern New Zealand on gonad indices of blues mussels, irrespective to their lineages, i.e. NHMg and $\mathrm{SH} M g$ indicated synchronous trend between male and female blue mussels (Smart et al 2020). Similar spawning, i.e. release gametes at the same time may facilitate hybridisation between the two lineages, and further studies should concentrate on observing if there are chances of backcrossing and future impacts on the native SHMg lineage (Gardner \& Skibinski 1990; Secor et al. 2001). Many studies have referred to the importance of spawning periods of closely related species to examine the scope of hybridisation (Gardner \& Skibinski 1990, Seed 1992; Seed \& Suchanek 1992; Wonham 2004; Westfall \& Gardner 2013; Oyarzún et al. 2016), especially where they co-exist (McDonald et al. 1991; Seed 1992; Elliott et al. 2008; Brannock et al. 2009). 
Hybridisation and repeated backcrossing with the parental species can risk the extinction of the native species (Fitzpatrick et al. 2010; Harrison 2012). Subsequently, the concern of hybridisation was also reported by Westfall \& Gardner (2013), they reported that continuous invasion, hybridisation and introgression preferring the non-native $\mathrm{NH} M g$ lineage could extirpate the native $\mathrm{SH} M g$ lineage. There is evidence of high rates of hybridisation between native and non-native Mytilus trossulus and Mytilus galloprovincialis, respectively, with low introgression in Japan (Brannock et al. 2009) and California, USA (Saarman \& Pogson 2015), whilst a higher rate of introgression in Australia and NZ (Westfall \& Gardner 2013). In the North Atlantic, hybridisation between M. edulis and M. galloprovincialis had led to asymmetric introgression favouring M. galloprovincialis alleles (Gardner \& Skibinski 1988; Bierne et al. 2002). In the north-eastern Pacific, low rates of hybridisation and limited introgression were observed between $M$. galloprovincialis and M. trossulus favouring larger sized M. galloprovincialis alleles (Anderson et al. 2002; Wonham 2004).

In summary, this study concluded that the co-occurring non-native, $\mathrm{NHMg}$ and native, $\mathrm{SH} M g$ lineages have no preference towards natural reefs or man-made habitats for their ecological functioning. This is because the reproductive output (GSI) and shell length were nearly similar between the two lineages at both the habitats. $\mathrm{NHMg}$ and $\mathrm{SH} M g$ lineages also showed similar reproductive patterns at both habitats for the 1-year study period. Two spawning events (late winter and late spring) with a major and a quick gametogenesis period observed. Future work comparing the performance of congeners should focus on the effects of highly varying environmental conditions on natural and man-made structures.

\subsubsection{Management implications}

It is challenging to predict invasion occurrences and success through accidental human mediation and to avoid the continuous invasions of $\mathrm{NHMg}$ lineage. Therefore, it is crucial to undertake management applications and strategies focussing on hull cleaning and ballast water exchange (Schwindt et al. 2014). A baseline study is required to identify the non-native $M$. galloprovincialis lineage and then to examine what impacts they have on the native communities, especially the co-existence of $\mathrm{NHMg}$ and SHMg over time (e.g., Gardner et al. 2016). However, with the ongoing addition of coastal structures, stepping stone invasions are ubiquitous (e.g., Apte et al. 2000) and once established, eradication is nearly impossible (Mack et al. 2000). M. galloprovincialis is an aggressive invader, with external fertilisation and the production of millions of larvae with a long-lived pelagic state it is impossible to stop its spread. 
The competitive traits of $M$. galloprovincialis, i.e. fast growth, tolerance to stress, high reproduction and immunity to disease is essential in terms of aquaculture/ shellfish farming (Branch \& Steffani 2004) and ironically is also important in terms of invasions.

In this study, it is evident that $\mathrm{NH} M g$ and $\mathrm{SH} M g$ respond similarly, in terms of their reproductive patterns. Furthermore, the lack of ecological differences - GSI, shell length, etc. - reflect the very close evolutionary history of $\mathrm{NHMg}$ and $\mathrm{SH} M g$ and raises a question about how important it is to invest in the management of $\mathrm{NHMg}$. From a manager's perspective, it may not be important to invest in the management of $\mathrm{NHMg}$ instead focus on different problems such as the high-risk invasive species. This study has highlighted that native, and non-native $M$. galloprovincialis have similar biological characteristics; therefore, eradication of non-native Northern M. galloprovincialis lineage may not be necessary. 


\section{CHAPTER 5}

\section{GENERAL DISCUSSION}

\subsection{Background}

The number of biological invasions has increased over the decades, and invasions are now ubiquitous (Firth et al. 2016; Olenin et al. 2016; Johnston et al. 2017). There is evidence of ports and harbours, increasing opportunities for non-native species to settle and proliferate (Zbawicka et al. 2019). This thesis aimed to investigate the marine man-made environments, their impacts on the marine biodiversity regarding species status and the factors facilitating the non-native species. In this thesis, the community composition and species status (native, nonnative and cryptogenic) between natural and man-made habitats were analysed. Chapter 1 presented basic information on habitat type and effects of man-made structures in the coastal environment and in relation to bioinvasions. Data Chapter 2 focussed on the national scale baseline port surveys (Australian and New Zealand port surveys) and examined the factors port type and latitudinal groups for the community composition and species status. The local-scale study (Wellington Harbour) was conducted using settlement tile arrays (PVC and slate tiles) in the reef and marina habitats (Chapter 3). The data was applied for comparative assessment of the community composition, ecological succession of species and frequencies of species status between the habitat types and substratum types. Lastly, in Chapter 4, the reproductive output (GSI, presumptive fitness) of the congener blue mussel lineages (non-native, $\mathrm{NHMg}$ and native $\mathrm{SH} M g$ ) was analysed at the natural reef and man-made marina habitats. By comparing the GSI results between the habitat type, the reproductive cycles (spawning and gametogenesis), and the reproductive output, between the lineages, were constructed. In the present chapter, the main conclusions from the previous chapters are summarised. Additionally, the limitations, future research and management suggestions are discussed.

\subsection{Chapter synthesis}

In chapter 2, the two national-scale baseline port surveys; Australian port survey (APS) and New Zealand port surveys (NZPS) assessed the community composition and species status as a function of surveyed ports, port type (major vs minor) and latitudinal groups. Results for APS showed that the community composition significantly varied as a function of the surveyed port. However, despite the higher frequencies of native species across all surveyed ports, there was 
no specific pattern in surveyed ports observed for community composition. The community composition and species status significant results for the factor port type with relatively abundant non-native species observed at major ports compared to minor ports. For latitudinal groups, the community structure and species status showed a significant relationship with an increase in non-native species with the increase in latitudes. For NZPS, results indicated significance for community composition and species status as a function of surveyed ports. There was a significant relationship observed for community composition as a function of latitudes with high significance observed between low $\left(35^{\circ} \mathrm{S}\right)$ and high latitudes $\left(40,45^{\circ} \mathrm{S}\right)$. Hence, the results for both the dataset indicated grouping of ports located at proximity, i.e., having common species. The natural dispersal of species or domestic marine traffic may be the pathways for the spread of species at regional scales (Coutts \& Taylor 2004; Floerl et al. 2004; Floerl \& Inglis 2005).

The findings of the dataset analyses highlight several on-going challenges such as major commercial ports being hotspots for marine invasions and the role of shipping as the main pathway for introductions at multiple spatial scales (Bishop et al. 2017). Thereby spread of species through regional transport connecting ports for domestic trade or recreational activities. However, the influence of human-mediated transfer of species may be of less importance for marine species which have typically 3-5 weeks of larval stage (for example, molluscs, polychaetes) (Shanks 2009). Therefore, the dispersal rates of the species might be an important factor to consider the propagule pressure at regional and local scales. The species observed at both APS and NZPS are benthic species such as tunicates, barnacles, mussels, crabs, bryozoans and polychaetes, which typically need a hard substratum to adhere. Nevertheless, for species such as bryozoans and ascidians, with 2-10 hours of larval could disperse long distances; however, it can reduce their chances of survival, reduced growth rates or smaller sized adults (Marshall et al. 2003; Burgess et al. 2012). The influence of anthropogenic activities results in alteration of connectivity in marine systems (Bishop et al. 2017) and a major challenge to identify the factors characterizing the bioinvasions at multiple spatial scales. This study, however, highlights that the responses in Australia are very different from those in New Zealand, which suggests that responses are regional or country-specific and not global.

In Chapter 3, the marine biological community composition and species' abundances regarding species status were compared between man-made, and natural habitats/substrata, respectively. The field tests were undertaken in Wellington Harbour using settlement tile arrays (PVC vs slate). The aim was to determine differences in the overall species assemblage and 
species status between habitat type (natural reef vs man-made habitat) and substratum type (PVC vs slate tile). Rapid colonisation of species was observed within 3 months of submersion, with nearly $64 \%$ cover of the bare tiles. The two-year study was not enough to observe the climax community. A total of 47 putative species were observed on the tiles in this two-year study; which is nearly $1 / 4^{\text {th }}$ of the number of species seen in Wellington Harbour sampled for New Zealand port survey (Chapter 2 B).

The ecological succession observed on both habitat type and substratum type showed a similar pattern of recruitment and post-settlement processes. The community structure may be influenced to a greater extent by stochastic recruitment (Chang \& Turner 2019). The species explaining most of the variation among and between habitat types and substratum types were; cryptogenic Biofilm type 1, Green sp. 1, native crustose brown seaweed, Ralfsia verrucosa, non-native red alga Bangia atropurpurea, non-native bryozoan Watersipora subtorquata, native tunicate Asterocarpa humilis and native bryozoan Membranipora membranacea. These species are typically seen fouling on ships hulls or marina infrastructures (Connell 2001; Wood $\&$ Probert 2013). For example, the of the larval life span of bryozoan species may range from one to a few weeks (Gordon 1977); however, in the case of sea squirts Asterocarpa humilis, their natural dispersal is very limited. The marina and reef sites were at $\sim 200 \mathrm{~m}$ distance from each other; therefore, their natural dispersal is possible. The community composition showed significant results as a function of habitat type and substratum type. The differences in biological communities between man-made (marina; PVC) and natural (reef; slate) habitats/tiles are explained by abundance differences, not by species differences. The cryptogenic species were abundant at both habitat type and substratum type. The non-native species were relatively abundant at marina sites; however, did not show preference to the two substratum types. This study acknowledges the on-going problem of the role of man-made structures as more suitable habitats for non-native species. The species dispersal rate plays an important role in the spread of species from marina sites to neighbouring natural habitats. These results suggest that Wellington Harbour is a well-mixed site, and control of invasive species cannot be easily achieved.

The aim of chapter 5 was to examine whether the reproductive out (GSI) of the native ( $\mathrm{SH} M g$ ) and non-native (NHMg) lineages of the blue mussel, Mytilus galloprovincialis, differed between natural (reef) and man-made (marina) habitats. To analyse the reproductive performance, the temporal variation in the reproductive output (GSI) of the $\mathrm{NH} M g$ and $\mathrm{SH} M g$ were measured for 1 year in Wellington Harbour. The shell length of the two mussel lineages, 
when compared between natural and man-made habitats, showed a significant difference, but the difference was trivial $(\sim 0.5 \mathrm{~mm})$. The GSI of the mussels indicated significant between habitat type and sample intervals and not for lineage $\times$ sample interval, indicating similar GSI values between native $\mathrm{SH} M g$ and non-native $\mathrm{NH} M g$. The GSI values were relatively greater at reef sites, thus, indicating increased spawning activity in the marina sites. These results were portrayed in the reproduction patterns of both lineages, with $\mathrm{NH} M g$ and $\mathrm{SH} M g$ showing similar timing of gametogenesis and spawning at both the reef and marina sites. The temporal variation of GSI showed with two spawning events (August and November). The mussels (NHMg and $\mathrm{SH} M g$ ) had a large spawning event in November in the marina sites. This presumably could be because of warmer temperatures in the semi-enclosed marina conditions. The results suggest that the ecologically similar response of $\mathrm{NH} M g$ and $\mathrm{SH} M g$ (GSI: $\mathrm{NH} M g=\mathrm{SH} M g$ ) could be due to their close evolutionary affinities.

Overall, this study highlights that the most species observed were native species suggesting that the local species pools are still important for overall diversity than the introductions, even in the highly modified habitats. Additionally, many cryptogenic species were observed across all the chapters; molecular approach to taxonomy and frequent surveillance programmes - to detect the cryptic introductions should be considered. At the local scale (Chapter 3 and 4), the reef sites are performing differently from the marina sites, with relatively higher non-native species in the marinas and better spawning activity by native and non-native species in the marinas.

\subsection{Statistical vs Biological significance}

The results of my study raise several questions with regards to statistical significance and biological relevance. Under a 95\% confidence interval, the denoted $P$-values exhibit statistical significance; however, under stricter parameters (i.e. 99\% CI), statistical significance is refuted. This calls into question the biological impacts being described in these tests and the magnitude of these impacts with regards to the animal's physiology.

To process large sample size data, statistical software is convenient to conclude results. Statistical significance is important to detect differences between treatments; however, assessing biological relevance should be of primary importance. Hence, both the statistical significance and biological relevance are important to evaluate a dataset. That is why, even if the results are statistically significant, the differences are small enough to consider them as not biologically important (Lovell 2013). Cohen's $d$ test is an effect size index that evaluates the 
size of an effect in a study. It is a standardised measure of the impact of a statistically significant intervention (independent variable). Cohen's $d$ equals the difference in the means divided by the average of the standard deviations (Cohen 1992). This test can be used to accompany $t$-test or ANOVA to examine the strength of the significant results. Cohen (1992) indicated an effect size of about 0.25 was "small", about 0.5 was "medium", and about 0.8 was "large".

\subsection{Limitations of the monitoring study}

Large scale monitoring datasets (APS and NZPS) are formed by quantifying single occurrences of species on a single date; however, factors at local scales such as environmental conditions, nutrient supply, pollution, habitat complexity and physical disturbances can lead to variations in species assemblages. For instance, Underwood \& Murphy (2008) found a seasonal latitudinal increase in species richness from north to south in winter but not in summer. Therefore, a complete census of available species in an area is impossible due to seasonal variations. Surveying and re-surveying sites to have better knowledge are not cost-efficient and are very timing consuming (Bishop \& Hutchings 2011).

Current surveillance programmes are conducted with preliminary taxonomic identification based on morphology instead of molecular techniques. Very few taxonomic experts and scientists have the training to identify congeneric native and non-native species, which results in the number of cryptic invasions not being identified (Ponchon et al. 2013). Consequently, the accuracy of identification of the native and non-native species is questionable. Such inadequacies in surveillance and monitoring programmes can hinder the process of well-developed biosecurity and management approaches to restrict invasions (Peters et al. 2017). In recent years, a variety of DNA based (molecular) techniques have been developed to derive information about organisms (Pochon et al. 2017). These molecular techniques can be used to identify species, especially non-native species (Zaiko et al. 2018). Several countries - USA, Canada, Australia and New Zealand have already adopted molecular genetic techniques to survey and early detection of non-native species and support management decisions.

For settlement tile study (Chapter 3), the settlement tile arrays justified the community composition and identifying impacts of habitats for 2 years. However, it should be kept in mind that the growth on PVC and slate tiles might be a representation of natural reef or marina habitats but not an exact copy. The study period of 2 years was not enough to observe a stable or climax state of the community, as there was always $20 \%$ bare space observed on the tiles. 
With respect to environmental factors, it is important to have accurate measurements in the study areas. The variability of growth between habitats and substrata could have explained with the environmental data. Unfortunately, due to calibration difficulties, environmental data could not be included in my study. Similarly, for Chapter 4, the fact that $\mathrm{NH} M g$ and $\mathrm{SH} M g$ reproductive activity - gametogenesis and spawning could have been influenced by environmental conditions. The environmental data could have explained the differences in GSI values between reef and marina sites.

\subsection{Management implications}

Australia and New Zealand have established some of the world's strongest biosecurity and management measures, i.e. comprehensive pre-border, at-border and post-border management responses (Hewitt \& Campbell 2007; Commonwealth of Australia 2013; Ojaveer et al. 2015). However, this study has highlighted the need for regulations that address the problem of regional or local spread of non-native species. Ports, harbours and other coastal structures play a role in facilitating non-native species by providing suitable habitats and substratum, which is evident in this study. The macrofouling species observed in the study such as the bryozoans, ascidians, arthropods, settle on readily available substrata irrespective to the substratum type. Non-native species are often $r$-selected strategists, i.e., fast-growing opportunist species, and the availability of bare space can be enough to facilitate their settlement and establishment. Maintenance of coastal structures, construction of new structures and marine traffic close to intertidal habitats should be managed appropriately as displacement of native assemblages due to these activities may provide opportunities for the invaders to settle on vacant surfaces (Clark and Johnston 2009; Airoldi and Bulleri 2011; Hedge and Johnston 2012). Maintenance of structures can be employed at suitable timings considering the spawning periods of species. For instance, many species do no show reproductive activities in winter, thereby encouraging the timing of a controlled maintenance approach (Hopkins and Forrest 2010).

Many eco-engineering approaches related to multifunctional designs of coastal structures have now been investigated such as the cost-effective approaches - designing coastal structures more similar to natural rocky reefs by building structures on a gentler slope (Department of Environment and Climate Change 2009). Also, increasing the surface area for the settlement of native species or restoring local biodiversity to restrict the establishment of non-native species (Sella and Perkol-Finkel 2015). However, there is a need to have a full understanding of the functional properties of the man-made structures. Different characteristics 
of man-made structures such as size, substratum material, construction design and orientation may alter the fouling community structure. The community structure in this study did not differ between natural and man-made substratum materials, though the size of the substrata and orientation was similar between habitat type. Eco-engineering and it is potential to reduce invasions are still at an experimental stage, and the designing of appropriate structures will largely depend on coastal attributes. Therefore, coastal structures need to be monitored for longer timescales and at different habitats since varying physicochemical conditions may have different impacts on species and their functioning.

The number of bioinvasions has increased over the decades, and invasions are now ubiquitous. Eradicating every invaded species will be an expensive and more so impossible task (Ruiz et al. 2000, 2009; Hewitt et al. 2004; Forrest \& Hopkins 2013). Much of the conservation management work to date has focussed on prevention of new invasions followed by eradication of non-native species (Melbourne et al. 2007; Hewitt et al. 2009; Cook et al. 2016). However, there is still no stopping the invasion pressure. Some researchers think that the introduction of non-native species can improve the stocks of declining native species, also the economically valuable species and benefit the economy, e.g. shellfish production industries (Leppäkoski et al. 2002; Schlaepfer et al. 2011; Cook et al. 2016). It is evident from the decade worth of studies that it is difficult to get to grips with invasions and their unpredictable consequences to the environment. The importance of bioinvasions varies on a case by case basis, as in some instances they can improve the functional diversity and can also pose a threat to the native species and their environment (Leppäkoski 2002; Glasby et al. 2007; Gallardo \& Aldridge 2013; Thomsen et al. 2014; Corriero et al. 2016; Gestoso et al. 2017; Riera et al. 2018). An ongoing increase in human population and demand for resources will put pressure on the marine environment, thereby altering ecosystem services. Better integrative ecological theories providing new knowledge to stakeholders and managers can help to deliver effective management approaches.

\subsection{Future work}

Based on my results, it is clear that non-native species are abundant in major commercial shipping ports with a high frequency of international marine traffic. This study also supports the growing evidence that non-native species are generally more abundant in man-made habitats (e.g. ports, harbours, marinas) compared to natural reefs. It is undisputed that large-scale surveys and monitoring can be costly. Still, frequent monitoring of major ports receiving high volumes of marine traffic can aid with early detection and eradication measures. 
The next step is to examine the environmental conditions (biotic and abiotic) that determine the invasions and proliferation of non-native species (not included in my study). The settlement tile array study indicated ecological succession patterns for 2 years; however, if the community reached its climax state (stable state) is still not known. Therefore, future studies with relatively long immersion periods for settlement tiles may be an effective monitoring approach and could detect the climax state of a community on both habitat/substratum types. It is important to improve the knowledge about life-history traits of a species - to understand the propagule lifespan, dispersal rate and recruitment timing. Lastly, manual identification of species has its major drawback, as stated in the 'Limitation section' above. It is advisable to find cost-effective ways such as molecular tools to identify species which are already providing accurate detection of non-native species (Westfall and Gardner 2010).

\subsection{Conclusion}

This study found that the fouling community composition on the natural reef and at man-made marina habitats was similar, although relative abundances of species differed. The results suggest that Wellington Harbour is well-mixed site and with natural sites being adjacent $(\sim 200$ $\mathrm{m}$ ) to marina sites; the dispersal of species from one site to another is highly possible. However, the differences in abundances at each habitat could probably be due to environmental conditions and community dynamics in the habitat. This study forms a baseline of the community composition of the modified habitats in an already modified busy harbour (Wellington harbour). Further, the congener M. galloprovincialis native and non-native lineages lack ecological differences - GSI, shell length, etc. at reef and marina sites may be due to the very close evolutionary history of $\mathrm{NHMg}$ and $\mathrm{SHMg}$. Additionally, it would be worthwhile to assess other biotic and abiotic factors such as grazing, predation, salinity, temperature, water flow and light to explain the differences in community composition between habitat type. Analyses of baseline surveys examined potential predictors for the distribution of non-native species and indicated major ports as hotpots for invaders as well as point of transfer. Combination of the number of major ports at high latitudes increases invasion pressure. Consequently, the transfer of marine traffic from major to minor ports risks domestic transfers. Globalisation and urban sprawl are expected to increase in future with requirements for more man-made coastal infrastructure such as ports, harbours and marinas. These findings suggest that most vulnerable habitats, such as the major ports should be prioritised and frequently monitored for non-native species for early detection. 


\section{References}

Ab Rahim, E. S., Nguyen, T. T. T., Ingram, B., Riginos, C., Weston, K. J., \& Sherman, C. D. H. 2016. Species composition and hybridisation of mussel species (Bivalvia: Mytilidae) in Australia. Marine and Freshwater Research, 67, 1955-1963.

Adams, T. P., Miller, R. G., Aleynik, D., \& Burrows, M. T. 2014. Offshore marine renewable energy devices as stepping stones across biogeographical boundaries. Journal of Applied Ecology, 51(2), 330-338.

Aguilera, M. A., Broitman, B. R., \& Thiel, M. 2014. Spatial variability in community composition on a granite breakwater versus natural rocky shores: Lack of microhabitats suppresses intertidal biodiversity. Marine Pollution Bulletin, 87(1), 257-268.

Airoldi, L. 2003. The effects of sedimentation on rocky coast assemblages. Oceanography and Marine Biology, 41, 161-236.

Airoldi, L., \& Beck, M. W. 2007. Loss, status and trends for coastal marine habitats of Europe. Oceanography and Marine Biology, 45, 345-405.

Airoldi, L., \& Bulleri, F. 2011. Anthropogenic disturbance can determine the magnitude of opportunistic species responses on marine urban infrastructures. PLoS ONE, 6(8), e22985.

Airoldi, L., Abbiati, M., Beck, M. W., Hawkins, S. J., Jonsson, P. R., Martin, D., Moschella, P. S., Sundelöf, A., Thompson, R. C., \& Åberg, P. 2005. An ecological perspective on the deployment and design of low-crested and other hard coastal defence structures. Coastal Engineering, 52(10-11), 1073-1087.

Airoldi, L., Bacchiocchi, F., Cagliola, C., Bulleri, F., \& Abbiati, M. 2005. Impact of recreational harvesting on assemblages in artificial rocky habitats. Marine Ecology Progress Series, 299, 55-66.

Airoldi, L., Balata, D., \& Beck, M. W. 2008. The Gray Zone: Relationships between habitat loss and marine diversity and their applications in conservation. Journal of Experimental Marine Biology and Ecology, 366(1-2), 8-15.

Airoldi, L., Connell, S. D., \& Beck, M. W. 2009. The Loss of Natural Habitats and the Addition of Artificial Substrata. Marine Hard Bottom Communities, 206, 269-280.

Airoldi, L., Fontana G., Ferrario F., Franzitta G., Perkol-Finkel S., Magnani A., Bianchelli S., Pusceddu A., Colangelo M. A., Thrush S. 2010. Detrital enrichment form urban structures and its far-field effects on soft-bottom assemblages. Rapp. Comm. Int. Mer Méditerranean, 39, 712.

Airoldi, L., Turon, X., Perkol-Finkel, S., \& Rius, M. 2015. Corridors for aliens but not for natives: Effects of marine urban sprawl at a regional scale. Diversity and Distributions, 21(7), 755-768.

Albano, M. J., \& Obenat, S. M. 2019. Fouling assemblages of native, non-indigenous and cryptogenic species on artificial structures, depths and temporal variation. Journal of Sea Research, 144, 1-15.

Altieri, A. H., \& Irving, A. D. 2017. Species coexistence and the superior ability of an invasive species to exploit a facilitation cascade habitat. PeerJ, 5(2), e2848. 
Andersen, M. C., Adams, H., Hope, B., \& Powell, M. 2004. Risk assessment for invasive species. In Risk Analysis, 24(4), 787-793.

Anderson, A. S., Bilodeau, A. L., Gilg, M. R., \& Hilbish, T. J. 2002. Routes of introduction of the Mediterranean mussel (Mytilus galloprovincialis) to Puget Sound and Hood Canal. Journal of Shellfish Research, 21(1):75-79.

Anderson, E. C., \& Thompson, E. A. 2002. A model-based method for identifying species hybrids using multilocus genetic data. Genetics, 160(3), 1217-1229.

Anderson, M. J., \& Underwood, A. J. 1994. Effects of substratum on the recruitment and development of an intertidal estuarine fouling assemblage. Journal of Experimental Marine Biology and Ecology, 184(2), 217-236.

Anderson, M. J., Crist, T. O., Chase, J. M., Vellend, M., Inouye, B. D., Freestone, A. L., Sanders, N. J., Cornell, H. V., Comita, L. S., Davies, K. F., Harrison, S. P., Kraft, N. J. B., Stegen, J. C., \& Swenson, N. G. 2011. Navigating the multiple meanings of $\beta$ diversity: A roadmap for the practicing ecologist. Ecology Letters, 14, 19-28.

Anderson, M. J., Gorley, R. N., \& Clarke, K. R. 2008. PERMANOVA+ for PRIMER: Guide to Software and Statistical Methods. Plymouth, UK.

Andersson, M. H., Berggren, M., Wilhelmsson, D., \& Öhman, M. C. 2009. Epibenthic colonization of concrete and steel pilings in a cold-temperate embayment: A field experiment. Helgoland Marine Research, 63(3), 249-260.

Anestis, A., Lazou, A., Pörtner, H. O., \& Michaelidis, B. 2007. Behavioral, metabolic, and molecular stress responses of marine bivalve Mytilus galloprovincialis during long-term acclimation at increasing ambient temperature. American Journal of Physiology Regulatory Integrative and Comparative Physiology, 293(2), 911-921.

Apte S., Holland B. S., Godwin L. S., Gardner J. P. A. 2000. Jumping ship: a stepping stone event mediating transfer of a non-indigenous species via a potentially unsuitable environment. Biological Invasions, 2, 75-79.

Arthur, T., Arrowsmith, L., Parsons, S., and Summerson, R. 2015. Monitoring for Marine Pests: A Review of the Design and Use of Australia's National Monitoring Strategy and Identification of Possible Improvements. Canberra, ACT: Australian Government Department of Agriculture, Water Resources.

Australian Government Department of Agriculture and Water Resources. 2019. Australian biofouling management requirements for international vessel arrivals. Consultation Regulation Impact Statement. Canberra, ACT: Australian Government Department of Agriculture, Water Resources, Biosecurity Animal Division.

Bacchiocchi, F., \& Airoldi, L. 2003. Distribution and dynamics of epibiota on hard structures for coastal protection. Estuarine, Coastal and Shelf Science, 56(5-6), 1157-1166.

Bagley, P. M., Smith, K. L., Bett, B. J., Priede, I. G., Rowe, G., Clarke, J., Wall, A., Ruh, H. A., Bailey, D. M., \& Bazica, B. 2015. The DELOS project: Development of a long-term observatory in an oil field environment in the Tropical Atlantic Ocean. In Seafloor Observatories: A New Vision of the Earth from the Abyss. Springer Praxis Books, 325344.

Bayne, B. L., Salkeld, P. N., \& Worrall, C. M. 1983. Reproductive effort and value in different populations of the marine mussel, Mytilus edulis L. Oecologia, 59(1), 18-26. 
Bayne, B. L., \& Thompson, R. J. 1970. Some physiological consequences of keeping Mytilus edulis in the laboratory. Helgo. wiss. Meeresunters, 20, 526-552.

Beca-Carretero, P., Rotini, A., Mejia, A., Migliore, L., Vizzini, S., \& Winters, G. 2019. Halophila stipulacea descriptors in the native area (Red Sea): A baseline for future comparisons with native and non-native populations. In Marine Environmental Research, 104828.

Becker, A., Taylor, M. D., Folpp, H., \& Lowry, M. B. 2018. Managing the development of artificial reef systems: The need for quantitative goals. Fish and Fisheries, 19(4), 740-752.

Bellard, C., Cassey, P., \& Blackburn, T. M. 2016. Alien species as a driver of recent extinctions. Biology Letters, 12(2), 20150623.

Berlow, E. L. 1997. From canalization to contingency: Historical effects in a successional rocky intertidal community. Ecological Monographs, 67(4), 435-460.

Beukema, J.J., Cadée, G.C., Dekker, R., 2002. Zoobenthic biomass limited by phytoplankton abundance: evidence from parallel changes in two long-term data series in the Wadden Sea. Journal of Sea Research, 48, 111-125.

Biosecurity New Zealand. 2010. Managing and controlling the risk posed to the marine environment from biofouling on arriving vessels. MAF Biosecurity New Zealand consultation paper 10/04. Wellington, MAF. 15 p.

Biosecurity New Zealand. 2020. Import health standard for ships ballast water from all countries. Retrieved from https://www.biosecurity.govt.nz/dmsdocument/1167/direct

Bishop, M. J., \& Hutchings, P. A. 2011. How useful are port surveys focused on target pest identification for exotic species management? Marine Pollution Bulletin, 62(1), 36-42.

Bishop, M. J., Mayer-Pinto, M., Airoldi, L., Firth, L. B., Morris, R. L., Loke, L. H. L., Hawkins, S. J., Naylor, L. A., Coleman, R. A., Chee, S. Y., \& Dafforn, K. A. 2017. Effects of ocean sprawl on ecological connectivity: impacts and solutions. Journal of Experimental Marine Biology and Ecology, 492, 7-30.

Borsa, P., Daguin, C., \& Bierne, N. 2007. Genomic reticulation indicates mixed ancestry in Southern hemisphere Mytilus spp. mussels. Biological Journal of the Linnean Society, 92(4), 747-754.

Borsa, P., Rolland, V., \& Daguin-Thiébaut, C. 2012. Genetics and taxonomy of Chilean smooth-shelled mussels, Mytilus spp. (Bivalvia: Mytilidae). Comptes Rendus - Biologies, 335(1), 51-61.

Borthagaray, A. I., \& Carranza, A. 2007. Mussels as ecosystem engineers: Their contribution to species richness in a rocky littoral community. Acta Oecologica, 31(3), 243-250.

Boudouresque, C. F., \& Verlaque, M. 2012. An overview of species introduction and invasion processes in marine and coastal lagoon habitats. Cahiers de Biologie Marine, 53(3), 309317.

Bownes, S. J., \& McQuaid, C. D. 2006. Will the invasive mussel Mytilus galloprovincialis Lamarck replace the indigenous Perna perna L. on the south coast of South Africa? Journal of Experimental Marine Biology and Ecology, 338(1), 140-151.

Bownes, S. J., \& McQuaid, C. D. 2010. Mechanisms of habitat segregation between an invasive 
(Mytilus galloprovincialis) and an indigenous (Perna perna) mussel: Adult growth and mortality. Marine Biology, 157(8), 1799-1810.

Braby, C. E., \& Somero, G. N. 2006. Following the heart: Temperature and salinity effects on heart rate in native and invasive species of blue mussels (genus Mytilus). Journal of Experimental Biology, 209(13), 2554-2566.

Bracewell, S. A., Robinson, L. A., Firth, L. B., \& Knights, A. M. 2013. Predicting free-space occupancy on novel artificial structures by an invasive intertidal barnacle using a removal experiment. PLoS ONE, 8(9), e74457.

Branch, G. M., \& Nina Steffani, C. 2004. Can we predict the effects of alien species? A casehistory of the invasion of South Africa by Mytilus galloprovincialis (Lamarck). Journal of Experimental Marine Biology and Ecology, 300(1-2), 189-215.

Branch, G. M., Odendaal, F., \& Robinson, T. B. 2008. Long-term monitoring of the arrival, expansion and effects of the alien mussel Mytilus galloprovincialis relative to wave action. Marine Ecology Progress Series, 370, 171-183.

Branch, G. M., Odendaal, F., \& Robinson, T. B. 2010. Competition and facilitation between the alien mussel Mytilus galloprovincialis and indigenous species: Moderation by wave action. Journal of Experimental Marine Biology and Ecology, 383(1), 65-78.

Brannock, P. M., Wethey, D. S., \& Hilbish, T. J. 2009. Extensive hybridization with minimal introgression in Mytilus galloprovincialis and M. trossulus in Hokkaido, Japan. Marine Ecology Progress Series, 383, 161-171.

Brockerhoff E. G., Liebhold A. M., Richardson B., Suckling D. M. 2010. Eradication of invasive forest insects: concept, methods, costs and benefits. New Zealand Journal of Forestry Science, 40, 117-135.

Browne, M. A., \& Chapman, M. G. 2011. Ecologically informed engineering reduces loss of intertidal biodiversity on artificial shorelines. Environmental Science and Technology, 45, 8204-8207.

Browne, M. A., \& Chapman, M. G. 2014. Mitigating against the loss of species by adding artificial intertidal pools to existing seawalls. Marine Ecology Progress Series, 497, 119129.

Browne, Mark A., \& Chapman, M. G. 2011. Ecologically informed engineering reduces the loss of intertidal biodiversity on artificial shorelines. Environmental Science and Technology, 45(19), 8204-8207.

Bulleri, F. 2005. Role of recruitment in causing differences between intertidal assemblages on seawalls and rocky shores. Marine Ecology Progress Series, 32(2), 101-102.

Bulleri, F. 2006. Is it time for urban ecology to include the marine realm? Trends in Ecology and Evolution, 21, 656-658.

Bulleri, F., \& Airoldi, L. 2005. Artificial marine structures facilitate the spread of a nonindigenous green alga, Codium fragile ssp. tomentosoides, in the north Adriatic Sea. Journal of Applied Ecology, 42(6), 1063-1072.

Bulleri, F., \& Chapman, M. G. 2004. Intertidal assemblages on artificial and natural habitats in marinas on the north-west coast of Italy. Marine Biology, 145(2), 381-391. 
Bulleri, F., \& Chapman, M. G. 2010. The introduction of coastal infrastructure as a driver of change in marine environments. Journal of Applied Ecology, 47(1), 26-35.

Bulleri, F. \& Chapman, M. G. 2015. Artificial physical structures. In book: Marine Ecosystems: Human Impacts on Biodiversity, Functioning and Services, Chapter 7, 167201.

Bulleri, F., Abbiati, M., \& Airoldi, L. 2006. The colonisation of human-made structures by the invasive alga Codium fragile ssp. tomentosoides in the north Adriatic Sea (NE Mediterranean). Marine Biodiversity, 183, 263-269.

Bulleri, F., Benedetti-Cecchi, L., Jaklin, A., \& Iveša, L. 2016. Linking disturbance and resistance to invasion via changes in biodiversity: A conceptual model and an experimental test on rocky reefs. Ecology and Evolution, 6(7), 2010-2021.

Burgess S. C., Treml E. A., \& Marshall, D. J. 2012. How do dispersal costs and habitat selection influence realized population connectivity? Ecology, 93, 1378-1387.

Burlakova, L. E., Karatayev, A. Y., \& Karatayev, V. A. 2012. Invasive mussels induce community changes by increasing habitat complexity. Hydrobiologia, 685(1), 121-134.

Burt, J., Bartholomew, A., \& Sale, P. F. 2011. Benthic development on large-scale engineered reefs: A comparison of communities among breakwaters of different age and natural reefs. Ecological Engineering, 37(2), 191-198.

Burt, J., Bartholomew, A., Bauman, A., Saif, A., \& Sale, P. F. 2009. Coral recruitment and early benthic community development on several materials used in the construction of artificial reefs and breakwaters. Journal of Experimental Marine Biology and Ecology, 373(1), 72-78.

Byers, J. E. 2002. Impact of non-indigenous species on natives enhanced by anthropogenic alteration of selection regimes. Oikos, 97, 449-458.

Cacabelos, E., Martins, G. M., Thompson, R., Prestes, A. C. L., Azevedo, J. M. N., \& Neto, A. I. 2016. Material type and roughness influence structure of intertidal communities on coastal defences. Marine Ecology, 37(4), 801-812.

Caceres Martinez, J., Robledo, J. A. F., \& Figueras, A. 1994. Settlement and post-larvae behaviour of Mytilus galloprovincialis: Field and laboratory experiments. Marine Ecology Progress Series, 112(1-2), 107-118.

Cáceres-Martínez, J., \& Figueras, A. 1998. Long-term survey on wild and cultured mussels (Mytilus galloprovincialis Lmk) reproductive cycles in the Ria de Vigo (NW Spain). Aquaculture, 162(1-2), 141-156.

Callaway, R. M. \& Ridenour, W. M. 2004. Novel weapons: Invasive success and the evolution of increased competitive ability. Frontiers in Ecology and the Environment, 2, 436-443.

Campbell, M. L., Gould, B., \& Hewitt, C. L. 2007. Survey evaluations to assess marine bioinvasions. Marine Pollution Bulletin, 55(7-9), 360-378.

Carlton, J. T. \& Ruiz, G. M. 2005. Vector science and integrated vector management in bioinvasion ecology: conceptual frameworks. In Invasive Alien Species: A New Synthesis (ed. H. A. Mooney, R. N. Mack, J. A. McNeely, L.E. Neville, P. J. Schei and J. K. Waage), pp. 36 - 58. Island Press, Washington, D C. 
Carvalho, S., Moura, A., Cúrdia, J., Cancela da Fonseca, L., \& Santos, M. N. 2013. How complementary are epibenthic assemblages in artificial and nearby natural rocky reefs? Marine Environmental Research, 92, 170-177.

Castilla, J. C., Guiñez, R., Caro, A. U., \& Ortiz, V. 2004. Invasion of a rocky intertidal shore by the tunicate Pyura praeputialis in the Bay of Antofagasta, Chile. Proceedings of the National Academy of Sciences of the United States of America, 101, 8517-8524.

Ceccherelli, G., Pinna, S., Cusseddu, V., \& Bulleri, F. 2014. The role of disturbance in promoting the spread of the invasive seaweed Caulerpa racemosa in seagrass meadows. Biological Invasions, 16, 2737-2745.

Ceccherelli, V., \& Rossi, R. 1984. Settlement, growth and production of the mussel Mytilus galloprovincialis. Marine Ecology Progress Series, 16, 173-184.

Chan, F. T., \& Briski, E. 2017. An overview of recent research in marine biological invasions. Marine Biology, 164, 121.

Chang, C. C., \& Turner, B. L. 2019. Ecological succession in a changing world. Journal of Ecology, 107(2), 503-509.

Chapman, J. W., \& Carlton, J. T. 1991. A Test of Criteria for Introduced Species: the Global Invasion by the Isopod Synidotea laevidorsalis (Miers, 1881). Journal of Crustacean Biology, 11(3), 386-400.

Chapman, M. G. 2003. Paucity of mobile species on constructed seawalls: Effects of urbanization on biodiversity. Marine Ecology Progress Series, 264, 21-29.

Chapman, M. G. 2006. Intertidal seawalls as habitats for molluscs. Journal of Molluscan Studies, 72(3), 247-257.

Chapman, M. G. 2012. Restoring Intertidal Boulder-Fields as Habitat for "Specialist" and "Generalist" Animals. Restoration Ecology, 20(2), 277-285.

Chapman, M. G. 2013. Constructing replacement habitat for specialist and generalist molluscsthe effect of patch size. Marine Ecology Progress Series, 473, 201-214.

Chapman, M. G., \& Blockley, D. J. 2009. Engineering novel habitats on urban infrastructure to increase intertidal biodiversity. Oecologia, 161(3), 625-635.

Chapman, M. G., \& Bulleri, F. 2003. Intertidal seawalls- New features of landscape in intertidal environments. Landscape and Urban Planning. 62(3),159-172.

Chapman, M. G., \& Clynick, B. G. 2006. Experiments testing the use of waste material in estuaries as habitat for subtidal organisms. Journal of Experimental Marine Biology and Ecology, 338(2), 164-178.

Chapman, M. G., \& Underwood, A. J. 2009. Evaluating the accuracy and precision of species - Area relationships for multiple estimators and different marine assemblages. Ecology, 90(3), 754-766.

Chapman, M. G., \& Underwood, A. J. 2011. Evaluation of ecological engineering of "armoured" shorelines to improve their value as habitat. Journal of Experimental Marine Biology and Ecology, 400(1-2), 302-313.

Chee S. Y., Othman A. G., Sim Y. K., Adam A. N. M., Firth L. B. 2017. Land reclamation and artificial islands: walking the tightrope between development and conservation. Global 
Ecology Conservation, 12, 80-95.

Cheung, W. W. L., Lam, V. W. Y., Sarmiento, J. L. 2009. Projecting global marine biodiversity impacts under climate change scenarios. Fish and Fisheries, 10, 235-251.

Choi, F. M. P., Murray, C. C., Therriault, T. W., \& Pakhomov, E. A. 2016. Intertidal invasion patterns in Canadian ports. Marine Biology, 163(9), 1-12.

Clark, G. F., \& Johnston, E. L. 2011. Temporal change in the diversity-invasibility relationship in the presence of a disturbance regime. Ecology Letters, 14(1), 52-57.

Clarke K.R., Warwick R.M. 2001. Change in Marine Communities: An Approach to Statistical Analysis and Interpretation (second ed.), PRIMER-E, Plymouth, UK.

Clarke, K. R. 1993. Non-parametric multivariate analyses of changes in community structure. Australian Journal of Ecology, 18(1), 117-143.

Clarke, K. R., \& Gorley, R. N. 2006. Plymouth routines in multivariate ecological research. PRIMER v6: Use manual/Tutorial. PRIMER-E: Plymouth, UK.

Clarke Murray C., Pakhomov E. A., Therriault T. W. 2011. Recreational boating: a large unregulated vector transporting marine invasive species. Diversity and Distributions, 17, 1161-1172.

Clynick, B. G., Chapman, M. G., \& Underwood, A. J. 2007. Effects of epibiota on assemblages of fish associated with urban structures. Marine Ecology Progress Series, 332, 201-210.

Cohen, J. 1992. A power primer. Psychological Bulletin, 112(1), 155-159.

Commonwealth of Australia. 2011. Marine Bioregional planning in the EEZ. Australian Department of the Environment. Retrieved from http://msp.ioc-unesco.org.

Commonwealth of Australia. 2013. Anti-fouling and in-water cleaning guidelines. CC BY 3.0, 26

Commonwealth of Australia. 2015. South-east marine region profile: A description of the ecosystems, conservation values and uses of the South-east Marine Region, 94.

Connell, J. H. 1961. The Influence of Interspecific Competition and Other Factors on the Distribution of the Barnacle Chthamalus stellatus. Ecology, 42(4), 710-723.

Connell, J. H. 1972. Community interactions on marine rocky intertidal shores. Annual Review of Ecology and Systematics, 3, 169-192.

Connell, J. H., \& Slatyer, R. O. 1977. Mechanisms of succession in natural communities and their role in community stability and organization. The American Naturalist, 111(982), 1119-1144.

Connell, S. D. 2001. Urban structures as marine habitats: An experimental comparison of the composition and abundance of subtidal epibiota among pilings, pontoons and rocky reefs. Marine Environmental Research, 52(2), 115-125.

Connell, S. D., \& Glasby, T. M. 1999. Do urban structures influence local abundance and diversity of subtidal epibiota? A case study from Sydney Harbour, Australia. Marine Environmental Research, 47(4), 373-387.

Cook, E., Brown, S., Payne, R., \& Macleod, A. 2016. Marine biosecurity: protecting indigenous marine species. Research and Reports in Biodiversity Studies, 5, 1-14. 
Coombes M. A., La Marca E. C., Naylor L. A., Thompson R. C. 2015. Getting into the groove: opportunities to enhance the ecological value of hard coastal infrastructure using finescale surface textures. Ecological Engineering, 77, 314-323.

Coombes M. A., Naylor L. A., Viles H. A., Thompson R. C. 2013. Bioprotection and disturbance: seaweed, microclimatic stability and conditions for mechanical weathering in the intertidal zone. Geomorphology, 202, 4-14.

Cope, R. C., Prowse, T. A. A., Ross, J. V., Wittmann, T. A., \& Cassey, P. 2015. Temporal modelling of ballast water discharge and ship-mediated invasion risk to Australia. Royal Society Open Science, 2(4), e150039.

Correia, M., Palma, J., Koldewey, H., \& Andrade, J. P. 2013. Can artificial holdfast units work as a habitat restoration tool for long-snouted seahorse (Hippocampus guttulatus Cuvier)? Journal of Experimental Marine Biology and Ecology, 448, 258-264.

Corriero, G., Pierri, C., Accoroni, S., Alabiso, G., Bavestrello, G., Barbone, E., Bastianini, M., Bazzoni, A. M., Bernardi Aubry, F., Boero, F., Buia, M. C., Cabrini, M., Camatti, E., Cardone, F., Cataletto, B., Cattaneo Vietti, R., Cecere, E., Cibic, T., Colangelo, P., Basset, A. 2016. Ecosystem vulnerability to alien and invasive species: A case study on marine habitats along the Italian coast. Aquatic Conservation: Marine and Freshwater Ecosystems, 26(2), 392-409.

Costanza, R., dArge, R., de Groot, R., Farber, S., Grasso, M., Hannon, B., Limburg, K., Naeem, S., Oneill, R.V., Paruelo, J., Raskin, R.G., Sutton, P., van den Belt, M., 1997. The value of the world's ecosystem services and natural capital. Nature, 387, 253-260.

Costanza, R., de Groot, R., Sutton, P., van der Ploeg, S., Anderson, S. J., Kubiszewski, I., Farber, S., \& Turner, R. K. 2014. Changes in the global value of ecosystem services. Global Environmental Change, 26, 152-158.

Coutts A. D. M., Piola R. F., Hewitt C. L., Connell S. D., Gardner J. P. A. 2010a. Effect of vessel voyage speed on survival of biofouling organisms: implications for translocation of non-indigenous marine species. Biofouling, 26, 1-13.

Coutts A. D. M., Piola R. F., Taylor M. D., Hewitt C. L., Gardner J. P. A., 2010. The Effect Of Vessel Speed On The Survivorship Of Biofouling Organisms At Different Hull Locations. Biofouling, 26, 539-553.

Coutts, A. D. M., \& Forrest, B. M. 2007. Development and application of tools for incursion response: Lessons learned from the management of the fouling pest Didemnum vexillum. Journal of Experimental Marine Biology and Ecology, 342 (1), 154-162.

Coutts, A. D. M., Moore, K. M., \& Hewitt, C. L. 2003. Ships' sea-chests: An overlooked transfer mechanism for non-indigenous marine species? Marine Pollution Bulletin, 46(11), 1510-1513.

Coutts, A.D.M.; Taylor, M.D. 2004. A preliminary investigation of biosecurity risks associated with biofouling on merchant vessels in New Zealand. New Zealand Journal of Marine and Freshwater Research, 38, 215-229.

Creed, J. C., \& De Paula, A. F. 2007. Substratum preference during recruitment of two invasive alien corals onto shallow-subtidal tropical rocky shores. Marine Ecology Progress Series, 330, 101-111.

Crooks A, J., \& Khim S, H. 1999. Architectural vs. biological effects of a habitat-altering 
exotic mussel, Musculista senhousia. Journal of Experimental Marine Biology and Ecology, 240(1), 53-75.

Crooks, J. A. 2002. Characterizing ecosystem-level consequences of biological invasions: The role of ecosystem engineers. Oikos, 97(2), 153-166.

Crooks, J. A., Chang, A. L., \& Ruiz, G. M. 2011. Aquatic pollution increases the relative success of invasive species. Biological Invasions, 13, 165-176.

Cunningham, C. W., \& Collins, T. M. 1994. Developing model systems for molecular biogeography: Vicariance and interchange in marine invertebrates. Molecular Ecology and Evolution: Approaches and Applications, 69, 405-433.

Curiel-Ramirez, S., \& Caceres-Martinez, J. 2004. Reproductive cycle of coexisting mussels, Mytilus californianus and Mytilus galloprovincialis, in Baja California, New Mexico. Journal of Shellfish Research, 23(2), 515-520.

Currie, D. J., Mittelbach, G. G., Cornell, H. V., Kaufman, D. M., Kerr, J. T., Oberdorff, T. (2004). Predictions and tests of climate-based hypotheses of broad-scale variation in taxonomic richness. Ecology Letters, 7 (12): 1121-1134.

Dafforn, K. A. 2017. Eco-engineering and management strategies for marine infrastructure to reduce establishment and dispersal of non-indigenous species. Management of Biological Invasions, 8(2), 153-161.

Dafforn, K. A., Glasby, T. M., \& Johnston, E. L. 2012. Comparing the invasibility of experimental "reefs" with field observations of natural reefs and artificial structures. PLoS ONE, 7(5), 1-16.

Dafforn, K. A., Glasby, T. M., Airoldi, L., Rivero, N. K., Mayer-Pinto, M., \& Johnston, E. L. 2015 a. Marine urbanization: An ecological framework for designing multifunctional artificial structures. Frontiers in Ecology and the Environment, 13(2), 82-90.

Dafforn, K. A., Johnston, E. L., \& Glasby, T. M. 2009. Shallow moving structures promote marine invader dominance. Biofouling, 25(3), 277-287.

Dafforn, K. A., Mayer-Pinto, M., Bugnot, A. B., Coleman, R. A., Morris, R. L., \& Johnston, E. L. 2016. Guiding principles for marine foreshore developments. Report Prepared for UrbanGrowth NSW. University of New South Wales, 1-53.

Dafforn, K. A., Glasby, T. M., Airoldi, L., Rivero, N. K., Mayer-Pinto, M., \& Johnston, E. L. 2015a. Marine urbanization: An ecological framework for designing multifunctional artificial structures. Frontiers in Ecology and the Environment, 13(2), 82-90.

Dafforn, K. A., Mayer-Pinto, M., Morris, R. L., \& Waltham, N. J. 2015b. Application of management tools to integrate ecological principles with the design of marine infrastructure. Journal of Environmental Management, 158(1), 61-73.

Daguin, C., \& Borsa, P. 2000. Genetic relationships of Mytilus galloprovincialis Lamarck populations worldwide: Evidence from nuclear-DNA markers. Geological Society Special Publication, 177, 389-397.

Dang, H., \& Lovell, C. R. 2000. Bacterial primary colonization and early succession on surfaces in marine waters as determined by amplified rRNA gene restriction analysis and sequence analysis of $16 \mathrm{~S}$ rRNA genes. Applied and Environmental Microbiology, 66(2), $467-475$. 
Dangendorf, S., Marcos, M., Wöppelmann, G., Conrad, C. P., Frederikse, T., \& Riva, R. 2017. Reassessment of 20th-century global mean sea level rise. Proceedings of the National Academy of Sciences of the United States of America, 114(23), 5946-5951.

Darwin C. 1860. The Voyage of the Beagle. Doubleday, New Jersey.

Davis M. A., 2003. Biotic globalization: Does competition from introduced species threaten biodiversity? Bioscience, 53, 481-489.

DAWR. 2017. Australian Ballast Water Management Requirements Version 7. Department of Agriculture and Water Resources. Retrieved from: http://www.agriculture.gov.au /biosecurity/avm/vessels/ballast/australian-ballast-water-management-requirements.

DAWR. 2019. Australian biofouling management requirements for international vessel arrivals - Consultation Regulation Impact Statement. Canberra: Department of Agriculture and Water Resources. Retrieved from https://haveyoursay.agriculture.gov.au/445

Dearborn, D. C., \& Kark, S. 2010. Motivations for conserving urban biodiversity. Conservation Biology, 24, 432-440.

Department of Conservation. 2005. Stop the spread of aquatic pests. Retrieved from www.doc.govt.nz/ Conservation/Freshwater/Aquatic-pests/index.asp.

Department for Transport Statistics United Kingdom. 2016. Port Freight Statistics 2016: Notes and definitions.

Department of Agriculture, Fisheries and Forestry (DAFF), Biosecurity Act 2015 No. 24 (NSW).

Department of Conservation and Ministry of Fisheries. 2011. Coastal marine habitats and marine protected areas in the New Zealand Territorial Sea: a broad scale gap analysis. Wellington, New Zealand.

Department of Environment, New Zealand Ministry for Primary Industries and Department of Agriculture. 2015. Anti-fouling and in-water cleaning guidelines.

Department of Environment and Climate Change. 2009. Environmentally Friendly Seawalls: A Guide to Improving the Environmental Value of Seawalls and Seawall-lined Foreshores in Estuaries. NSW Department of Environment and Climate Change, Sydney, Australia, $1-34$.

deRivera, C., Ruiz, G., Crooks, J., Wasson, K., Lonhart, S., Fofonoff, P., Steves, B., Rumrill, S., Brancato, M., Pegau, S., Bulthuis, D., Preisler, R., Schoch, C., Bowlby, E., DeVogelaere, A., Crawford, M., Gittings, S., Hines, A., Takata, L., Powell, S. 2005. Broad-scale Non-indigenous Species Monitoring Along the West Coast in National Marine Sanctuaries and National Estuarine Research Reserves: Report to National Fish \& Wildlife Foundation. Otro, 1-24.

Dethier, M. N., Toft, J. D., \& Shipman, H. 2017. Shoreline Armoring in an Inland Sea: ScienceBased Recommendations for Policy Implementation. Conservation Letters, 10(5), 626633.

Devlaming, V., Grossman, G., \& Chapman, F. 1982. On the use of the gonosomatic index. Comparative Biochemistry and Physiology - Part A: Physiology, 73(1), 31-39. 
Dias, P. J., Fotedar, S., \& Snow, M. 2014. Characterisation of mussel (Mytilus spp.) populations in Western Australia and evaluation of potential genetic impacts of mussel spat translocation from interstate. Marine and Freshwater Research, 65, 486-496.

Díaz, C., Sobenes, C., \& Machino, S. 2019. Comparative growth of Mytilus chilensis (Hupé 1854) and Mytilus galloprovincialis (Lamarck 1819) in aquaculture longline system in Chile. Aquaculture, 507, 21-27.

Dobretsov, S., \& Wahl, M. 2001. Recruitment preferences of blue mussel spat (Mytilus edulis) for different substrata and microhabitats in the White Sea (Russia). Hydrobiologia, 445, $27-35$.

Dodgshun T.J., Taylor M. D. \& Forrest B. M. 2007. Human-mediated pathways of spread for non-indigenous marine species in New Zealand, DOC Research \& Development series Technical Report. 266.

Dong, Y. wei, Huang, X. wei, Wang, W., Li, Y., \& Wang, J. 2016. The marine "great wall" of China: Local- and broad-scale ecological impacts of coastal infrastructure on intertidal macrobenthic communities. Diversity and Distributions, 22(7), 731-744.

Duarte, C. M., Pitt, K. A., Lucas, C. H., Purcell, J. E., Uye, S. I., Robinson, K., Brotz, L., Decker, M. B., Sutherland, K. R., Malej, A., Madin, L., Mianzan, H., Gili, J. M., Fuentes, V., Atienza, D., Pages, F., Breitburg, D., Malek, J., Graham, W. M., \& Condon, R. H. 2013. Is global ocean sprawl a cause of jellyfish blooms? Frontiers in Ecology and the Environment, 11(2), 91-97.

Dugan, J. E., Airoldi, L., Chapman, M. G., Walker, S. J., \& Schlacher, T. 2012. Estuarine and Coastal Structures: Environmental Effects, A Focus on Shore and Nearshore Structures. Treatise on Estuarine and Coastal Science, 8, 17-41.

Dumont, C. P., Gaymer, C. F., \& Thiel, M. 2011. Predation contributes to invasion resistance of benthic communities against the non-indigenous tunicate Ciona intestinalis. Biological Invasions, 13, 2023-2034.

Dutton, J. M., \& Hofmann, G. E. 2008. Spatial and temporal variation in distribution and protein ubiquitination for Mytilus congeners in the California hybrid zone. Marine Biology, 154(6), 1067-1075.

Ehrenfeld. 2003. Globalisation: Effects on Biodiversity, Environment and Society. Conservation and Society, 1(1), 99-111.

Ehrlich, P. R. 1986. Which animal will invade? In: Mooney H. A. and Drake J. A. (eds) Ecology of Biological Invasions of North American and Hawaii, pp 79-95. SpringerVerlag, New York.

Elton, C. S. 1958. The Ecology of Invasions by Animals and Plants. The Ecology of Invasions by Animals and Plants, 15-32.

Elton, C. S. 1958. The Ecology of Invasions by Animals and Plants. London: Chapman and Hall.

Epstein, G., \& Smale, D. A. 2018. Environmental and ecological factors influencing the spillover of the non-native kelp, Undaria pinnatifida, from marinas into natural rocky reef communities. Biological Invasions, 20, 1049-1072

Erlandsson, J., Pal, P., \& McQuaid, C. D. 2006. Re-colonisation rate differs between co- 
existing indigenous and invasive intertidal mussels following major disturbance. Marine Ecology Progress Series, 320, 169-176

Evans, A. J., Firth, L. B., Hawkins, S. J., Morris, E. S., Goudge, H., \& Moore, P. J. 2016. Drillcored rock pools: An effective method of ecological enhancement on artificial structures. Marine and Freshwater Research, 67(1), 123-130.

FAO 2018, Food and Agriculture Organisation of the United Nations. World aquaculture production by species groups. Retrieved from http://www.fao.org.

Fauvelot, C., Bertozzi, F., Costantini, F., Airoldi, L., \& Abbiati, M. 2009. Lower genetic diversity in the limpet Patella caerulea on urban coastal structures compared to natural rocky habitats. Marine Biology, 156(11), 2313-2323.

Fava, F., Ponti, M., \& Abbiati, M. 2016. Role of recruitment processes in structuring coralligenous benthic assemblages in the northern Adriatic continental shelf. PLoS ONE, 11(10), e0163494.

Ferrario, F., Iveša, L., Jaklin, A., Perkol-Finkel, S., \& Airoldi, L. 2016. The overlooked role of biotic factors in controlling the ecological performance of artificial marine habitats. Journal of Applied Ecology, 53(1), 16-24.

Ferrario, J., Caronni, S., Occhipinti-Ambrogi, A., \& Marchini, A. 2017. Role of commercial harbours and recreational marinas in the spread of non-indigenous fouling species. Biofouling, 30(8), 651-660.

Firth, L. B., Browne, K. A., Knights, A. M., Hawkins, S. J., \& Nash, R. 2016. Eco-engineered rock pools: A concrete solution to biodiversity loss and urban sprawl in the marine environment. Environmental Research Letters, 11(9), 094015-094015.

Firth, L. B., Grant, L. M., Crowe, T. P., Ellis, J. S., Wiler, C., Convery, C., \& O’Connor, N. E. 2017. Factors affecting the prevalence of the trematode parasite Echinostephilla patellae (Lebour, 1911) in the limpet Patella vulgata (L.). Journal of Experimental Marine Biology and Ecology, 492, 99-104.

Firth, L. B., Knights, A., Bridger, D., Evans, A., Mieszkowska, N., Moore, P., O'connor, N., Sheehan, E., Thompson, R., \& Hawkins, S. 2016. Ocean Sprawl: Challenges and Opportunities for Biodiversity Management In A Changing World. In, Hughes, R. N., Hughes, D. J., Smith, I. P. and Dale, A. C. (eds.) Oceanography and Marine Biology: an annual review. Taylor \& Francis, 54, 193-269.

Firth, L. B., Mieszkowska, N., Grant, L. M., Bush, L. E., Davies, A. J., Frost, M. T., Moschella, P. S., Burrows, M. T., Cunningham, P. N., Dye, S. R., \& Hawkins, S. J. 2015. Historical comparisons reveal multiple drivers of decadal change of an ecosystem engineer at the range edge. Ecology and Evolution, 5(15), 1-13.

Firth, L. B., Mieszkowska, N., Thompson, R. C., \& Hawkins, S. J. 2013. Climate change and adaptational impacts in coastal systems: The case of sea defences. Environmental Sciences: Processes and Impacts, 15, 1665-1670

Firth, L. B., Schofield, M., White, F. J., Skov, M. W., \& Hawkins, S. J. 2014. Biodiversity in intertidal rock pools: Informing engineering criteria for artificial habitat enhancement in the built environment. Marine Environmental Research, 102, 122-130.

Firth, L. B., Thompson, R. C., Bohn, K., Abbiati, M., Airoldi, L., Bouma, T. J., Bozzeda, F., Ceccherelli, V. U., Colangelo, M. A., Evans, A., Ferrario, F., Hanley, M. E., Hinz, H., 
Hoggart, S. P. G., Jackson, J. E., Moore, P., Morgan, E. H., Perkol-Finkel, S., Skov, M. W., Hawkins, S. J. 2014. Between a rock and a hard place: Environmental and engineering considerations when designing coastal defence structures. Coastal Engineering, 87, 122135.

Firth, L. B., Thompson, R. C., White, F. J., Schofield, M., Skov, M. W., Hoggart, S. P. G., Jackson, J., Knights, A. M., \& Hawkins, S. J. 2013. The importance of water-retaining features for biodiversity on artificial intertidal coastal defence structures. Diversity and Distributions, 19(10), 1275-1283.

Firth, L., Knights, A., Bridger, D., Evans, A., Mieszkowska, N., Moore, P., O'connor, N., Sheehan, E., Thompson, R., \& Hawkins, S. 2016. Ocean Sprawl: Challenges and Opportunities for Biodiversity Management In A Changing World. In, Hughes, R. N., Hughes, D. J., Smith, I. P. and Dale, A. C. (eds.) Oceanography and Marine Biology: an annual review. Taylor \& Francis, 54, 193-269.

Firth, L.B., Browne, K. A., Knights, A. M., Hawkins, S. J., \& Nash, R. 2016. Eco-engineered rock pools: A concrete solution to biodiversity loss and urban sprawl in the marine environment. Environmental Research Letters, 11(9), 094015-094015.

Fitzpatrick, B. M., Johnson, J. R., Kump, D. K., Smith, J. J., Voss, S. R., \& Shaffer, H. B. 2010. Rapid spread of invasive genes into a threatened native species. Proceedings of the National Academy of Sciences of the United States of America, 107(8), 3606-3610.

Fletcher, R. L., \& Callow, M. E. 1992. The settlement, attachment and establishment of marine algal spores. British Phycological Journal, 27(3), 303-329.

Floerl, O., Inglis, G.J. 2005, Starting the invasion pathway: the interaction between source populations and human transport vectors. Biological Invasions, 7, 589-606.

Floerl, O., Inglis G. J., Dey K., Smith A. 2009. The importance of transport hubs in steppingstone invasions. Journal of Applied Ecology, 46(1): 37-45.

Floerl, O., Inglis, G. J., Peacock, L., \& Plew, D. 2012. The Efficacy of Settlement Plate Arrays for Marine Surveillance, MPI Technical Paper, 2012/16, 91.

Floerl, O., Pool, T.K.; Inglis, G.J. 2004, Positive interactions between non-indigenous species facilitate transport by human vectors. Ecological Applications, 14, 1724-1736.

Forrest, B. M., \& Atalah, J. 2017. Significant impact from blue mussel Mytilus galloprovincialis biofouling on aquaculture production of green-lipped mussels in New Zealand. Aquaculture Environment Interactions, 9(1), 115-126.

Forrest, B. M., \& Hopkins, G. A. 2013. Population control to mitigate the spread of marine pests: Insights from management of the asian kelp Undaria pinnatifida and colonial ascidian Didemnum vexillum. Management of Biological Invasions, 4(4), 317-326.

Forrest, B. M., Gardner, J. P. A., \& Taylor, M. D. 2009. Internal borders for managing invasive marine species. Journal of Applied Ecology, 46(1), 46-54.

Foss, S. F., Ode, P. R., Sowby, M., \& Ashe, M. 2007. Non-indigenous aquatic organisms in the coastal waters of California. California Fish and Game, 93(3), 111-129.

Foster, V., Giesler, R. J., Wilson, A. M. W., Nall, C. R., \& Cook, E. J. 2016. Identifying the physical features of marina infrastructure associated with the presence of non-native species in the UK. Marine Biology, 163(8), 173. 
Francisco, P. M., Mori, G. M., Alves, F. M., Tambarussi, E. V., \& de Souza, A. P. 2018. Population genetic structure, introgression, and hybridization in the genus Rhizophora along the Brazilian coast. Ecology and Evolution, 8(6), 3491-3504.

Freestone, A. L., Ruiz, G. M., \& Torchin, M. E. 2013. Stronger biotic resistance in tropics relative to temperate zone: Effects of predation on marine invasion dynamics. Ecology, 94(6), 1370-1377.

Gallardo, B., \& Aldridge, D. C. 2013. Evaluating the combined threat of climate change and biological invasions on endangered species. Biological Conservation, 160, 225-233.

Garciá Molinos, J., Halpern, B. S., Schoeman, D. S., Brown, C. J., Kiessling, W., Moore, P. J., Pandolfi, J. M., Poloczanska, E. S., Richardson, A. J., \& Burrows, M. T. 2016. Climate velocity and the future global redistribution of marine biodiversity. Nature Climate Change, 6, 83-88.

Gardner, J. P. A. 2004. A historical perspective of the genus Mytilus (Bivalvia: Mollusca) in New Zealand: Multivariate morphometric analyses of fossil, midden and contemporary blue mussels. Biological Journal of the Linnean Society, 82(3), 329-344.

Gardner J. P. A., Oyarzún P., Toro J., Wenne R., Zbawicka M. 2020. Phylogeography of Southern Hemisphere blue mussels of the genus Mytilus: evolution, biosecurity, aquaculture and food labeling. Oceanography and Marine Biology: Annual Reviews, in submission.

Gardner J. P. A., Wenne R., Westfall K. R. Zbawicka M. 2016. Invasive mussels threaten regional scale genetic diversity in mainland and remote offshore locations: the need for baseline data and enhanced protection in the Southern Ocean. Global Change Biology, 22, 3182-3195.

Gardner, J. P. A., \& Skibinski, D. O. F. 1988. Historical and size-dependent genetic variation in hybrid mussel populations. Heredity, 61(1), 93-105.

Gardner, J. P. A., \& Skibinski, D. O. F. 1990. Genotype-dependent fecundity and temporal variation of spawning in hybrid mussel (Mytilus) populations. Marine Biology, 105(1), $153-162$.

Gardner, J. P. A., \& Skibinski, D. O. F. 1991. Mitochondrial DNA and allozyme covariation in a hybrid mussel population. Journal of Experimental Marine Biology and Ecology, 149(1), 45-54.

Gardner, J. P. A., \& Thompson, R. J. 2001. The effects of coastal and estuarine conditions on the physiology and survivorship of the mussels Mytilus edulis, M. trossulus and their hybrids. Journal of Experimental Marine Biology and Ecology, 265(2), 119-140.

Gardner, J. P. A., Zbawicka, M., Westfall, K. M., \& Wenne, R. 2016. Invasive blue mussels threaten regional scale genetic diversity in mainland and remote offshore locations: the need for baseline data and enhanced protection in the Southern Ocean. Global Change Biology, 22(9), 3182-3195.

Geller, J. B. 1999. Decline of a native mussel masked by sibling species invasion. Conservation Biology, 13(3), 661-664.

Geller, J. B., Darling, J. A., \& Carlton, J. T. 2010. Genetic Perspectives on Marine Biological Invasions. Annual Review of Marine Science, 2, 367-393. 
Geller, J. B., Darling, J. A., Carlton, J. T., 2010. Genetic perspectives on marine biological invasions. Annual Review of Marine Science, 2, 367-393.

Gérard, K., Bierne, N., Borsa, P., Chenuil, A., \& Féral, J. P. 2008. Pleistocene separation of mitochondrial lineages of Mytilus spp. mussels from Northern and Southern Hemispheres and strong genetic differentiation among southern populations. Molecular Phylogenetics and Evolution, 49(1), 84-91.

Gestoso, I., Ramalhosa, P., Oliveira, P., \& Canning-Clode, J. 2017. Marine protected communities against biological invasions: A case study from an offshore island. Marine Pollution Bulletin, 119(1), 72-80.

Glasby, T. M. 2001. Development of sessile marine assemblages on fixed versus moving substrata. Marine Ecology Progress Series, 215, 37-47.

Glasby, T. M., Connell, S. D., Holloway, M. G., \& Hewitt, C. L. 2007. Nonindigenous biota on artificial structures: Could habitat creation facilitate biological invasions? Marine Biology, 151, 887-895.

GloBallast. 2014. The IMO Ballast Water Management Convention.www.globallast.imo.org.

GloFouling. 2017. The IMO Biofouling Management Convention. www.glofouling.imo.org.

Goldsmit, J., Nudds, S. H., Stewart, D. B., Higdon, J. W., Hannah, C. G., \& Howland, K. L. 2019. Where else? Assessing zones of alternate ballast water exchange in the Canadian eastern Arctic. Marine Pollution Bulletin, 139, 74-90.

Goldstien, S. J., Inglis, G. J., Schiel, D. R., \& Gemmell, N. J. 2013. Using Temporal Sampling to Improve Attribution of Source Populations for Invasive Species. PLoS ONE. 8(6), e65656.

Gollasch, S., David, M., Voigt, M., Dragsund, E., Hewitt, C., \& Fukuyo, Y. 2007. Critical review of the IMO international convention on the management of ships' ballast water and sediments. Harmful Algae, 6(4), 585-600.

Goodsell, P. J., Chapman, M. G., \& Underwood, A. J. 2007. Differences between biota in anthropogenically fragmented habitats and in naturally patchy habitats. Marine Ecology Progress Series, 351, 15-23.

Gordon, D. P. 1977. The Aging Process in Bryozoans. In Biology of Bryozoans; Woollacott, R. M., Zimmer, R. L., Eds.; Academic Press: New York, NY, USA, 335-376.

Gosling, E. M. 1992. Genetics of Mytilus. In the mussel Mytilus: ecology, physiology, genetics and culture, 309-382.

Grant, W. S., \& Cherry, M. I. 1985. Mytilus galloprovincialis Lmk. in Southern Africa. Journal of Experimental Marine Biology and Ecology, 90(2), 179-191.

Green, D. S., Rocha, C., \& Crowe, T. P. 2013. Effects of non-indigenous oysters on ecosystem processes vary with abundance and context. Ecosystems, 16, 881-893.

Green, P. T., O’Dowd, D. J., Abbott, K. L., Jeffery, M., Retallick, K., \& Mac Nally, R. 2011. Invasional meltdown: Invader-invader mutualism facilitates a secondary invasion. Ecology, 92(9), 1758-1768.

Gribben, P. E., I’Ons, S., Phillips, N. E., Geange, S. W., Wright, J. T., \& Murray, B. R. 2013. Biogeographic comparisons of the traits and abundance of an invasive crab throughout its 
native and invasive ranges. Biological Invasions. 15, 1877-1885.

Griffen, B. D., Altman, I., Hurley, J., \& Mosblack, H. 2011. Reduced fecundity by one invader in the presence of another: A potential mechanism leading to species replacement. Journal of Experimental Marine Biology and Ecology, 406(1-2), 6-13.

Griffiths, C. L., Hockey, P. A., Van Erkom Schurink, C., \& Le Roux, P. J. 1992. Marine invasive aliens on South African shores: Implications for community structure and tropillc functioning. South African Journal of Marine Science, 12(1), 713-722.

Grosholz, E. D. 2005. Recent biological invasion may hasten invasional meltdown by accelerating historical introductions. Proceedings of the National Academy of Sciences of the United States of America, 102(4), 1088-1091.

Grosholz, E., Olin, P., Williams, B., Man, R. T., Grant, S., Avenue, V., Rosa, S., Box, P. O., \& Bay, B. 2000. Reducing predation on manila clams by nonindigenous European green crabs. Journal of Shellfish Research, 20(3), 913-919.

Guerra-García, J. M., \& García-Gómez, J. C. 2004. Crustacean assemblages and sediment pollution in an exceptional case study: A harbour with two opposing entrances. Crustaceana, 77(3), 353-370.

Guerra-García, J. M., Corzo, J., Espinosa, F., \& García-Gómez, J. C. 2004. Assessing habitat use of the endangered marine mollusc Patella ferruginea (Gastropoda, Patellidae) in northern Africa: Preliminary results and implications for conservation. Biological Conservation, 116(3), 319-326.

Hänfling, B. 2007. Understanding the establishment success of non-indigenous fishes: Lessons from population genetics. Journal of Fish Biology, 71, 115 - 135.

Hänfling, B., Edwards, F., \& Gherardi, F. 2011. Invasive alien Crustacea: Dispersal, establishment, impact and control. BioControl, 56(4), 573-595.

Hansen, M. J., \& Clevenger, A. P. 2005. The influence of disturbance and habitat on the presence of non-native plant species along transport corridors. Biological Conservation, 125(2), 249-259.

Harrison, R. G. 2012. The language of speciation. Evolution, 66(12), 3643-3657.

Hayes, K.R., Cannon, R., Neil , K., Inglis, G., 2005. Sensitivity and cost considerations for the detection and eradication of marine pests in ports. Marine Pollution Bulletin, 50, 823-834.

Hayes, K. R., Inglis, G., \& Barry, S. C. 2019. The assessment and management of marine pest risks posed by shipping: The Australian and New Zealand experience. Frontiers in Marine Science, 22.

Hedge L. H., Johnston E. L. 2012. Propagule pressure determines recruitment from a commercial shipping pier. Biofouling, 28, 73-85.

Heery, E. C., Bishop, M. J., Critchley, L. P., Bugnot, A. B., Airoldi, L., Mayer-Pinto, M., Sheehan, E. V., Coleman, R. A., Loke, L. H. L., Johnston, E. L., Komyakova, V., Morris, R. L., Strain, E. M. A., Naylor, L. A., \& Dafforn, K. A. 2017. Identifying the consequences of ocean sprawl for sedimentary habitats. Journal of Experimental Marine Biology and Ecology, 492, 31-48.

Heery, E. C., Dafforn, K. A., Smith, J. A., Ushiama, S., \& Mayer-Pinto, M. 2018. Not all 
artificial structures are created equal: Pilings linked to greater ecological and environmental change in sediment communities than seawalls. Marine Environmental Research, 142, 286-294.

Herbert, R. J. H., Southward, A. J., Sheader, M., \& Hawkins, S. J. 2007. Influence of recruitment and temperature on distribution of intertidal barnacles in the English Channel. Journal of the Marine Biological Association of the United Kingdom, 87(2), 487-499.

Hewitt, C. L. \& Campbell, M. L. 2007. Mechanisms for the prevention of marine bioinvasions for better biosecurity. Marine Pollution Bulletin, 55, 395-401.

Hewitt, C. L. 2002. Distribution and Biodiversity of Australian Tropical Marine Bioinvasions. Pacific Science, 56(2), 213-222.

Hewitt, C. L., \& Hayes, K. R. 2002. Risk assessment of marine biological invasions. In Invasive aquatic species of Europe. Distribution, impacts and management, Springer Netherlands, 456-466.

Hewitt, C. L., \& Martin, R. B. 2001. Centre for Research on Introduced Marine Pests Technical Report No . 22. Revised Protocols for Baseline Port Surveys for Introduced Marine Species : Survey Design Sampling Protocols and Specimen Handling, 46.

Hewitt, C. L., Campbell, M. L., 2007. Mechanisms for the prevention of marine bioinvasions for better biosecurity. Marine Pollution Bulletin, 55, 395-401.

Hewitt, C. L., Campbell, M. L., Thresher, R. E., Martin, R. B., Boyd, S., Cohen, B. F., Currie, D. R., Gomon, M. F., Keough, M. J., Lewis, J. A., Lockett, M. M., Mays, N., McArthur, M. A., O’Hara, T. D., Poore, G. C. B., Ross, D. J., Storey, M. J., Watson, J. E., \& Wilson, R. S. 2004. Introduced and cryptogenic species in Port Phillip Bay, Victoria, Australia. Marine Biology, 144, 183-202.

Hewitt, C. L., Gollasch, S., \& Minchin, D. 2009. The Vessel as a Vector - Biofouling, Ballast Water and Sediments. Biological Invasions in Marine Ecosystems, 204, 117-131.

Hewitt, C. L., Willing, J., Bauckham, A., Cassidy, A. M., Cox, C. M. S., Jones, L., \& Wotton, D. M. 2004. New Zealand marine biosecurity: Delivering outcomes in a fluid environment. New Zealand Journal of Marine and Freshwater Research. 38(3), 429-438.

Hewitt, C., Campbell, M., Thresher, R., \& Martin, R. 1999. Marine Biological Invasions of Port Phillip Bay, Victoria. CSIRO CRIMP Technical Report No. 20.

Hickman, R. W. 1979. Allometry and growth of the green- lipped mussel Perna canaliculus in New Zealand. Marine Biology, 51, 311-327.

Hilbish, T. J., Mullinax, A., Dolven, S. I., Meyer, A., Koehn, R. K., \& Rawson, P. D. 2000. Origin of the anti-tropical distribution pattern in marine mussels (Mytilus spp.): Routes and timing of transequatorial migration. Marine Biology, 136(1), 69-77.

Hinkel, J., Lincke, D., Vafeidis, A. T., Perrette, M., Nicholls, R. J., Tol, R. S. J., Marzeion, B., Fettweis, X., Ionescu, C., \& Levermann, A. 2014. Coastal flood damage and adaptation costs under 21st century sea-level rise. Proceedings of the National Academy of Sciences of the United States of America, 111(9), 3292-3297.

Hobday, A., Hewitt, C., Condie, S., Cahill, M., Mansbridge, M., Ling, S. D. 2002. Mapping the Australian ballast water uptake and deballasting contingency zones, CSIRO Marine Research, MR-OEEZ 02-06. 
Hockey, P. A. R., \& Van Erkom Schurink, C. 1992. The invasive biology of the mussel Mytilus galloprovincialis on the southern african coast. Transactions of the Royal Society of South Africa, 48(1), 123-139.

Holland B. S, Dawson M. N, Crow G. L, Hofmann D. K. 2004. Global phylogeography of Cassiopea (Scyphozoa: Rhizostomeae): molecular evidence for cryptic species and multiple invasions of the Hawaiian Islands. Marine Biology 145, 1119-1128.

Holland B. S. 2000. Genetics of marine bioinvasions. Hydrobiologia, 420, 63-71.

Holloway, M. G., \& Connell, S. D. 2002. Why do floating structures create novel habitats for subtidal epibiota? Marine Ecology Progress Series, 235, 43-52.

Honkoop, P.J.C., Beukema, J.J., 1997. Loss of body mass in winter in three intertidal bivalve species: An experimental and observational study of the interacting effects between water temperature, feeding time and feeding behaviour. Journal of Experimental Marine Biology and Ecology, 212, 277-297.

Hopkins G. A., Forrest B. M. 2010. A preliminary assessment of biofouling and nonindigenous marine species associated with commercial slow-moving vessels arriving in New Zealand. Biofouling, 26, 613-621.

Hopkins G. A., Forrest B. M., Jiang W., Gardner J. P. A. 2011a. Successful eradication of a non-indigenous marine bivalve from a subtidal soft sediment environment. Journal of Applied Ecology, 48, 424-431.

Hopkins G. A., Forrest B. M., Piola R. F., Gardner J. P. A. 2011b. Factors affecting survivorship of defouled communities and the effect of fragmentation on establishment success. Journal of Experimental Marine Biology and Ecology, 396, 233-243.

Huang, X. W., Wang, W., \& Dong, Y. W. 2015. Complex ecology of China's seawall. Science, 347 (6226), 1079.

Hulme, P. E. 2006. Beyond control: Wider implications for the management of biological invasions. Journal of Applied Ecology, 43, 835-84.

Hulme, P. E. 2009. Trade, transport and trouble: managing invasive species pathways in an era of globalization. Journal of Applied Ecology, 46(1), 10-18.

Inglis, G., Gust, N., Fitridge, I., Floerl, O., Woods, C., Kospartov, M., Hayden, B., \& Fenwick, G. 2005. Gulf Harbour Marina: Baseline survey for non-indigenous marine species (Research Project ZBS2000-04). In Biosecurity New Zealand. Technical Paper No: 2005/12.

Inglis, G., Gust, N., Fitridge, I., Floerl, O., Woods, C., Kospartov, M., Hayden, B., \& Fenwick, G. 2005. Opua Marina: Baseline survey for non-indigenous marine species (Research Project ZBS2000-04). In Biosecurity New Zealand. Technical Paper No: 2005/15.

Inglis, G., Gust, N., Fitridge, I., Floerl, O., Woods, C., Kospartov, M., Hayden, B., \& Fenwick, G. (2005). Port of Bluff: Baseline survey for non-indigenous marine species (Research Project ZBS2000-04). In Biosecurity New Zealand. Technical Paper No: 2005/09.

Inglis, G., Gust, N., Fitridge, I., Floerl, O., Woods, C., Kospartov, M., Hayden, B., \& Fenwick, G. 2006. Dunedin Harbour: Baseline survey for non-indigenous marine species (Research Project ZBS2000-04). In Biosecurity New Zealand. Technical Paper No: 2005/10. 
Inglis, G., Gust, N., Fitridge, I., Floerl, O., Woods, C., Kospartov, M., Hayden, B., \& Fenwick, G. 2006. Port of Auckland: Baseline survey for non-indigenous marine species (Research Project ZBS2000-04). In Biosecurity New Zealand. Technical Paper No: 2005/08.

Inglis, G., Gust, N., Fitridge, I., Floerl, O., Woods, C., Kospartov, M., Hayden, B., \& Fenwick, G. 2006. Port of Gisborne: Baseline survey for non-indigenous marine species (Research Project ZBS2000-04). In Biosecurity New Zealand. Technical Paper No: 2005/11.

Inglis, G., Gust, N., Fitridge, I., Floerl, O., Woods, C., Kospartov, M., Hayden, B., \& Fenwick, G. 2006. Port of Lyttelton: Baseline survey for non-indigenous marine species (Research Project ZBS2000-04). In Biosecurity New Zealand. Technical Paper No: 2005/01.

Inglis, G., Gust, N., Fitridge, I., Floerl, O., Woods, C., Kospartov, M., Hayden, B., \& Fenwick, G. 2006. Port of Napier: Baseline survey for non-indigenous marine species (Research Project ZBS2000-04). In Biosecurity New Zealand. Technical Paper No: 2005/13.

Inglis, G., Gust, N., Fitridge, I., Floerl, O., Woods, C., Kospartov, M., Hayden, B., \& Fenwick, G. 2006. Port of Picton: Baseline survey for non-indigenous marine species (Research Project ZBS2000-04). In Biosecurity New Zealand. Technical Paper No: 2005/03.

Inglis, G., Gust, N., Fitridge, I., Floerl, O., Woods, C., Kospartov, M., Hayden, B., \& Fenwick, G. 2006. Port of Taranaki: Baseline survey for non-indigenous marine species (Research Project ZBS2000-04). In Biosecurity New Zealand. Technical Paper No: 2005/04.

Inglis, G., Gust, N., Fitridge, I., Floerl, O., Woods, C., Kospartov, M., Hayden, B., \& Fenwick, G. 2006. Port of Tauranga: Baseline survey for non-indigenous marine species (Research Project ZBS2000-04). In Biosecurity New Zealand. Technical Paper No: 2005/05.

Inglis, G., Gust, N., Fitridge, I., Floerl, O., Woods, C., Kospartov, M., Hayden, B., \& Fenwick, G. 2006. Port of Timaru: Baseline survey for non-indigenous marine species (Research Project ZBS2000-04). In Biosecurity New Zealand. Technical Paper No: 2005/06.

Inglis, G., Gust, N., Fitridge, I., Floerl, O., Woods, C., Kospartov, M., Hayden, B., \& Fenwick, G. 2006. Port of Wellington: Baseline survey for non-indigenous marine species (Research Project ZBS2000-04). In Biosecurity New Zealand. Technical Paper No: 2005/09.

Inglis, G., Gust, N., Fitridge, I., Floerl, O., Woods, C., Kospartov, M., Hayden, B., \& Fenwick, G. 2006. Whangarei Harbour: Baseline survey for non-indigenous marine species (Research Project ZBS2000-04). In Biosecurity New Zealand. Technical Paper No: 2005/16.

Inglis, G., Gust, N., Fitridge, I., Floerl, O., Woods, C., Kospartov, M., Hayden, B., \& Fenwick, G. 2008. Port of Lyttelton: Second baseline survey for non-indigenous marine species (Research Project ZBS2000-04). In Biosecurity New Zealand. Technical Paper No: 2008/02.

Inglis, G., Gust, N., Fitridge, I., Floerl, O., Woods, C., Kospartov, M., Hayden, B., \& Fenwick, G. 2008. Port of Nelson: Baseline survey for non-indigenous marine species (Research Project ZBS2000-04). In Biosecurity New Zealand. Technical Paper No: 2008/05.

Inglis, G., Gust, N., Fitridge, I., Floerl, O., Woods, C., Kospartov, M., Hayden, B., \& Fenwick, G. 2008. Port of Taranaki: Second baseline survey for non-indigenous marine species (Research Project ZBS2000-04). In Biosecurity New Zealand. Technical Paper No: 2008/03. 
Inglis, G., Gust, N., Fitridge, I., Floerl, O., Woods, C., Kospartov, M., Hayden, B., \& Fenwick, G. 2008. Port of Tauranga: Second baseline survey for non-indigenous marine species (Research Project ZBS2000-04). In Biosecurity New Zealand. Technical Paper No: 2008/08.

Inglis, G., Gust, N., Fitridge, I., Floerl, O., Woods, C., Kospartov, M., Hayden, B., \& Fenwick, G. 2008. Port of Timaru: Second baseline survey for non-indigenous marine species (Research Project ZBS2000-04). In Biosecurity New Zealand. Technical Paper No: 2008/03.

Inglis, G., Gust, N., Fitridge, I., Floerl, O., Woods, C., Kospartov, M., Hayden, B., \& Fenwick, G. 2008. Port of Wellington: Second baseline survey for non-indigenous marine species (Research Project ZBS2000-04). In Biosecurity New Zealand. Technical Paper No: 2008/06.

Inglis, G. J., \& Seaward, K. 2016. Indicators of non-indigenous species in marine systems. NIWA Client Report No. CHC2016-024, 74.

Inglis, G., Morrisey, D., Woods, C., Sinner, J. \& Newton, M. 2014. Managing the domestic spread of harmful marine organisms. Part A - Operational tools for management. Report prepared for New Zealand Ministry for Primary Industries. National Institute of Water and Atmospheric Research. Christchurch, 166.

International Maritime Organization (IMO). 2011. Report of the Marine Environment Protection Committee on the sixty-second session. MEPCI62\24.

International Maritime Organization (IMO). 2015. Guidelines and Guidance Documents related to the Implementation of the International Convention for the Control and Management of Ships' Ballast Water and Sediments, In UN - International Maritime Organization, www.imo.org.

International Maritime Organization (IMO). 2017. Guidelines and Guidance Documents related to the Implementation of the International Convention for the Control and Management of Ships' Ballast Water and Sediments, In UN - International Maritime Organization, www.imo.org.

Jackson, C. R., Churchill, P. F., \& Roden, E. E. 2001. Successional changes in bacterial assemblage structure during epilithic biofilm development. Ecology, 82(2), 555-566.

James, K., \& Shears, N. T. 2016. Proliferation of the invasive kelp Undaria pinnatifida at aquaculture sites promotes spread to coastal reefs. Marine Biology, 163(2), 34.

Jeschke J. M., Gómez Aparicio L., Haider S. 2012. Support for major hypotheses in invasion biology is uneven and declining. NeoBiota, 14, 1-20.

Johnston, E. L., \& Keough, M. J. 2002. Direct and indirect effects of repeated pollution events on marine hard-substrate assemblages. Ecological Applications, 12(4), 1212-1228.

Johnston, E. L., Dafforn, K. A., Clark, G. F., Rius, M., \& Floerl, O. 2017. How anthropogenic activities affect the establishment and spread of non-indigenous species post-arrival. In Oceanography and Marine Biology: An Annual Review, 55, 389-419.

Johnston, E. L., Marzinelli, E. M., Wood, C. A., Speranza, D. \& Bishop, J. D. D. 2011. Bearing the burden of boat harbours: heavy contaminant and fouling loads in a native habitatforming alga. Marine Pollution Bulletin, 62, 2137-2144. 
Johnston, E. L., Mayer-Pinto, M., Hutchings, P. A., Marzinelli, E. M., Ahyong, S. T., Birch, G., Booth, D. J., Creese, R. G., Doblin, M. A., Figueira, W., Gribben, P. E., Pritchard, T., Roughan, M., Steinberg, P. D., \& Hedge, L. H. 2015. Sydney Harbour: What we do and do not know about a highly diverse estuary. Marine and Freshwater Research, 66(12), 1073-1087.

Johnston, E. L., Piola, R. F., \& Clark, G. F. 2009. The Role of Propagule Pressure in Invasion Success. Biological Invasions in Marine Ecosystems, 204, 133-151.

Johnston, Emma L., Dafforn, K. A., Clark, G. F., Rius, M., \& Floerl, O. 2017. How anthropogenic activities affect the establishment and spread of non-indigenous species post-arrival. In Oceanography and Marine Biology: An Annual Review, 55, 389-419.

Jones, E., \& Thornber, C. S. 2010. Effects of habitat-modifying invasive macroalgae on epiphytic algal communities. Marine Ecology Progress Series, 400, 87-100.

Kaiser, B., \& Burnett, K. 2010. Spatial economic analysis of early detection and rapid response strategies for an invasive species. Resource and Energy Economics, 32, 566-585.

Kaluza, P., Kölzsch, A., Gastner, M. T., \& Blasius, B. 2010. The complex network of global cargo ship movements. Journal of the Royal Society Interface, 7(48), 1093-1103.

Katsanevakis, S., Wallentinus, I., Zenetos, A., Leppäkoski, E., Çinar, M. E., Oztürk, B., Grabowski, M., Golani, D., \& Cardoso, A. C. 2014. Impacts of invasive alien marine species on ecosystem services and biodiversity: A pan-European review. Aquatic Invasions, 9(4), 391-423.

Keith, S. A., Herbert, R. J. H., Norton, P. A., Hawkins, S. J., \& Newton, A. C. 2011. Individualistic species limitations of climate-induced range expansions generated by meso-scale dispersal barriers. Diversity and Distributions, 17(2), 275-286.

Kennedy, E. V., Ordoñez, A., Lewis, B. E., \& Diaz-Pulido, G. 2017. Comparison of recruitment tile materials for monitoring coralline algae responses to a changing climate. Marine Ecology Progress Series, 569(1), 129-144.

Kimbro, D. L., Grosholz, E. D., Baukus, A. J., Nesbitt, N. J., Travis, N. M., Attoe, S., \& Coleman-Hulbert, C. 2009. Invasive species cause large-scale loss of native California oyster habitat by disrupting trophic cascades. Oecologia, 160, 563-575.

Klein J. C., Underwood A. J., Chapman M. G. 2011. Urban structures provide new insights into interactions among grazers and habitat. Ecological Application, 21(2), 427-438.

Knights, A. M., Firth, L. B., \& Walters, K. 2012. Interactions between multiple recruitment drivers: Post-settlement predation mortality and flow-mediated recruitment. PLoS ONE 7(4), e35096.

Kohler, K. E., \& Gill, S. M. 2006. Coral Point Count with Excel extensions (CPCe): A Visual Basic program for the determination of coral and substrate coverage using random point count methodology. Computers and Geosciences, 32(9), 1259-1269.

Kueffer, C., \& Kaiser-Bunbury, C. N. 2014. Reconciling conflicting perspectives for biodiversity conservation in the Anthropocene. Frontiers in Ecology and the Environment, 21(2), 131-137.

Lachowicz, L. S. 2005. Population biology of mussels (Aulacomya maoriana, Mytilus galloprovincialis and Perna canaliculus) from rocky intertidal shores in Wellington 
Harbour, New Zealand. (Doctoral thesis, Victoria University of Wellington, NewZealand).Retrieved from https://researcharchive.vuw.ac.nz/xmlui/handle10063/164.

Lai, S., Loke, L. H. L., Bouma, T. J., \& Todd, P. A. 2018. Biodiversity surveys and stable isotope analyses reveal key differences in intertidal assemblages between tropical seawalls and rocky shores. Marine Ecology Progress Series, 587, 41-53.

Lam, N. W. Y., Huang, R., \& Chan, B. K. K. 2009. Variations in intertidal assemblages and zonation patterns between vertical artificial seawalls and natural rocky shores: A case study from Victoria Harbour, Hong Kong. Zoological Studies, 48(2), 184-195.

Larraín M. A., Zbawicka M., Araneda C., Gardner J. P. A., Wenne R. 2018. Native and invasive taxa on the Pacific coast of South America: Impacts on aquaculture, traceability and biodiversity of blue mussels (Mytilus spp.). Evolutionary Applications, 11, 298-311.

Leclerc, J. C., \& Viard, F. 2018. Habitat formation prevails over predation in influencing fouling communities. Ecology and Evolution, 8(1), 477-492.

Lee, S. Y., \& Morton, B. 1985. The introduction of the Mediterranean mussel Mytilus galloprovincialis into Hong Kong. Malacological Review, 18(1-2), 107-109.

Lehtiniemi, M., Ojaveer, H., David, M., Galil, B., Gollasch, S., McKenzie, C., Minchin, D., Occhipinti-Ambrogi, A., Olenin, S., Pederson, J., 2015. Dose of truth-Monitoring marine non-indigenous species to serve legislative requirements. Marine Policy, 54, 26-35.

Leppäkoski, E. 2002. Harmful Non-Native Species in the Baltic Sea - An Ignored Problem. In Baltic Coastal Ecosystems, 253-275.

Leppäkoski, E., Gollasch, S., \& Olenin, S. 2002. Invasive Aquatic Species of Europe. Distribution, Impacts and Management. Invasive Aquatic Species of Europe. Distribution, Impacts and Management, 53.

Levine, J. M. 2000. Species diversity and biological invasions: Relating local process to community pattern. Science, 288(5467), 852-854.

Lewis, P. N., Hewitt, C. L., Riddle, M., \& McMinn, A. 2003. Marine introductions in the Southern Ocean: An unrecognised hazard to biodiversity. Marine Pollution Bulletin, 46(2), 213-223.

Liversage, K., \& Chapman, M. G. 2018. Coastal ecological engineering and habitat restoration: Incorporating biologically diverse boulder habitat. Marine Ecology Progress Series, 593, 173-185.

Liversage, K., Janetzki, N., \& Benkendorff, K. 2014. Associations of benthic fauna with different rock types, and evidence of changing effects during succession. Marine Ecology Progress Series, 505, 131-143.

Lo, V. B., Levings, C. D., \& Chan, K. M. A. 2012. Quantifying potential propagule pressure of aquatic invasive species from the commercial shipping industry in Canada. Marine Pollution Bulletin, 64(2), 295-302.

Lockwood, J. L., Cassey, P., \& Blackburn, T. M. 2005. The role of propagule pressure in explaining species invasions. Trends in Ecology and Evolution, 20(5), 223-228.

Lockwood, J. L., Cassey, P. \& Blackburn, T. M. 2009. The more you introduce the more you get: the role of colonization and propagule pressure in invasion ecology. Diversity and 
Distributions, 15, $904-910$.

Lockwood, J. L., Hoopes, M. F., Marchetti, M. P. 2007. Invasion Ecology, 2nd Edition, WileyBlackwell, Malden, USA, 304.

Loke, L. H. L., \& Todd, P. A. 2016. Structural Complexity and component type increase intertidal biodiversity independently of area. Ecology, 97(2), 383-393.

Loke, L. H. L., Jachowski, N. R., Bouma, T. J., Ladle, R. J., \& Todd, P. A. 2014. Complexity for artificial substrates (CASU): Software for creating and visualising habitat complexity. PLoS ONE, 9(2), e87990.

Loke, L. H. L., Liao, L. M., Bouma, T. J., \& Todd, P. A. 2016. The succession of seawall algal communities on artificial substrates. Raffles Bulletin of Zoology, 32, 1-10.

Lotze, H. K., Worm, B., \& Sommer, U. 2020. Nordic Society Oikos Propagule Banks, Herbivory and Nutrient Supply Control Population Development and Dominance Patterns in Macroalgal Blooms Author ( $\mathrm{s}$ ): Heike K . Lotze , Boris Worm and Ulrich Sommer Published by: Wiley on behalf of Nordic Society O. 89(1), 46-58.

Lovell, D. P. 2013. Biological importance and statistical significance. Journal of Agricultural and Food Chemistry, 61(35), 8340-8348.

Lowe S., Browne M., Boudjelas S. 2004. 100 of the world's worst invasive species: a selection from the global invasive species database. Invasive Species Specialist Group, Auckland.

Lowe, S., Browne, M., Boudjelas, S., \& Poorter, M. De. 2000. 100 of the World's Worst Invasive Alien Species A selection from the Global Invasive Species Database. The Invasive Species Specialist Group (ISSG) a specialist group of the Species Survival Commission (SSC) of the World Conservation Union (IUCN), 12.

Ma, Z., Melville, D. S., Lui, J., Chen, Y., Yang, H., Ren, W., Zhang, Z., Peirsma, T. \& Li, B. 2014. Rethinking China's new great wall. Science, 346 (6212), 912-914.

Macdonald, E., \& King, E. G. 2018. Novel ecosystems: A bridging concept for the consilience of cultural landscape conservation and ecological restoration. Landscape and Urban Planning, 177, 148-159.

Mack, R. N., Simberloff, D., Lonsdale, W. M., Evans, H., Clout, M., \& Bazzaz, F. A. 2000. Biotic invasions: Causes, epidemiology, global consequences, and control. Ecological Applications, 10 (3), 689-710.

MacKie, J. A., Darling, J. A., \& Geller, J. B. 2012. Ecology of cryptic invasions: Latitudinal segregation among Watersipora (Bryozoa) species. Scientific Reports, 2, 1-10.

MAF, 1993. Biosecurity Act 1993. Public Act 1993 No 95.

Malachowicz, M., \& Wenne, R. 2019. Mantle transcriptome sequencing of Mytilus spp. and identification of putative biomineralization genes. Peer Journal 6(9), e6245.

Mallela, J., Milne, B. C., \& Martinez-Escobar, D. 2017. A comparison of epibenthic reef communities settling on commonly used experimental substrates: PVC versus ceramic tiles. Journal of Experimental Marine Biology and Ecology, 486, 290-295.

Marraffini, M. L., \& Geller, J. B. 2015. Species richness and interacting factors control invasibility of a marine community. Proceedings of the Royal Society B: Biological Sciences, 282(1812). 
Marshall, D. J., Pechenik, J. A., \& Keough M. J. 2003. Larval activity levels and delayed metamorphosis affect post-larval performance in the colonial ascidian Diplosoma listerianum. Marine Ecological Progress Series, 246, 153-162.

Martin, D., Bertasi, F., Colangelo, M. A., de Vries, M., Frost, M., Hawkins, S. J., Macpherson, E., Moschella, P. S., Satta, M. P., Thompson, R. C. \& Ceccherelli, V. U. 2005. Ecological impact of coastal defence structures on sediment and mobile fauna: evaluating and forecasting consequences of unavoidable modifications of native habitats. Coastal Engineering, 52, 1027-1051.

Martins, G. M., Neto, A. I., \& Cacabelos, E. 2016. 7 Marine Environmental Research, 113, 8894.

Martins, G. M., Thompson, R. C., Neto, A. I., Hawkins, S. J., \& Jenkins, S. R. 2010. Enhancing stocks of the exploited limpet Patella candei d'Orbigny via modifications in coastal engineering. Biological Conservation, 143(1), 203-211.

Mayer-Pinto, M., Cole, V. J., Johnston, E. L., Bugnot, A., Hurst, H., Airoldi, L., Glasby, T. M., \& Dafforn, K. A. 2018. Functional and structural responses to marine urbanisation. Environmental Research Letters, 13(1), 1-17.

Mayer-Pinto, M., Dafforn, K. A., Bugnot, A. B., Glasby, T. M., \& Johnston, E. L. 2018. Artificial structures alter kelp functioning across an urbanised estuary. Marine Environmental Research, 139, 136-143.

McDonald, J. H., Seed, R., \& Koehn, R. K. 1991. Allozymes and morphometric characters of three species of Mytilus in the Northern and Southern Hemispheres. Marine Biology, 111(3), 323-333.

McKenzie, C. H., Reid V., Lambert, G., Matheson, K., Minchin, D., Brown, L., Gollasch, S., Simard, N., Therriault, T., and Pederson, J. 2017. Alien Species Alert: Didemnum vexillum Kott 2002, Current invasion status, ecosystem impact and mitigation options for an invasive colonial tunicate. ICES Cooperative Research Report No. 335, 33.

McKinney, M. L. \& Lockwood, J. L. 1999. Biotic homogenization: a few winners replacing many losers in the next mass extinction. Trends in Ecology \& Evolution, 14, 450 - 453.

Mead, A., Carlton, J. T., Griffiths, C. L., \& Rius, M. 2011. Revealing the scale of marine bioinvasions in developing regions: A South African re-assessment. Biological Invasions, 13(9), 1991-2008.

Megina, C., González-Duarte, M. M., \& López-González, P. J. 2016. Benthic assemblages, biodiversity and invasiveness in marinas and commercial harbours: an investigation using a bioindicator group. Biofouling, 32(4), 465-475.

Melbourne, B. A., \& Hastings, A. 2009. Highly variable spread rates in replicated biological invasions: Fundamental limits to predictability. Science, 325(5947), 1536-1539.

Melbourne, B. A., Cornell, H. V., Davies, K. F., Dugaw, C. J., Elmendorf, S., Freestone, A. L., Hall, R. J., Harrison, S., Hastings, A., Holland, M., Holyoak, M., Lambrinos, J., Moore, K., \& Yokomizo, H. 2007. Invasion in a heterogeneous world: Resistance, coexistence or hostile takeover? Ecology Letters, 10(1), 77-94.

Miller, D. A. W., Pacifici, K., Sanderlin, J. S. \& Reich, B. J. The recent past and promising future for data integration methods to estimate species' distributions. Methods in Ecology and Evolution, 10, 22-37, 
Mills, K. A., Hamer, P. A., \& Quinn, G. P. 2017. Artificial reefs create distinct fish assemblages: a study of fish assemblage response to the deployment of artificial patch reefs. Marine Ecology Progress Series, 585, 155-173.

Mineur, F., Cook, E. J., Minchin, D., Bohn, K., Macleod, A., \& Maggs, C. A. 2012. Changing coasts: Marine aliens and artificial structures. In Oceanography and Marine Biology: An Annual Review, 50, 189-234.

Ministry for the Environment, \& Stats NZ. 2016. Our marine environment 2016. In New Zealand's Environmental Reporting Series.

Ministry of Primary Industries (MPI). 2014. Craft risk management standard: biofouling on vessels arriving to New Zealand. Ministry for Primary Industries, Wellington, New Zealand.

Ministry of Primary Industries (MPI). 2018. Technical Guidance on Biofouling Management for Vessels Arriving to New Zealand. MPI Technical Paper No: 2018/07.

Molnar, J. L., Gamboa, R. L., Revenga, C., \& Spalding, M. D. 2008. Assessing the global threat of invasive species to marine biodiversity. Frontiers in Ecology and the Environment, 6(9), 485-492.

Morand, P., \& Briand, X. 1996. Excessive growth of macroalgae: A symptom of environmental disturbance. Botanica Marina, 39(6), 491-516.

Moreira, J., Chapman, M. G., \& Underwood, A. J. 2006. Seawalls do not sustain viable populations of limpets. Marine Ecology Progress Series, 322, 179-188.

Moreira, J., Chapman, M. G., \& Underwood, A. J. 2007. Maintenance of chitons on seawalls using crevices on sandstone blocks as habitat in Sydney Harbour, Australia. Journal of Experimental Marine Biology and Ecology, 347(1-2), 134-143.

Morris, R. L., Chapman, M. G., Firth, L. B., \& Coleman, R. A. 2017. Increasing habitat complexity on seawalls: Investigating large- and small-scale effects on fish assemblages. Ecology and Evolution, 7(22), 9567-9579.

Morris R. L., Konlechner T. M., Ghisalberti M., Swearer S. E. 2018a. From grey to green: efficacy of eco-engineering solutions for nature-based coastal defence. Global Change Biology, 24(5), 1827-1842.

Morris, R. L., Golding, S., Dafforn, K. A., \& Coleman, R. A. 2018b. Can coir increase native biodiversity and reduce colonisation of non-indigenous species in eco-engineered rock pools? Ecological Engineering, 120, 622-630.

Morris, R. L., Heery, E. C., Loke, L. H. L., Lau, E., Strain, E. M. A., Airoldi, L., Alexander, K. A., Bishop, M. J., Coleman, R. A., Cordell, J. R., Dong, Y. W., Firth, L. B., Hawkins, S. J., Heath, T., Kokora, M., Lee, S. Y., Miller, J. K., Perkol-Finkel, S., Rella, A., Leung, K. M. Y. 2019. Design options, implementation issues and evaluating success of ecologically engineered shorelines. In Oceanography and Marine Biology, 57, 169-228.

Morris, R. L., Porter, A. G., Figueira, W. F., Coleman, R. A., Fobert, E. K., \& Ferrari, R. 2018b. Fish-smart seawalls: a decision tool for adaptive management of marine infrastructure. Frontiers in Ecology and the Environment, 16(5), 278-287.

Moschella, P. S., Abbiati, M., Åberg, P., Airoldi, L., Anderson, J. M., Bacchiocchi, F., Bulleri, F., Dinesen, G. E., Frost, M., Gacia, E., Granhag, L., Jonsson, P. R., Satta, M. P., Sundelöf, 
A., Thompson, R. C., \& Hawkins, S. J. 2005. Low-crested coastal defence structures as artificial habitats for marine life: Using ecological criteria in design. Coastal Engineering, 52(10-11), 1053-1071.

Moss, B. 2017. Marine reptiles, birds and mammals and nutrient transfers among the seas and the land: An appraisal of current knowledge. Journal of Experimental Marine Biology and Ecology, 492, 63-80.

Munari, C. 2013. Benthic community and biological trait composition in respect to artificial coastal defence structures: A study case in the northern adriatic sea. Marine Environmental Research, 90, 47-54.

Munari, C., Corbau, C., Simeoni, U. \& Mistri, M. 2011. Coastal defence through low crested breakwater structures: Jumping out of the frying pan into the fire? Marine Pollution Bulletin, 62, 1641-1651.

Munsch, S. H., Cordell, J. R., Toft, J. D., \& Morgan, E. E. 2014. Effects of seawalls and piers on fish assemblages and juvenile salmon feeding behaviour. North American Journal of Fisheries Management, 32(4), 814-827.

Naylor, L. A., Coombes, M. A., Venn, O., Roast, S. D., \& Thompson, R. C. 2012. Facilitating ecological enhancement of coastal infrastructure: The role of policy, people and planning. Environmental Science and Policy, 22, 36-46.

Neumann, B., Vafeidis, A. T., Zimmermann, J., \& Nicholls, R. J. 2015. Future coastal population growth and exposure to sea-level rise and coastal flooding - A global assessment. PLoS ONE, 10(3), e0118571.

Nicastro, K. R., Zardi, G. I., \& McQuaid, C. D. 2010. Differential reproductive investment, attachment strength and mortality of invasive and indigenous mussels across heterogeneous environments. Biological Invasions, 12(7), 2165-2177.

O'Brien, C. E., Johnston, M. W., \& Kerstetter, D. W. 2017. Ports and pests: Assessing the threat of aquatic invasive species introduced by maritime shipping activity in Cuba. Marine Pollution Bulletin, 125(1-2), 92-102.

O’Shaughnessy, K. A., Hawkins, S. J., Evans, A. J., Hanley, M. E., Lunt, P., Thompson, R. C., Francis, R. A., Hoggart, S. P. G., Moore, P. J., Iglesias, G., Simmonds, D., Ducker, J., \& Firth, L. B. 2019. Design catalogue for eco-engineering of coastal artificial structures: a multifunctional approach for stakeholders and end-users. Urban Ecosystems, 23, 431-443.

Occhipinti-Ambrogi A. 2007. Global change and marine communities: alien species and climate change. Marine Pollution Bulletin, 55, 342-352.

Ojaveer, H., Galil, B. S., Campbell, M. L., Carlton, J. T., Canning-Clode, J., Cook, E. J., Davidson, A. D., Hewitt, C. L., Jelmert, A., Marchini, A., McKenzie, C. H., Minchin, D., Occhipinti-Ambrogi, A., Olenin, S., \& Ruiz, G. 2015. Classification of Non-Indigenous Species Based on Their Impacts: Considerations for Application in Marine Management. PLoS Biology, 13(4), 1-13.

Ojaveer, H., Galil, B. S., Carlton, J. T., Alleway, H., Goulletquer, P., Lehtiniemi, M., Marchini, A., Miller, W., Occhipinti-Ambrogi, A., Peharda, M., Ruiz, G. M., Williams, S.L., Zaiko, A., 2018. Historical baselines in marine bioinvasions: Implications for policy and management. PLoS One, 13, e0202383.

Okaniwa, N., Miyaji, T., Sasaki, T., \& Tanabe, K. 2010. Shell growth and reproductive cycle 
of the Mediterranean mussel Mytilus galloprovincialis in Tokyo Bay, Japan: Relationship with environmental conditions. Plankton and Benthos Research, 5, 214-220.

Olenin, S., \& Leppäkoski, E. 1999. Non-native animals in the Baltic Sea: Alteration of benthic habitats in coastal inlets and lagoons. Hydrobiologia, 393, 233-243.

Olenin, S., Gollasch, S., Lehtiniemi, M., Sapota, M., \& Zaiko, A. 2017. Biological invasions. In: Snoeijs-Leijonmalm P., Schubert H., Radziejewska T. ed. Biological Oceanography of the Baltic Sea, Springer, 193-232.

Olyarnik, S. V., Bracken, M. E. S., Byrnes, J. E., Hughes, A. R., Hultgren, K. M., \& Stachowicz, J. J. 2009. Ecological Factors Affecting Community Invasibility. Biological Invasions in Marine Ecosystems, 204, 215-238.

Oricchio, F. T., Pastro, G., Vieira, E. A., Flores, A. A. V., Gibran, F. Z., \& Dias, G. M. 2016. Distinct community dynamics at two artificial habitats in a recreational marina. Marine Environmental Research, 122, 85-92.

Oyarzún, P. A., Toro, J. E., Cañete, J. I., \& Gardner, J. P. A. 2016. Bioinvasion threatens the genetic integrity of native diversity and a natural hybrid zone: Smooth-shelled blue mussels (Mytilus spp.) in the Strait of Magellan. Biological Journal of the Linnean Society, 117(3), 574-585.

Oyarzún, P. A., Toro, J. E., Jaramillo, R., Guiñez, R., Briones, C., \& Astorga, M. 2011. Ciclo gonadal del chorito Mytilus chilensis (Bivalvia: Mytilidae) en dos localidades del sur de Chile. Latin American Journal of Aquatic Research, 39(3), 512-525.

Padilla, D. K., \& Williams, S. L. 2004. Beyond ballast water: Aquarium and ornamental trades as sources of invasive species in aquatic ecosystems. Frontiers in Ecology and the Environment, 2(3), 131-138.

Paine, R. T. 1966. Food Web Complexity and Species Diversity. The American Society of Naturalists, 100, 65-75.

Paine, R. T., \& Levin, S. A. 1981. Intertidal Landscapes : Disturbance and the Dynamics of Pattern Author (s): R . T . Paine and Simon A . Levin Published by : Wiley on behalf of the Ecological Society of America Stable, Ecological Monographs, 51(2), 145-178.

Pandolfi, J. M. 2008. Succession. In General Ecology, 3416-3424.

Papacostas K. J., Rielly-Carroll E. W., Georgian S. E. 2017. Biological mechanisms of marine invasions. Marine Ecology Progress Series, 565, 251-268.

Parker, J. D., Torchin, M. E., Hufbauer, R. A., Lemoine, N. P., Alba, C., Blumenthal, D. M., Bossdorf, O., Byers, J. E., Dunn, A. M., Heckman, R. W., Hejda, M., Jarošík, V., Kanarek, A. R., Martin, L. B., Perkins, S. E., Pyšek, P., Schierenbeck, K., Schlöder, C., Van Klinken, R., Wolfe, L. M. 2013. Do invasive species perform better in their new ranges? Ecology, 94(5), 985-994,

Pastro, G., Dias, G. M., Pereira-Filho, G. H., \& Gibran, F. Z. 2017. The consequences of smallscale variations in habitat conditions driven by a floating marina on reef fish assemblages of S.E. Brazil. Ocean and Coastal Management, 141, 98-106.

Pawlik, J. R. 1992. Chemical ecology of the settlement of benthic marine invertebrates. In Oceanography and marine biology: an annual review, 30, 273-335. 
People, J. 2006. Mussel beds on different types of structures support different macroinvertebrate assemblages. Austral Ecology, 31(2), 271-281.

Perkol-Finkel, S., Ferrario, F., Nicotera, V., \& Airoldi, L. 2012. Conservation challenges in urban seascapes: Promoting the growth of threatened species on coastal infrastructures. Journal of Applied Ecology, 49(6), 1457-1466.

Perkol-Finkel, S., Hadary, T., Rella, A., Shirazi, R., \& Sella, I. 2018. Seascape architecture incorporating ecological considerations in the design of coastal and marine infrastructure. Ecological Engineering, 120, 645-654.

Perkol-Finkel, S., Shashar, N., \& Benayahu, Y. 2006. Can artificial reefs mimic natural reef communities? The roles of structural features and age. Marine Environmental Research, 61(2), 121-135.

Peters, K., Sink, K., \& Robinson, T. B. 2017. Raising the flag on marine alien fouling species. Management of Biological Invasions, 8(1), 1-11.

Petes, L. E., Menge, B. A., \& Harris, A. L. 2008. Intertidal mussels exhibit energetic trade-offs between reproduction and stress resistance. Ecological Monographs, 78(3), 387-402.

Petraitis, P. S., \& Latham R. E. 1999. The importance of scale in testing the origins of alternative community states. Ecology, 80(2), 429-442.

Pettersen, A. K., Turchini, G. M., Jahangard, S., Ingram, B. A., \& Sherman, C. D. H. 2010. Effects of different dietary microalgae on survival, growth, settlement and fatty acid composition of blue mussel (Mytilus galloprovincialis) larvae. Aquaculture, 309(1-4), 115-124.

Pickett, T., \& David, A. A. 2018. Global connectivity patterns of the notoriously invasive mussel, Mytilus galloprovincialis Lmk using archived CO1 sequence data. BMC Research Notes, 11(1), 1-7.

Piola, R. F., \& Johnston, E. L. 2008. Pollution reduces native diversity and increases invader dominance in marine hard-substrate communities. Diversity and Distributions, 14(2), 329-342.

Piola, R. F., Dafforn, K. A., \& Johnston, E. L. 2009. The influence of antifouling practices on marine invasions. Biofouling, 25(7), 633-644.

Pister, B. 2009. Urban marine ecology in southern California: The ability of riprap structures to serve as rocky intertidal habitat. Marine Biology, 156, 861-873.

Pochon, X., Bott, N. J., Smith, K. F., Wood, S. A., 2013. Evaluating detection limits of nextgeneration sequencing for the surveillance and monitoring of international marine pests. PLoS One 8, e73935.

Pochon, X., Zaiko, A., Fletcher, L.M., Laroche, O., Wood, S.A., 2017. Wanted dead or alive? Using metabarcoding of environmental DNA and RNA to distinguish living assemblages for biosecurity applications. PLoS One, 12, e0187636.

Pollard, D. A., \& Pethebridge, R. L. 2002. Report on Port Kembla Introduced Marine Pest Species Survey. NSW Fisheries Final Report Series, 41.

Pörtner, H. O., \& Peck, M. A. 2010. Climate change effects on fishes and fisheries: Towards a cause-and-effect understanding. Journal of Fish Biology, 77(8), 1745-1779. 
Purroy, A., Bukša, F., Puljas, S., \& Peharda, M. 2019. Variations in the reproductive investment of a venerid bivalve, Callista chione. Journal of the Marine Biological Association of the United Kingdom, 99(7), 1579-1589.

Pyšek, P., \& Richardson, D. M. 2010. Invasive Species, Environmental Change and Management, and Health. Annual Review of Environment and Resources, 35(1), 25-55.

Rahel, F. J., \& Olden, J. D. 2008. Assessing the effects of climate change on aquatic invasive species. Conservation Biology, 22(3), 521-533.

Read, G. B., Inglis, G., Stratford, P., \& Ahyong, S. T. 2011. Arrival of the alien fanworm Sabella spallanzanii (Gmelin, 1791) (Polychaeta: Sabellidae) in two New Zealand harbours. Aquatic Invasions, 6(3), 273-279.

Reise, K., Buschbaum, C., Buttger, H., \& Wegner, M. K. 2017. Invading oysters and native mussels: From hostile takeover to compatible bedfellows. Ecosphere, 8(9), e01949.

Ricciardi, A., 2007. Are modern biological invasions an unprecedented form of global change? Conservation Biology, 21(2), 329-336

Ricciardi, A., Blackburn, T. M., Carlton, J. T., Dick, J. T. A., Hulme, P. E., Iacarella, J. C., Jeschke, J. M., Liebhold, A. M., Lockwood, J. L., MacIsaac, H. J., Pysek, P., Richardson, D. M., Ruiz, G. M., Simberloff, D., Sutherland, W. J., Wardle, D. A., Aldridge, D. C., 2017. Invasion Science: A Horizon Scan of Emerging Challenges and Opportunities. Trends in Ecology \& Evolution, 32, 464-474.

Riera, L., Ramalhosa, P., Canning-Clode, J., \& Gestoso, I. 2018. Variability in the settlement of non-indigenous species in benthic communities from an oceanic island. Helgoland Marine Research, 72(1), 1-15.

Riginos, C., \& Cunningham, C. W. 2005. Local adaptation and species segregation in two mussel (Mytilus edulis $\times$ Mytilus trossulus) hybrid zones. Molecular Ecology, 14(2), 381400.

Rilov, G., Crooks, J. A., 2009. Biological Invasions in Marine Ecosystems: Ecological, Management, and Geographic Perspectives. Springer.

Rius, M., \& McQuaid, C. D. 2006. Wave action and competitive interaction between the invasive mussel Mytilus galloprovincialis and the indigenous Perna perna in South Africa. Marine Biology, 150(1), 69-78.

Rius, M., Turon, X., Bernardi, G., Volckaert, F. A. M., Viard, F., 2015. Marine invasion genetics: from spatio-temporal patterns to evolutionary outcomes. Biological Invasions 17, 869-885.

Rivero, N. K., Dafforn, K. A., Coleman, M. A., \& Johnston, E. L. 2013. Environmental and ecological changes associated with a marina. Biofouling, 29(7), 803-815.

Rodhouse, P. G., McDonald, J. H., Newell, R. I. E., \& Koehn, R. K. 1986. Gamete production, somatic growth and multiple-locus enzyme heterozygosity in Mytilus edulis. Marine Biology, 90(2), 209-214.

Rodriguez, L. F. 2006. Can invasive species facilitate native species? Evidence of how, when, and why these impacts occur. Biological Invasions, 8(4), 927-939.

Roman, J., \& Darling, J. A. 2007. Paradox lost: genetic diversity and the success of aquatic 
invasions. In Trends in Ecology and Evolution, 22(9), 454-64.

Ruiz, G. M., Fofonoff, P. W., Carlton, J. T., Wonham, M. J., \& Hines, A. H. 2000. Invasion of Coastal Marine Communities in North America: Apparent Patterns, Processes, and Biases. Annual Review of Ecology and Systematics, 31, 481-531.

Ruiz, G. M., Fofonoff, P. W., Steves, B., Foss, S. F., Shiba, S. N. 2011. Marine invasion history and vector analysis of California: a hotspot for Western North America. Diversity and Distributions, 17, 362-373.

Ruiz, G. M., Fofonoff, P., Hines, A. H., \& Grosholz, E. D. 1999. Non-indigenous species as stressors in estuarine and marine communities: Assessing invasion impacts and interactions. Limnology and Oceanography, 44(3), 950-972.

Ruiz, G. M., Freestone, A. L., Fofonoff, P. W., \& Simkanin, C. 2009. Habitat Distribution and Heterogeneity in Marine Invasion Dynamics: the Importance of Hard Substrate and Artificial Structure. M. Wahl (ed.), Marine Hard Bottom Communities, Ecological Studies, 206.

Russell, L. K., Hepburn, C. D., Hurd, C. L., \& Stuart, M. D. 2008. The expanding range of Undaria pinnatifida in southern New Zealand: Distribution, dispersal mechanisms and the invasion of wave-exposed environments. Biological Invasions, 10, 103-115.

Saarman, N. P., \& Pogson, G. H. 2015. Introgression between invasive and native blue mussels (genus Mytilus) in the central California hybrid zone. Molecular Ecology, 24(18), 47234738.

Sakai, A. K., Allendorf, F. W., Holt, J. S., Lodge, M., Molofsky, J. 2001. The Population Biology of Invasive Species. Annual Review of Ecology and Systematics, 32, 305-332.

Sala, O. E., Chapin, F. S., Armesto, J. J., Berlow, E. \& Bloomfield, J. 2000. Global Biodiversity Scenarios for the Year 2100. Science, 287, 1770-1774.

Salta, M., Wharton, J. A., Blache, Y., Stokes, K. R., \& Briand, J. F. 2013. Marine biofilms on artificial surfaces: Structure and dynamics. Environmental Microbiology, 15(11), 28792893.

Salvaterra, T., Green, D. S., Crowe, T. P., \& O'Gorman, E. J. 2013. Impacts of the invasive alga Sargassum muticum on ecosystem functioning and food web structure. Biological Invasions, 15, 2563-3576.

Sammarco, P. W., Atchison, A. D., \& Boland, G. S. 2004. Expansion of coral communities within the Northern Gulf of Mexico via offshore oil and gas platforms. Marine Ecology Progress Series, 280, 129-143.

Sammarco, P. W., Brazeau, D. A., \& Sinclair, J. 2012. Genetic connectivity in scleractinian corals across the northern Gulf of Mexico: Oil/gas platforms, and relationship to the Flower Garden Banks. PLoS ONE 7(4), e30144.

Santos, S., Cardoso, J. F. M. F., Carvalho, C., Luttikhuizen, P. C., \& van der Veer, H. W. 2011. Seasonal variability in somatic and reproductive investment of the bivalve Scrobicularia plana (da Costa, 1778) along a latitudinal groups. Estuarine, Coastal and Shelf Science, 92(1), 19-26.

Saura, S., Bodin, Ö., \& Fortin, M. J. 2014. Stepping stones are crucial for species' long-distance dispersal and range expansion through habitat networks. Journal of Applied Ecology, 
51(1), 171-182.

Sax, D. F. 2001. Latitudinal groupss and geographic ranges of exotic species: Implications for biogeography. Journal of Biogeography, 28(1), e0118571.

Sax, D. F. 2002. Native and naturalized plant diversity are positively correlated in scrub communities of California and Chile. Diversity and Distributions, 8, 193-210.

Schiel, D. R. 2011. Biogeographic patterns and long-term changes on New Zealand coastal reefs: Non-trophic cascades from diffuse and local impacts. Journal of Experimental Marine Biology and Ecology. 400(1-2), 33-51.

Schiel, D. R., Underwood, A. J., \& Chapman, M. G. 2019. Biogeographic Comparisons of Pattern and Process on Intertidal Rocky Reefs of New Zealand and South-Eastern Australia. Interactions in the Marine Benthos, Cambridge University Press, 391-413.

Schwindt, E., López Gappa, J., Raffo, M. P., Tatián, M., Bortolus, A., Orensanz, J. M., Alonso, G., Diez, M. E., Doti, B., Genzano, G., Lagger, C., Lovrich, G., Piriz, M. L., Mendez, M. M., Savoya, V., \& Sueiro, M. C. 2014. Marine fouling invasions in ports of Patagonia (Argentina) with implications for legislation and monitoring programs. Marine Environmental Research, 99, 60-68.

Scyphers, S. B., Gouhier, T. C., Grabowski, J. H., Beck, M. W., Mareska, J., \& Powers, S. P. 2015. Natural shorelines promote the stability of fish communities in an urbanized coastal system. PLoS ONE, 10(6), e0118580.

Seaward, K., Acosta, H., Inglis, G. J., Wood, B., Riding, T. A. C., Wilkens, S., \& Gould, B. 2015. The marine biosecurity porthole - A web-based information system on nonindigenous marine species in New Zealand. Management of Biological Invasions, 6(2), $177-184$.

Secor, C. L., Day, A. J., \& Hilbish, T. J. 2001. Factors influencing differential mortality within a marine mussel (Mytilus spp.) hybrid population in southwestern England: Reproductive effort and parasitism. Marine Biology, 138, 731-739.

Secord D. 2003. Biological control of marine invasive species: cautionary tales and land-based lessons. Biological Invasions, 5,117-131.

Seebens, H., Gastner, M. \& Blasius, B. 2013. The risk of marine bioinvasion caused by global shipping. Ecology Letters, 16(6), 782-790.

Seebens, H., Schwartz, N., Schupp, P. J., \& Blasius, B. 2016. Predicting the spread of marine species introduced by global shipping. Proceedings of the National Academy of Sciences of the United States of America, 113 (20), 5646-5651.

Seed, R., \& Suchanek, T. H. 1992. Population and community ecology of Mytilus. (E. Gosling (ed.); 25th ed.). The mussel Mytilus: ecology, physiology, genetics and culture. Developments in Aquaculture and Fisheries Science, 25, 589.

Seehausen, O. 2004. Hybridization and adaptive radiation. In Trends in Ecology and Evolution, 19(4), 198-207.

Sella I., Perkol-Finkel S. 2015. Blue is the new green-Ecological enhancement of concrete based coastal and marine infrastructure. Ecological Engineering, 84, 260-272.

Serrano, E., Coma, R., Ribes, M., Weitzmann, B., Garcia, M. \& Ballesteros, E. 2013. Rapid 
northward spread of a zooxanthellate coral enhanced by artificial structures and sea warming in the western Mediterranean. PLoS One, 8, e52739.

Shanks, A. L. 2009. Pelagic larval duration and dispersal distance revisited. The Biological Bulletin, 216, 373-385.

Shea, K., \& Chesson, P. 2002. Community ecology theory as a framework for biological invasions. In Trends in Ecology and Evolution, 17(4), 170-176.

Sheehan, E. V, Cartwright, A. Y., Witt, M. J., Attrill, M. J., Vural, M., \& Holmes, L. A. 2018. Development of epibenthic assemblages on artificial habitat associated with marine renewable infrastructure. ICES Journal of Marine Science, 1-12.

Shields, J. L., Heath, J. W., \& Heath, D. D. 2010. Marine landscape shapes hybrid zone in a broadcast spawning bivalve: Introgression and genetic structure in Canadian west coast Mytilus. Marine Ecology Progress Series, 399, 211-223

Shields, J.L., Barnes, P., \& Heath, D. D. 2008. Growth and survival differences among native, introduced and hybrid blue mussels (Mytilus spp.): Genotype, environment and interaction effects. Marine Biology, 154, 919-928.

Shinen, J. S., \& Morgan, S. G. 2009. Mechanisms of invasion resistance: competition among intertidal mussels promotes establishment of invasive species and displacement of native species. Marine Ecology Progress Series, 383, 187-197.

Simberloff, D. 2006. Invasional meltdown 6 years later: important phenomenon, unfortunate metaphor, or both? Ecology Letters, 9, $912-919$.

Simberloff, D. 2009. The role of propagule pressure in biological invasions. Annual Review of Ecology, Evolution, and Systematics, 40, 81 - 102.

Simberloff, D., \& Von Holle, B. 1999. Positive interactions of nonindigenous species: Invasional meltdown? Biological Invasions, 1(1), 21-32.

Simberloff, D., Martin, J. L., Genovesi, P., Maris, V., Wardle, D. A., Aronson, J., Courchamp, F., Galil, B., García-Berthou, E., Pascal, M., Pyšek, P., Sousa, R., Tabacchi, E., \& Vilà, M. 2013. Impacts of biological invasions: What's what and the way forward. In Trends in Ecology and Evolution, 28(1), 58-66.

Simpson, M., Coleman, R. A., Morris, R. L., \& Harasti, D. 2019. Seahorse Hotels: Use of artificial habitats to support populations of the endangered White's seahorse Hippocampus whitei. Marine Environmental Research, 157, e104861.

Simpson, T. J. S., Smale, D. A., McDonald, J. I., \& Wernberg, T. 2017. Large scale variability in the structure of sessile invertebrate assemblages in artificial habitats reveals the importance of local-scale processes. Journal of Experimental Marine Biology and Ecology, 494, 10-19.

Sinner, J., Forrest, B.M., Newton, M., Hopkins, G.A., Inglis, G., Woods, C. \& Morrisey, D. 2013. Managing the domestic spread of harmful marine organisms, Part B: statutory framework and analysis of options. Report prepared for New Zealand Ministry for Primary Industries. Cawthron Institute report No. 2442. Nelson, 73.

Skein, L., Alexander, M. E., \& Robinson, T. B. 2020. Co-occurring predators increase biotic resistance against an invasive prey. Marine Environmental Research,157, e104929. 
Skibinski, D. O. F., Ahmad, M., \& Beardmore, J. A. 1978. Genetic Evidence for Naturally Occurring Hybrids Between Mytilus edulis and Mytilus galloprovincialis. Society for the Study of Evolution, 32(2), 354-364.

Smart, D. C., Heenan, S., Lokman, P. M., \& Lamare, M. D. (2020). Seasonal reproduction of the blue mussel (Mytilus galloprovincialis) from two locations in southern New Zealand. New Zealand Journal of Marine and Freshwater Research, DOI: 10.1080/00288330.2020.1757472.

Smith, R. S., Johnston, E. L., \& Clark, G. F. 2014. The role of habitat complexity in community development is mediated by resource availability. PLoS ONE, 9(7), 1-13.

Snyder, W. E. and Evans, E. W. 2006. Ecological effects of invasive arthropod generalist predators. Annual Review of Ecology and Systematics, 37, 95-122.

Sorte, C. J. B., Williams, S. L. and Carlton, J. T. 2010. Marine range shifts and species introductions: comparative spread rates and community impacts. Global Ecology and Biogeography 19, $303-316$.

Sousa, W. P. 1979. Experimental Investigations of Disturbance and Ecological Succession in a Rocky Intertidal Algal Community. Ecological Monographs, 49(3), 227-254.

Sousa, W. P. 1985. Disturbance and Patch Dynamics on Rocky Intertidal Shores. The Ecology of Natural Disturbance and Patch Dynamics, 472.

Spagnolo, A., Cuicchi, C., Punzo, E., Santelli, A., Scarcella, G., \& Fabi, G. 2014. Patterns of colonization and succession of benthic assemblages in two artificial substrates. Journal of Sea Research, 88, 78-86.

Spalding, M. D., Fox, H. E., Allen, G. R., Davidson, N., Ferdaña, Z. A., Finlayson, M., Halpern, B. S., Jorge, M. A., Lombana, A., Lourie, S. A., Martin, K. D., McManus, E., Molnar, J., Recchia, C. A., \& Robertson, J. 2007. Marine Ecoregions of the World: A Bioregionalization of Coastal and Shelf Areas. BioScience, 57(7), 573-583.

Spinuzzi, K. R. Schneider, L. J. Walters, W. S. Yuan, E. A. 2013. Tracking the distribution of non-native marine invertebrates (Mytella charruana, Perna viridis and Megabalanus coccopoma) along the South-eastern USA, Marine Biodiversity Records, 6, e55.

Stachowicz, J. J., Best, R. J., Bracken, M. E. S., \& Graham, M. H. 2008. Complementarity in marine biodiversity manipulations: Reconciling divergent evidence from field and mesocosm experiments. Proceedings of the National Academy of Sciences of the United States of America, 105(48), 18842-18847.

Stachowicz, J. J., Fried, H., Osman, R. W., \& Whitlatch, R. B. 2002. Biodiversity, invasion resistance, and marine ecosystem function: Reconciling pattern and process. Ecology, 83(9), 2575-2590.

Steffani, C. N., \& Branch, G. M. 2003. Growth rate, condition, and shell shape of Mytilus galloprovincialis: Responses to wave exposure. Marine Ecology Progress Series, 246, 197-209.

Steffani, C. N., \& Branch, G. M. 2005. Mechanisms and consequences of competition between an alien mussel, Mytilus galloprovincialis, and an indigenous limpet, Scutellastra argenvillei. Journal of Experimental Marine Biology and Ecology, 317(2), 127-142.

Stohlgren, T. J., Barnett D. T. \& Kartesz J. T. 2003. The rich get richer: patterns of plant 
invasions in the United States. Frontiers in Ecology and the Environment, 1, 11-14.

Stohlgren, T. J., C. Jarnevich, G. W. Chong \& P. H. Evangelista, 2006. Scale and plant invasions: a theory of biotic acceptance. Preslia, 78, 405-426.

Strain, E. M. A., Morris, R. L., Coleman, R. A., Figueira, W. F., Steinberg, P. D., Johnston, E. L., \& Bishop, M. J. 2018a. Increasing microhabitat complexity on seawalls can reduce fish predation on native oysters. Ecological Engineering, 120, 637-644.

Strain, E. M. A., Olabarria, C., Mayer-Pinto, M., Cumbo, V., Morris, R. L., Bugnot, A. B., Dafforn, K. A., Heery, E., Firth, L. B., Brooks, P. R., \& Bishop, M. J. 2018b. Ecoengineering urban infrastructure for marine and coastal biodiversity: Which interventions have the greatest ecological benefit? Journal of Applied Ecology, 55(1), 426-441.

Suchanek, T. H. 1981. The role of disturbance in the evolution of life-history strategies in the intertidal mussels Mytilus edulis and Mytilus californianus. Oecologia, 50(2), 143-152.

Suchanek, T. H., Geller, J. B., Kreiser, B. R., \& Mitton, J. B. 1997. Zoogeographic distributions of the sibling species Mytilus galloprovincialis and M. trossulus (Bivalvia: Mytilidae) and their hybrids in the North Pacific. Biological Bulletin, 193(2), 187-194.

Tamburri, M. N., Luckenbach, M. W., Breitburg, D. L., \& Bonniwell, S. M. 2008. Settlement of Crassostrea ariakensis Larvae: Effects of Substrate, Biofilms, Sediment and Adult Chemical Cues. Journal of Shellfish Research, 27(3), 601-608.

Tamelander, J., Riddering, L., Haag, F., Matheickal, J. \& No, G.M.S. 2010. Guidelines for development of a national ballast water management strategy, GloBallast Partnerships Project Coordination Unit, International Maritime Organization.

Tan, E. L. Y., Mayer-Pinto, M., Johnston, E. L., \& Dafforn, K. A. 2015. Differences in intertidal microbial assemblages on urban structures and natural rocky reef. Frontiers in Microbiology, 6, 1-13.

Tay, Y. C., Noreen, A. M. E., Suharsono, Chou, L. M., \& Todd, P. A. 2015. Genetic connectivity of the broadcast spawning reef coral Platygyra sinensis on impacted reefs, and the description of new microsatellite markers. Coral Reefs, 34, 301-311.

Theuerkauf, K. W., Eggleston, D. B., \& Theuerkauf, S. J. 2018. An exotic species alters patterns of marine community development. Ecological Monographs, 88(1), 92-108.

Thompson, R. 1984. Production, reproductive effort, reproductive value and reproductive cost in a population of the blue mussel Mytilus edulis from a subarctic environment. Marine Ecology Progress Series, 16, 249-257.

Thompson, R. C., Crowe, T. P., \& Hawkins, S. J. 2002. Rocky intertidal communities: past environmental changes, present status and predictions for the next 25 years. Environmental Conservation, 29(2), 168-191.

Thomsen, M. S., Wernberg, T., South, P. M., \& Schiel, D. R. 2016. Non-native seaweeds drive changes in marine coastal communities around the world. Seaweed Phylogeography: Adaptation and Evolution of Seaweeds under Environmental Change, 147-185.

Thomsen, M., Wernberg, T., Olden, J., Byers, J. E., Bruno, J., Silliman, B., \& Schiel, D. 2014. Forty years of experiments on aquatic invasive species: are study biases limiting our understanding of impacts? NeoBiota, 22, 1-22. 
Thresher, R. E., C. L. Hewitt and M. L. Campbell. 1999. Synthesis: introduced and cryptogenic species in Port Phillip Bay. pp 283-295. In: C. L. Hewitt, M. L. Campbell, R. E. Thresher and R. B. Martin, (eds). Marine Biological Invasions of Port Phillip Bay, Victoria. CRIMP Technical Report No. 20. CSIRO Marine Research, Hobart.

Tilman, D., May, R. M., Lehman, C. L., \& Nowak, M. A. 1994. Habitat destruction and the extinction debt. Nature, 371, 65-66.

Tobin P. C., Kean J. M., Suckling D. M., Mccullough D. G., Herms D. A., Stringer L. D. 2014. Determinants of successful arthropod eradication programs. Biological Invasions, 16, 401-414.

Toro, J. E. 1998. Molecular identification of four species of mussels from Southern Chile by PCR-based nuclear markers: the potential use in studies involving planktonic surveys. Journal of Shellfish Research, 17(4-5), 1203-1205.

Toro, J. E., Thompson, R. J., \& Innes, D. J. 2002. Reproductive isolation and reproductive output in two sympatric mussel species (Mytilus edulis, M. trossulus) and their hybrids from Newfoundland. Marine Biology, 141(5), 897-909.

Trussell, G. C., Ewanchuk, P. J., Bertness, M. D., \& Silliman, B. R. 2004. Trophic cascades in rocky shore tide pools: Distinguishing lethal and nonlethal effects. Oecologia, 139(3), 427-432.

Tyrrell, M. C., \& Byers, J. E. 2007. Do artificial substrates favour nonindigenous fouling species over native species? Journal of Experimental Marine Biology and Ecology, 342(1), 54-60.

Underwood, A. J., \& Murphy, R. J. 2008. Unexpected patterns of facilitatory grazing revealed by quantitative imaging. Marine Ecology Progress Series, 358, 85-94.

Valentine, J. P., \& Johnson, C. R. 2003. Establishment of the introduced kelp Undaria pinnatifida in Tasmania depends on disturbance to native algal assemblages. Journal of Experimental Marine Biology and Ecology, 295(1), 63-90.

Van de Koppel, J., van der Heide, T., Altieri, A. H., Eriksson, B. K., Bouma, T. J., Olff, H., \& Silliman, B. R. 2015. Long-Distance Interactions Regulate the Structure and Resilience of Coastal Ecosystems. Annual Review of Marine Science, 7, 139-158.

Van Erkom Schurink, C., \& Griffiths, C. L. 1991. A comparison of reproductive cycles and reproductive output in four southern African mussel species. Marine Ecology Progress Series, 76(2), 123-134.

Vaselli, S., Bulleri, F., \& Benedetti-Cecchi, L. 2008. Hard coastal-defence structures as habitats for native and exotic rocky-bottom species. Marine Environmental Research, 66(4), 395403.

Vermeij, G. J. 1991. Anatomy of an invasion: The trans-Arctic interchange. Paleobiology, 17(3), 281-307.

Von Holle, B. 2011. Invasional Meltdown. In book: Encyclopedia of Biological Invasions, 360-364.

Walles, B., Troost, K., van den Ende, D., Nieuwhof, S., Smaal, A. C., \& Ysebaert, T. 2016. From artificial structures to self-sustaining oyster reefs. Journal of Sea Research, 108, 19. 
Waltham, N. J., \& Dafforn, K. A. 2018. Ecological engineering in the coastal seascape. In Ecological Engineering, 120, 554-559.

Walther, G. R., Post, E., Convey, P., Menzel, A., Parmesan, C., Beebee, T. J., Fromentin, J. M., Hoegh-Guldberg, O. \& Bairlein, F. 2002. Ecological responses to recent climate change. Nature, 416(6879), 389-395.

Walther, G. R., Roques, A., Hulme, P. E., Sykes, M. T., Pyšek, P., Kuhn, I., Zobel, M., Bacher, S., Botta-Dukat, Z., Bugmann, H., Czucz, B., Dauber, J., Hickler, T., Jarošik, V., Kenis, M., Klotz, S., Minchin, D., Moora, M., Netwig, W., Ott, J., Panov, V. E., Reineking, B., Robinet, C., Semenchenko, V., Solarz, W., Thuiller, W., Vila, M., Vohland K., \& Settele, J. 2009. Alien species in a warmer world: risks and opportunities. Trends in Ecology \& Evolution, 24(12), 686-693.

Wells, F. E. 2018. A low number of invasive marine species in the tropics: A case study from Pilbara (Western Australia). Management of Biological Invasions, 9(3), 227-237.

Westfall, K. M. 2011. Molecular ecology and systematics of blue mussels (genus Mytilus) (Mytilidae; Bivalvia; Mollusca) in the Southern hemisphere (Doctoral thesis, Victoria University of Wellington, Wellington, New Zealand). Retrieved from http://hdl.handle.net/10063/1815.

Westfall, K. M., \& Gardner, J. P. A. 2010. Genetic diversity of Southern hemisphere blue mussels (Bivalvia: Mytilidae) and the identification of non-indigenous taxa. Biological Journal of the Linnean Society, 101(4), 898-909.

Westfall, K. M., \& Gardner, J. P. A. 2013. Interlineage Mytilus galloprovincialis Lmk. 1819 hybridization yields inconsistent genetic outcomes in the Southern hemisphere. Biological Invasions, 15(7), 1493-1506.

Westfall, K. M., Wimberger, P. H., \& Gardner, J. P. A. 2010. An RFLP assay to determine if Mytilus galloprovincialis Lmk. (Mytilidae; Bivalvia) is of Northern or Southern hemisphere origin. Molecular Ecology Resources, 10(3), 573-575.

Wilkins, N. P., Fujino, K., \& Gosling, E. M. 1983. The Mediterranean mussel Mytilus galloprovincialis Lmk. in Japan. Biological Journal of the Linnean Society, 20(4), 365374.

Willan R. C., Russell B. C., Murfet N. B., Moore K. L., McEnnulty F. R., Horner S. K., Hewitt C. L., Dally G. M., Campbell M. L., Bourke S. T. 2000. Outbreak of Mytilopsis sallei (Recluz, 1849) (Bivalvia: Dreissenidae) in Australia. Molluscan Research, 20(2), 25-30.

Williams G. A., Davies M. S. \& Nagarkar S. 2000. Primary succession on a seasonal tropical rocky shore: the relative roles of spatial heterogeneity and herbivory. Marine Ecology Progress Series, 203, 81-94.

Williams S. L, Bracken M. E. \& Jones E. 2013. Additive effects of physical stress and herbivores on intertidal seaweed biodiversity. Ecology, 94(5): 1089-1101.

Williamson, M. H. 1996. Biological invasions. Population and community biology series, Vol. 15. Chapman and Hall, London. 244 p.

Wonham, M. J. 1999. Factors limiting the spread of the introduced Mediterranean mussel Mytilus galloprovincialis on Washington's outer coast. In Peterson, J. (Ed.), Marine Bioinvasions. Proceedings of the First National Conference. Massachusetts Institute of Technology, 1-423. 
Wonham, M. J. 2004. Mini-review: Distribution of the Mediterranean mussel Mytilus galloprovincialis (Bivalvia: Mytilidae) and hybrids in the northeast Pacific. Journal of Shellfish Research, 23(2), 535-543.

Wood, A. C. L., \& Probert, P. K. 2013. Bryozoan-dominated benthos of Otago shelf, New Zealand: Its associated fauna, environmental setting and anthropogenic threats. Journal of the Royal Society of New Zealand, 43(4), 231-249.

Woods, C., Seaward, K., Inglis, G., 2015. Marine High-Risk Site Surveillance Annual report for all ports and marinas 2014-15, MPI Technical Paper (Project 12099).

Woods, C., Seaward, K., Pryor Rodgers, L., \& Inglis, G. J. 2018. Marine High-Risk Site Surveillance Programme. MPI Technical Paper 2018/45, 209.

Wotton, D. M., \& Hewitt, C. L. 2004. Marine biosecurity post-border management: Developing incursion response systems for New Zealand. Journal of Marine and Freshwater Research, 38, 553-559

Wyatt, A. S. J., Hewitt, C. L., Walker, D. I., \& Ward, T. J. 2005. Marine introductions in the Shark Bay World Heritage Property, Western Australia: A preliminary assessment. Diversity and Distributions, 11(1), 33-44.

Zaiko, A., Martinez, J. L., Ardura, A., Clusa, L., Borrell, Y. J., Samuiloviene, A., Roca, A., Garcia-Vazquez, E., 2015. Detecting nuisance species using NGST: Methodology shortcomings and possible application in ballast water monitoring. Marine Environmental Research, 112, 64-72.

Zaiko, A., Pochon, X., Garcia-Vazquez, E., Olenin, S., Wood, S.A., 2018. Advantages and Limitations of Environmental DNA/RNA Tools for Marine Biosecurity: Management and Surveillance of Non-indigenous Species. Frontiers in Marine Science, 5.

Zaiko, A., Schimanski, K., Pochon, X., Hopkins, G.A., Goldstien, S., Floerl, O. \& Wood, S.A. 2016. Metabarcoding improves detection of eukaryotes from early biofouling communities: implications for pest monitoring and pathway management. Biofouling, 32, 671-684.

Zardi, G. I., McQuaid, C. D., \& Nicastro, K. R. 2007. Balancing survival and reproduction: Seasonality of wave action, attachment strength and reproductive output in indigenous Perna perna and invasive Mytilus galloprovincialis mussels. Marine Ecology Progress Series, 334, 155-163.

Zardi, G. I., Nicastro, K. R., McQuaid, C. D., \& Erlandsson, J. 2008. Sand and wave induced mortality in invasive (Mytilus galloprovincialis) and indigenous (Perna perna) mussels. Marine Biology, 153(5), 853-858.

Zazzaro, D. 2016. The biology of the triangle barnacle, Balanus trigonus, fouling green-lipped mussel farms in the Hauraki Gulf (Doctoral thesis, The University of Auckland, New Zealand). Retrieved from http://hdl.handle.net/2292/31904.

Zbawicka, M., Gardner, J. P. A., \& Wenne, R. 2019. Cryptic diversity in smooth-shelled mussels on Southern Ocean islands: Connectivity, hybridisation and a marine invasion. Frontiers in Zoology, 16(1), 1-12.

Zwerschke, N., Emmerson, M. C., Roberts, D., \& O'Connor, N. E. 2016. Benthic assemblages associated with native and non-native oysters are similar. Marine Pollution Bulletin, 111(1-2), 305-310. 


\section{Appendix}

Table A1. SIMPER analysis: average similarity in the status of species as a function of the surveyed port.

\begin{tabular}{|c|c|c|c|c|c|c|c|c|c|c|}
\hline \multicolumn{3}{|c|}{$\begin{array}{c}\text { Abbot Point } \\
\text { Average similarity: } 65.04\end{array}$} & \multicolumn{2}{|c|}{$\begin{array}{c}\text { Adelaide } \\
\text { Average similarity: } \mathbf{7 4 . 0 2}\end{array}$} & \multicolumn{2}{|c|}{$\begin{array}{c}\text { Albany } \\
\text { Average similarity: } 64.69\end{array}$} & \multicolumn{2}{|c|}{$\begin{array}{l}\text { Bunbury } \\
\text { Average similarity: } 56.51\end{array}$} & \multicolumn{2}{|c|}{$\begin{array}{c}\text { Burnie } \\
\text { Average similarity: } 68.56\end{array}$} \\
\hline Species & Abund & $\mathrm{C} \%$ & Abund & $\mathrm{C} \%$ & Abund & $\mathrm{C} \%$ & Abund & $\mathrm{C} \%$ & Abund & $\mathrm{C} \%$ \\
\hline Non-native & 0.86 & 13.76 & 1.78 & 36.84 & 1.18 & 47.62 & 0.84 & 45.3 & 0.82 & 13.7 \\
\hline Cryptogenic & 0.21 & 0.58 & 1.02 & 16.46 & 0.37 & 4.41 & 0.12 & 0.66 & 0.33 & 1.59 \\
\hline \multicolumn{3}{|c|}{$\begin{array}{c}\text { Devonport } \\
\text { Average similarity: } 68.00\end{array}$} & \multicolumn{2}{|c|}{$\begin{array}{c}\text { Geelong } \\
\text { Average similarity: } 85.75\end{array}$} & \multicolumn{2}{|c|}{$\begin{array}{c}\text { Esperance } \\
\text { Average similarity: } 64.91\end{array}$} & \multicolumn{2}{|c|}{$\begin{array}{c}\text { Geraldton } \\
\text { Average similarity: } 82.48\end{array}$} & \multicolumn{2}{|c|}{$\begin{array}{l}\text { Gladstone } \\
\text { Average similarity: } 77.62\end{array}$} \\
\hline Species & Abund & $\mathrm{C} \%$ & Abund & $\mathrm{C} \%$ & Abund & $\mathrm{C} \%$ & Abund & $\mathrm{C} \%$ & Abund & $\mathrm{C} \%$ \\
\hline Native & 2.12 & 81.69 & 2.17 & 43.31 & 2.17 & 94.46 & 1.28 & 99.87 & 2.17 & 83.11 \\
\hline Non-native & 0.73 & 17.28 & 2.23 & 40.86 & 0.41 & 5.16 & 0.11 & 0.13 & 0.68 & 16.89 \\
\hline Cryptogenic & 18 & 1.03 & 0.92 & 15.83 & 0.12 & 0.38 & 0 & 0 & 0 & 0 \\
\hline \multicolumn{3}{|c|}{$\begin{array}{c}\text { Eden } \\
\text { Average similarity: } 71.56\end{array}$} & \multicolumn{2}{|c|}{$\begin{array}{l}\text { Fremantle } \\
\text { Average similarity: } 69.84\end{array}$} & \multicolumn{2}{|c|}{$\begin{array}{c}\text { Hay Point } \\
\text { Average similarity: } 71.34\end{array}$} & \multicolumn{2}{|c|}{$\begin{array}{l}\text { Launceston } \\
\text { Average similarity: } 84.50\end{array}$} & \multicolumn{2}{|c|}{$\begin{array}{l}\text { Mourilyan } \\
\text { Average similarity: } 67.12\end{array}$} \\
\hline Native & 2.44 & 52.79 & 2.26 & 59.34 & 3.38 & 89.98 & 4.3 & 61.97 & 2.87 & 79.12 \\
\hline Non-native & 1.09 & 20.55 & 0.79 & 13.74 & 0.3 & 1.95 & 1.41 & 18.13 & 0.57 & 6.94 \\
\hline Cryptogenic & 1.12 & 26.66 & 0.96 & 26.91 & 0.64 & 8.07 & 1.47 & 19.9 & 0.7 & 13.93 \\
\hline \multicolumn{3}{|c|}{$\begin{array}{l}\text { Hastings } \\
\text { Average similarity: } \mathbf{8 5 . 0 3}\end{array}$} & \multicolumn{2}{|c|}{$\begin{array}{c}\text { Hobart } \\
\text { Average similarity: } \mathbf{8 7 . 2 8}\end{array}$} & \multicolumn{2}{|c|}{$\begin{array}{l}\text { Lady Barron } \\
\text { Average similarity: } 59.92\end{array}$} & \multicolumn{2}{|c|}{$\begin{array}{l}\text { Lucinda } \\
\text { Average similarity: } 52.43\end{array}$} & \multicolumn{2}{|c|}{$\begin{array}{c}\text { Mackay } \\
\text { Average similarity: } 72.9\end{array}$} \\
\hline
\end{tabular}




\begin{tabular}{|c|c|c|c|c|c|c|c|c|c|c|}
\hline Species & Abund & $\mathrm{C} \%$ & Abund & $\mathrm{C} \%$ & Abund & $\mathrm{C} \%$ & Abund & $\mathrm{C} \%$ & Abund & $\mathrm{C} \%$ \\
\hline Native & 2.64 & 76.82 & 3.05 & 41.82 & 1.39 & 78.67 & 2.4 & 65.92 & 3.44 & 82 \\
\hline Non-native & 1.12 & 23.18 & 3.11 & 40.39 & 0.85 & 20.47 & 0.96 & 29.58 & 0.97 & 15.83 \\
\hline Cryptogenic & 0 & 0 & 1.54 & 17.8 & 0.2 & 0.86 & 0.43 & 4.49 & 0.35 & 2.17 \\
\hline \multicolumn{3}{|c|}{$\begin{array}{c}\text { Melbourne } \\
\text { Average similarity: } 67.94\end{array}$} & \multicolumn{2}{|c|}{$\begin{array}{c}\text { Newcastle } \\
\text { Average similarity: } 68.68\end{array}$} & \multicolumn{2}{|c|}{$\begin{array}{c}\text { Port Hedland } \\
\text { Average similarity: } \mathbf{7 3 . 2 3}\end{array}$} & \multicolumn{2}{|c|}{$\begin{array}{c}\text { Port Lincoln } \\
\text { Average similarity: } 66.55\end{array}$} & \multicolumn{2}{|c|}{$\begin{array}{c}\text { Portland } \\
\text { Average similarity: } \mathbf{7 9 . 1 1}\end{array}$} \\
\hline Species & Abund & $\mathrm{C} \%$ & Abund & $\mathrm{C} \%$ & Abund & $\mathrm{C} \%$ & Abund & $\mathrm{C} \%$ & Abund & $\mathrm{C} \%$ \\
\hline Native & 1.38 & 41.23 & 2.35 & 63.92 & 2.8 & 92.67 & 1.94 & 93.43 & 2.49 & 70.35 \\
\hline Non-native & 1.27 & 37.88 & 1.06 & 18.82 & 0.43 & 4.85 & 0.41 & 6.42 & 1.23 & 28.96 \\
\hline Cryptogenic & 0.74 & 20.89 & 0.81 & 17.26 & 0.3 & 2.48 & 0.07 & 0.14 & 0.23 & 0.69 \\
\hline \multicolumn{3}{|c|}{$\begin{array}{c}\text { Townsville } \\
\text { Average similarity: } \mathbf{5 7 . 7 2}\end{array}$} & \multicolumn{2}{|c|}{$\begin{array}{c}\text { Weipa } \\
\text { Average similarity: } 61.01\end{array}$} & & & & & & \\
\hline Species & Abund & $\mathrm{C} \%$ & Abund & $\mathrm{C} \%$ & & & & & & \\
\hline Native & 2.64 & 82.38 & 2.02 & 84.65 & & & & & & \\
\hline Non-native & 0.79 & 11.84 & 0.36 & 3.98 & & & & & & \\
\hline Cryptogenic & 0.51 & 5.78 & 0.5 & 11.36 & & & & & & \\
\hline
\end{tabular}

$\mathrm{C} \%=$ percent contribution 
Table A2. Species identified in the 27 port surveys around Australia and species status - native, non-native and cryptogenic species.

\begin{tabular}{|c|c|c|}
\hline Species & Phyla & Species status \\
\hline Acanthochitona bednalli & Mollusca & Native \\
\hline Acanthochitona granostriata & Mollusca & Native \\
\hline Acanthochitona kimberi & Mollusca & Native \\
\hline Acanthochitona pilsbryi & Mollusca & Native \\
\hline Acanthochitona retrojecta & Mollusca & Native \\
\hline Acanthochitona sueurii & Mollusca & Native \\
\hline Acanthodesia cf. savartii & Bryozoa & Cryptogenic \\
\hline Acanthophora cf. muscoides & Rhodophyta & Native \\
\hline Acanthophora dendroides & Rhodophyta & Native \\
\hline Acanthophora muscoides & Rhodophyta & Native \\
\hline Acanthophora spicifera & Rhodophyta & Native \\
\hline Acanthopleura gaimardi & Mollusca & Native \\
\hline Acasta cf. dofleini & Arthropoda & Native \\
\hline Acasta dofleini & Arthropoda & Native \\
\hline Acasta pectinipes & Arthropoda & Native \\
\hline Achaeus lacertosus & Arthropoda & Native \\
\hline Achelia assimilis & Arthropoda & Native \\
\hline Achelia shepherdi & Arthropoda & Native \\
\hline Aclophoropsis festiva & Mollusca & Native \\
\hline Acrocarpia paniculata & Ochrophyta & Native \\
\hline Acrosorium uncinatum & Rhodophyta & Native \\
\hline Acrosorium venulosum & Rhodophyta & Native \\
\hline Actaea cf. ruppelli & Arthropoda & Native \\
\hline Actaea peronii & Arthropoda & Native \\
\hline Actaeodes hirsutissimus & Arthropoda & Native \\
\hline Actinia cf. tenebrosa & Cnidaria & Native \\
\hline Actinia tenebrosa & Cnidaria & Native \\
\hline Actinocucumis cf. typica & Echinodermata & Native \\
\hline Aetea anguina & Bryozoa & Cryptogenic \\
\hline Aglaophenia cf. parvula & Hydroid & Native \\
\hline Aglaophenia cf. plumosa & Hydroid & Native \\
\hline Aglaophenia delicatula & Hydroid & Native \\
\hline Aglaophenia parvula & Hydroid & Native \\
\hline Aglaophenia plumosa & Hydroid & Native \\
\hline Agnewia tritoniformis & Mollusca & Native \\
\hline Akera soluta & Mollusca & Native \\
\hline Alabes dorsalis & Chordata & Native \\
\hline Aliaporcellana cf. pygmaea & Arthropoda & Native \\
\hline Aliaporcellana suluensis & Arthropoda & Native \\
\hline
\end{tabular}




\begin{tabular}{|c|c|c|}
\hline Alitta succinea & Annelida & Non-native \\
\hline Allorchestes compressus & Arthropoda & Native \\
\hline Alope orientalis & Arthropoda & Native \\
\hline Alpheus australiensis & Arthropoda & Native \\
\hline Alpheus cf. australiensis & Arthropoda & Native \\
\hline Alpheus cf. eulimene & Arthropoda & Native \\
\hline Alpheus cf. facetus & Arthropoda & Native \\
\hline Alpheus cf. paracrinitus & Arthropoda & Native \\
\hline Alpheus cf. parasocialis & Arthropoda & Native \\
\hline Alpheus cf. spongiarum & Arthropoda & Native \\
\hline Alpheus cf. villosus & Arthropoda & Native \\
\hline Alpheus chiragricus & Arthropoda & Native \\
\hline Alpheus cristatus & Arthropoda & Native \\
\hline Alpheus facetus & Arthropoda & Native \\
\hline Alpheus gracilis & Arthropoda & Native \\
\hline Alpheus hippothoe & Arthropoda & Native \\
\hline Alpheus novaezelandiae & Arthropoda & Native \\
\hline Alpheus richardsoni & Arthropoda & Native \\
\hline Alpheus socialis & Arthropoda & Native \\
\hline Alpheus villosus & Arthropoda & Native \\
\hline Amarinus laevis & Arthropoda & Native \\
\hline Amaryllis macrophthalmus & Arthropoda & Native \\
\hline Amastigia cf. texta & Bryozoa & Native \\
\hline Amathia biseriata & Bryozoa & Native \\
\hline Amathia brongniartii & Bryozoa & Native \\
\hline Amathia cf. connexa & Bryozoa & Native \\
\hline Amathia cf. distans & Bryozoa & Non-native \\
\hline Amathia cf. semiconvoluta & Bryozoa & Native \\
\hline Amathia connexa & Bryozoa & Native \\
\hline Amathia distans & Bryozoa & Non-native \\
\hline Amathia tortuosa & Bryozoa & Cryptogenic \\
\hline Amathia vidovici & Bryozoa & Native \\
\hline Amblychilepas oblonga & Mollusca & Native \\
\hline Ammothea ovatoides & Arthropoda & Native \\
\hline Ammothella stocki & Arthropoda & Native \\
\hline Amphipholis squamata & Echinodermata & Native \\
\hline Amphisbetia minima & Cnidaria & Native \\
\hline Amphitrite pachyderma & Annelida & Native \\
\hline Amphitritides ithya & Annelida & Native \\
\hline Amphiura (Amphiura) constricta & Echinodermata & Native \\
\hline Amphiura (Amphiura) poecila & Echinodermata & Native \\
\hline Amphiura (Amphiura) tenuis & Echinodermata & Native \\
\hline Amphiura (Amphiura) trisacantha & Echinodermata & Native \\
\hline Amphiura (Ophiopeltis) parviscutata & Echinodermata & Native \\
\hline
\end{tabular}




\begin{tabular}{|c|c|c|}
\hline Anachis atkinsoni & Mollusca & Native \\
\hline Anachis troglodytes & Mollusca & Native \\
\hline Anadara granosa & Mollusca & Native \\
\hline Anapella amygdala & Mollusca & Native \\
\hline Ancorina robusta & Porifera & Native \\
\hline Ancorina suina & Porifera & Native \\
\hline Anisodonta subalata & Mollusca & Native \\
\hline Anodontia omissa & Mollusca & Native \\
\hline Anomia trigonopsis & Mollusca & Native \\
\hline Anoplodactylus digitatus & Arthropoda & Native \\
\hline Anoplodactylus evansi & Arthropoda & Native \\
\hline Anoplodactylus glandulifer & Arthropoda & Native \\
\hline Anotrichium elongatum & Rhodophyta & Native \\
\hline Anotrichium subtile & Rhodophyta & Native \\
\hline Antedon incommoda & Echinodermata & Native \\
\hline Antennella secundaria & Cnidaria & Non-native \\
\hline Anthohebella parasitica & Cnidaria & Native \\
\hline Anthothoe albocincta & Cnidaria & Native \\
\hline Anthothoe cf. albocincta & Cnidaria & Native \\
\hline Antithamnion pinnafolium & Rhodophyta & Native \\
\hline Antithamnionella glandifera & Rhodophyta & Native \\
\hline Antithamnionella ternifolia & Rhodophyta & Cryptogenic \\
\hline Aora maculata & Arthropoda & Native \\
\hline Aplidium cf. lenticulum & Chordata & Native \\
\hline Aplysilla cf. rosea & Porifera & Non-native \\
\hline Apocorophium acutum & Arthropoda & Non-native \\
\hline Arachnopusia unicornis & Bryozoa & Non-native \\
\hline Arca avellana & Mollusca & Native \\
\hline Arca navicularis & Mollusca & Native \\
\hline Armandia intermedia & Annelida & Native \\
\hline Artacamella dibranchiata & Annelida & Native \\
\hline Arthrocardia wardii & Rhodophyta & Native \\
\hline Ascidia cf. latesiphonica & Chordata & Native \\
\hline Ascidia cf. liberata & Chordata & Native \\
\hline Ascidia cf. munda & Chordata & Native \\
\hline Ascidia cf. sydneiensis & Chordata & Non-native \\
\hline Ascidia cf. thompsoni & Chordata & Native \\
\hline Ascidia challengeri & Chordata & Native \\
\hline Ascidia decepta & Chordata & Native \\
\hline Ascidia empheres & Chordata & Native \\
\hline Ascidia latesiphonica & Chordata & Native \\
\hline Ascidia munda & Chordata & Native \\
\hline Ascidia sydneiensis & Chordata & Non-native \\
\hline Ascidiella aspersa & Chordata & Non-native \\
\hline
\end{tabular}




\begin{tabular}{|c|c|c|}
\hline Ascorhynchus tenuirostris & Arthropoda & Native \\
\hline Asparagopsis taxiformis & Rhodophyta & Native \\
\hline Asterias amurensis & Chordata & Non-native \\
\hline Asterocarpa humilis & Chordata & Native \\
\hline Astralium pileolum & Mollusca & Native \\
\hline Astralium tentoriformis & Mollusca & Native \\
\hline Astrangia woodsi & Cnidaria & Native \\
\hline Athanas dimorphus & Arthropoda & Native \\
\hline Athanas parvus & Arthropoda & Native \\
\hline Atys cylindrica & Mollusca & Native \\
\hline Audouinella caespitosum & Rhodophyta & Native \\
\hline Augeneria verdis & Annelida & Native \\
\hline Augenerilepidonotus dictyolepis & Annelida & Native \\
\hline Austraeolis cacaotica & Mollusca & Native \\
\hline Austrobalanus imperator & Arthropoda & Native \\
\hline Austrodecus tubiferum & Arthropoda & Native \\
\hline Austromegabalanus nigrescens & Arthropoda & Native \\
\hline Austrophyllis alcicornis & Rhodophyta & Native \\
\hline Balanus amphitrite & Arthropoda & Cryptogenic \\
\hline Balanus cf. amphitrite & Arthropoda & Cryptogenic \\
\hline Balanus cf. reticulatus & Arthropoda & Native \\
\hline Balanus cf. variegatus & Arthropoda & Native \\
\hline Balanus cf. vestitus & Arthropoda & Native \\
\hline Balanus improvisus & Arthropoda & Non-native \\
\hline Balanus reticulatus & Arthropoda & Non-native \\
\hline Balanus trigonus & Arthropoda & Cryptogenic \\
\hline Balanus variegatus & Arthropoda & Native \\
\hline Barbatia bistrigata & Mollusca & Native \\
\hline Barbatia cf. helblingi & Mollusca & Native \\
\hline Barbatia cf. pistachia & Mollusca & Native \\
\hline Barbatia foliata & Mollusca & Native \\
\hline Barbatia helblingi & Mollusca & Native \\
\hline Barbatia pistachia & Mollusca & Native \\
\hline Barbatia riculata & Mollusca & Native \\
\hline Barbatia wendti & Mollusca & Native \\
\hline Beania magellanica & Bryozoa & Native \\
\hline Beania mirabilis & Bryozoa & Native \\
\hline Bedeva hanleyi & Mollusca & Native \\
\hline Bedeva paivae & Mollusca & Native \\
\hline Bembicium auratum & Mollusca & Native \\
\hline Bembicium nanum & Mollusca & Native \\
\hline Bhawania amboinensis & Annelida & Native \\
\hline Bhawania cf. amboinensis & Annelida & Native \\
\hline Bicellariella ciliata & Bryozoa & Native \\
\hline
\end{tabular}




\begin{tabular}{|c|c|c|}
\hline Bicellariella gracilis & Bryozoa & Native \\
\hline Bicrisia edwardsiana & Bryozoa & Native \\
\hline Biffarius arenosus & Arthropoda & Native \\
\hline Biflustra perfragilis & Bryozoa & Native \\
\hline Bimeria australis & Cnidaria & Native \\
\hline Bimeria currumbinensis & Cnidaria & Native \\
\hline Bispira cf. porifera & Annelida & Native \\
\hline Bittium granarium & Mollusca & Native \\
\hline Boccardia cf. chilensis & Annelida & Non-native \\
\hline Boccardia chilensis & Annelida & Cryptogenic \\
\hline Boccardia proboscidea & Annelida & Non-native \\
\hline Boccardiella cf. bihamata & Annelida & Native \\
\hline Botrylloides leachi & Chordata & Non-native \\
\hline Botrylloides magnicoecum & Chordata & Cryptogenic \\
\hline Botrylloides perspicuus & Chordata & Native \\
\hline Botryllus cf. tuberatus & Chordata & Native \\
\hline Botryllus schlosseri & Chordata & Non-native \\
\hline Botryllus tuberatus & Chordata & Native \\
\hline Botryocladia obovata & Rhodophyta & Native \\
\hline Botryocladia sonderi & Rhodophyta & Native \\
\hline Bougainvillia cf. balei & Cnidaria & Native \\
\hline Bougainvillia muscus & Cnidaria & Non-native \\
\hline Bowerbankia gracilis & Bryozoa & Non-native \\
\hline Bowerbankia imbricata & Bryozoa & Non-native \\
\hline Brachidontes cf. rostratus & Mollusca & Native \\
\hline Brachidontes erosa & Mollusca & Native \\
\hline Brachidontes maritimus & Mollusca & Native \\
\hline Brachidontes rostratus & Mollusca & Native \\
\hline Branchiomma nigromaculata & Annelida & Native \\
\hline Branchiosyllis australis & Annelida & Native \\
\hline Branchiosyllis exilis & Annelida & Native \\
\hline Bryopsis plumosa & Chlorophyta & Non-native \\
\hline Bugula cf. avicularia & Bryozoa & Non-native \\
\hline Bugula cf. flabellata & Bryozoa & Non-native \\
\hline Bugula cf. robusta & Bryozoa & Native \\
\hline Bugula cf. serrata & Bryozoa & Native \\
\hline Bugula cf. stolonifera & Bryozoa & Non-native \\
\hline Bugula dentata & Bryozoa & Native \\
\hline Bugula flabellata & Bryozoa & Non-native \\
\hline Bugula neritina & Bryozoa & Non-native \\
\hline Bugula phillipinata & Bryozoa & Native \\
\hline Bugula robusta & Bryozoa & Native \\
\hline Bugula serrata & Bryozoa & Native \\
\hline Bugula stolonifera & Bryozoa & Non-native \\
\hline
\end{tabular}




\begin{tabular}{|c|c|c|}
\hline Bugula vectifera & Bryozoa & Native \\
\hline Bulla punctulata & Mollusca & Native \\
\hline Caberea boryi & Bryozoa & Native \\
\hline Caberea dichotoma & Bryozoa & Native \\
\hline Caberea dolabrata & Bryozoa & Native \\
\hline Caberea helicina & Bryozoa & Native \\
\hline Caberea lata & Bryozoa & Native \\
\hline Caberea rostrata & Bryozoa & Native \\
\hline Cabestana tabulata & Mollusca & Native \\
\hline Callipallene emaciata micracantha & Arthropoda & Native \\
\hline CallistoMollusca antiquus & Mollusca & Native \\
\hline Callithamnion violaceum & Rhodophyta & Native \\
\hline Callogobius тисоsиs & Chordata & Native \\
\hline Callophyllis lambertii & Rhodophyta & Native \\
\hline Callucina lacteola & Mollusca & Native \\
\hline Calthalotia mundula & Mollusca & Native \\
\hline Calyptotheca cf. wasinensis & Bryozoa & Native \\
\hline Calyptotheca triangula & Bryozoa & Native \\
\hline Canda cf arachnoides & Bryozoa & Native \\
\hline Caprella acanthogaster & Arthropoda & Non-native \\
\hline Caprella cf. danilevskii & Arthropoda & Non-native \\
\hline Caprella cf. equilibra & Arthropoda & Non-native \\
\hline Caprella equilibra & Arthropoda & Cryptogenic \\
\hline Caprella penantis & Arthropoda & Cryptogenic \\
\hline Caprella scaura & Arthropoda & Non-native \\
\hline Cardita cf. crassicosta & Mollusca & Native \\
\hline Cardita excavata & Mollusca & Native \\
\hline Cardita muricata & Mollusca & Native \\
\hline Cardita preissii & Mollusca & Native \\
\hline Cardita variegata & Mollusca & Native \\
\hline Carijoa cf. multiflora & Cnidaria & Native \\
\hline Catenicella buskii & Bryozoa & Native \\
\hline Catenicella cf. uberrima & Bryozoa & Native \\
\hline Catenicella elegans & Bryozoa & Native \\
\hline Caulerpa brownii & Chlorophyta & Native \\
\hline Caulerpa cactoides & Chlorophyta & Native \\
\hline Caulerpa cf. brachypus & Chlorophyta & Native \\
\hline Caulerpa longifolia & Chlorophyta & Native \\
\hline Caulerpa nummularia & Chlorophyta & Native \\
\hline Caulerpa obscura & Chlorophyta & Native \\
\hline Caulerpa peltata & Chlorophyta & Native \\
\hline Caulerpa racemosa & Chlorophyta & Native \\
\hline Caulerpa racemosa var. laetivirens & Chlorophyta & Native \\
\hline Caulerpa racemosa var. turbinata & Chlorophyta & Native \\
\hline
\end{tabular}




\begin{tabular}{|c|c|c|}
\hline Caulerpa sedoides f. geminata & Chlorophyta & Native \\
\hline Caulerpa taxifolia & Chlorophyta & Native \\
\hline Caulibugula dendrograpta & Bryozoa & Non-native \\
\hline Caulibugula haddoni & Bryozoa & Native \\
\hline Cellana conciliata & Mollusca & Native \\
\hline Cellaria pilosa & Bryozoa & Native \\
\hline Cellaria punctata & Bryozoa & Native \\
\hline Cellaria tenuirostris & Bryozoa & Native \\
\hline Celleporaria bispinata & Bryozoa & Native \\
\hline Celleporaria cf. columnaris & Bryozoa & Native \\
\hline Celleporaria cf. fusca & Bryozoa & Native \\
\hline Celleporaria cf. mamillata & Bryozoa & Native \\
\hline Celleporaria cf. nodulosa & Bryozoa & Native \\
\hline Celleporaria cf. oculata & Bryozoa & Native \\
\hline Celleporaria columnaris & Bryozoa & Native \\
\hline Celleporaria foliata & Bryozoa & Native \\
\hline Celleporaria fusca & Bryozoa & Native \\
\hline Celleporaria nodulosa & Bryozoa & Native \\
\hline Cenolia trichoptera & Echinodermata & Native \\
\hline Centroceras clavulatum & Rhodophyta & Non-native \\
\hline Ceramium cliftonianum & Rhodophyta & Native \\
\hline Ceramium filiculum & Rhodophyta & Native \\
\hline Ceramium flaccidum & Rhodophyta & Cryptogenic \\
\hline Ceramium isogonum & Rhodophyta & Native \\
\hline Ceramium macilentum & Rhodophyta & Native \\
\hline Ceramium pusillum & Rhodophyta & Native \\
\hline Ceramium sympodiale & Rhodophyta & Native \\
\hline Ceramium tasmanicum & Rhodophyta & Native \\
\hline Ceramium virgatum & Rhodophyta & Cryptogenic \\
\hline Ceratonereis amphidonta & Annelida & Native \\
\hline Ceratonereis cf. costae & Annelida & Native \\
\hline Ceratonereis cf. mirabilis & Annelida & Native \\
\hline Ceratonereis mirabilis & Annelida & Native \\
\hline Ceratonereis perkinsi & Annelida & Native \\
\hline Cerceis tridentata & Arthropoda & Native \\
\hline Chaetozone setosa & Annelida & Native \\
\hline Chama asperella & Mollusca & Native \\
\hline Chama cf. fibula & Mollusca & Native \\
\hline Chama cf. ruderalis & Mollusca & Native \\
\hline Chama fibula & Mollusca & Non-native \\
\hline Chama lazarus & Mollusca & Native \\
\hline Chama limbula & Mollusca & Native \\
\hline Chama pacifica & Mollusca & Native \\
\hline Chama ruderalis & Mollusca & Native \\
\hline
\end{tabular}




\begin{tabular}{|c|c|c|}
\hline Chamaesipho tasmanica & Arthropoda & Native \\
\hline Champia parvula & Rhodophyta & Cryptogenic \\
\hline Champia viridis & Rhodophyta & Native \\
\hline Chaperiopsis cervicornis & Bryozoa & Native \\
\hline Charybdis cf. anisodon & Arthropoda & Native \\
\hline Charybdis cf. hellerii & Arthropoda & Native \\
\hline Charybdis hellerii & Arthropoda & Non-native \\
\hline Chelonaplysilla cf. violacea & Porifera & Native \\
\hline Chelonaplysilla violacea & Porifera & Native \\
\hline Chlamys aktinos & Mollusca & Native \\
\hline Chlorodiella laevissima & Arthropoda & Native \\
\hline Chlorotocella gibber & Arthropoda & Native \\
\hline Chondria fusifolia & Rhodophyta & Native \\
\hline Chondria simpliciuscula & Rhodophyta & Native \\
\hline Chondria succulenta & Rhodophyta & Native \\
\hline Chordaria cladosiphon & Ochrophyta & Native \\
\hline Chorizocarpa cf. michaelseni & Chordata & Native \\
\hline Chorizocarpa cf. sydneyensis & Chordata & Native \\
\hline Chorizocarpa sydneyensis & Chordata & Native \\
\hline Chromodoris cf. epicuria & Mollusca & Native \\
\hline Chthamalus antennatus & Arthropodas & Native \\
\hline Chthamalus malayensis & Arthropodas & Native \\
\hline Cilicaea crassicaudata & Arthropoda & Native \\
\hline Cilicaea latreillei & Arthropoda & Native \\
\hline Ciona intestinalis & Chordata & Non-native \\
\hline Cirolana erodiae & Arthropoda & Native \\
\hline Cirolana harfordi & Ispods & Non-native \\
\hline Cirriformia cf. capensis & Annelida & Native \\
\hline Cirriformia cf. filigera & Annelida & Native \\
\hline Cirriformia filigera & Annelida & Native \\
\hline Cirriformia tentaculata & Annelida & Native \\
\hline Cladophora albida & Chlorophyta & Native \\
\hline Cladophora feredayi & Chlorophyta & Native \\
\hline Cladophora lehmanniana & Chlorophyta & Non-native \\
\hline Cladophora subsimplex & Chlorophyta & Native \\
\hline Clanculus undatus & Mollusca & Native \\
\hline Clarkcoma canaliculata & Echinodermata & Native \\
\hline Clathrina adusta & Porifera & Native \\
\hline Clava cf. simplex & Cnidaria & Native \\
\hline Cleidothaerus cf. plicifera & Mollusca & Native \\
\hline Cleotrivia globosa & Mollusca & Native \\
\hline Clytia cf. gracilis & Cnidaria & Native \\
\hline Clytia cf. hemisphaerica & Cnidaria & Non-native \\
\hline Clytia cf. paulensis & Cnidaria & Non-native \\
\hline
\end{tabular}




\begin{tabular}{|c|c|c|}
\hline Clytia gravieri & Cnidaria & Native \\
\hline Clytia hemisphaerica & Cnidaria & Cryptogenic \\
\hline Clytia johnstoni & Cnidaria & Native \\
\hline Clytia paulensis & Cnidaria & Cryptogenic \\
\hline Cnemidocarpa areolata & Chordata & Native \\
\hline Cnemidocarpa cf. barbata & Chordata & Native \\
\hline Cnemidocarpa completa & Chordata & Native \\
\hline Cnemidocarpa fissa & Chordata & Native \\
\hline Cnemidocarpa floccosa & Chordata & Native \\
\hline Cnemidocarpa lobata & Chordata & Native \\
\hline Cnemidocarpa radicosa & Chordata & Native \\
\hline Cnemidocarpa stolonifera & Chordata & Native \\
\hline Codium fragile ssp tomentosoides & Chlorophyta & Non-native \\
\hline Coeloclonium cf. umbellulum & Rhodophyta & Native \\
\hline Coeloclonium umbellulum & Rhodophyta & Native \\
\hline Colpomenia sinuosa & Ochrophyta & Cryptogenic \\
\hline Conopeum cf. seurati & Bryozoa & Native \\
\hline Conopeum reticulum & Bryozoa & Non-native \\
\hline Corallina officinalis & Rhodophyta & Cryptogenic \\
\hline Coralliophila mira & Mollusca & Native \\
\hline Cordylophora caspia & Cnidaria & Non-native \\
\hline Corella eumyota & Chordata & Native \\
\hline Corydendrium parasiticum & Cnidaria & Native \\
\hline Coscinasterias muricata & Chordata & Native \\
\hline Cosmetalepas concatenatus & Mollusca & Native \\
\hline Craspedoplax variabilis & Mollusca & Native \\
\hline Crassimarginatella cf. papulifera & Bryozoa & Native \\
\hline Crassimarginatella papulifera & Bryozoa & Native \\
\hline Crassostrea gigas & Mollusca & Non-native \\
\hline Cricophorus nutrix & Cnidaria & Native \\
\hline Crisia acropora & Bryozoa & Native \\
\hline Crisia cf. acropora & Bryozoa & Native \\
\hline Crisia margaritacea & Bryozoa & Native \\
\hline Cronia avellana & Mollusca & Native \\
\hline Crucigera cf. inconstans & Annelida & Native \\
\hline Crucigera inconstans & Annelida & Native \\
\hline Cryptodromia cf. tumida & Arthropoda & Native \\
\hline Cryptoplax striata & Mollusca & Native \\
\hline Cryptosula pallasiana & Bryozoa & Non-native \\
\hline Culicia australiensis & Cnidaria & Native \\
\hline Culicia cf. tenella & Cnidaria & Native \\
\hline Culicia tenella & Cnidaria & Cryptogenic \\
\hline Cutleria multifida & Ochrophyta & Non-native \\
\hline Cyamiomactra cf. problematica & Mollusca & Native \\
\hline
\end{tabular}




\begin{tabular}{|c|c|c|}
\hline Cyclicopora longipora & Bryozoa & Native \\
\hline Cymatium exaratum & Mollusca & Native \\
\hline Cymatium labiosum & Mollusca & Native \\
\hline Cypraea helvola & Mollusca & Native \\
\hline Cypraea subviridis & Mollusca & Native \\
\hline Cystiscus angasi & Mollusca & Native \\
\hline Dasya capillaris & Rhodophyta & Native \\
\hline Dasya cf. caraibica & Rhodophyta & Native \\
\hline Dasya crescens & Rhodophyta & Native \\
\hline Dasya extensa & Rhodophyta & Native \\
\hline Dasya hookeri & Rhodophyta & Native \\
\hline Dasya iyengarii & Rhodophyta & Native \\
\hline Dasya villosa & Rhodophyta & Native \\
\hline Demonax leucaspis & Annelida & Native \\
\hline Dendostrea cf. folium & Mollusca & Native \\
\hline Dendostrea cf. sandvichensis & Mollusca & Native \\
\hline Dendostrea folium & Mollusca & Native \\
\hline Dendostrea sandvichensis & Mollusca & Native \\
\hline Dendrilla cactos & Porifera & Native \\
\hline Dendrilla cf. rosea & Porifera & Native \\
\hline Densipora corrugata & Bryozoa & Native \\
\hline Dictyopteris mиelleri & Ochrophyta & Native \\
\hline Dictyopteris nigricans & Ochrophyta & Native \\
\hline Dictyopteris plagiogramma & Ochrophyta & Native \\
\hline Dictyota bartayresiana & Ochrophyta & Native \\
\hline Dictyota cervicornis & Ochrophyta & Native \\
\hline Dictyota dichotoma & Ochrophyta & Cryptogenic \\
\hline Dictyota divaricata & Ochrophyta & Native \\
\hline Dictyota furcellata & Ochrophyta & Native \\
\hline Dilophus marginatus & Ochrophyta & Native \\
\hline Dimorphostylis colefaxi & Arthropoda & Native \\
\hline Diodora cf. jukesii & Mollusca & Native \\
\hline Diodora cf. lincolnensis & Mollusca & Native \\
\hline Diodora jukesii & Mollusca & Native \\
\hline Diopatra dentata & Annelida & Native \\
\hline Diphasia digitalis & Cnidaria & Native \\
\hline Diphasia subcarinata & Cnidaria & Native \\
\hline Diplosoma ferrugem & Chordata & Native \\
\hline Diplosoma listerianum & Chordata & Non-native \\
\hline Diplosoma velatum & Chordata & Native \\
\hline Dipolydora flava & Annelida & Cryptogenic \\
\hline Dipolydora giardi & Annelida & Cryptogenic \\
\hline Dipolydora socialis & Annelida & Non-native \\
\hline Distaplia cf. australensis & Chordata & Native \\
\hline
\end{tabular}




\begin{tabular}{|c|c|c|}
\hline Distaplia stylifera & Chordata & Native \\
\hline Distaplia violetta & Chordata & Native \\
\hline Distaplia viridis & Chordata & Native \\
\hline Dofleinia armata & Cnidaria & Native \\
\hline Doriopsilla peculiaris & Mollusca & Native \\
\hline Doris cameroni & Mollusca & Native \\
\hline Dorvillea australiensis & Annelida & Native \\
\hline Dulichiella australis & Arthropoda & Native \\
\hline Dumea latipes & Arthropoda & Native \\
\hline Durvillaea potatorum & Ochrophyta & Native \\
\hline Dynamena crisoides & Cnidaria & Native \\
\hline Dynamena mertoni & Cnidaria & Native \\
\hline Echinothamnion hookeri & Rhodophyta & Native \\
\hline Ecklonia radiata & Ochrophyta & Native \\
\hline Ecteinascidia cf. diaphanis & Chordata & Native \\
\hline Ecteinascidia rubricollis & Chordata & Native \\
\hline Ectocarpus siliculosus & Ochrophyta & Non-native \\
\hline Ehlersia ferrugina & Annelida & Native \\
\hline Elasmopus rapax & Arthropoda & Non-native \\
\hline Electra tenella & Bryozoa & Cryptogenic \\
\hline Electroma georgiana & Mollusca & Native \\
\hline Electroma physoides & Mollusca & Native \\
\hline Elminius covertus $s$ & Arthropodas & Native \\
\hline Elminius modestus s & Arthropodas & Native \\
\hline Elysia ornata & Mollusca & Native \\
\hline Elzerina blainvillii & Bryozoa & Native \\
\hline Emarginula devota & Mollusca & Native \\
\hline Emarginula patula & Mollusca & Native \\
\hline Endeis straughani & Arthropoda & Native \\
\hline Engina armillata & Mollusca & Native \\
\hline Ensiculus cultellus & Mollusca & Native \\
\hline Enteromorpha intestinalis & Chlorophyta & Cryptogenic \\
\hline Epitonium cf. perplexum & Mollusca & Native \\
\hline Epopella simplex $s$ & Arthropodas & Native \\
\hline Ericthonius pugnax & Arthropoda & Native \\
\hline Euchelus cf. ampullus & Mollusca & Native \\
\hline Euchone limnicola & Annelida & Non-native \\
\hline Euclavella claviformis & Chordata & Native \\
\hline Eucoelium mariae & Chordata & Native \\
\hline Eudendrium aylingae & Cnidaria & Native \\
\hline Eudendrium capillare & Cnidaria & Native \\
\hline Eudendrium cf. capillare & Cnidaria & Native \\
\hline Eudendrium cf. generale & Cnidaria & Native \\
\hline Eudendrium cf. kirkpatricki & Cnidaria & Native \\
\hline
\end{tabular}




\begin{tabular}{|c|c|c|}
\hline Eudendrium glomeratum & Cnidaria & Native \\
\hline Eudendrium pennycuikae & Cnidaria & Native \\
\hline Eudistoma laysani & Chordata & Native \\
\hline Eumarcia fumigata & Mollusca & Native \\
\hline Eumida cf. sanguinea & Annelida & Native \\
\hline Eumida fuscolutata & Annelida & Native \\
\hline Eumida sanguinea & Annelida & Native \\
\hline Eunice afra punctuata & Annelida & Native \\
\hline Eunice antennata & Annelida & Native \\
\hline Eunice australis & Annelida & Native \\
\hline Eunice bassensis & Annelida & Native \\
\hline Eunice cf. afra punctuata & Annelida & Native \\
\hline Eunice cf. australis & Annelida & Native \\
\hline Eunice cf. bowerbanki & Annelida & Native \\
\hline Eunice cf. complanata & Annelida & Native \\
\hline Eunice cf. hirschi & Annelida & Native \\
\hline Eunice cf. ornata & Annelida & Native \\
\hline Eunice cf. plicata & Annelida & Native \\
\hline Eunice complanata & Annelida & Native \\
\hline Eunice hirschi & Annelida & Native \\
\hline Eunice laticeps & Annelida & Native \\
\hline Eunice siciliensis & Annelida & Native \\
\hline Eunice torresiensis & Annelida & Native \\
\hline Eunice tubifex & Annelida & Native \\
\hline Eunice vittata & Annelida & Native \\
\hline Eupolymnia koorangia & Annelida & Native \\
\hline Euptilota articulata & Rhodophyta & Native \\
\hline Euraphia withersi & Arthropoda & Native \\
\hline Euthelepus cf. marchinbar & Annelida & Native \\
\hline Fenestrulina mutabilis & Bryozoa & Native \\
\hline Ficopomatus enigmaticus & Annelida & Non-native \\
\hline Filellum serratum & Cnidaria & Cryptogenic \\
\hline Fragum retusum & Mollusca & Native \\
\hline Fultodromia cf. nodipes & Arthropoda & Native \\
\hline Fulvia tenuicostata & Mollusca & Native \\
\hline Galathea australiensis & Arthropoda & Native \\
\hline Galeolaria caespitosa & Annelida & Native \\
\hline Gastrochaena cuneiformis & Mollusca & Native \\
\hline Gelidium pusillum & Rhodophyta & Non-native \\
\hline Gnathia biorbis & Arthropoda & Native \\
\hline Gonothyraea loveni & Cnidaria & Non-native \\
\hline Gracilaria arcuata & Rhodophyta & Native \\
\hline Gracilaria cf. secundata & Rhodophyta & Native \\
\hline Grahamina gymnota & Chordata & Non-native \\
\hline
\end{tabular}




\begin{tabular}{|c|c|c|}
\hline Granata imbricata & Mollusca & Native \\
\hline Grateloupia filicina luxurians & Rhodophyta & Native \\
\hline Gregarinidra serrata & Bryozoa & Native \\
\hline Griffithsia monilis & Rhodophyta & Native \\
\hline Griffithsia subcylindrica & Rhodophyta & Native \\
\hline Griffithsia teges & Rhodophyta & Native \\
\hline Gymnangium gracilicaule & Cnidaria & Native \\
\hline Gymnangium hians & Cnidaria & Native \\
\hline Gymnangium longirostre & Cnidaria & Native \\
\hline Halecium cf. lighti & Cnidaria & Native \\
\hline Halecium cf. tenellum & Cnidaria & Native \\
\hline Halecium cf. undulatum & Cnidaria & Native \\
\hline Halecium delicatulum & Cnidaria & Cryptogenic \\
\hline Halecium fragile & Cnidaria & Native \\
\hline Halecium sessile & Cnidaria & Native \\
\hline Halicarcinus innominatus & Arthropoda & Non-native \\
\hline Halicarcinus ovatus & Arthropoda & Native \\
\hline Halicarcinus rostratus & Arthropoda & Native \\
\hline Halimeda cuneata $N \_C h l o r o p h y t a$ & Chlorophyta & Native \\
\hline Haliotis cf. conicopora & Mollusca & Native \\
\hline Haliplanella lineata & Cnidaria & Non-native \\
\hline Halocynthia dumosa & Chordata & Native \\
\hline Halopteris buskii & Cnidaria & Native \\
\hline Halopteris campanula & Cnidaria & Native \\
\hline Halopteris novaezelandiae & Ochrophyta & Native \\
\hline Halopteris plagiocampa & Cnidaria & Native \\
\hline Halopteris ramulosa & Ochrophyta & Native \\
\hline Hapalochlaena maculosa & Mollusca & Native \\
\hline Haraldiophyllum sinuosum & Rhodophyta & Native \\
\hline Harmothoe cf. praeclara & Annelida & Native \\
\hline Harmothoe cf. waahli & Annelida & Native \\
\hline Harmothoe charlottae & Annelida & Native \\
\hline Harmothoe dictyophora & Annelida & Native \\
\hline Harmothoe phillipensis & Annelida & Native \\
\hline Harmothoe praeclara & Annelida & Native \\
\hline Harmothoe waahli & Annelida & Native \\
\hline Hartmeyeria formosa & Chordata & Native \\
\hline Hebella costata & Cnidaria & Native \\
\hline Hebellopsis scandens & Cnidaria & Native \\
\hline Heliocidaris erythrogramma & Echinodermata & Native \\
\hline Helograpsus haswellianus & Arthropoda & Native \\
\hline Hemiaegina minuta & Arthropoda & Native \\
\hline Hemitoma subemarginata & Mollusca & Native \\
\hline Herdmania тотиs & Chordata & Non-native \\
\hline
\end{tabular}




\begin{tabular}{|c|c|c|}
\hline Hermaea evelinemarcusae & Mollusca & Native \\
\hline Herpetopoma aspersa & Mollusca & Native \\
\hline Herpetopoma atrata & Mollusca & Native \\
\hline Herpetopoma rubra & Mollusca & Native \\
\hline Herposiphonia rostrata & Rhodophyta & Native \\
\hline Heteroclinus perspicillatus & Chordata & Native \\
\hline Heteropanope cf. changensis & Arthropoda & Native \\
\hline Heteropanope cf. longipedes & Arthropoda & Native \\
\hline Heterozostera tasmanica & Tracheophyta & Native \\
\hline Hexaminius popeiana & Arthropoda & Native \\
\hline Hiatella arctica & Mollusca & Non-native \\
\hline Hiatella australis & Mollusca & Native \\
\hline Hincksia granulosa & Ochrophyta & Non-native \\
\hline Hincksia sandriana & Ochrophyta & Non-native \\
\hline Hincksia sordida & Ochrophyta & Native \\
\hline Hincksinoflustra denticulata & Bryozoa & Native \\
\hline Hippolyte caradina & Arthropoda & Native \\
\hline Hippopetraliella magna & Bryozoa & Native \\
\hline Hippothoa distans & Bryozoa & Non-native \\
\hline Holothuria cf. fuscocinerea & Echinodermata & Native \\
\hline Huenia bifurcata & Arthropoda & Native \\
\hline Hyastenus auctus & Arthropoda & Native \\
\hline Hyastenus cf. convexus & Arthropoda & Native \\
\hline Hyastenus convexus & Arthropoda & Native \\
\hline Hyastenus elatus & Arthropoda & Native \\
\hline Hyastenus sebae & Arthropoda & Native \\
\hline Hyatella intestinalis & Porifera & Native \\
\hline Hyboscolex dicranochaetus & Annelida & Native \\
\hline Hydrococcus brazieri & Mollusca & Native \\
\hline Hydroides cf. brachyacanthus & Annelida & Native \\
\hline Hydroides cf. ezoensis & Annelida & Non-native \\
\hline Hydroides diramphus & Annelida & Non-native \\
\hline Hydroides elegans & Annelida & Cryptogenic \\
\hline Hydroides ezoensis & Annelida & Non-native \\
\hline Hydroides lunulifera & Annelida & Native \\
\hline Hydroides minax & Annelida & Native \\
\hline Hydroides recta & Annelida & Native \\
\hline Hydroides tambalagamensis & Annelida & Native \\
\hline Hydroides trivesiculosus & Annelida & Native \\
\hline Hydroides tuberculatus & Annelida & Native \\
\hline Hydroides uncinata & Annelida & Native \\
\hline Hymenena curdieana & Rhodophyta & Native \\
\hline Hyotissa cf. hyotis & Mollusca & Native \\
\hline Hyotissa hyotis & Mollusca & Native \\
\hline
\end{tabular}




\begin{tabular}{|c|c|c|}
\hline Hypnea cervicornis & Rhodophyta & Native \\
\hline Hypnea cf. spinella & Rhodophyta & Native \\
\hline Hypnea charoides & Rhodophyta & Native \\
\hline Hypnea musciformis & Rhodophyta & Non-native \\
\hline Hypnea ramentacea & Rhodophyta & Native \\
\hline Hypnea valentiae & Rhodophyta & Native \\
\hline Hypselodoris obscura & Mollusca & Native \\
\hline Iais californica & Arthropoda & Native \\
\hline Ibla cumingi & Arthropoda & Native \\
\hline Ibla quadrivalvis & Arthropoda & Native \\
\hline Idanthyrsus armatus & Annelida & Native \\
\hline Idanthyrsus australiensis & Annelida & Native \\
\hline Idiellana pristis & Cnidaria & Native \\
\hline Inermonephtys cf. palpata & Annelida & Native \\
\hline Iphione muricata & Annelida & Native \\
\hline Irus carditoides & Mollusca & Native \\
\hline Irus crebrelamellatus & Mollusca & Native \\
\hline Irus crenatus & Mollusca & Native \\
\hline Irus cumingii & Mollusca & Native \\
\hline Irus griseus & Mollusca & Native \\
\hline Irus irus & Mollusca & Native \\
\hline Isanemonia australis & Cnidaria & Native \\
\hline IschnoMollusca cf. arbutus & Mollusca & Native \\
\hline IschnoMollusca virgatus & Mollusca & Native \\
\hline Isognomon albisoror & Mollusca & Native \\
\hline Isognomon cf. ephippium & Mollusca & Native \\
\hline Isognomon cf. isognomon & Mollusca & Native \\
\hline Isognomon cf. nucleus & Mollusca & Native \\
\hline Isognomon cf. perna & Mollusca & Native \\
\hline Isognomon ephippium & Mollusca & Native \\
\hline Isognomon isognomon & Mollusca & Native \\
\hline Isognomon nucleus & Mollusca & Native \\
\hline Isognomon perna & Mollusca & Native \\
\hline Isolda pulchella & Annelida & Native \\
\hline Istiblennius meleagris & Chordata & Native \\
\hline Jania adhaerens & Rhodophyta & Native \\
\hline Jania verrucosa & Rhodophyta & Native \\
\hline Jasmineira elegans & Annelida & Native \\
\hline Jassa marmorata & Arthropoda & Non-native \\
\hline Jassa slatteryi & Arthropoda & Cryptogenic \\
\hline Jellyella tuberculata & Bryozoa & Cryptogenic \\
\hline Jujubinus lepidus & Mollusca & Native \\
\hline Kellia adamsi & Mollusca & Native \\
\hline Kellia cf. adamsi & Mollusca & Native \\
\hline
\end{tabular}




\begin{tabular}{|c|c|c|}
\hline Kellia cf. yorkensis & Mollusca & Native \\
\hline Kellia physema & Mollusca & Native \\
\hline Kellia rotunda & Mollusca & Native \\
\hline Kellia tumida & Mollusca & Native \\
\hline Lafoeina amirantensis & Cnidaria & Native \\
\hline Langerhansia cervantensis & Annelida & Native \\
\hline Lanice bidewa & Annelida & Native \\
\hline Lanice cf. bidewa & Annelida & Native \\
\hline Lanicides attenuata & Annelida & Native \\
\hline Lanicides cf. fascia & Annelida & Native \\
\hline Lanicola lobata & Annelida & Native \\
\hline Lasaea australis & Mollusca & Native \\
\hline Laurencia arbuscula & Rhodophyta & Native \\
\hline Laurencia filiformis & Rhodophyta & Native \\
\hline Laurencia majuscula & Rhodophyta & Native \\
\hline Lauridromia dehaani & Arthropoda & Native \\
\hline Leitoscoloplos bifurcatus & Annelida & Native \\
\hline Lenormandia marginata & Rhodophyta & Native \\
\hline Leonnates cf. decipens & Annelida & Native \\
\hline Leonnates cf. stephensoni & Annelida & Native \\
\hline Leonnates decipens & Annelida & Native \\
\hline Leonnates jousseaumei & Annelida & Native \\
\hline Lepidonotus carinulatus & Annelida & Native \\
\hline Lepidonotus cf. carinulatus & Annelida & Native \\
\hline Lepidonotus cf. glaucus & Annelida & Native \\
\hline Lepidonotus glaucus & Annelida & Native \\
\hline Lepidonotus purpureus & Annelida & Native \\
\hline Lepidonotus yorkianus & Annelida & Native \\
\hline Leptochelia cf. dubia & Arthropoda & Native \\
\hline Leptochelia dubia & Arthropoda & Cryptogenic \\
\hline Leptograpsus variegatus & Arthropoda & Native \\
\hline Leptomithrax gaimardii & Arthropoda & Native \\
\hline Leptomithrax sternocostulatus & Arthropoda & Native \\
\hline LeptoMollusca badius & Mollusca & Native \\
\hline LeptoMollusca liratus & Mollusca & Native \\
\hline LeptoMollusca mathewsianus & Mollusca & Native \\
\hline Leptosynapta dolabrifera & Echinodermata & Native \\
\hline Leucothoe commensalis & Arthropoda & Native \\
\hline Leucothoe goowera & Arthropoda & Native \\
\hline Ligia australiensis & Arthropoda & Native \\
\hline Limaria cf. fragilis & Mollusca & Native \\
\hline Limaria fragilis & Mollusca & Native \\
\hline Limaria orientalis & Mollusca & Non-native \\
\hline Limnoria quadripunctata & Arthropoda & Non-native \\
\hline
\end{tabular}




\begin{tabular}{|c|c|c|}
\hline Lissoclinum cf. roseum & Chordata & Native \\
\hline Lissodendoryx cf. isodictyalis & Porifera & Native \\
\hline Lissoporcellana cf. spinuligera & Arthropoda & Native \\
\hline Lithophaga malaccana & Mollusca & Native \\
\hline Lithophaga teres & Mollusca & Native \\
\hline Litocheira bispinosa & Arthropoda & Native \\
\hline Litozamia peterdi & Mollusca & Native \\
\hline Littoraria articulata & Mollusca & Native \\
\hline Littorina acutispira & Mollusca & Native \\
\hline Lobopelma microscala & Annelida & Native \\
\hline Lobophora variegata & Ochrophyta & Native \\
\hline Lobospira bicuspidata & Ochrophyta & Native \\
\hline Loimia cf. ingens & Annelida & Native \\
\hline Loimia ingens & Annelida & Native \\
\hline Lomentaria monochlamydea & Rhodophyta & Native \\
\hline Lomis hirta & Arthropoda & Native \\
\hline Longicarpus modestus & Annelida & Native \\
\hline Lopha cristagalli & Mollusca & Native \\
\hline Lophurella periclados & Rhodophyta & Native \\
\hline Lovenella chiquitita & Cnidaria & Native \\
\hline Lumbrineris cf. coccinea & Annelida & Native \\
\hline Lumbrineris cf. latreilli & Annelida & Native \\
\hline Lumbrineris cf. tetraura & Annelida & Native \\
\hline Lumbrineris coccinea & Annelida & Native \\
\hline Lumbrineris inflata & Annelida & Native \\
\hline Lumbrineris latreilli & Annelida & Native \\
\hline Lumbrineris setosa & Annelida & Native \\
\hline Lysidice cf. natalensis & Annelida & Native \\
\hline Lysidice collaris & Annelida & Cryptogenic \\
\hline Lysidice ninetta & Annelida & Native \\
\hline Lysilla cf. laciniata & Annelida & Native \\
\hline Lysilla jennacubinae & Annelida & Native \\
\hline Lysilla laciniata & Annelida & Native \\
\hline Macrobrachium intermedium & Arthropoda & Native \\
\hline Macrocystis angustifolia & Ochrophyta & Native \\
\hline Macromedaeus cf. distinguendus & Arthropoda & Native \\
\hline Macrophiothrix cf. variabilis & Echinodermata & Native \\
\hline Macrorhynchia cf. philippina & Cnidaria & Native \\
\hline Macrorhynchia philippina & Cnidaria & Native \\
\hline Macrorhynchia phoenicia & Cnidaria & Native \\
\hline Macrothamnion cf. secundum & Rhodophyta & Native \\
\hline Macrothamnion pellucidum & Rhodophyta & Native \\
\hline Malleus decurtatus & Mollusca & Native \\
\hline Malleus meridianus & Mollusca & Native \\
\hline
\end{tabular}




\begin{tabular}{|c|c|c|}
\hline Maoricolpus roseus & Mollusca & Non-native \\
\hline Margaretta barbata & Bryozoa & Native \\
\hline Marphysa sanguinea species complex & Annelida & Native \\
\hline Megabalanus occator & Arthropoda & Non-native \\
\hline Megabalanus rosa & Arthropoda & Non-native \\
\hline Megabalanus tintinnabulum & Arthropoda & Non-native \\
\hline Melita matilda & Arthropoda & Native \\
\hline Membranipora membranacea & Bryozoa & Cryptogenic \\
\hline Menaethius monoceros & Arthropoda & Native \\
\hline Menipea roborata & Bryozoa & Native \\
\hline Metagoniolithon radiatum & Rhodophyta & Native \\
\hline Metaprotella cf. haswelliana & Arthropoda & Native \\
\hline Metavermilia acanthophora & Annelida & Native \\
\hline Metavermilia cf. acanthophora & Annelida & Native \\
\hline Microcosmus australis & Chordata & Native \\
\hline Microcosmus cf. australis & Chordata & Native \\
\hline Microcosmus cf. squamiger & Chordata & Native \\
\hline Microcosmus cf. stoloniferus & Chordata & Native \\
\hline Microcosmus exasperatus & Chordata & Native \\
\hline Microcosmus helleri & Chordata & Native \\
\hline Microcosmus pupa & Chordata & Native \\
\hline Microcosmus squamiger & Chordata & Native \\
\hline Microcosmus stoloniferus & Chordata & Native \\
\hline Microporella lunifera & Bryozoa & Native \\
\hline Mimachlamys asperrima & Mollusca & Native \\
\hline Mimachlamys australis & Mollusca & Native \\
\hline Mimachlamys famigerator & Mollusca & Native \\
\hline Minuspio cirrifera & Annelida & Native \\
\hline Mitrella cf. eximia & Mollusca & Native \\
\hline Mitrella cf. lincolnensis & Mollusca & Native \\
\hline Mitrella lincolnensis & Mollusca & Native \\
\hline Mitrella semiconvexa & Mollusca & Native \\
\hline Mitrella tayloriana & Mollusca & Native \\
\hline Mitrella venulata & Mollusca & Native \\
\hline Modiolus albicostatus & Mollusca & Native \\
\hline Modiolus areolatus & Mollusca & Native \\
\hline Modiolus auriculatus & Mollusca & Native \\
\hline Modiolus cf. albicostatus & Mollusca & Native \\
\hline Modiolus cf. areolatus & Mollusca & Native \\
\hline Modiolus victoriae & Mollusca & Native \\
\hline Molgula ficus & Chordata & Native \\
\hline Monia zelandica & Mollusca & Native \\
\hline Monocorophium acherusicum & Arthropoda & Non-native \\
\hline Monocorophium insidiosum & Arthropoda & Non-native \\
\hline
\end{tabular}




\begin{tabular}{|c|c|c|}
\hline Monomyces radiatus & Cnidaria & Native \\
\hline Monophorus angasi & Mollusca & Native \\
\hline Monostaechas quadridens & Cnidaria & Native \\
\hline Monotheca cf. obliqua & Cnidaria & Native \\
\hline Monotheca compressa & Cnidaria & Native \\
\hline Monotheca flexuosa & Cnidaria & Native \\
\hline Monotheca pulchella & Cnidaria & Native \\
\hline Montfortula rugosa & Mollusca & Native \\
\hline Mopsella klunzingeri & Cnidaria & Native \\
\hline Mopsella zimmeri & Cnidaria & Native \\
\hline Mucropetraliella cf. vultur & Bryozoa & Native \\
\hline Mucropetraliella ellerii & Bryozoa & Native \\
\hline Mucropetraliella nodulosa & Bryozoa & Native \\
\hline Mucropetraliella vultur & Bryozoa & Native \\
\hline Musculista senhousia & Mollusca & Non-native \\
\hline Musculus cf. imиs & Mollusca & Native \\
\hline Musculus cf. miranda & Mollusca & Native \\
\hline Musculus cf. nanus & Mollusca & Native \\
\hline Musculus chinensis & Mollusca & Native \\
\hline Musculus cumingianus & Mollusca & Native \\
\hline Musculus impactus & Mollusca & Native \\
\hline Musculus nanus & Mollusca & Native \\
\hline Myriogramme gunniana & Rhodophyta & Native \\
\hline Myriogramme pulchella & Rhodophyta & Native \\
\hline Mytilus edulis & Mollusca & Cryptogenic \\
\hline Mytilus edulis planulatus & Mollusca & Native \\
\hline Mytilus galloprovincialis & Mollusca & Non-native \\
\hline Mytilus planulatus & Mollusca & Native \\
\hline Myxicola infundibulum & Annelida & Non-native \\
\hline Naineris australis & Annelida & Native \\
\hline Naineris cf. australis & Annelida & Native \\
\hline Nannastacus inflatus & Arthropoda & Native \\
\hline Nassarius burchardi & Mollusca & Native \\
\hline Nassarius nigellus & Mollusca & Native \\
\hline Nassarius pauperatus & Mollusca & Native \\
\hline Nassarius pyrrhus & Mollusca & Native \\
\hline Naxia tumida & Arthropoda & Native \\
\hline Neanthes cf. flindersi & Annelida & Native \\
\hline Neanthes cf. kerguelensis & Annelida & Native \\
\hline Neanthes cricognatha & Annelida & Native \\
\hline Neanthes kerguelensis & Annelida & Native \\
\hline Neanthes uniseriata & Annelida & Native \\
\hline Neanthes vaalii & Annelida & Native \\
\hline Nectocarcinus integrifrons & Arthropoda & Native \\
\hline
\end{tabular}




\begin{tabular}{|c|c|c|}
\hline Nectocarcinus tuberculosus & Arthropoda & Native \\
\hline Nellia oculata & Bryozoa & Native \\
\hline Nellia tenella & Bryozoa & Native \\
\hline Nematonereis unicornis & Annelida & Native \\
\hline Nematonereis unicornis species complex & Annelida & Native \\
\hline Neoleprea booligal & Annelida & Native \\
\hline Neorhynchoplax cf. minima & Arthropoda & Native \\
\hline Neorhynchoplax octagonalis & Arthropoda & Native \\
\hline Neovermilia cf. globula & Annelida & Native \\
\hline Neovermilia globula & Annelida & Native \\
\hline Nephtys australiensis & Annelida & Native \\
\hline Nephtys longipes & Annelida & Native \\
\hline Nereis bifida & Annelida & Native \\
\hline Nereis cf. denhamensis & Annelida & Native \\
\hline Nereis cockburnensis & Annelida & Native \\
\hline Nereis denhamensis & Annelida & Native \\
\hline Nicolea amnis & Annelida & Native \\
\hline Nicolea cf. amnis & Annelida & Native \\
\hline Nizymenia australis & Rhodophyta & Native \\
\hline Nodilittorina praetermissa & Mollusca & Native \\
\hline Nolella alta & Bryozoa & Native \\
\hline Notoacmea flammea & Mollusca & Native \\
\hline Notoacmea petterdi & Mollusca & Native \\
\hline Notomastus estuarius & Annelida & Native \\
\hline Notomastus latericeus & Annelida & Native \\
\hline Notomithrax cf. ursus & Arthropoda & Native \\
\hline Notomithrax minor & Arthropoda & Native \\
\hline Notomithrax ursus & Arthropoda & Native \\
\hline Notophyllum splendens & Annelida & Native \\
\hline Notoplax addenda & Mollusca & Native \\
\hline Notopontonia cf. platycheles & Arthropoda & Native \\
\hline Nymphon molleri & Arthropoda & Native \\
\hline Obelia angulosa & Cnidaria & Native \\
\hline Obelia bicuspidata & Cnidaria & Native \\
\hline Obelia bispinosa & Cnidaria & Native \\
\hline Obelia cf. dichotoma & Cnidaria & Native \\
\hline Obelia cf. geniculata & Cnidaria & Native \\
\hline Obelia cf. longissima & Cnidaria & Native \\
\hline Obelia dichotoma & Cnidaria & Non-native \\
\hline Obelia longissima & Cnidaria & Cryptogenic \\
\hline Odontosyllis australiensis & Annelida & Native \\
\hline Odostomia occultidens & Mollusca & Native \\
\hline Oenone fulgida & Annelida & Non-native \\
\hline Onchidella cf. patelloides & Mollusca & Native \\
\hline
\end{tabular}




\begin{tabular}{|c|c|c|}
\hline Onchidella patelloides & Mollusca & Native \\
\hline Opercularella humilis & Cnidaria & Native \\
\hline Opheliidae Travisia & Annelida & Native \\
\hline Ophiacantha heterotyla & Echinodermata & Native \\
\hline Ophiacantha pica & Echinodermata & Native \\
\hline Ophiactis cf. resiliens & Echinodermata & Native \\
\hline Ophiactis cf. savignyi & Echinodermata & Native \\
\hline Ophiactis macrolepidota & Echinodermata & Native \\
\hline Ophiactis resiliens & Echinodermata & Native \\
\hline Ophiactis savignyi & Echinodermata & Native \\
\hline Ophiocentrus pilosa & Echinodermata & Native \\
\hline Ophiocentrus verticillata & Echinodermata & Native \\
\hline Ophiodissa carchesium & Cnidaria & Native \\
\hline Ophiomyxa australis & Echinodermata & Native \\
\hline Ophiothrix caespitosa & Echinodermata & Native \\
\hline Ophiothrix martensi & Echinodermata & Native \\
\hline Ophiothrix spongicola & Echinodermata & Native \\
\hline Ophiothrix vicina & Echinodermata & Native \\
\hline Orthopyxis caliculata & Cnidaria & Native \\
\hline Orthopyxis integra & Cnidaria & Native \\
\hline Orthopyxis mollis & Cnidaria & Native \\
\hline Ostrea angasi & Mollusca & Native \\
\hline Oulactis muscosa & Cnidaria & Non-native \\
\hline Oxynoe viridis & Mollusca & Native \\
\hline Pachycheles sculptus & Arthropoda & Native \\
\hline Padina elegans & Ochrophyta & Native \\
\hline Padina sanctae-crucis & Ochrophyta & Native \\
\hline Pagurus cf. hirtimanus & Arthropoda & Native \\
\hline Palaemon cf. serenus & Arthropoda & Native \\
\hline Palaemon serenus & Arthropoda & Native \\
\hline Palaemonella cf. rotumana & Arthropoda & Native \\
\hline Palaemonella rotumana & Arthropoda & Native \\
\hline Paleanotus chrysolepis & Annelida & Native \\
\hline Palola cf. siciliensis & Annelida & Native \\
\hline Palola siciliensis & Annelida & Native \\
\hline Paphies striata & Mollusca & Native \\
\hline Parablennius tasmanianus & Chordata & Native \\
\hline Paracalix ambiplica & Cnidaria & Native \\
\hline Paracerceis sculpta & Arthropoda & Non-native \\
\hline Paracilicaea gigas & Arthropoda & Native \\
\hline Paracilicaea septemdentata & Arthropoda & Native \\
\hline Paradella dianae & Arthropoda & Non-native \\
\hline Paradella octaphymata & Arthropoda & Native \\
\hline Paradexamine churinga & Arthropoda & Native \\
\hline
\end{tabular}




\begin{tabular}{|c|c|c|}
\hline Paradexamine moorhousei & Arthropoda & Native \\
\hline Paragrapsus gaimardii & Arthropoda & Native \\
\hline Paragrapsus quadridentatus & Arthropoda & Native \\
\hline Parahyotissa imbricata & Mollusca & Native \\
\hline Parahyotissa numisma & Mollusca & Native \\
\hline Paralepidonotus ampulliferus & Annelida & Native \\
\hline Paraleucothoe novaehollandiae & Arthropoda & Native \\
\hline Paranchialina angusta & Arthropoda & Native \\
\hline Parascyphus simplex & Cnidaria & Native \\
\hline Parasmittina cf. cheilodon & Bryozoa & Native \\
\hline Parasmittina cf. delicatula & Bryozoa & Native \\
\hline Paratanais ignotus & Arthropoda & Native \\
\hline Parawaldeckia dilkera & Arthropoda & Native \\
\hline Parawaldeckia yamba & Arthropoda & Native \\
\hline Paridotea ungulata & Arthropoda & Native \\
\hline Parthenope cf. longispinus & Arthropoda & Native \\
\hline Patelloida insignis & Mollusca & Native \\
\hline Patelloida mufria & Mollusca & Native \\
\hline Patiriella brevispina & Chordata & Native \\
\hline Patiriella regularis & Chordata & Non-native \\
\hline Pecten fumatus & Mollusca & Native \\
\hline Pennaria disticha & Cnidaria & Non-native \\
\hline Pennaria wilsoni & Cnidaria & Native \\
\hline Periclimenes andamanensis & Arthropoda & Native \\
\hline Periclimenes cf. andamanensis & Arthropoda & Native \\
\hline Periclimenes cf. elegans & Arthropoda & Native \\
\hline Periclimenes grandis & Arthropoda & Native \\
\hline Periclimenes obscurus & Arthropoda & Native \\
\hline Perinereis amblyodonta & Annelida & Native \\
\hline Perinereis nigropunctata & Annelida & Native \\
\hline Perinereis variodentata & Annelida & Native \\
\hline Perithallia caudata & Ochrophyta & Native \\
\hline Petrolisthes elongatus & Arthropoda & Non-native \\
\hline Petrolisthes militaris & Arthropoda & Native \\
\hline Peyssonnelia capensis & Rhodophyta & Native \\
\hline Peyssonnelia cf. capensis & Rhodophyta & Native \\
\hline Phallusia arabica & Chordata & Native \\
\hline Phallusia barbarica & Chordata & Native \\
\hline Phallusia julinea & Chordata & Native \\
\hline Phallusia obesa & Chordata & Native \\
\hline Phascolosoma annulatum & Sipuncula & Native \\
\hline Phascolosoma stephensoni & Sipuncula & Native \\
\hline Phasianella variegata & Mollusca & Native \\
\hline Phasianotrochus irisodontes & Mollusca & Native \\
\hline
\end{tabular}




\begin{tabular}{|c|c|c|}
\hline Pherusa cf. parmata & Annelida & Native \\
\hline Pherusa parmata & Annelida & Native \\
\hline Phialella quadrata & Cnidaria & Non-native \\
\hline Philippia lutea & Mollusca & Native \\
\hline Phlyctenanthus australis & Cnidaria & Native \\
\hline Phycodrys australasica & Rhodophyta & Native \\
\hline Phyllamphicteis cf. foliata & Annelida & Native \\
\hline Phyllodoce novaehollandiae & Annelida & Native \\
\hline Pileolaria cf. roseopigmentata & Annelida & Native \\
\hline Pilodius miersi & Arthropoda & Native \\
\hline Pilumnopeus cf. serratifrons & Arthropoda & Native \\
\hline Pilumnopeus serratifrons & Arthropoda & Non-native \\
\hline Pilumnus acer & Arthropoda & Native \\
\hline Pilumnus cf. australis & Arthropoda & Native \\
\hline Pilumnus cf. longicornis & Arthropoda & Native \\
\hline Pilumnus cf. minutus & Arthropoda & Non-native \\
\hline Pilumnus cf. rufopunctatus & Arthropoda & Native \\
\hline Pilumnus cf. tomentosus & Arthropoda & Native \\
\hline Pilumnus etheridgei & Arthropoda & Native \\
\hline Pilumnus fissifrons & Arthropoda & Native \\
\hline Pilumnus longicornis & Arthropoda & Native \\
\hline Pilumnus minutus & Arthropoda & Non-native \\
\hline Pilumnus monilifer & Arthropoda & Native \\
\hline Pilumnus semilanatus & Arthropoda & Native \\
\hline Pilumnus terraereginae & Arthropoda & Native \\
\hline Pilumnus tomentosus & Arthropoda & Native \\
\hline Pinctada albina & Mollusca & Native \\
\hline Pinctada cf. sugillata & Mollusca & Native \\
\hline Pinctada maculata & Mollusca & Native \\
\hline Pinctada margaritifera & Mollusca & Native \\
\hline Pinctada sugillata & Mollusca & Native \\
\hline Pinna bicolor & Mollusca & Native \\
\hline Pinnotheres hickmani & Arthropoda & Native \\
\hline Pisidia dispar & Arthropoda & Native \\
\hline Pisidia gordoni & Arthropoda & Native \\
\hline Pista australis & Annelida & Native \\
\hline Pista cf. brevibranchia & Annelida & Native \\
\hline Pista trunca & Annelida & Native \\
\hline Pista typha & Annelida & Native \\
\hline Pistorius bidens & Arthropoda & Native \\
\hline Plagusia chabrus & Arthropoda & Non-native \\
\hline Plagusia glabra & Arthropoda & Native \\
\hline Planopilumnus penicillatus & Arthropoda & Native \\
\hline Planostrea pestigris & Mollusca & Native \\
\hline
\end{tabular}




\begin{tabular}{|c|c|c|}
\hline Platynereis antipoda & Annelida & Native \\
\hline Platynereis polyscalma & Annelida & Native \\
\hline Platysiphonia delicata & Rhodophyta & Non-native \\
\hline Platythalia quercifolia & Ochrophyta & Native \\
\hline Plaxiphora albida & Mollusca & Native \\
\hline Plaxiphora matthewsi & Mollusca & Native \\
\hline Plesiocolochirus ignava & Echinodermata & Native \\
\hline Pleurobranchaea maculata & Mollusca & Native \\
\hline Plocamium angustum & Rhodophyta & Native \\
\hline Plumularia branchiata & Cnidaria & Native \\
\hline Plumularia caliculata & Cnidaria & Native \\
\hline Plumularia cf. setacea & Cnidaria & Non-native \\
\hline Plumularia setacea & Cnidaria & Non-native \\
\hline Plumularia setaceoides & Cnidaria & Native \\
\hline Podarke angustifrons & Annelida & Native \\
\hline Podarkeopsis galangaui & Annelida & Native \\
\hline Polyandrocarpa australiensis & Chordata & Native \\
\hline Polyandrocarpa sagamiensis & Chordata & Non-native \\
\hline Polycarpa aurita & Chordata & Native \\
\hline Polycarpa biforis & Chordata & Native \\
\hline Polycarpa cf. obscura & Chordata & Native \\
\hline Polycarpa cf. olitoria & Chordata & Native \\
\hline Polycarpa cf. pedunculata & Chordata & Native \\
\hline Polycarpa contecta & Chordata & Native \\
\hline Polycarpa nigricans & Chordata & Native \\
\hline Polycarpa obscura & Chordata & Native \\
\hline Polycarpa olitoria & Chordata & Native \\
\hline Polycarpa papillata & Chordata & Native \\
\hline Polycarpa pedunculata & Chordata & Native \\
\hline Polycarpa pigmentata & Chordata & Native \\
\hline Polycarpa stirpes & Chordata & Native \\
\hline Polycarpa viridis & Chordata & Native \\
\hline Polycirrus boholensis & Annelida & Native \\
\hline Polydora cornuta & Annelida & Non-native \\
\hline Polydora hoplura & Annelida & Cryptogenic \\
\hline Polydora protuberata & Annelida & Native \\
\hline Polyonyx cf. obesulus & Arthropoda & Native \\
\hline Polyonyx obesulus & Arthropoda & Native \\
\hline Polyophthalmus cf. pictus & Annelida & Native \\
\hline Polyophthalmus pictus & Annelida & Native \\
\hline Polysiphonia blandii & Rhodophyta & Non-native \\
\hline Polysiphonia brodiei & Rhodophyta & Non-native \\
\hline Polysiphonia cf. infestans & Rhodophyta & Native \\
\hline Polysiphonia cf. subtilissima & Rhodophyta & Native \\
\hline
\end{tabular}




\begin{tabular}{|c|c|c|}
\hline Polysiphonia crassiuscula & Rhodophyta & Native \\
\hline Polysiphonia decipiens & Rhodophyta & Native \\
\hline Polysiphonia ferulacea & Rhodophyta & Native \\
\hline Polysiphonia infestans & Rhodophyta & Cryptogenic \\
\hline Polysiphonia scopulorum & Rhodophyta & Native \\
\hline Polysiphonia senticulosa & Rhodophyta & Non-native \\
\hline Polysiphonia subtilissima & Rhodophyta & Non-native \\
\hline Polysyncraton cf. millepore & Chordata & Native \\
\hline Polysyncraton rugosum & Chordata & Native \\
\hline Pomatoceros taeniata & Annelida & Native \\
\hline Pomatoleios kraussii & Annelida & Native \\
\hline Pomatostegus stellatus & Annelida & Native \\
\hline Poricellaria ratoniensis & Bryozoa & Native \\
\hline Porina tubulifera & Bryozoa & Native \\
\hline Portunus pelagicus & Arthropoda & Native \\
\hline Potamilla cf. laciniosa & Annelida & Native \\
\hline Potamilla laciniosa & Annelida & Native \\
\hline Potamilla neglecta & Annelida & Native \\
\hline Pretostrea rosacea & Mollusca & Native \\
\hline Priolepis nuchifasciata & Chordata & Native \\
\hline Prionospio multipinnulata & Annelida & Native \\
\hline Proceraea filiformis & Annelida & Native \\
\hline Proterato lachryma & Mollusca & Native \\
\hline Protocirrineris chrysoderma & Annelida & Native \\
\hline Protula cf. palliata & Annelida & Native \\
\hline Pseudoamphicteis papillosa & Annelida & Native \\
\hline Pseudobranchiomma cf. orientalis & Annelida & Native \\
\hline Pseudobranchiomma orientalis & Annelida & Native \\
\hline Pseudocerceis furculata & Arthropoda & Native \\
\hline Pseudocerceis trilobata & Arthropoda & Native \\
\hline Pseudoceros reticularis & Platyhelminthes & Native \\
\hline Pseudonereis anomala & Annelida & Native \\
\hline Pseudopolydora cf. kempi & Annelida & Native \\
\hline Pseudopolydora kempi & Annelida & Cryptogenic \\
\hline Pseudopotamilla cf. laciniosa & Annelida & Native \\
\hline Pseudopotamilla laciniosa & Annelida & Native \\
\hline Pseudopotamilla reniformis & Annelida & Native \\
\hline Pseudoproclea australis & Annelida & Native \\
\hline Pteria cf. coturnix & Mollusca & Native \\
\hline Pterocirrus cf. magalhaensis & Annelida & Native \\
\hline Pterocladia rectangularis & Rhodophyta & Native \\
\hline Pterosiphonia pennata & Rhodophyta & Native \\
\hline Pustulostrea cf. tuberculata & Mollusca & Native \\
\hline Pustulostrea tuberculata & Mollusca & Native \\
\hline
\end{tabular}




\begin{tabular}{|c|c|c|}
\hline Pyrene bidentata & Mollusca & Native \\
\hline Pyrene scripta & Mollusca & Native \\
\hline Pyrene testudinaria & Mollusca & Native \\
\hline Pyura australis & Chordata & Native \\
\hline Pyura cf. robusta & Chordata & Native \\
\hline Pyura cf. stolonifera & Chordata & Native \\
\hline Pyura confragosa & Chordata & Native \\
\hline Pyura elongata & Chordata & Native \\
\hline Pyura fissa & Chordata & Native \\
\hline Pyura gibbosa draschii & Chordata & Native \\
\hline Pyura gibbosa & Chordata & Native \\
\hline Pyura irregularis & Chordata & Native \\
\hline Pyura molguloides & Chordata & Native \\
\hline Pyura robusta & Chordata & Native \\
\hline Pyura sacciformis & Chordata & Native \\
\hline Pyura stolonifera & Chordata & Native \\
\hline Pyura tasmanensis & Chordata & Native \\
\hline Redigobius macrostoma & Chordata & Native \\
\hline Reteporella fissa & Bryozoa & Native \\
\hline Reteporella subimmersa "Fossil" & Bryozoa & Native \\
\hline Rhabdozoum wilsoni & Bryozoa & Native \\
\hline Rhinothelepus lobatus & Annelida & Native \\
\hline Rhodoglossum gigartinoides & Rhodophyta & Native \\
\hline Rhodosoma turcicum & Chordata & Native \\
\hline Rhodymenia cf. sonderi & Rhodophyta & Native \\
\hline Rhodymenia leptophylla & Rhodophyta & Native \\
\hline Rhodymenia sonderi & Rhodophyta & Native \\
\hline Rhynchozoon cf. splendens & Bryozoa & Native \\
\hline Ruditapes largillierti & Mollusca & Non-native \\
\hline Sabella cf. spallanzanii & Annelida & Native \\
\hline Sabella spallanzanii & Annelida & Non-native \\
\hline Sabellate australiensis & Annelida & Native \\
\hline Sabellate cf. indica & Annelida & Native \\
\hline Sabellate cf. spectabilis & Annelida & Native \\
\hline Sabellate indica & Annelida & Native \\
\hline Saccostrea cucullata & Mollusca & Native \\
\hline Saccostrea echinata & Mollusca & Native \\
\hline Saccostrea glomerata & Mollusca & Native \\
\hline Salmacina australis & Annelida & Native \\
\hline Salmacis belli & Echinodermata & Native \\
\hline Salmacis cf. belli & Echinodermata & Native \\
\hline Sarsia cf. eximia & Cnidaria & Native \\
\hline Sarsia cf. radiata & Cnidaria & Native \\
\hline Sarsia eximia & Cnidaria & Cryptogenic \\
\hline
\end{tabular}




\begin{tabular}{|c|c|c|}
\hline Sarsia radiata & Cnidaria & Native \\
\hline Sassia subdistorta & Mollusca & Native \\
\hline Savignyella lafontii & Bryozoa & Cryptogenic \\
\hline Scaeochlamys livida & Mollusca & Native \\
\hline Schistomeringos loveni & Annelida & Native \\
\hline Schizophrys aspera & Arthropoda & Native \\
\hline Schizoporella errata & Bryozoa & Non-native \\
\hline Schizoporella unicornis & Bryozoa & Non-native \\
\hline Schottera nicaeensis & Rhodophyta & Non-native \\
\hline Scoloplos cf. novaehollandiae & Annelida & Native \\
\hline Scoloplos cylindrifer & Annelida & Native \\
\hline Scoloplos normalis & Annelida & Native \\
\hline Scoloplos simplex & Annelida & Native \\
\hline Scruparia ambigua & Bryozoa & Non-native \\
\hline Scrupocellaria cf. diadema & Bryozoa & Native \\
\hline Scrupocellaria cf. maderensis & Bryozoa & Native \\
\hline Scrupocellaria cf. spatulata & Bryozoa & Native \\
\hline Scrupocellaria ornithorhynchus & Bryozoa & Native \\
\hline Scyllarides haanii & Arthropoda & Native \\
\hline Septifer bilocularis & Mollusca & Native \\
\hline Septifer cf. bilocularis & Mollusca & Native \\
\hline Serpula cf. jukesii & Annelida & Native \\
\hline Serpula cf. rubens & Annelida & Native \\
\hline Serpula cf. vittata & Annelida & Native \\
\hline Serpula cf. watsoni & Annelida & Native \\
\hline Serpula jukesii & Annelida & Native \\
\hline Serpula rubens & Annelida & Native \\
\hline Sertularella cf. robusta & Cnidaria & Native \\
\hline Sertularella diaphana & Cnidaria & Native \\
\hline Sertularella robusta & Cnidaria & Native \\
\hline Sertularella simplex & Cnidaria & Native \\
\hline Sertularella tricuspidata & Cnidaria & Native \\
\hline Sertularia cf. longa & Cnidaria & Native \\
\hline Sertularia ligulata & Cnidaria & Native \\
\hline Sertularia orthogonalis & Cnidaria & Cryptogenic \\
\hline Sertularia stechowi & Cnidaria & Native \\
\hline Sertularia tenuis & Cnidaria & Native \\
\hline Sidneioides cf. tamaramae & Chordata & Native \\
\hline Sinum cf. zonale & Mollusca & Native \\
\hline Siphonaria diemenensis & Mollusca & Native \\
\hline Siphonaria funiculata & Mollusca & Native \\
\hline Siphonaria zelandica & Mollusca & Native \\
\hline Smittoidea maunganuiensis & Bryozoa & Native \\
\hline Sphacelaria cf. cirrosa & Ochrophyta & Native \\
\hline
\end{tabular}




\begin{tabular}{|c|c|c|}
\hline Sphaeroma quoyanum & Arthropoda & Native \\
\hline Sphaeroma sculpta & Arthropoda & Native \\
\hline Sphaeroma walkeri & Arthropoda & Non-native \\
\hline Spirobranchus cf. polytrema & Annelida & Native \\
\hline Spirobranchus cf. tetraceros & Annelida & Native \\
\hline Spirobranchus coronatus & Annelida & Native \\
\hline Spirobranchus tetraceros & Annelida & Native \\
\hline Spondylus nicobaricus & Mollusca & Native \\
\hline Spondylus violascens & Mollusca & Native \\
\hline Sporochnus comosus & Ochrophyta & Native \\
\hline Spyridia dasyoides & Rhodophyta & Native \\
\hline Spyridia filamentosa & Rhodophyta & Native \\
\hline Stavelia cf. subdistorta & Mollusca & Native \\
\hline Stavelia subdistorta & Mollusca & Native \\
\hline Stelletta cf. clavosa & Porifera & Native \\
\hline Stenothoe cf. marina & Arthropoda & Native \\
\hline Stenothoe miersi & Arthropoda & Native \\
\hline Stenothoe valida & Arthropoda & Cryptogenic \\
\hline Stephanollona orbicularis & Bryozoa & Native \\
\hline Stereotheca elongata & Cnidaria & Native \\
\hline Sthenelais pettiboneae & Annelida & Native \\
\hline Stichopus mollis & Echinodermata & Native \\
\hline Stictosiphonia intricata & Rhodophyta & Native \\
\hline Stimdromia lateralis & Arthropoda & Native \\
\hline Stolonica australis & Chordata & Native \\
\hline Stomatella impertusa & Mollusca & Native \\
\hline Streblosoma acymatum & Annelida & Native \\
\hline Streblosoma cf. atos & Annelida & Native \\
\hline Streblosoma cf. latitudinum & Annelida & Native \\
\hline Streblosoma latitudinum & Annelida & Native \\
\hline Striatobalanus amaryllis & Arthropoda & Native \\
\hline Striatobalanus cf. amaryllis & Arthropoda & Native \\
\hline Striostrea cf. mytiloides & Mollusca & Native \\
\hline Striostrea mytiloides & Mollusca & Native \\
\hline Strombiformis topaziaca & Mollusca & Native \\
\hline Styela canopus & Chordata & Non-native \\
\hline Styela clava & Chordata & Non-native \\
\hline Styela plicata & Chordata & Non-native \\
\hline Stylactis betkensis & Cnidaria & Native \\
\hline Stylomma palmatum & Annelida & Native \\
\hline Stylopallene cheilorhynchus & Arthropoda & Native \\
\hline Subadyte pellucida & Annelida & Native \\
\hline Suberites cupuloides & Porifera & Native \\
\hline Sycozoa brevicauda & Chordata & Native \\
\hline
\end{tabular}




\begin{tabular}{|c|c|c|}
\hline Sycozoa cerebriformis & Chordata & Native \\
\hline Syllidia armata & Annelida & Native \\
\hline Syllis australiensis & Annelida & Native \\
\hline Syllis gracilis australiensis & Annelida & Native \\
\hline Syllis gracilis & Annelida & Non-native \\
\hline Symplectoscyphus indivisus & Cnidaria & Native \\
\hline Synalpheus cf. bituberculatus & Arthropoda & Native \\
\hline Synalpheus cf. neptunus & Arthropoda & Native \\
\hline Synalpheus cf. streptodactylus & Arthropoda & Native \\
\hline Synalpheus cf. tumidomanus & Arthropoda & Native \\
\hline Synalpheus hastilicrassus & Arthropoda & Native \\
\hline Synalpheus neomeris & Arthropoda & Native \\
\hline Synalpheus neptunus & Arthropoda & Native \\
\hline Synalpheus streptodactylus & Arthropoda & Native \\
\hline Synalpheus tumidomanus & Arthropoda & Native \\
\hline Synnotum aegyptiacum & Bryozoa & Native \\
\hline Synnotum cf. aegyptiacum & Bryozoa & Native \\
\hline Synnotum cf. pembaense & Bryozoa & Native \\
\hline SypharoMollusca pellisserpentis & Mollusca & Native \\
\hline Tanais cf. dulongi & Arthropoda & Native \\
\hline Tellina albinella & Mollusca & Native \\
\hline Tellina botanica & Mollusca & Native \\
\hline Tellina cf. tenuilamellata & Mollusca & Native \\
\hline Tellina parvitas & Mollusca & Native \\
\hline Temnopleurus michaelseni & Echinodermata & Native \\
\hline Terebella cf. ehrenbergi & Annelida & Native \\
\hline Terebella tantabiddycreekensis & Annelida & Native \\
\hline Tesseropora cf. wireni & Arthropoda & Non-native \\
\hline Tesseropora rosea & Arthropoda & Native \\
\hline Tethya communis & Porifera & Native \\
\hline Tetraclita coerulescens & Arthropoda & Native \\
\hline Tetraclita squamosa & Arthropoda & Native \\
\hline Tetraclitella purpurascens & Arthropoda & Native \\
\hline Thais echinata & Mollusca & Native \\
\hline Thais orbita & Mollusca & Native \\
\hline Thalamita cf. spinimana & Arthropoda & Native \\
\hline Thalamita danae & Arthropoda & Native \\
\hline Thalamoporella gothica & Bryozoa & Non-native \\
\hline Thamnoclonium dichotomum & Rhodophyta & Native \\
\hline Thelepus alatus & Annelida & Native \\
\hline Thelepus australiensis & Annelida & Native \\
\hline Thelepus cf. alatus & Annelida & Native \\
\hline Thelepus cf. boja & Annelida & Native \\
\hline Thelepus cf. extensus & Annelida & Native \\
\hline
\end{tabular}




\begin{tabular}{|c|c|c|}
\hline Thelepus extensus & Annelida & Native \\
\hline Thelepus robustus & Annelida & Native \\
\hline Themiste cf. fusca & Sipuncula & Native \\
\hline Theora cf. lubrica I_Mollusca & Mollusca & Non-native \\
\hline Theora lubrica I_Mollusca & Mollusca & Non-native \\
\hline Thor amboinensis & Arthropoda & Native \\
\hline Thor paschalis & Arthropoda & Native \\
\hline Thormora argus & Annelida & Native \\
\hline Thormora jukesii & Annelida & Native \\
\hline Thusaenys irami & Arthropoda & Native \\
\hline Timoclea cardioides & Mollusca & Native \\
\hline Tosia australis & Chordata & Native \\
\hline Trachinops caudimaculatus & Chordata & Native \\
\hline Tricellaria aculeata & Bryozoa & Native \\
\hline Tricellaria cf. inopinata & Bryozoa & Non-native \\
\hline Tricellaria inopinata & Bryozoa & Cryptogenic \\
\hline Tricellaria occidentalis & Bryozoa & Non-native \\
\hline Tricellaria porteri & Bryozoa & Cryptogenic \\
\hline Trichomusculus barbatus & Mollusca & Native \\
\hline Trichomusculus cf. barbatus & Mollusca & Native \\
\hline Trichomya hirsutus & Mollusca & Native \\
\hline Tricolia tomlini & Mollusca & Native \\
\hline Tridentiger trigonocephalus & Chordata & Non-native \\
\hline Trinorfolkia clarkei $N \_$bony Chordata & Chordata & Native \\
\hline Triphyllozoon cf. moniliferum & Bryozoa & Native \\
\hline Triphyllozoon moniliferum & Bryozoa & Native \\
\hline Triphyllozoon munitum & Bryozoa & Native \\
\hline Trypanosyllis gigantea & Annelida & Native \\
\hline Trypanosyllis taeniformis & Annelida & Native \\
\hline Trypostega venusta & Bryozoa & Native \\
\hline Tubastrea coccinea & Stony Cnidaria & Native \\
\hline Tubastrea diaphana & Stony Cnidaria & Native \\
\hline Tubastrea micranthus & Stony Cnidaria & Native \\
\hline Tubularia cf. crocea & Cnidaria & Non-native \\
\hline Tubularia crocea & Cnidaria & Non-native \\
\hline Tubulipora cf. maragitacea "Fossil" & Bryozoa & Native \\
\hline Tugali cicatricosa & Mollusca & Native \\
\hline Tugali parmophoidea & Mollusca & Native \\
\hline Turritopsis cf. nutricula & Cnidaria & Native \\
\hline Turritopsis nutricula & Cnidaria & Non-native \\
\hline Typosyllis armillaris & Annelida & Native \\
\hline Typosyllis cervantensis & Annelida & Native \\
\hline Typosyllis cf. armillaris & Annelida & Native \\
\hline Typosyllis cf. cervantensis & Annelida & Native \\
\hline
\end{tabular}




\begin{tabular}{|c|c|c|}
\hline Typosyllis cf. crassicirrata & Annelida & Native \\
\hline Typosyllis cf. gerhardi & Annelida & Native \\
\hline Typosyllis hyalina & Annelida & Native \\
\hline Typosyllis lutea & Annelida & Native \\
\hline Typosyllis pseudopapillata & Annelida & Native \\
\hline Typosyllis raygeorgei & Annelida & Native \\
\hline Ulva australis & Chlorophyta & Native \\
\hline Ulva lactuca & Chlorophyta & Cryptogenic \\
\hline Ulva laetevirens & Chlorophyta & Native \\
\hline Ulva rigida & Chlorophyta & Cryptogenic \\
\hline Ulva stenophylla & Chlorophyta & Non-native \\
\hline Undaria pinnatifida & Ochrophyta & Non-native \\
\hline Uniophora dyscrita & Chordata & Native \\
\hline Uniophora granifera & Chordata & Native \\
\hline Venerupis anomala & Mollusca & Native \\
\hline Venerupis cf. anomala & Mollusca & Native \\
\hline Venerupis galactites & Mollusca & Native \\
\hline Venerupis iridescens & Mollusca & Native \\
\hline Vermiliopsis cf. infundibilum & Annelida & Native \\
\hline Vulsella spongiarum & Mollusca & Native \\
\hline Vulsella vulsella & Mollusca & Native \\
\hline Wallucina assimilis & Mollusca & Native \\
\hline Watersipora arcuata & Bryozoa & Non-native \\
\hline Watersipora subtorquata & Bryozoa & Non-native \\
\hline Xenostrobus cf. inconstans & Mollusca & Native \\
\hline Xenostrobus cf. pulex & Mollusca & Native \\
\hline Xenostrobus inconstans & Mollusca & Native \\
\hline Xenostrobus pulex & Mollusca & Native \\
\hline Xenostrobus securis & Mollusca & Native \\
\hline Yoldia lata & Mollusca & Native \\
\hline Zonaria crenata & Ochrophyta & Native \\
\hline Zonaria turneriana & Ochrophyta & Native \\
\hline Zoobotryon verticillatum & Bryozoa & Non-native \\
\hline Zuzara venosa & Arthropoda & Native \\
\hline Zygometra cf. microdiscus & Echinodermata & Native \\
\hline
\end{tabular}


Table A3. Species identified in the 15 port surveys around New Zealand and species status native, non-native and cryptogenic species.

\begin{tabular}{|c|c|c|}
\hline Species & Phyla & Species status \\
\hline Acanthochitona violacea & Mollusca & Native \\
\hline Acanthochitona zelandica & Mollusca & Native \\
\hline Acanthoclinus fuscus & Chordata & Native \\
\hline Acanthoclinus littoreus & Chordata & Native \\
\hline Achelia assimilis & Arthropoda & Native \\
\hline Acontiostoma tuberculata & Arthropoda & Native \\
\hline Acraspedanthus elongatus & Echinodermata & Native \\
\hline Acrocirrus trisectus & Annelida & Native \\
\hline Acrosorium decumbens & Rhodophyta & Native \\
\hline Adamsiella chauvinii & Rhodophyta & Native \\
\hline Adocia cf.parietalioides & Porifera & Native \\
\hline Adocia cf.venustina & Porifera & Native \\
\hline Aetea australis & Bryozoa & Cryptogenic \\
\hline Aetea truncata & Bryozoa & Native \\
\hline Aiptasiomorpha minima & Echinodermata & Native \\
\hline Alloiodoris lanuginata & Mollusca & Native \\
\hline Allostichaster insignis & Chordata & Native \\
\hline Allostichaster polyplax & Chordata & Native \\
\hline Alpheus novaezealandiae & Arthropoda & Native \\
\hline Alpheus socialis & Arthropoda & Native \\
\hline Amaryllis macrophthalma & Arthropoda & Native \\
\hline Amphilochus filidactylus & Arthropoda & Native \\
\hline Amphipholis squamata & Echinodermata & Native \\
\hline Amphisbetia bispinosa & Hydroid & Native \\
\hline Amphisbetia fasciculata & Hydroid & Native \\
\hline Amphisbetia minima & Hydroid & Native \\
\hline Anguinella palmata & Bryozoa & Non-native \\
\hline Anisoiphimedia haurakiensis & Arthropoda & Native \\
\hline Anotrichium crinitum & Rhodophyta & Native \\
\hline Antithamnion applicitum & Rhodophyta & Native \\
\hline Antithamnion pectinatum & Rhodophyta & Native \\
\hline Antithamnionella adnata & Rhodophyta & Native \\
\hline Aora maculata & Arthropoda & Native \\
\hline Aora typica & Arthropoda & Native \\
\hline Aplidium adamsi & Chordata & Native \\
\hline Aplidium benhami & Chordata & Native \\
\hline Aplidium knoxi & Chordata & Native \\
\hline Aplidium phortax & Chordata & Cryptogenic \\
\hline Apocorophium acutum & Arthropoda & Non-native \\
\hline Apoglossum montagneanum & Rhodophyta & Native \\
\hline
\end{tabular}




\begin{tabular}{|c|c|c|}
\hline Apoglossum oppositifolium & Rhodophyta & Native \\
\hline Archidoris nanula & Mollusca & Native \\
\hline Archidoris wellingtonensis & Mollusca & Native \\
\hline Armandia maculata & Annelida & Native \\
\hline Ascidiella aspersa & Chordata & Non-native \\
\hline Asteracmea suteri & Mollusca & Native \\
\hline Asterocarpa cerea & Chordata & Cryptogenic \\
\hline Asterocarpa coerulea & Chordata & Native \\
\hline Aulacomya atra maoriana & Mollusca & Native \\
\hline Austrolittorina antipodum & Mollusca & Native \\
\hline Austrominius modestus & Arthropoda & Native \\
\hline Balanus trigonus & Arthropoda & Cryptogenic \\
\hline Beania discodermiae & Bryozoa & Native \\
\hline Beania magellanica & Bryozoa & Native \\
\hline Beania plurispinosa & Bryozoa & Native \\
\hline Betaeopsis aequimanus & Arthropoda & Native \\
\hline Bicellariella ciliata & Bryozoa & Native \\
\hline Biemna rhabderemioides & Porifera & Native \\
\hline Bitectipora mucronifera & Bryozoa & Native \\
\hline Bitectipora rostrata & Bryozoa & Native \\
\hline Boccardia acus & Annelida & Native \\
\hline Boccardia chilensis & Annelida & Native \\
\hline Boccardia knoxi & Annelida & Native \\
\hline Boccardia lamellata & Annelida & Native \\
\hline Boccardia otakouica & Annelida & Native \\
\hline Boccardia syrtis & Annelida & Native \\
\hline Borniola reniformis & Mollusca & Native \\
\hline Bostrychia harveyi & Rhodophyta & Native \\
\hline Bostrychia moritziana & Rhodophyta & Native \\
\hline Bostrychia tenuissima & Rhodophyta & Native \\
\hline Botrylliodes leachii & Chordata & Cryptogenic \\
\hline Botryllus stewartensis & Chordata & Native \\
\hline Bougainvillia muscus & Hydroid & Cryptogenic \\
\hline Branchiomma curta & Annelida & Native \\
\hline Brongniartella australis & Rhodophyta & Native \\
\hline Bryopsis vestita & Chlorophyta & Native \\
\hline Buccinulum linea & Mollusca & Native \\
\hline Buccinulum vittatum & Mollusca & Native \\
\hline Bugula dentata & Bryozoa & Native \\
\hline Bugula flabellata & Bryozoa & Non-native \\
\hline Bugula neritina & Bryozoa & Non-native \\
\hline Bugula stolonifera & Bryozoa & Non-native \\
\hline Caberea rostrata & Bryozoa & Native \\
\hline Caberea zelandica & Bryozoa & Native \\
\hline
\end{tabular}




\begin{tabular}{|c|c|c|}
\hline Cabestana spengleri & Mollusca & Native \\
\hline Cadlina willani & Mollusca & Native \\
\hline Calliostoma tigris & Mollusca & Native \\
\hline Callipallene novaezealandiae & Arthropoda & Native \\
\hline Callophyllis calliblepharoides & Rhodophyta & Native \\
\hline Callophyllis variegata & Rhodophyta & Native \\
\hline Callyspongia cf. bathami & Porifera & Native \\
\hline Callyspongia cf.irregularis & Porifera & Native \\
\hline Callyspongia diffusa & Porifera & Cryptogenic \\
\hline Callyspongia ramosa & Porifera & Cryptogenic \\
\hline Callyspongia stellata & Porifera & Native \\
\hline Caloglossa leprieurii & Rhodophyta & Native \\
\hline Cancer amphioetus & Arthropoda & Non-native \\
\hline Cancer gibbosulus & Arthropoda & Non-native \\
\hline Cancer novaezelandiae & Arthropoda & Native \\
\hline Caprella equilibra & Arthropoda & Native \\
\hline Caprella mutica & Arthropoda & Non-native \\
\hline Caprellina longicollis & Arthropoda & Native \\
\hline Capreolia implexa & Rhodophyta & Native \\
\hline Carazziella quadricirrata & Annelida & Native \\
\hline Carpophyllum flexuosum & Ochrophyta & Native \\
\hline Caulerpa brownii & Chlorophyta & Native \\
\hline Cellana ornata & Mollusca & Native \\
\hline Cellaria tenuirostris & Bryozoa & Native \\
\hline Celleporaria nodulosa & Bryozoa & Non-native \\
\hline Celleporella delta & Bryozoa & Native \\
\hline Celleporella tongima & Bryozoa & Native \\
\hline Celleporina proximalis & Bryozoa & Native \\
\hline Ceradocopsis carnleyi & Arthropoda & Native \\
\hline Ceramium aff. Apiculatum & Rhodophyta & Native \\
\hline Ceramium apiculatum & Rhodophyta & Native \\
\hline Ceramium flaccidum & Rhodophyta & Native \\
\hline Ceramium rubrum & Rhodophyta & Native \\
\hline Ceramium vestitum & Rhodophyta & Native \\
\hline Chaemosipho columna & Arthropoda & Native \\
\hline Chaperia granulosa & Bryozoa & Native \\
\hline Chaperiopsis cervicornis & Bryozoa & Native \\
\hline Chelonaplysilla cf.violacea & Porifera & Cryptogenic \\
\hline Chiastosella watersi & Bryozoa & Native \\
\hline Chondracanthus chapmanii & Rhodophyta & Native \\
\hline Chondropsis topsentii & Porifera & Non-native \\
\hline Chromodoris aureomarginata & Mollusca & Native \\
\hline Cilicaea canaliculata & Arthropoda & Native \\
\hline Ciona intestinalis & Chordata & Non-native \\
\hline
\end{tabular}




\begin{tabular}{|c|c|c|}
\hline Cirolana kokoru & Arthropoda & Native \\
\hline Cirolana quechso & Arthropoda & Native \\
\hline Cladophora feredayi & Chlorophyta & Native \\
\hline Cladophoropsis herpestica & Chlorophyta & Native \\
\hline Cladostephus spongiosus & Ochrophyta & Native \\
\hline Clathria (Isociella) cf. incrustans & Porifera & Native \\
\hline Clathria (Microciona) dendyi & Porifera & Native \\
\hline Clathria (Microciona) coccinea & Porifera & Native \\
\hline Clathria cf.lissosclera & Porifera & Native \\
\hline Clathria cf.terraenovae & Porifera & Native \\
\hline Clavisyllis alternata & Annelida & Native \\
\hline Cleantis tubicola & Arthropoda & Native \\
\hline Cliona celata & Porifera & Non-native \\
\hline Clytia elongata & Hydroid & Native \\
\hline Clytia hemisphaerica & Hydroid & Cryptogenic \\
\hline Cnemidocarpa bicornuta & Chordata & Native \\
\hline Cnemidocarpa nisiotus & Chordata & Native \\
\hline Cnemidocarpa otagoensis & Chordata & Native \\
\hline Cnemidocarpa regalis & Chordata & Native \\
\hline Colomastix magnirama & Arthropoda & Native \\
\hline Colomastix subcastellata & Arthropoda & Native \\
\hline Cominella glandiformis & Mollusca & Native \\
\hline Cominella quoyana & Mollusca & Native \\
\hline Conopeum seurati & Bryozoa & Non-native \\
\hline Cookia sulcata & Mollusca & Native \\
\hline Coralline (Melobesia) & Rhodophyta & Cryptogenic \\
\hline Corella eumyota & Chordata & Cryptogenic \\
\hline Corynactis australis & Echinodermata & Cryptogenic \\
\hline Coscinasterias muricata & Chordata & Native \\
\hline Crassicorophium bonnellii & Arthropoda & Non-native \\
\hline Crassimarginatella fossa & Bryozoa & Native \\
\hline Crassostrea gigas & Mollusca & Non-native \\
\hline Crella (Pytheas) incrustans & Porifera & Cryptogenic \\
\hline Crella (Pytheas)affinis & Porifera & Native \\
\hline Crepidacantha crinispina & Bryozoa & Native \\
\hline Crisia tenuis & Bryozoa & Native \\
\hline Cryptogenicconchus porosus & Mollusca & Native \\
\hline Cryptogenicsula pallasiana & Bryozoa & Non-native \\
\hline Cutleria multifida & Ochrophyta & Non-native \\
\hline Cyclicopora longipora & Bryozoa & Non-native \\
\hline Dasya collabens & Rhodophyta & Native \\
\hline Dasya subtilis & Rhodophyta & Native \\
\hline Delesserian epiphytes & Rhodophyta & Native \\
\hline Dellichthys morelandi & Chordata & Native \\
\hline
\end{tabular}




\begin{tabular}{|c|c|c|}
\hline Demonax aberrans & Annelida & Native \\
\hline Dendrodoris citrina & Mollusca & Native \\
\hline Desmacella ambigua & Porifera & Native \\
\hline Desmarestia ligulata & Ochrophyta & Native \\
\hline Diadumene neozelandica & Echinodermata & Native \\
\hline Dicithais orbita & Mollusca & Native \\
\hline Dictyociona cf.atoxa C2_Porifera & Porifera & Cryptogenic \\
\hline Dictyodendrilla dendyi & Porifera & Native \\
\hline Dictyota dichotoma & Ochrophyta & Native \\
\hline Didemnum incanum & Chordata & Cryptogenic \\
\hline Didemnum vexillum & Chordata & Cryptogenic \\
\hline Diplosoma listerianum & Chordata & Cryptogenic \\
\hline Dipolydora armata & Annelida & Non-native \\
\hline Dipolydora flava & Annelida & Non-native \\
\hline Dodecaceria berkeleyi & Annelida & Native \\
\hline Dorvillea australiensis & Annelida & Native \\
\hline Dromia wilsoni & Arthropoda & Cryptogenic \\
\hline Ecklonia radiata & Ochrophyta & Native \\
\hline Electra tenella & Bryozoa & Non-native \\
\hline Endarachne binghamiae & Ochrophyta & Native \\
\hline Epopella plicata & Arthropoda & Native \\
\hline Ericthonius pugnax & Arthropoda & Non-native \\
\hline Erythroglossum undulatissimum & Rhodophyta & Native \\
\hline Escharoides angela & Bryozoa & Native \\
\hline Escharoides excavata & Bryozoa & Native \\
\hline Eudendrium capillare & Hydroid & Non-native \\
\hline Eudendrium generale & Hydroid & Non-native \\
\hline Eulalia bilineata & Annelida & Cryptogenic \\
\hline Eulalia capensis & Annelida & Native \\
\hline Eulalia microphylla & Annelida & Native \\
\hline Eunice australis & Annelida & Native \\
\hline Euplacella communis & Porifera & Cryptogenic \\
\hline Euryspongia cf. arenaria & Porifera & Native \\
\hline Eurystomella foraminigera & Bryozoa & Native \\
\hline Eusiroides monoculoides & Arthropoda & Native \\
\hline Ficopomatus enigmaticus & Annelida & Non-native \\
\hline Filellum serpens & Hydroid & Non-native \\
\hline Filograna implexa & Annelida & Native \\
\hline Flabelligera affinis & Annelida & Native \\
\hline Forsterygion lapillum & Chordata & Native \\
\hline Galeolaria hystrix & Annelida & Native \\
\hline Galeopsis porcellanicus & Bryozoa & Native \\
\hline Gammaropsis chiltoni & Arthropoda & Native \\
\hline Gammaropsis dentifera & Arthropoda & Native \\
\hline
\end{tabular}




\begin{tabular}{|c|c|c|}
\hline Gammaropsis haswelli & Arthropoda & Native \\
\hline Gammaropsis longimana & Arthropoda & Native \\
\hline Gammaropsis typica & Arthropoda & Native \\
\hline Gigartina atropurpurea & Rhodophyta & Native \\
\hline Gloiocladia saccata & Rhodophyta & Native \\
\hline Glossophora kunthii & Ochrophyta & Native \\
\hline Glycera benhami & Annelida & Native \\
\hline Gondogeneia danai & Arthropoda & Native \\
\hline Gracilaria truncata & Rhodophyta & Native \\
\hline Grahamina capito & Chordata & Native \\
\hline Grahamina gymnota & Chordata & Native \\
\hline Grantessa intusarticulata & Porifera & Non-native \\
\hline Griffithsia antarctica & Rhodophyta & Native \\
\hline Griffithsia crassiuscula & Rhodophyta & Non-native \\
\hline Griffithsia teges & Rhodophyta & Cryptogenic \\
\hline Halecium corrrugatissimum & Hydroid & Native \\
\hline Halecium sessile & Hydroid & Cryptogenic \\
\hline Halicarcinus cookii & Arthropoda & Native \\
\hline Halicarcinus innominatus & Arthropoda & Native \\
\hline Halicarcinus tongi & Arthropoda & Native \\
\hline Halicarcinus varius & Arthropoda & Native \\
\hline Halicarcinus whitei & Arthropoda & Native \\
\hline Halichondria panicea & Porifera & Cryptogenic \\
\hline Haliclona cf.isodictyale & Porifera & Native \\
\hline Haliclona cf.punctata & Porifera & Native \\
\hline Haliclona cf.tenacior & Porifera & Native \\
\hline Haliclona glabra & Porifera & Native \\
\hline Haliclona heterofibrosa & Porifera & Cryptogenic \\
\hline Haliclona maxima & Porifera & Native \\
\hline Haliclona stelliderma & Porifera & Native \\
\hline Halimena aoteoroa & Arthropoda & Native \\
\hline Haliplanella lineata & Echinodermata & Non-native \\
\hline Halisarca dujardini & Porifera & Non-native \\
\hline Haplocheira barbimana & Arthropoda & Native \\
\hline Haplosyllis spongicola & Annelida & Native \\
\hline Harmothoe macrolepidota & Annelida & Native \\
\hline Hebellopsis scandens & Hydroid & Native \\
\hline Helice crassa & Arthropoda & Native \\
\hline Heterosiphonia concinna & Rhodophyta & Native \\
\hline Heterosiphonia squarrosa & Rhodophyta & Native \\
\hline Hiatella arctica & Mollusca & Native \\
\hline Hincksia mitchelliae & Ochrophyta & Native \\
\hline Hippolyte bifidirostris & Arthropoda & Native \\
\hline Hippolyte multicolorata & Arthropoda & Native \\
\hline
\end{tabular}




\begin{tabular}{|c|c|c|}
\hline Homaxinella erecta & Porifera & Native \\
\hline Hyale rubra & Arthropoda & Native \\
\hline Hyboscolex longiseta & Annelida & Native \\
\hline Hydroides elegans & Annelida & Non-native \\
\hline Hydroides ezoensis & Annelida & Non-native \\
\hline Hymenena curdieana & Rhodophyta & Cryptogenic \\
\hline Hymenena variolosa & Rhodophyta & Native \\
\hline Hymeniacidon perleve & Porifera & Cryptogenic \\
\hline Hymenosoma depressum & Arthropoda & Native \\
\hline Hypsistozoa fasmeriana & Chordata & Native \\
\hline Iophon proximum & Porifera & Cryptogenic \\
\hline Ircinia akaroa & Porifera & Native \\
\hline Irus reflexus & Mollusca & Native \\
\hline Ischyrocerus longimanus & Arthropoda & Native \\
\hline Ischyromene cordiforaminalis & Arthropoda & Native \\
\hline Jassa marmorata & Arthropoda & Non-native \\
\hline Jassa slatteryi & Arthropoda & Non-native \\
\hline Jassa staudei & Arthropoda & Non-native \\
\hline Jasus edwardsi & Arthropoda & Native \\
\hline Joeropsis neozelandica & Arthropoda & Cryptogenic \\
\hline Kellia cycladiformis & Mollusca & Native \\
\hline Lafoeina amirantensis & Hydroid & Non-native \\
\hline Lamellaria cerebroides & Mollusca & Native \\
\hline Lamellaria ophione & Mollusca & Native \\
\hline Lasaea hinemoa & Mollusca & Native \\
\hline Lepidastheniella comma & Annelida & Native \\
\hline Lepidonotus banksi & Annelida & Native \\
\hline Lepidonotus fiordlandica & Annelida & Native \\
\hline Lepidonotus jacksoni & Annelida & Native \\
\hline Lepidonotus polychromus & Annelida & Native \\
\hline Leptograpsus variegatus & Arthropoda & Native \\
\hline Leptomya retiaria & Mollusca & Native \\
\hline Leuconopsis obsoleta & Mollusca & Native \\
\hline Leucosolenia cf. discoveryi & Porifera & Non-native \\
\hline Leucothoe trailli & Arthropoda & Native \\
\hline Liljeborgia akaroica & Arthropoda & Native \\
\hline Liljeborgia barhami & Arthropoda & Native \\
\hline Liljeborgia hansoni & Arthropoda & Native \\
\hline Limaria orientalis & Mollusca & Non-native \\
\hline Lissoclinum notti & Chordata & Native \\
\hline Lissodendoryx isodictyalis & Porifera & Cryptogenic \\
\hline Lomentaria umbellata & Rhodophyta & Native \\
\hline Lophopagurus (L.)thompsoni & Arthropoda & Native \\
\hline Lophopagurus (Lophopagurus)pumilus & Arthropoda & Native \\
\hline
\end{tabular}




\begin{tabular}{|c|c|c|}
\hline Lophothamnion hirtum & Rhodophyta & Native \\
\hline Lumbricalus aotearoae & Annelida & Native \\
\hline Lumbrineris sphaerocephala & Annelida & Native \\
\hline Lysidice ninetta & Annelida & Native \\
\hline Macroclymenella stewartensis & Annelida & Native \\
\hline Mallacoota subcarinata & Arthropoda & Native \\
\hline Maoricrypta costata & Mollusca & Native \\
\hline Marphysa capensis & Annelida & Native \\
\hline Marphysa unibranchiata & Annelida & Native \\
\hline Megabalanus tintinnabulum linzei & Arthropoda & Native \\
\hline Megalomma kaikourense & Annelida & Native \\
\hline Megalomma suspiciens & Annelida & Native \\
\hline Melita festiva & Arthropoda & Native \\
\hline Melita inaequistylis & Arthropoda & Native \\
\hline Meridiastra mortenseni & Chordata & Native \\
\hline Mesanthura affinis & Arthropoda & Native \\
\hline Micrelenchus tenebrosus & Mollusca & Native \\
\hline Microcladia novae-zelandiae & Rhodophyta & Native \\
\hline Microcosmus australis & Chordata & Native \\
\hline Microcosmus hirsutus & Chordata & Native \\
\hline Microcosmus squamiger & Chordata & Cryptogenic \\
\hline Microporella agonistes & Bryozoa & Native \\
\hline Microporella speculum & Bryozoa & Native \\
\hline Microzonia velutina & Ochrophyta & Native \\
\hline Modiolarca impacta & Mollusca & Native \\
\hline Modiolus areolatus & Mollusca & Native \\
\hline Molgula amokurae & Chordata & Native \\
\hline Molgula mortenseni & Chordata & Native \\
\hline Monocorophium acherusicum & Arthropoda & Non-native \\
\hline Monocorophium sextonae & Arthropoda & Non-native \\
\hline Monocorophium sp. aff. M. insidiosum & Arthropoda & Cryptogenic \\
\hline Monotheca flexuosa & Hydroid & Native \\
\hline Musculista senhousia & Mollusca & Non-native \\
\hline Mycale (Carmia) hentscheli & Porifera & Native \\
\hline Mycale (Carmia) tasmani & Porifera & Native \\
\hline Myriogramme denticulata & Rhodophyta & Native \\
\hline Myrionema strangulans & Ochrophyta & Native \\
\hline Mytilus galloprovincialis & Mollusca & Cryptogenic \\
\hline Natatolana rossi & Arthropoda & Native \\
\hline Nauticaris marionis & Arthropoda & Native \\
\hline Neanthes cricognatha & Annelida & Native \\
\hline Neanthes kerguelensis & Annelida & Native \\
\hline Neastacilla aff. Tuberculata & Arthropoda & Native \\
\hline Neohymenicus pubescens & Arthropoda & Native \\
\hline
\end{tabular}




\begin{tabular}{|c|c|c|}
\hline Neoleprea papilla & Annelida & Native \\
\hline Neosabellaria kaiparaensis & Annelida & Native \\
\hline Neovermilia sphaeropomatus & Annelida & Native \\
\hline Nereiphylla castanea & Annelida & Native \\
\hline Nereis falcaria & Annelida & Native \\
\hline Nicolea armilla & Annelida & Native \\
\hline Nicolea maxima & Annelida & Native \\
\hline Notoacmea helmsi & Mollusca & Native \\
\hline Notoacmea parviconoidea & Mollusca & Native \\
\hline Notobalanus vestitus & Arthropoda & Native \\
\hline Notomegabalanus decorus & Arthropoda & Native \\
\hline Notomithrax minor & Arthropoda & Native \\
\hline Notomithrax peronii & Arthropoda & Native \\
\hline Notomithrax ursus & Arthropoda & Native \\
\hline Obelia bidentata & Hydroid & Cryptogenic \\
\hline Obelia dichotoma & Hydroid & Cryptogenic \\
\hline Obelia geniculata & Hydroid & Native \\
\hline Obelia longissima & Hydroid & Non-native \\
\hline Onchidella nigricans & Mollusca & Native \\
\hline Onithochiton neglectus & Mollusca & Native \\
\hline Opercularella humilis & Hydroid & Native \\
\hline Ophiactis resiliens & Echinodermata & Native \\
\hline Ophiocentrus novaezealandiae & Echinodermata & Native \\
\hline Ophiodromus angustifrons & Annelida & Native \\
\hline Ophionereis fasciata & Echinodermata & Native \\
\hline Ophlitospongia reticulata & Porifera & Native \\
\hline Orchomene aahu & Arthropoda & Native \\
\hline Orchomene sp. Aff. O. aahu & Arthropoda & Cryptogenic \\
\hline Ostrea aupouria & Mollusca & Native \\
\hline Ostrea chilensis & Mollusca & Native \\
\hline Paguristes setosus & Arthropoda & Native \\
\hline Pagurus novizealandiae & Arthropoda & Native \\
\hline Pagurus traversi & Arthropoda & Native \\
\hline Palaemon affinis & Arthropoda & Native \\
\hline Pallenopsis obliqua & Arthropoda & Native \\
\hline Paradexamine pacifica & Arthropoda & Native \\
\hline Paraidanthyrsus quadricornis & Annelida & Native \\
\hline Paranthura cf. flagellata & Arthropoda & Native \\
\hline Parascyphus simplex & Hydroid & Native \\
\hline Parawaldeckia angusta & Arthropoda & Native \\
\hline Parawaldeckia sp. aff. Angusta & Arthropoda & Cryptogenic \\
\hline Parawaldeckia sp. aff. P. karaka & Arthropoda & Cryptogenic \\
\hline Parawaldeckia sp. aff. P. stephenseni & Arthropoda & Cryptogenic \\
\hline Parawaldeckia stephenseni & Arthropoda & Native \\
\hline
\end{tabular}




\begin{tabular}{|c|c|c|}
\hline Parawaldeckia vesca & Arthropoda & Native \\
\hline Parorchestia tenuis & Arthropoda & Native \\
\hline Patelloida corticata & Mollusca & Native \\
\hline Patiriella mortenseni & Chordata & Native \\
\hline Patiriella oliveri & Chordata & Cryptogenic \\
\hline Patiriella regularis & Chordata & Native \\
\hline Pectinaria australis & Annelida & Native \\
\hline Peltopes peninsulae & Arthropoda & Native \\
\hline Pennaria disticha & Hydroid & Non-native \\
\hline Pentagonaster pulchellus & Chordata & Native \\
\hline Periclimenes yaldwyni & Arthropoda & Native \\
\hline Perinereis amblyodonta & Annelida & Native \\
\hline Perinereis camiguinoides & Annelida & Native \\
\hline Perinereis pseudocamiguina & Annelida & Native \\
\hline Perinereis vallata & Annelida & Native \\
\hline Perna canaliculus & Mollusca & Native \\
\hline Petrocheles spinosus & Arthropoda & Native \\
\hline Petrolisthes elongatus & Arthropoda & Native \\
\hline Petrolisthes novaezelandiae & Arthropoda & Native \\
\hline Pherusa parmata & Annelida & Native \\
\hline Phialella quadrata & Hydroid & Cryptogenic \\
\hline Phorbas cf.anchorata & Porifera & Native \\
\hline Phorbas fulva & Porifera & Native \\
\hline Phycodrys quercifolia & Rhodophyta & Native \\
\hline Pilumnopeus serratifrons & Arthropoda & Cryptogenic \\
\hline Pilumnus lumpinus & Arthropoda & Native \\
\hline Pilumnus novaezealandiae & Arthropoda & Native \\
\hline Pinnotheres atrinocola & Arthropoda & Native \\
\hline Pinnotheres novaezelandiae & Arthropoda & Native \\
\hline Pista pegma & Annelida & Native \\
\hline Plagusia chabrus & Arthropoda & Cryptogenic \\
\hline Plakina monolopha & Porifera & Cryptogenic \\
\hline Plakina trilopha & Porifera & Cryptogenic \\
\hline Plaxiphora caelata & Mollusca & Native \\
\hline Plaxiphora obtecta & Mollusca & Native \\
\hline Pleurobranchaea maculata & Mollusca & Native \\
\hline Plocamia novizelanicum & Porifera & Native \\
\hline Plocamium angustum & Rhodophyta & Native \\
\hline Plocamium cartilagineum & Rhodophyta & Native \\
\hline Plocamium cirrhosum & Rhodophyta & Native \\
\hline Plocamium leptophyllum & Rhodophyta & Native \\
\hline Plocamium microcladioides & Rhodophyta & Native \\
\hline Plumularia brachiata & Hydroid & Native \\
\hline Plumularia setacea & Hydroid & Cryptogenic \\
\hline
\end{tabular}




\begin{tabular}{|c|c|c|}
\hline Plumularia setaceoides & Hydroid & Native \\
\hline Plumularia spirocladia & Hydroid & Native \\
\hline Podocerus cristatus & Arthropoda & Native \\
\hline Podocerus karu & Arthropoda & Native \\
\hline Podocerus manawatu & Arthropoda & Native \\
\hline Podocerus wanganui & Arthropoda & Native \\
\hline Pododesmus zelandicus & Mollusca & Native \\
\hline Polycarpa pegasus & Chordata & Native \\
\hline Polycera hedgpathi & Mollusca & Cryptogenic \\
\hline Polycheria obtusa & Arthropoda & Native \\
\hline Polycheria sp. aff. P. obtusa & Arthropoda & Cryptogenic \\
\hline Polyclinum sluteri & Chordata & Native \\
\hline Polydora hoplura & Annelida & Non-native \\
\hline Polysiphonia abscissoides & Rhodophyta & Native \\
\hline Polysiphonia brodiaei & Rhodophyta & Non-native \\
\hline Polysiphonia sertularioides & Rhodophyta & Non-native \\
\hline Polysiphonia subtilissima & Rhodophyta & Non-native \\
\hline Polyzoa reticulata & Chordata & Native \\
\hline Pontophilus australis & Arthropoda & Native \\
\hline Pratulum pulchellum & Mollusca & Native \\
\hline Proscoloplos bondi & Annelida & Native \\
\hline Protocirrineris nuchalis & Annelida & Native \\
\hline Psammoclema cf. crassum & Porifera & Non-native \\
\hline Pseudaxinella australis & Porifera & Native \\
\hline Pseudophycis breviuscula & Chordata & Native \\
\hline Pseudopista rostrata & Annelida & Native \\
\hline Pseudopolydora paucibranchiata & Annelida & Non-native \\
\hline Pseudopotamilla alba & Annelida & Native \\
\hline Pseudopotamilla laciniosa & Annelida & Native \\
\hline Pseudosphaeroma campbellense & Arthropoda & Native \\
\hline Pseudosuberites sulcatus & Porifera & Cryptogenic \\
\hline Pterocirrus brevicornis & Annelida & Native \\
\hline Pterothamnion simile & Rhodophyta & Native \\
\hline Pyromaia tuberculata & Arthropoda & Non-native \\
\hline Pyura cancellata & Chordata & Native \\
\hline Pyura carnea & Chordata & Native \\
\hline Pyura lutea & Chordata & Native \\
\hline Pyura pachydermatina & Chordata & Native \\
\hline Pyura picta & Chordata & Native \\
\hline Pyura pulla & Chordata & Native \\
\hline Pyura rugata & Chordata & Native \\
\hline Pyura spinosissima & Chordata & Native \\
\hline Pyura subuculata & Chordata & Native \\
\hline Pyura suteri & Chordata & Native \\
\hline
\end{tabular}




\begin{tabular}{|c|c|c|}
\hline Pyura trita & Chordata & Native \\
\hline Ranella australasia & Mollusca & Native \\
\hline Rhizoclonium implexum & Chlorophyta & Native \\
\hline Rhodophyllis centrocarpa & Rhodophyta & Native \\
\hline Rhodophyllis lacerata & Rhodophyta & Cryptogenic \\
\hline Rhodymenia aff.dichotoma & Rhodophyta & Cryptogenic \\
\hline Rhodymenia foliifera & Rhodophyta & Native \\
\hline Rhodymenia leptophylla & Rhodophyta & Native \\
\hline Rhodymenia linearis & Rhodophyta & Native \\
\hline Rhodymenia obtusa & Rhodophyta & Native \\
\hline Rhynchozoon larreyi & Bryozoa & Cryptogenic \\
\hline Rhyssoplax aerea & Mollusca & Native \\
\hline Risellopsis varia & Mollusca & Native \\
\hline Romanchella perrieri & Annelida & Native \\
\hline Ruditapes largillierti & Mollusca & Native \\
\hline Rynkatorpa uncinata & Echinodermata & Native \\
\hline Sabellidae Indet & Annelida & Cryptogenic \\
\hline Salacia bicalycula & Hydroid & Native \\
\hline Sarcothalia livida & Rhodophyta & Native \\
\hline Sargassum scabridum & Ochrophyta & Native \\
\hline Sargassum sinclairii & Ochrophyta & Native \\
\hline Schistomeringos loveni & Annelida & Native \\
\hline Schizoporella errata & Bryozoa & Non-native \\
\hline Schizoseris dichotoma & Rhodophyta & Native \\
\hline Schizoseris griffithsia & Rhodophyta & Native \\
\hline Schizosmittina cinctipora & Bryozoa & Native \\
\hline Schottea cf.taupoensis & Arthropoda & Native \\
\hline Schottea sp. & Arthropoda & Native \\
\hline Scoloplos cylindrifer & Annelida & Native \\
\hline Scoloplos simplex & Annelida & Native \\
\hline Scruparia ambigua & Bryozoa & Cryptogenic \\
\hline Scrupocellaria ornithorhyncus & Bryozoa & Native \\
\hline Scutus breviculus & Mollusca & Native \\
\hline Scytosiphon lomentaria & Ochrophyta & Native \\
\hline Seba typica & Arthropoda & Native \\
\hline sedis Adenocystis utricularis & Ochrophyta & Native \\
\hline Sertularella robusta & Hydroid & Native \\
\hline Sertularia marginata & Hydroid & Non-native \\
\hline Sigapatella novaezelandiae & Mollusca & Native \\
\hline Sigapatella tenuis & Mollusca & Native \\
\hline Siphonaria australis & Mollusca & Native \\
\hline Smittina rosacea & Bryozoa & Native \\
\hline Smittina torques & Bryozoa & Native \\
\hline Smittoidea maunganuiensis & Bryozoa & Native \\
\hline
\end{tabular}




\begin{tabular}{|c|c|c|}
\hline Spirobranchus cariniferus & Annelida & Native \\
\hline Spirobranchus polytrema & Annelida & Non-native \\
\hline Steginoporella magnifica & Bryozoa & Native \\
\hline Stenothoe miersii & Arthropoda & Cryptogenic \\
\hline Stenothoe moe & Arthropoda & Native \\
\hline Stenothoe sp. aff. S. gallensis & Arthropoda & Non-native \\
\hline Stenothoe valida & Arthropoda & Cryptogenic \\
\hline Stereotheca elongata & Hydroid & Native \\
\hline Stichopus mollis & Echinodermata & Native \\
\hline Stictosiphonia hookeri & Rhodophyta & Native \\
\hline Stictosiphonia vaga & Rhodophyta & Native \\
\hline Stomacontion sp. aff. S. pungpunga & Arthropoda & Cryptogenic \\
\hline Streblosoma toddae & Annelida & Native \\
\hline Styela clava & Chordata & Non-native \\
\hline Styela plicata & Chordata & Cryptogenic \\
\hline Stylotella agminata & Porifera & Non-native \\
\hline Suberites cf. affinis & Porifera & Native \\
\hline Sycon cf. ornatum & Porifera & Native \\
\hline Symplectoscyphus johnstoni & Hydroid & Native \\
\hline Symplectoscyphus subarticulatus & Hydroid & Native \\
\hline Synthecium campylocarpum & Hydroid & Non-native \\
\hline Synthecium elegans & Hydroid & Native \\
\hline Synthecium subventricosum & Hydroid & Non-native \\
\hline Sypharochiton pelliserpentis & Mollusca & Native \\
\hline Sypharochiton sinclairi & Mollusca & Native \\
\hline Talochlamys zelandiae & Mollusca & Native \\
\hline Tedania battershilli & Porifera & Native \\
\hline Tedania diversiraphidiophora & Porifera & Native \\
\hline Tedania spinostylota & Porifera & Native \\
\hline Terebella plagiostoma & Annelida & Native \\
\hline Terebellides narribri & Annelida & Native \\
\hline Tethya burtoni & Porifera & Native \\
\hline Thelepus extensus & Annelida & Native \\
\hline Timarete anchylochaetus & Annelida & Native \\
\hline Trematocarpus aciculare & Rhodophyta & Native \\
\hline Tricellaria inopinata & Bryozoa & Non-native \\
\hline Trichomusculus barbatus & Mollusca & Native \\
\hline Trochus tiaratus & Mollusca & Native \\
\hline Trochus viridus & Mollusca & Native \\
\hline Trypanosyllis gigantea & Annelida & Native \\
\hline Trypanosyllis zebra & Annelida & Native \\
\hline Tubulipora cf.connata & Bryozoa & Native \\
\hline Tugali suteri & Mollusca & Native \\
\hline Turbo smaragdus & Mollusca & Native \\
\hline
\end{tabular}




\begin{tabular}{|l|c|c|}
\hline Typosyllis prolifera & Annelida & Native \\
\hline Ulva spathulata & Chlorophyta & Native \\
\hline Undaria pinnatifida & Ochrophyta & Non-native \\
\hline Valdemunitella valdemunitella & Bryozoa & Native \\
\hline Ventojassa frequens & Arthropoda & Native \\
\hline Vosmaeria torquata & Porifera & Native \\
\hline Vosmaeropsis cf macera & Porifera & Non-native \\
\hline Watersipora arcuata & Bryozoa & Non-native \\
\hline Watersipora subtorquata & Bryozoa & Non-native \\
\hline Wittrockiella salina & Chlorophyta & Native \\
\hline Xanthidae sexlobata & Arthropoda & Cryptogenic \\
\hline Xenostrobus pulex & Mollusca & Native \\
\hline Xenostrobus securis & Mollusca & Native \\
\hline Xymene huttoni & Mollusca & Native \\
\hline Xymene plebeius & Mollusca & Native \\
\hline Xymene traversi & Mollusca & Native \\
\hline Zoobotryon verticillatum & Bryozoa & Non-native \\
\hline
\end{tabular}

Table A4. Pairwise PERMANOVA test for the community composition for the interaction factors; Habitat $\times$ Sample interval and Substratum $\times$ Sample interval. Significance marked in bold $(P<0.05)$.

\begin{tabular}{|c|c|c|c|c|c|}
\hline & $\mathbf{t}$ & $P($ perm $)$ & \multicolumn{3}{|c|}{ Avg. similarity } \\
\hline \multicolumn{3}{|c|}{ Habitat $\times$ Sample interval } & Reef & Marina & Reef $\times$ Marina \\
\hline Time 1 & 2.3252 & 0.0001 & 53.26 & 34.635 & 38.531 \\
\hline Time 2 & 2.5417 & 0.0001 & 53.506 & 28.553 & 34.692 \\
\hline Time 3 & 2.9758 & 0.0001 & 38.784 & 34.948 & 28.262 \\
\hline Time 4 & 2.7269 & 0.0001 & 46.081 & 39.424 & 36.314 \\
\hline Time 5 & 2.7292 & 0.0001 & 33.818 & 46.235 & 33.038 \\
\hline Time 6 & 2.8138 & 0.0001 & 39.637 & 31.627 & 27.887 \\
\hline Time 7 & 2.6967 & 0.0001 & 31.772 & 27.918 & 22.611 \\
\hline Time 8 & 1.9043 & 0.0003 & 28.754 & 31.092 & 26.693 \\
\hline \multicolumn{3}{|c|}{ Substratum $\times$ Sample interval } & Slate & PVC & PVC $\times$ Slate \\
\hline Time 1 & 0.918 & 0.5365 & 38.265 & 44.499 & 41.011 \\
\hline Time 2 & 1.7555 & 0.0043 & 35.717 & 41.666 & 36.952 \\
\hline Time 3 & 1.4254 & 0.0299 & 28.808 & 37.251 & 31.971 \\
\hline Time 4 & 2.1249 & 0.0003 & 34.432 & 47.581 & 38.002 \\
\hline Time 5 & 1.8585 & 0.0013 & 33.124 & 42.273 & 35.289 \\
\hline Time 6 & 1.5002 & 0.0221 & 32.321 & 32.372 & 31.063 \\
\hline Time 7 & 1.8748 & 0.0003 & 26.386 & 28.844 & 24.767 \\
\hline Time 8 & 1.9284 & 0.0005 & 27.166 & 32.606 & 26.729 \\
\hline
\end{tabular}


